Florida International University FIU Digital Commons

4-21-2011

\title{
Living Positive: Life in Community Among Puerto Rican Men Living with HIV in Boston
}

Francisco Sastre

Florida International University, fsast001@fiu.edu

DOI: $10.25148 /$ etd.FI1 1050609

Follow this and additional works at: https://digitalcommons.fiu.edu/etd

\section{Recommended Citation}

Sastre, Francisco, "Living Positive: Life in Community Among Puerto Rican Men Living with HIV in Boston" (2011). FIU Electronic Theses and Dissertations. 393.

https://digitalcommons.fiu.edu/etd/393

This work is brought to you for free and open access by the University Graduate School at FIU Digital Commons. It has been accepted for inclusion in FIU Electronic Theses and Dissertations by an authorized administrator of FIU Digital Commons. For more information, please contact dcc@fiu.edu. 


\title{
FLORIDA INTERNATIONAL UNIVERSITY \\ Miami, Florida
}

LIVING POSITIVE: LIFE IN COMMUNITY AMONG PUERTO RICAN MEN

LIVING WITH HIV IN BOSTON

\author{
A dissertation submitted in partial fulfillment of the \\ requirements for the degree of \\ DOCTOR OF PHILOSOPHY \\ in \\ COMPARATIVE SOCIOLOGY \\ by
}

Francisco Sastre

2011 
To: Dean Kenneth Furton

College of Arts and Sciences

This dissertation, written by Francisco Sastre, and entitled Living Positive: Life in Community among Puerto Rican Men Living with HIV in Boston, having been approved in respect to style and intellectual content, is referred to you for judgment.

We have read this dissertation and recommend that it be approved.

Mario De La Rosa

Michael Barton Laws

Maria Aysa-Lastra

Dennis Wiedman

Sarah J. Mahler, Major Professor

Date of Defense: April 21, 2011

The dissertation of Francisco Sastre is approved.

\begin{tabular}{r}
$\begin{array}{r}\text { Dean Kenneth Furton } \\
\text { College of Arts and Sciences }\end{array}$ \\
\hline Interim Dean Kevin O'Shea \\
University Graduate School
\end{tabular}

Florida International University, 2011 


\section{DEDICATION}

I dedicate this dissertation to my family: Papi, Mami, Fernando, and Jorge. Their unconditional love and support cannot be measured. Their commitment to family has tough me a lot about love, commitment, and what is important in life. 


\section{ACKNOWLEDGMENTS}

This dissertation was only possible because of the support, encouragement, and love of my own community. I want to first thank the members of my committee for their encouragement, guidance, and knowledge. Dr. Sarah Mahler, my major professor, guided me through every step of the process and challenged me to think outside the box. Her mentorship was has been vital to my formation as a social scientist. She taught me the value and amazing responsibility of teaching. I am honored to have been her student - she is truly a teacher, a great example that I wish to follow in the future. I am grateful to Dennis Wiedman and Maria Aysa-Lastra for their continuous support and guidance. They always had an open door to listen and helped me realize the significance of staying focused on the important things in life. Mario De La Rosa opened the doors of CRUSADA and I stayed there for six years. His mentorship and guidance was indispensable to my success as a graduate research student. Bart Laws laid the foundation of my research career and I will forever be thankful for giving me a chance.

I am very grateful to FIU's Graduate School for its generous DYF Fellowship, the National Institutes of Health (NIH), and the Centro de Estudios Puertorriqueños at Hunter College for their support which has financially sustained my dissertation research and writing. I am very appreciative to LHI, the Boston Living Center, HOPE, Pathways to Wellness, and MAC for their trust. I am indebted to the Puerto Rican men that took time to share their lives with me unconditionally. They helped me with the study and in the process they taught me a lot about living. Also many thanks to Alfredo Hernandez, Carlos Maysonet, and Claudia Arroyave - their friendship, and their special talents and skills were an essential contribution to my study. 
I cannot thank enough the Aguilar Family in Boston. The smiles in Alex and Max brightened my days and reminded me of the simple joys of life. Their home was not just a place to live during my field research, it was home. I cannot say enough about all the people in CRUSADA, particularly Natalia and Rosa. Thank you for keeping me on track and for checking in on me. Also, endless gratitude to Arnaldo. Thank you for your time and your wisdom in polishing every chapter. I am also very grateful of my Flamingo Road/ Potential family. Your prayers carried me through.

I am grateful to Team Mahler for their encouragement, support, and their friendship; it has been an honor to share this journey with them. I am also thankful to Beth Ann for giving sacrificially so much to make sure I reached my dream—gracias guapa. My gratitude to my best friend Brandom for always been honest and sincere with me; he challenges me daily to be a better person. I have also endless gratitude to Julieta, my partner in prayer and ministry. Thank you for all the prayers, encouragement, support, love, and care "to keep running the good race."

Finally, special and heartfelt thanks to my family. I am indebted to my parents for always teaching me that the value in life is in following our heart's desires and loving one another. Papi, me mostraste que el amor no tiene límites. Gracias por apoyarme y ser una inspiración cuando estaba cansado. Mami, gracias por amarme y apoyar mis sueños. To Fernando and Jorge, my best brothers. Thank you for taking care of mom and dad so I could follow my heart. I do not take for granted all you do for our family. Thank you for coming to Miami to visit—I love having you guys around again. Above all, I give thanks to my Lord and Savior Jesus Christ, for He is the one that makes all things possible. I am truly blessed. 


\section{ABSTRACT OF THE DISSERTATION \\ LIVING POSITIVE: LIFE IN COMMUNITY AMONG PUERTO RICAN MEN \\ LIVING WITH HIV IN BOSTON}

by

Francisco Sastre

Florida International University, 2011

Miami, Florida

Professor Sarah J. Mahler, Major Professor

Negative experiences of stigmatization, discrimination, and rejection are common among people living with HIV in the United States, and particularly when they are also members of a minority group. Some three decades after the first cases of AIDS were identified, people infected with HIV continue to be perceived and characterized negatively. While an HIV/AIDS diagnosis is typically associated with negativity, this study investigates the extent to which collective experiences among HIV-positive people result in healthy responses and positive social adjustment. This study is focused on the ways in which HIV-positive Puerto Rican men in Boston live positive despite being diagnosed with HIV. Rather than wrapping themselves in the social stigma of HIV and the isolation that entails, they participate in processes that affirm themselves and their peers. In so doing, they help generate both healthy and meaningful lives for themselves and others. The study examines the process in which Puerto Rican men living with HIV in Boston participate, promote, and reaffirm an HIV community, la comunidad, as a social entity with a unique culture and identity. This study also investigates how this 
community influences, supports, and encourages the adoption of positive transformations for living long term with HIV.

On the basis of nine months of field research, this qualitative study employed both focus groups and interviews with fifty HIV-positive Puerto Rican men in Boston. These men were recruited, using convenience sampling, from different community-based organizations (CBOs) that provide HIV/AIDS services in Boston.

The study finds that HIV-positive Puerto Rican men in Boston build community, not in response to social exclusion, but built on shared positive practices and strategies for living healthy with HIV. These men come together to negotiate and form a unique cultural community expressed in norms, beliefs, and practices that, although centered on HIV, are designed for living healthy. These expressions reaffirm a sense of community in everyday settings and transform the lives of these men with positive behaviors and healthy lifestyles. The findings reveal that this transformation takes place in the context of a community, with the support, encouragement, and at times, policing of others. La comunidad is where the lives of these men are transformed as they learn, adopt, and experience living positive with HIV. 


\section{TABLE OF CONTENTS}

CHAPTER

PAGE

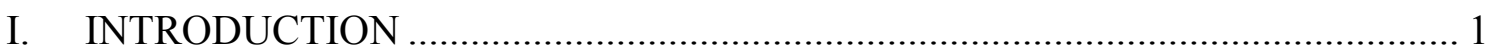

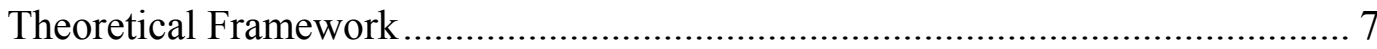

Conceptualizing Community ..................................................................... 8

The Social Construction of Community ……………......................................... 13

Theorizing Modern Communities........................................................... 14

Imagined Communities ......................................................................... 16

Deterritorialized Communities............................................................... 17

Symbolic Communities....................................................................... 19

Community-defying Elements: Rituals and Symbols .................................... 22

The "otherization" of People into Community ……………................................... 27

Case Study: La Comunidad of Puerto Rican Men Living with HIV in Boston.... 32

Methodological and Ethical Considerations ................................................. 33

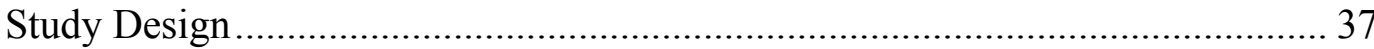

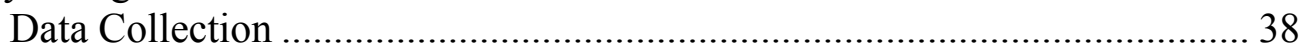

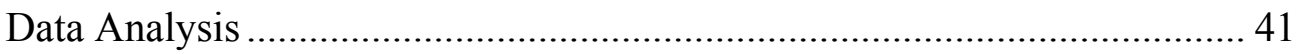

Methodological Limitations......................................................................... 46

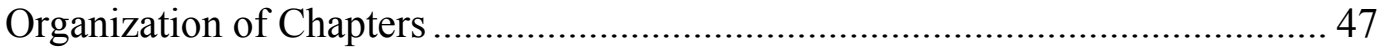

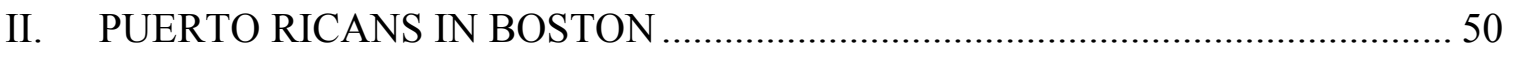

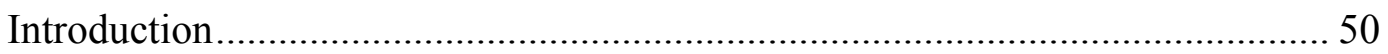

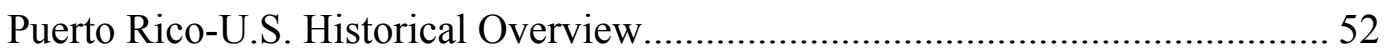

Puerto Ricans in Boston......................................................................... 59

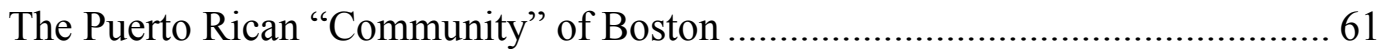

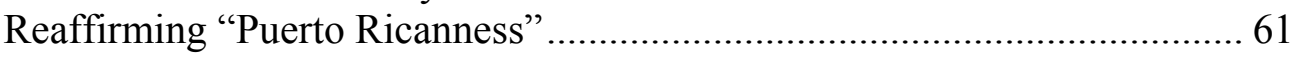

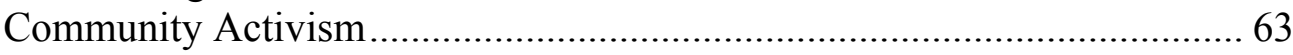

Community Multi-service Organizations ……………................................ 66

"La comunidad"................................................................................ 70

Puerto Rican and Latino Response to HIV/AIDS in Boston .................................. 72

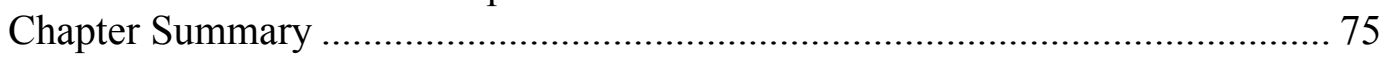

III. DIAGNOSED “COMMUNITAS”: ESTABLISHING LA COMUNIDAD ........... 77

Boundaries, Boundary-work, and Community ………….................................. 79

Boundaries that Produce Communities of Exclusion ..................................... 85

HIV Diagnosis: the Gateway into Community …………...................................... 87

Labeling the Community: Becoming "ill" at Diagnosis ............................... 87

HIV Diagnosis: The Rite of Passage into Community ............................. 92

Defining the "ill"............................................................................... 95

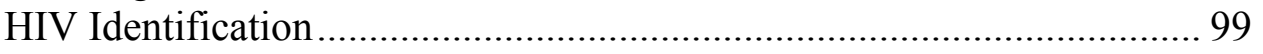

Boundary-Work through Ostracism: Shared Experiences

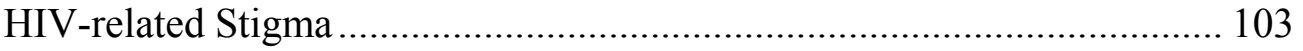

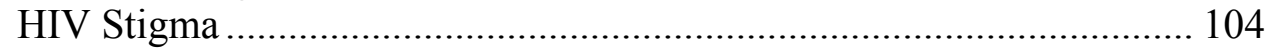


Experiences of Stigma: Separating the "Bad" from the "Good" ........... 106

Buffering the Stigmatization............................................................... 110

Belonging: Inside the Boundary of La Comunidad .......................................... 114

Community Belonging: Membership Redefined ...................................... 116

Belonging to Community: Socializing and Learning from Others.......... 119

Entering the Community: Membership Rituals ...................................... 121

Adopting the Norms of la Comunidad: a New Way of Living ................... 127

Community Values and Beliefs: Trust, Respect, and Honesty ................ 130

Living in a Moral Community ............................................................ 136

Policing the Boundaries of la Comunidad ............................................. 140

Agency and Boundary-work within the Structure of Community

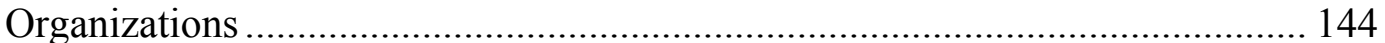

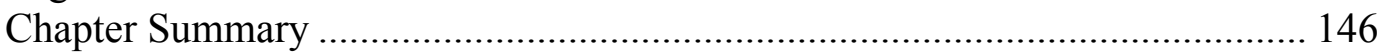

IV. A PLACE OF THEIR OWN: LIFE IN LA COMUNIDAD ................................. 150

From Illness to Cultural Community ............................................................. 152

The Deaf Community ............................................................................. 153

The Alcoholics Anonymous Community ……………………………...... 155

The Socialization Process ................................................................................ 158

Elements of Community ………………......................................................... 162

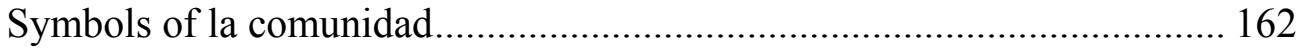

HIV Personalities and Key Figures....................................................... 162

Community Organizations .................................................................. 165

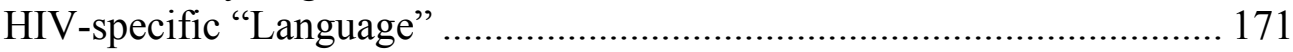

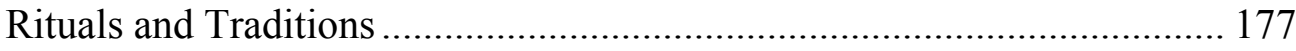

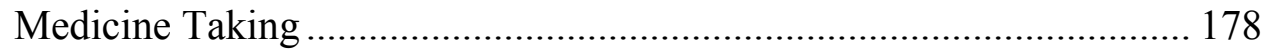

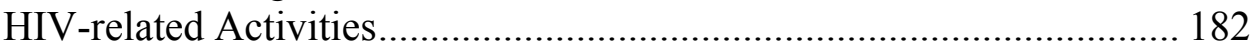

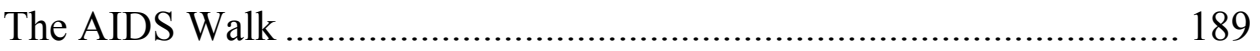

Social Life in La Comunidad .............................................................................. 193

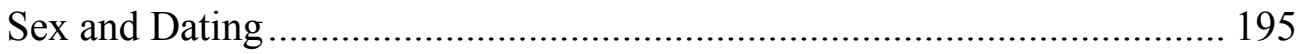

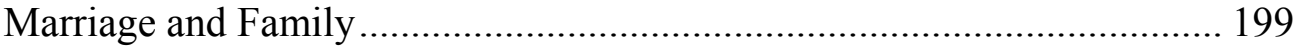

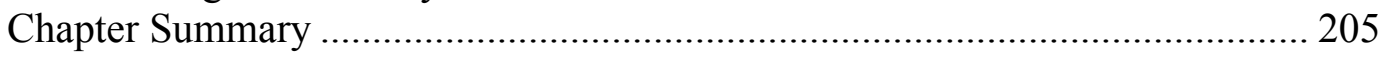

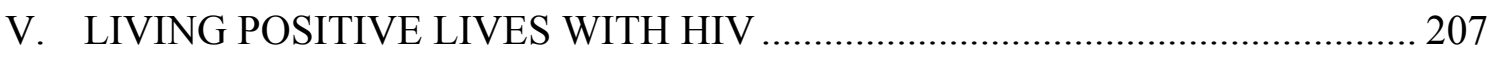

Living Everyday Positive Lives.................................................................... 209

Changes in Lifestyle .......................................................................... 210

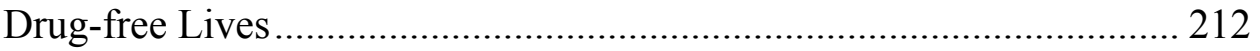

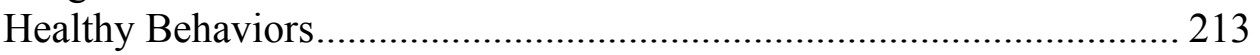

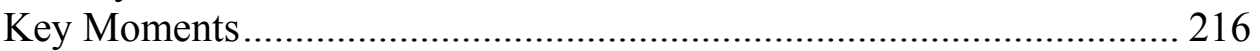

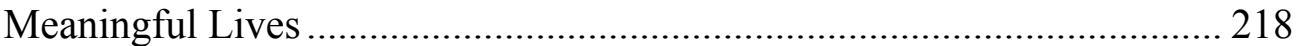

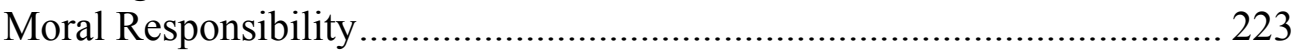

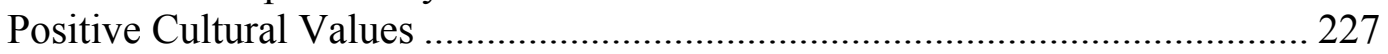

Illness and Culture - Scholarly Approaches .............................................. 227

Machismo and Familismo .......................................................................... 229

"Positive" Machismo and Familismo …………........................................ 231 


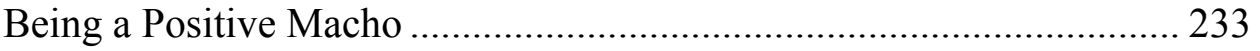

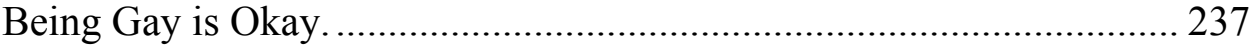

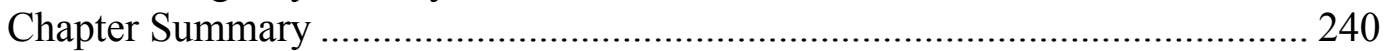

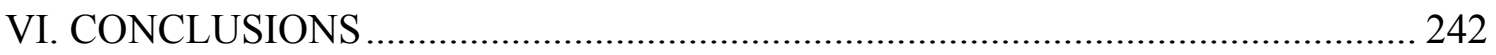

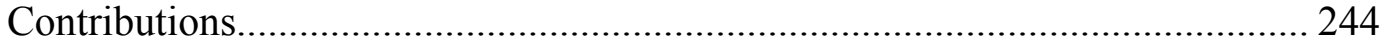

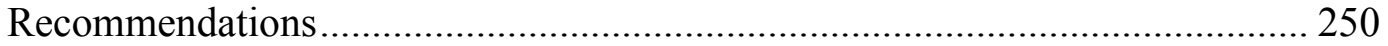

Looking Ahead: the Future of Community Studies in HIV/AIDS .................... 254

A Final Reflection.................................................................................. 257

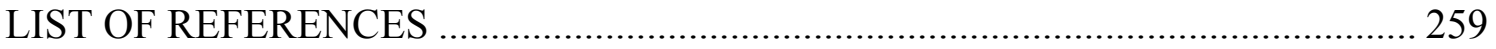

VITA 


\section{LIST OF TABLES}

CHAPTER

PAGE

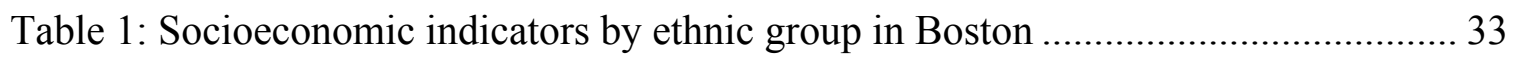

Table 2: demographics and HIV history of focus groups' participants ............................. 38

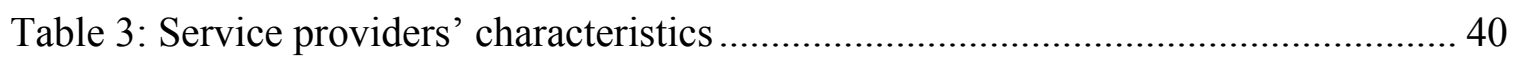

Table 4: number of coding instances by pre-determined code category ....................... 44

Table 5: number of coding instances by code type ............................................... 44

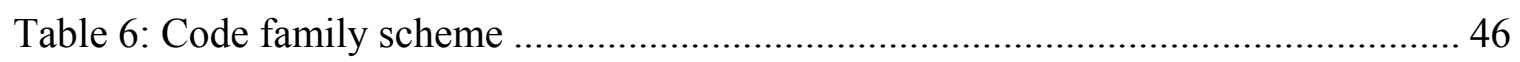

Table 7: Socioeconomic indicators by race and Puerto Rican ancestry in the U.S. ........ 59

Table 8: Location of HIV testing and diagnosis ................................................. 90

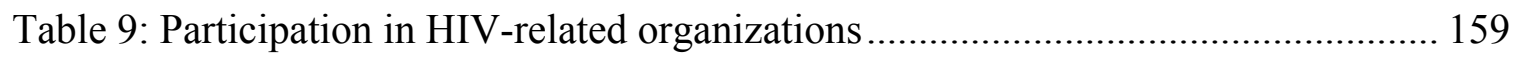

Table 10: Respondents with membership/receiving services from HIV CBOs ............. 167

Table 11: Description of attendance to HIV-related activities .................................. 182

Table 12: Hispanic cultural values as risks and protective factors for HIV .................. 229 


\section{CHAPTER I.}

\section{INTRODUCTION}

I entered the world of HIV/AIDS unexpectedly. When I moved to Boston as a trailing spouse in 2001, I searched for a job working with the large Latino community there, hoping to apply the knowledge I gained while earning my new master's degree. Known for having considerable resources and services available to Latinos, I was confident that my training in Latino cultural studies, along with my advanced research skills, would be well received in Boston. However, the diversion of funding away from community programs post $9 / 11$ marked a period of scarce job opportunities in the city. Yet, against all odds, and to my surprise, six months after relocating to Boston I was offered a job at a Latino public health organization evaluating the agency's HIV/AIDS programs. The job offer was an unexpected offer given my lack of background in public health, specifically in HIV/AIDS. Nevertheless, I thought that it would be a good opportunity to sharpen my program evaluation skills. Although highly knowledgeable about the facts of HIV and AIDS, I did not realize then that I was bringing to the job many preconceived notions about the illness. I viewed the world of HIV/AIDS through a lens of stereotypes, sickness, and death. In retrospect, I now see that it was comforting to be able to dehumanize the illness into data points, program outcomes, and monthly reports. After a short while on the job, however, I realized that the world of misery I expected was incorrect; what I encountered, conversely, was a world of people whose stories were of survival more than sickness, determination more than destitution, and accomplishments more than acquiescence. In fact, the HIV world I have experienced and 
come to know well since 2001 is a world of transformed positive lives and living. It is a world where many people live positive.

I clearly recall experiencing my HIV "awakening" in the stories shared by the HIV-positive clients I met while at the agency, "victims" who later became interviewees for this study. Antonio, a Puerto Rican man in his late 50s, told me of his decision to stop using drugs after 32 years of daily use once he learned he was HIV positive. He was very emotional when he recounted the death of his girlfriend from AIDS because he blames himself for starting her on drugs. Had he not gotten her addicted, she would not have become infected with HIV while injecting drugs with a dirty needle. Today, still regretting his actions of the past, he is encouraged by his new life and spends significant time talking to other HIV-positive people on the importance of estar limpio (staying clean), eating healthy, and exercising. In fact, he has found a new calling as an amateur yoga instructor and many of his peers regularly attend his home-based classes.

Not so different, Diego, a Boricua ${ }^{1}$ middle-aged man living with HIV since 1991, stressed to me how much the HIV diagnosis had changed his life. For him, memories of living on the streets, injecting and dealing drugs, and being in prison, seemed far in the past, almost as a life belonging to someone else. This 42 year-old Boston marathon runner, married man and first-time father, has been drug free for 6 years. His face lights up when he talks about his 3 month-old newborn and proudly shows the baby's picture in his wallet to anyone around him. He humbly depicts these accomplishments as he downplays the suffering and challenges in his life.

\footnotetext{
${ }^{1}$ Common ethnic reference used among Puerto Ricans that reflects the indigenous name for the island of Puerto Rico - Borinquen
} 
I was also impressed by Rudy. He described to me how he has come a long way since being infected with HIV more than 20 years ago by his boyfriend. He shared how challenging it was, as a Puerto Rican gay man, to disclose his HIV status to his family; how hard it was, as well, to overcome the HIV-related depression that affected him long after he received the diagnosis. Yet, he was also quick to mention how meaningful it has become for him to help other HIV-positive people as a Peer Educator at an HIV agency in Boston. This otherwise shy and soft-spoken man, when not talking to clients about the importance of having a positive attitude to fight HIV, is accompanying them to medical appointments and therapy sessions to make sure they receive the care they need.

The stories of these Puerto Rican men suggest experiences of HIV different from the overwhelmingly negative experiences associated with an HIV diagnosis--as widely documented in the literature (Herek et al. 2002; Farmer 2006; Baer 2003; Helman 2000; Varas-Diaz 2005) and, even more so, depicted in the popular media in films (e.g., Philadelphia, Kids), documentaries (e.g., AIDS, The Terrible Silence), and in theatrical productions (e.g., Rent, The Bugchasers). Some three decades after the first cases of AIDS were identified, HIV/AIDS continues to be perceived and characterized negatively. In fact, while there is now wider knowledge and understanding about HIV/AIDS and people are living with HIV infections much longer than before, there are still strong remnants of stigma and discrimination against people living with HIV/AIDS.

Historically, health campaign messages and the media's headlines have shaped the perception of HIV/AIDS with recurrent images and metaphors associating the illness to plagues, moral punishment, and even wars (Helman 2000; Clatts and Mutchler 1989). HIV/AIDS was portrayed as a self-inflicted illness by amoral people outside the social 
mainstream; people who, thus, merited such horrendous afflictions (Helman 2000). In popular perception, AIDS was God's retribution for individuals' immoral character and behavior, thus, socially justifying the alienation of people affected by the disease (Helman 2000; Herek et al. 2002; Brimlow et al. 2003). For example, in the early years of the epidemic, HIV was considered the "gay plague" because of the disproportionate spread of infections among the urban gays (VerMeulen 1982). Some time later, it became to be known as WOG, the Wrath of God (Douglas, Kalman, and Kalman 1985). Still, and only a few years ago, a health care professional confessed to me her belief that HIV was in fact God's way of punishing immorality. These images and perceptions socially define HIV unlike many illnesses of the past.

In the United States, racial and ethnic minorities, the groups primarily affected by the HIV epidemic, have been impacted the most by the negative notions attached to the illness. These groups face additional social stressors, especially discrimination and substandard living conditions that are associated with low socio-economic status as well as with being racial or ethnic minorities themselves. Studying the impact of HIV among disadvantaged groups, research has sometimes explained HIV as a form of structural violence on the poor and marginalized Baer 2003; Farmer 2004; (Poundstone 2004) contributing in particularly helpful ways to understanding broad social perceptions and attitudes towards HIV. According to Brimlow et al. (2003), HIV/AIDS-related stigma and discrimination is evident in common feelings of avoidance and isolation towards people affected by the virus, as well as in the belief that they are responsible and deserving of their illness. Furthermore, as Herek et al. (2002:371) explain, the "stigmatizing attitudes are strongly correlated with misunderstanding the mechanism of 
HIV transmission and overestimating the risk of casual contact, and with the negative attitudes towards social groups disproportionately affected by the epidemic, especially gay men and injecting drug users.”

Among minorities, culture also shapes the negative perceptions and attitudes towards HIV/AIDS. Certain cultural values associated with Latinos in particular are also linked to AIDS stigma and isolation of Latinos living with HIV/AIDS (Varas-Diaz 2005). Beliefs such as machismo (male pride and virility) promote negative perceptions of homosexuality and increase homophobia (De La Cancela 1986; Ortiz-Torrez et al. 2000). Since homosexuality is not perceived to be part of the traditional family, familismo (greater identification with and dependence upon the family and subordination of individuals to the family collective (Herbst et al. 2007; Perez et al. n.d.) has been identified as a source of conflict among gay/bisexual Latinos and their families (Herbst 2007). Consequently, this stigma contributes to the separation of gay/bisexual Latinos from their family and the reduction of family support (Marin and Gomez 1998). Given strong social pressure to conform to their cultural norms, many gay/bisexual Latino men choose to hide their sexual orientation, resulting in increased risky behaviors that contribute to the spread of HIV (Marin 2003; Diaz et al. 2004; Levy et al. 2005). In fact, many often avoid disclosing their seropositive status to family members because of fear of rejection (Zea et al. 2004).

Negative experiences, including discrimination, solitude, isolation, and rejection are common among people living with HIV (Herek et al. 2002; Brimlow et al. 2003; Varas-Diaz 2005). Yet, although an HIV/AIDS diagnosis is characteristically associated with negativity, the experiences of people like Antonio, Diego, and Rudy reflect 
alternative ways to "living positive" lives with HIV to enhance their quality of life. Similarly, many other Puerto Ricans like these men find ways to live productive lives despite or perhaps because of the HIV diagnosis. Their stories are telling of their disposition in confronting HIV while challenging the grim medical diagnosis and social intolerance attached to HIV.

Mindful of the preceding, this study is not about HIV or stigma per se. HIV and all it implies constitute merely the gateway to a phenomenon which this study explores. This study focuses on the ways in which Puerto Rican men in Boston, upon receiving an HIV diagnosis, transform their lives positively to living with HIV. Rather than isolating themselves completely and wrapping themselves in the social stigma of HIV, they participate in processes of affirmation of themselves and the groups they belong to and work with; in so doing, they help prolong both healthy and meaningful lives for themselves and others. Building on the notion that an HIV-positive diagnosis is a lifechanging event (Roth and Nelson 1997), the study proposes that positive adaptations to living long term with HIV are encouraged, take place, and they are sustained collectively, in communitas $^{2}$. The proposition is to view these Puerto Rican men not as victims of HIV, but, instead, as actors who build a community for themselves and their HIVpositive peers who also choose to live positively. In short, the aim of my study is to examine the Puerto Rican men living with HIV who participate, promote, and reaffirm an HIV community in Boston. They refer to this as their comunidad, the larger community of which their group is a particular part. My study also aims to analyze how, over time,

\footnotetext{
${ }^{2}$ Communitas: an intense community spirit, feeling of great social equality, solidarity, and togetherness
} 
this community influences and supports the adoption of positive transformations for living long term with HIV. In essence, this study is about community.

It is important to note at the outset, that the men included in this study are not the entire HIV, gay and/or Puerto Rican community in Boston. Other men and women participate in the activities of and belong to la comunidad. The selection of this group was not intended to ignore other members or imply that they are irrelevant. However, as a group these men are the primary actors driving and, thus, displaying the everyday processes of community-building described in the following pages. The decision to focus on these men alone is not intended to generalize for a wider HIV community, is in an effort to describe how this particular group of men experience, understand, build and sustain la comunidad.

\section{Theoretical Framework}

In the 1990s, the advent of new treatments transformed HIV/AIDS into a chronic illness, changing the focus of coping to managing living long-term with the illness (Baumgartner 2007). Despite evidence of communal coping and adjusting among people affected by a variety of chronic illnesses (Cain 1991; Gray et al. 1996; Humphreys 2000; Ussher et al. 2006), literature describing collective coping of those with HIV/AIDS is virtually absent. Instead, the HIV literature has focused on individual coping strategies and responses to the illness. Moreover, whether intentionally or not, the same literature tends to characterize the people affected by the illness as victims and powerless over the illness, suggesting that experiences and responses to living with HIV are limited to supraindividual structural factors (e.g., poverty, minority status) and cultural determinants that, 
nonetheless, are experienced by individuals (Suarez 1996; Simoni 2000, 2002; RamirezPower 2003; Valles 2003; Loue 2006).

In contrast, my study presents how individuals participating in collective experiences of HIV aid in healthy psychological responses and positive social adjustments. In the words of my interviewees, adjusting to the diagnosis and living with HIV is associated to being part of la comunidad. They share in creating and living what they call "community" as part their new lives with HIV. Examining "community" as an ongoing social construction shifts analytical focus away from describing the group as if a static entity toward examining how people individually and collectively create and sustain the very means to survive and even thrive while living with a diagnosis once considered a death sentence. Using this perspective shifts the focus of concern from HIV and its individual victims to HIV as a catalyst for community formation. With a variety of aid from many different resources—clinics, support organizations, family as well as among themselves - they create a system of support, integration, and affirmation very different from the experiences of stigma and exclusion many others with HIV face. The alternative strategy proposed by my study, evoking on a collective approach to adjusting to HIV as a chronic illness, invites a community-oriented analysis in this study.

\section{Conceptualizing Community}

"Community" is one of those quotidian concepts that, precisely because it means so much and is used so widely, has remained an elusive, hard to define concept in the social science literature. As this dissertation revolves around understanding what "community" is for the Puerto Rican HIV-positive men I interviewed, I have to engage 
the large, disparate literatures on community to find the approach or approaches that best inform the men's usage. I begin this search with a brief overview.

The most obvious point is that "community" is about commonality. Community, however, can be as vague as the concept itself. For a long time, the concept of community was primarily related to some spatial concept of a locality or the equivalent between society and place (Brunt 2001); it described a geographical place, primarily as an area of common living (MacIver 1931; Smith 1939; Durant 1939; Mannheim 1940; Warner and Lunt 1941; Keur and Keur 1955; Warren 1963; Smith 2001). Thus, many authors defined community as a variation of a "territorial group of people with a common mode of living striving for common objectives" (Durant 1939:ix). However, with rapid population growth, urbanization and increasing complexity in societies in eighteenth century onward, communities began to be less identified with common geospatial units and more with people united around common interests who therein achieve a special level of intimacy and responsibility towards one another (Smith 1939; Nisbet 1966; Elias 1974; Lee and Newby 1983). Definitions of community were then applied to describing "all forms of relationships which are characterized by a high degree of personal intimacy, emotional depth, moral commitment, social cohesion and continuity in time" (Nisbet 1966:47). Unfortunately, the definition of community characterizes a wide variety of human groups without bringing much conceptual precision.

Aside from this limited consensus describing communities as social groups enjoying some cohesion and emotional ties, little additional common ground has been found among hundreds of attempts to further define the concept of "community" (inter alia Hillery 1955; Mason 2000; Brunt 2001; Wood and Judikis 2002). What has been 
refined to some degree is the understanding of this cohesion and emotion. Scholars generally agree, for example, that for a community to exist, a group of people must feel a sense of belonging (Anderson 1991; Keller 2003), share a collective identity (Jenkins 2004; Taylor 2002), and recognize a set of perceived boundaries separating their group from others (Barth 1969; Cohen 1985). In fact, communities do not tend to endure without these critical characteristics that help cement the commonality of human experiences into social units (McMillan and George 1986; Wood and Judikis 2002).

The term "community," then, is used to represent or symbolize a form of social life in which people perceive that they not have just something in common with others. Rather, they feel they belong together, a notion of social cohesiveness or, as some refer to it, social solidarity. As a social species, humans need a sense of belonging which is vital for human satisfaction, identification, and security (Cohen 1985; Howell 2002). The sense of belonging is created through a shared "consciousness of commonality" to form community even in the absence of homogeneity (Dyck 2002). An important characteristic of community is that belonging is experienced both as personal and collective since community is constituted and felt internally by people who can objectively be seen as diverse but is externally conceived as a homogenous unit -- a “group" (Amit 2002; Dyck 2002; Howell 2002; Olwig 2002; Jenkins 2004). As noted by Wood and Judikis (2002:1), "we, as individuals, are as much a product of our collective communities as the communities are a product of our collective membership." Not surprisingly, Olwig (2002) describes community in terms of "fields of belonging" because without the sense of common purpose and interest community cannot exist, an argument widely accepted in the scholarship of community across social science 
disciplines (McMillan and Chavis 1986; Dyck 2002; Woods and Judikis 2002; Mason 2000).

Although essential for any community to exist and endure, belonging still presents challenges to conducting an analysis with a community framework. The literature typically asserts belonging as a fundamental characteristic of communities but does not always enter into discussions of how belonging comes into existence. Is it merely the fact of being born into a "community" enough to generate the feelings and identification or do people have to do community to create and sustain community? In my dissertation, I will chronicle and analyze a variety of different ways HIV-positive men do community through boundaries, symbols, and rituals. Even though they are not necessarily conscious of producing community in the process, these practices make them know when they are "home" in their community (i.e., inside their groups' boundaries) and this, in turn, "generates the special obligations to attend to the well-being of other members" (Mason 2000:32).

The creation of collectivities obligates the production of community-specific boundaries that delimit who belongs, when members are inside versus outside this community, and if and how people can enter and exit the community. In essence, these determine membership into the community identifying the insiders versus outsiders of the community. Although frequently associated with communities, a geospatial locality with a clearly defined border is not an essential component for establishing community. Rather, all that is needed is for people to feel a collective identity (Cohen 1985; Anderson 1991) as well as to have a sense of and enforce its boundaries. Although community is arguably easiest to create in face-to-face groupings such as those among food foragers 
during the longest phase of human existence on Earth, people have found multiple ways to create community without such face-to-face contact—a fact that helps explain why communities are constructed and sustained all the time in the $21^{\text {st }}$ century among people who might never meet in real life. There is not necessarily need for face-to-face contact. On the other hand, however, communities need for people to know their social borders, their boundaries. Being aware of boundaries is not difficult for members given that processes involved in creating collective identity (that is to distinguish a group) produce the differences from others as well (Barth 1969; Jenkins 2004). In his acclaimed work on social boundaries, Fredrik Barth (1969) argues that it is at the boundaries where collective identities are consolidated, but only in reference to another group. Consequently, groups' creation of collective identities also creates and reinforces boundaries between their groups and others. Community, in this manner, produces difference while simultaneously providing belonging to the community (Barth 1969). This belonging is expressed and its meaning communicated through ritual, symbols, and traditions that embody the collective identity of the community.

Thus, identifying and analyzing creative, solidarity-promoting tools and processes of community building and maintenance become very relevant in using community as the framework driving the analysis of the collective experiences of Puerto Rican men living with HIV. Whether the formation of a community results from face-to-face interaction or is established solely on common interests and experiences, a sense of belonging, collective identity, and social boundaries are important to establishing and maintaining such a community. Each community utilizes varying materials and tools to build their collective identity materially and symbolically, though people utilize similar 
constructions processes- symbols, rituals, etc. It is these materials that construct each community's uniqueness and thus boundaries. Furthermore, when communities are not taken as static entities but as ongoing social constructions of collective identity involving the integration of new members and the reproduction of belonging-cum-solidarity for existing members, then analysis can also involve examining how members exercise agency in community building and maintenance. Similarly, given that communities by their "nature" involve social boundaries, community building is also boundary construction and community maintenance is also boundary maintenance.

Whereas an HIV diagnosis is an obvious boundary delineating the community under study, as with other communities, the processes of boundary construction and maintenance responsible for building and sustaining the community are complex. In the community under study, boundaries are also negotiated internally involving intricate ongoing social processes of exclusion and inclusion, producing fluid community membership. Thus, setting boundaries with ongoing social process speaks of a dynamic community that is far more than just a group of people sharing a common stigmatized medical diagnosis. For these men, la comunidad is a social product that evokes similar experiences of HIV, one in which they, ultimately, are actors in the production and maintenance of the community.

\section{The Social Construction of Community}

The notion of community as a social construction is well argued in the literature (Suttles 1972; Cohen 1985; Anderson 1991; Appadurai 1996; Day 2006). For social constructivists, myself included, human interactions produce social spaces where individuals find belonging, identity, and solidarity (McMillan and Chavis 1986; Brunt 
2001; Jenkins 2002). In this manner, the primary agents for generating community are individuals yet the effects are collective (Amit 2002; Olwig 2002; Wood and Judikis 2002; Day 2006). Day (2006:156 emphasis mine) maintains that "communities are brought into being through the interpretative activities of their members, and registered among the concepts which they use in everyday talk and interaction."

Communities are thus constructed out of different processes of human interaction. The question to ask, then, is what are these processes? Different theorists have addressed this question. For example, Olwig (2002) differentiates between the degree of participation of members in shaping their communities and how the resulting communities vary in tandem. Communities of "sentiment" involve minimum to low active participation by their members in the processes of community formation as they are constructed "indirectly through the generating of feelings believed to be shared by a large collectivity" (Olwig 2002:126). The members of these communities are not passive however, as they are actively involved in practices for perpetuating the community; they

just do not have to dedicate much effort. Communities of "belonging," on the other hand, require that the actors be intimately involved in grass-roots-like processes of negotiating meaning, defining the community's identity and culture (Olwig 2002). The members in these communities are involved in maintaining and reaffirming the community as well.

\section{Theorizing Modern Communities}

For social constructivists looking at community, the physical proximity and emotional closeness of members aids in the process of community formation, but is not the fundamental basis for an entity (Anderson 1991; Smith 1991; Appadurai 1996; Amit 2002). In modern societies, communities challenge the notion of "locality" and face-to- 
face relations as sine qua non of community itself. Instead, group solidarity and collective identity are crafted and maintained by different means of relatedness functioning to create community membership and social boundaries simultaneously (Barth 1969; Cohen 1985; Anderson 1991; Appadurai 1996).

In these contemporary social environments, individuals adopt new mechanisms to relate to others despite not being in physical proximity as was the case for most of human history. Modern communities can be created with social tools that establish bonds between people linking them by common interests and backgrounds (McMillan and Chavis 1986; Anderson 1991; Brunt 2001; Jenkins 2002). People find identification with others along the lines of race and ethnicity, nationalism, disaporic ties as well as across cultural lines into specific social groups such as clubs, churches, and sports. People, thus, can hold membership simultaneously in many communities which provide multiple forms of identification influencing social behavior and actions (Etzioni 1993; Selznick 1995; Wood and Judikis 2002; Hale 2004). Embedded in these communities of commonality, there is also a component of differentiation along which boundaries are drawn (Barth 1969). As such, community becomes a form of "peoplehood" in a paradoxical process in which people perceive they have something in common with others and such commonality provides a source for differentiation from others (Cohen 1985).

These shared sociocultural characteristics are the building blocks driving the social construction of communities in modern pluralistic societies. The construction of these social units is as dynamic and diverse as the processes driving the formation of communities. Communities in these modern social environments are formed through processes that are imagined, de-territorializing, and often symbolic. 


\section{Imagined Communities}

Benedict Anderson's (1991) seminal work on Imagined Communities lays the foundation to understanding some of the processes involved in building community in modern societies despite the absence of face-to-face contact of a traditional community. Anderson (1991) argued the construction of communities as a top-down approach where communities are crafted by a dominant group or elite class in society yet adopted by the many (Anderson 1991; Smith 1991; Amit 2002). Anderson's construction of community follows Olwig's (2002) description for communities of sentiments and eliminates the need for members to come in contact with each other to realize a social unit, minimizing the required participation of members in the building process. In fact, in Anderson's (1991) "imagined" community there is no need for face-the-face interaction for community to exist. Instead, he argues for the construction of community in which members share sentiments of belonging to an entity with a unique history, culture, and identity, which is made real and reproduced by institutions of power (Anderson 1991).

What is salient in the concept of community proposed by Anderson is that members participate in the processes by reaffirming community through adopting the cultural rituals and symbols embodying and signifying these sentiments (e.g., flags, sports teams, holidays, etc.). Consequently, imagined does not suggest imaginary or invented (Mason 2000; Jenkins 2002). On the contrary, these communities are real and their existence, as clearly articulated by Mason (2000:39), “depends upon people conceiving of themselves as related to one another." The relatedness in this form of community is imagined because all members in society do not know each other and do not engage in face-to-face relationships. In fact, they often do not even participate in 
determining the structure, identity, and symbols of group, "yet in the minds of each lives the image of their communion" (Anderson 1991:6).

Anderson developed the notion of "imagined" community to analyze how nationbuilding projects produced profound feelings of nationalism without the need for face-toface contact. In the early stages of nation-building at the turn of the XIX century, the availability of print media, primarily newspapers, was the principal mechanism for spreading the feelings of community and mutual identification (Anderson 1991). In later periods, Anderson points to other nation-building tools used by the state such as the census, maps, and museums as instrumental in cultivating and sustaining the sense of belonging and relatedness responsible for the production of national identity and solidarity.

\section{Deterritorialized Communities}

Anderson's breakthrough concept of community formation has been further elaborated to encompass diasporic communities. The presence of a strong national sentiment and collective cultural identity in Diasporas despite the lack of face-to-face contact between members and their homeland speaks of intricate building-bocks participating in the community-building process. Arjun Appadurai $(1996,2003)$ put forth the notion of "deterritorialization" and "disjuncture" to describe the re-affirmation of a nation outside the political borders of a national territory. Appadurai explains that in an era of globalization it is difficult to speak about the supremacy of the nation-state as the sine qua non community of belonging, but instead the focus should be placed on understanding the dynamics of interaction between people in Diasporas and their home countries. Therefore, the idea of nation, a community of citizens, cannot be limited to the 
confines of political boundaries, but it extends to where the people are making rightful claims for participation in the interest of their homeland (Appadurai 2003).

Appadurai explains that because of the nature of the global economy there are new types of imagined community landscapes. These landscapes, Appadurai explains (2003:31), “are the building blocks of what (extending Benedict Anderson) [are called] imagined worlds, that is, the multiple worlds which are constituted by the historically situated imaginations of persons and groups spread around the globe." These new types of imagined worlds are the agents promoting the experiences and actions that ignore the borders of the nation-state.

Undoubtedly, Anderson and Appadurai's concepts are not just limited to the processes of nation building, but can be applied to other forms of communities, including people brought together by an HIV diagnosis. Anderson's notion of how communities are reproduced and sustained over time through cultural symbols provides an insightful theoretical starting point to examine the importance of rituals, symbols, and practices among Boston's HIV-positive Puerto Rican men and the role these play in producing and sustaining a sense of community. Appadurai's ideas on community are equally important to the study at hand given the nature of HIV as a global pandemic that has impacted people worldwide disregarding political and cultural boundaries. In fact, the stigma and negative perceptions of people infected with HIV are a common denominator in all societies, constituting what some now refer to as an HIV global community (Kleinman 1997; Piot et al. 2001; Evans et al. 2004). Findings from the current study are potentially as de-territorializing as the spread of HIV, its negative perceptions, or the practices of nationhood across political boundaries articulated by Appadurai. However, the face-to- 
face and agency-driven nature of la comunidad of these HIV-positive Puerto Rican men in Boston is different than the depictions of communities conceptualized by Anderson and Appadurai. Instead, the framework for communities created symbolically can best capture the processes behind the creation and affirmation of this specific community. Symbolic Communities

Anthony Cohen (1985) views community as a symbolically constructed form of social organization. Cohen's (1985) conceptualization of a "symbolic community" removes common spatiality or ancestry as a requirement for the existence of a community. In so doing, he also removes an often unstated assumption among many people that a community is a group of people in face-to-face contact. Face-to-face contact is not necessary, as I have argued above, so long as people feel they belong to their community, a feeling typically symbolized using a totem, name, etc. Community, thus, is established with symbolic boundaries in a dual process in which people (1) perceive they have something in common with others and (2) such commonality provides a source for their differentiation from others. Because of the symbolic nature of this form of social community, Cohen (1985:98) explains that community does not require physical boundaries, instead "[c]ommunity exists in the minds of its members... By extension, the distinctiveness of communities and, thus, the reality of their boundaries, similarly lie in the mind, in the meaning which people attach to them, not in their structural forms."

Cohen's view shifts the analytical focus toward the symbolic processes community members themselves employ in producing, maintaining and changing their communities instead of on the ways non-members produce communities through hegemonic processes, particularly exclusion. From his perspective, Cohen is more 
interested at looking how people inside a boundary construct that boundary and, in so doing, their sense of community while many other theorists view the same phenomenon from outside forces that also construct the boundary. A classic example of hegemonic exclusion producing community would be the Nazis' treatment of Jews. Stigma and hatred of Jews was used to exclude them and an externally applied symbol, the yellow star, came to signify this membership (Friedman 1955; Schoenberner 2004).

In contrast, my research, much like Cohen, while it does not ignore exclusion as operative, focuses on group membership produced by members themselves. It is the inside perspective that offers a bigger window to viewing members' activities which affirm their community. Such processes nor the belonging they engender are not necessarily visible to nonmembers, as "often these boundaries will be extremely subtle, and possibly quite invisible to anyone who is not part of, or very close to, the community itself" (Day 2002:159). For example, recovering alcoholics do not carry any particular mark that identifies them as part of an Alcoholic Anonymous (AA) community. Alcoholic Anonymous members come together as a community by accepting alcoholism as a problem in their lives. AA members learn from participating in the community (e.g., support groups, sponsor-sponsee relationship, 12-step program) how to manage living a life in recovery free from alcohol. As the AA case illustrates, when members belong to communities they learn community-specific elements while nonmembers can be completely unaware of these communities' existence even if they are in contact with them or its members. Consequently, community resides in the minds of people and can be expressed; it is also constructed through many real activities which are observable and can be analyzed. My dissertation records both the perceptions of Puerto Rican HIV- 
positive men about living in community as well as the ways they build and sustain community.

Cohen's argument about how communities are symbolic yet often unnoticed by nonmembers is crucial to the conceptualization of an HIV community in which members suffer from taboos and stigmas. An HIV diagnosis symbolizes a status change—albeit not a membership into the communities I studied — that is typically kept private. It is not a public symbol of community membership. The HIV diagnosis is a prerequisite to membership in the communities I studied but it is not by itself sufficient. It serves as a boundary between potential members and everyone else, however. Therefore, the HIV diagnosis is one of several mechanisms utilized to participate in the HIV community among the Puerto Rican men I studied. As will be discussed later, the diagnosis and the social boundary it symbolizes is critical to many types of "boundary work" these men undertake to affirm the community. Subsequently, Cohen's notion of symbolic community is crucial to understanding the process of de-stigmatization of HIV with new meaning based on the interaction and practices engaged by these men to living long term with HIV collectively. As Cohen explained,

community itself and everything within it, conceptual as well as material, has a symbolic dimension, and further, that this dimension does not exist as some kind of consensus of sentiment. Rather, it exists as something for people "to think with". The symbols of community are mental constructs: they provide people with the means to make meaning. In so doing, they also provide them with the means to express the particular meaning which the community has for them (Cohen 1985: 19).

As it is described in the pages of this dissertation, for this group of men living positive lives with HIV is a lifelong strategy to affirming community. In the words of 
these men, for them, this is done through symbolic processes that involve ongoing faceto-face interactions. Their involvement in a symbolic construction of community gives new meaning to what it means to live with HIV despite the stigma and exclusion attached to the illness.

\section{Community-defying Elements: Rituals and Symbols}

As discussed above, the notion that communities are not static but dynamic, that they are best understood as social constructions, is well argued in the literature (inter alia Suttles 1972; Cohen 1985; Anderson 1991; Appadurai 1996; Day 2006). However, many scholars have asserted that communities are social constructions more than examining these processes of construction, without a concerted focus on exploring in depth the internal processes, community expressions, and how the negotiations of boundaries contribute to perpetuating community. To this point, Anderson has done one of the best jobs of identifying activities involved in socially constructing nation-states as communities. However, there are many other communities and a question, relevant to this study, is what are the basic building blocks of communities that can be identified explicitly and then use to understand la comunidad of Puerto Rican men living with HIV in Boston?

Symbols, rituals, and traditions are powerful expressions that carry important information and meaning that accompany the production of community (Cohen 1985; Anderson 1991; Muniz and O'Guinn 2001). Despite the centrality of these communitydefining elements by scholars, their recognition is much less frequent than the recognition that communities are socially constituted through interactions. Thus, the literature in this area is not as well developed as one would like regarding community- 
building processes and tends to focus on specific types of communities. For example, among the most cited literature in their vein addresses how people construct and maintain nations as communities (Gellner 1983; Hobsbawn 1990; Anderson 1991). At a micro level, there are some theorists such as Erving Goffman who studied ritual actions as constitutive of all kinds of "communities" such as institutions even (Goffman 1961). And there are a few ethnographies of treatment communities (Cain 1980; Skoll 1992; Humphreys 2000; Brandes 2002) and "illness" communities (Becker 1980; Goldin 1984; Cleve and Crouch 1989) which, like this dissertation, focus in on how individuals create and recreate community by doing community; in other words, by engaging in practices specific to the group that defines who they are as a group and as individuals by membership.

Rituals are fundamental community-specific expressions and interactions that construct and reproduce community. The community-building properties of rituals involve more than a shared physical performance; they establish and enhance belonging among those involved (Rappaport 1979). "One obvious aspect of ritual is that it not only brings people together in physical assembly," noted Driver (1991:153), "but also tends to unite them emotionally." In anthropology, Arnold van Gennep (1960) examined the importance of rituals in the transition of individuals between social positions or generational statuses in a society. These rituals, rite of passages, have the attribute to bring people into membership and in communion with a group at a different status. The White Coat ceremony, for example, is the essential rite of passage among medical students to change from laypeople to becoming members of the healthcare profession community (Veatch 2002). Victor Turner in his seminal work The Ritual Process (1977) 
explored further the importance of rituals in community building. For Turner, rituals are inherently communal. He identifies a special sense of community (commuintas) that is forged from experiencing specific rituals together that accompany the social status changes described by van Gennep during a period of uncertainty, absent of any status (liminality). Turner's notion of commuintas reminds us of the bond and comradeship developed among young recruits during military boot camp. These recruits endure arduous even demoralizing physical and emotional treatment as part of the training to becoming soldiers, a period of time that solidifies the solidarity and a storing sense of duty towards one another (Yarmolinsky 1971; Arkin 1978).

Rituals are important to establishing identity and determining belonging. Douglas and Ishwerwood (1979:65) argued that rituals "serve to contain the drift of meaning...[they] are conventions that set up invisible public definitions." Similarly, traditions, equally important for community, defined as "set of practices which seek to celebrate and inculcate certain behavioral norm and values," transmit the expected conducts for members of a given community (Marshall 1994:537). For example, rituals and traditions have been fundamental to the construction and maintenance of the gay community in the U.S. (D'Augelli and Garnets 1995; Plummer 1995). "Coming out of the closet" rituals facilitate the transition from living in secrecy to embracing the gay identity and accepting public membership into the community (Zimmerman 1984; D’Augelli and Garnets 1995). Other rituals and traditions including Pride Day parades, the National Coming Out Day, and even displaying publically the Rainbow flag serve to strengthen solidarity and community culture with messages of pride and dignity unifying the members through the public expression of their identity despite the social 
discrimination and stigma attached to their sexual orientation (D'Emilio 1983; D'Augelli and Garnets 1995; Frazer 1999). Benedict Anderson (1991) refers to this process of community building in terms of the "imagining" of a community. Fundamentally, people's common history and culture provide a sense of shared meaning and identification in the observance of specific community defining elements that functions to promote the existence of solidarity and a collective identity (Anderson 1991).

The widespread reverence for cultural insignias and community symbols are intimate to the social process of community-building. For example, in so-called "simple" societies, totemism combines symbols (the totem itself) and rituals (the performances people do to show their association with the totem) has helped people belonging to different sectors of a society nonetheless find belonging within this larger social unit (Service 1958; Levi-Strauss 1963; Radcliffe-Brown 1965). A sense of belonging is created through the "objectified" collective sentiments expressed in the collective rituals associated with the sacredness of the totem (Durkheim 1965). Totemism does more than maintain solidarity through collective rituals; it also functions to foster a unique identity as well (Radcliffe-Brown 1965). In other words, the totem of a clan serves the same role as the flag of a modern nation (Durkheim 1965; Radcliffe-Brown 1965). In fact, a flag can be interpreted as a national totem although the connection between "primitive" totems and modern "totems" is much more easily seen in sports teams' animal mascots and their ritualized activities on behalf of the teams. Totems promote communal acts that unite people reaffirming and reproducing their respective communities. Etzioni (2004:7) views such rituals as "provid[ing] one major mechanism for the re-creation of a society in which members worship the same objects and share experiences that help form and 
sustain deep emotional bonds among the members." In the HIV world, the red ribbon is a well-recognized totemic symbol representing awareness and a symbol of the fight against AIDS and wearers identify as members of the global AIDS community, particularly on December 1-World AIDS Day. Widely recognized symbols like the HIV red ribbon do not preclude groups from adopting their own totems, symbols specific to their own experiences. I found this to be the case with the Puerto Rican men I interviewed. For these men, as described at length in chapter 4 of this dissertation, these symbols embody the community they experience in terms of living positive.

Rituals and symbols as community building tools foster the creation of and then the reinforcement of feelings of commonality. As community-specific cultural expressions they function as mechanisms that determine association to community, and in the process, these provide a specific identification of distinctiveness that serves to establish the difference between "us" and "them." As noted by Holocombe (2004:163) embedded in the collective identification of rituals and traditions there is an ongoing process of community re-creation in which the "community as a collectivity reproduces itself in relation to other communities and more simply [identifies] 'others' as outsiders" (Holcombe 2004:163). These performances are an integral part of the lifestyle of a community's members, transmitting and reproducing the meaning of the group within and beyond the community (Muniz and O'Guinn 2001). For Bolivian immigrants in Buenos Aires, Argentina, celebrating their patron saint, La Virgen de Copacabana, is a yearly event awaited with great anticipation in the community (Laumonier 1983; Grimson 1999; Sastre 2000). For Bolivians, the collective expression of popular religion asserts that there is a distinctive Bolivian community in Buenos Aires despite the ongoing 
oppression and rejection experienced in the host society (Grimson 1999; Sastre 2000).

As the Bolivian case illustrates, rituals and symbols are important repositories of meaning holding valuable information in the nature of a community, including its foundation, culture, and important to setting boundaries.

\section{The "Otherization" of People into Community}

As discussed above in the many ways that communities are socially constructed, the efforts of members' actions need to be taken into account. The agency role of community members is extremely important in my overall research on the Puerto Rican HIV-positive men. However, no discussion can exclude the fact that processes of exclusion are central in community formation too, particularly when studying minorities or marginalized populations, as in the case of HIV-positive people. The experiences of stigma and marginality are key determinants shaping the boundaries and even characteristics of these communities including specific cultural material such as rituals, symbols, and practices. As such, any endeavor to describe a specific HIV community must acknowledge the importance of exclusion in the process of community formation and belonging as well as in process of generating alternative notions to de-stigmatizing HIV.

Practices of exclusion are responsible for community formation in modern pluralistic societies as well. As argued above, the growth of small-scale societies necessitated alternative forms of belonging and identification that would bind people together who could not know each other face-to-face. One of the most important means to foster the feeling of belonging is to identify and ostracize those who do not belong - to exclude (Cohen 1985; Anderson 1991; Appadurai 1996). Such processes of strengthening 
community on the basis of exclusion, in turn, evoke processes of "otherization" by categorizing groups of people. The idea of "otherization' is clearly articulated in Barth's work (1969) where he argues that groups and identities are established with social boundaries in reference to another group, determining who does and does not belong into real or imagined communities. Exclusion in this sense functions to establish status and monopolize resources by redefining communities and redrawing boundaries, consequently stipulating differences as having real social value (Young 2001; Lamont and Molnar 2002). Social differences, then, become the basis for social hierarchies (Massey 2007). Not surprisingly, community, says Young (2001:48), is “invoked to ensure domination of one group over the other, a key instrument for social exclusion." In this sense, community becomes a means to enhance social differences by turning them into stratifications used to discriminate. Groups of people (the "us") determine who is seen as the "other" (the "them") and heap social rejection upon "others" when there are reasons for these distinctions to be developed into social hierarchies — such as when groups fight over resources. The more powerful one group is over others, the more it can construct the others' community characteristics despite the efforts of the "others" to the contrary. In some cases, this stigma defining the "other" status becomes associated with one characteristic that supersedes all others.

In some cases the stigma becomes the most important identity of the people who are attached to that stigma. Such cases are referred to as constituting "terminal" identities. Terminal identity, as explained by Epstein (2006:101), functions differently for people not under exclusion than for those who are stigmatized. In the former case, terminal identity "represents the process by which the person seeks to integrate his 
various statuses and roles, as well as diverse experiences, into a coherent image of self." My status as a PhD student and how I performed and fulfill this role is important to my identification, but it does not constitute my personal identity. Being a Christian, Hispanic, male, divorced, marathon runner, and public health worker among others, all in addition to my student-consuming role contribute to my terminal identity without having one identification trumping the others. Terminal in this sense does not constitute that one is principal over others, but all are integrative and, thus, are exercised predominantly given different setting and social situations.

However, in the case of groups being stigmatized, the terminal identity attaches to and thus pronounces the stigmatized characteristic. No other characteristic matters as much — as in the case of HIV. While the status of Puerto Rican men in Boston living with HIV, including the way in which they express their Puerto-Ricanness, minority status, and gender role is important to their personal and community identification, it is unlikely that these formulate their principal identification. Instead, these men's experiences of illness, stigma, fear, and discrimination linked to their HIV diagnosis overwhelm their personal and social identification. HIV is predominant as the terminal identity of these men. And, unlike surviving through a $\mathrm{PhD}$ program which is actually temporary, my terminal identity is complemented by other factors, living with HIV/AIDS has no end.

Terminal identities involving stigmas, then, can and should be identified and analyzed as markers of particularly brutal forces of social exclusion. This does not mean, however, that such communities are defeated by this labeling; rather, there is ample evidence from a variety of highly ostracized peoples from slaves to Jews in ghettoes to 
communities of people living with physical disabilities that such marginalized groups still provide their members support, solidarity, and a sense of belonging and identity. In some such cases, marginalization engenders collective resistance to oppression (Vigil 1988; Moore 1991; Kubrin 2005) and stigmatized stereotypes (Mitchell and Feagin 1995; Duneier 1999; Bourgois 2003). In this sense, new identities and cultural practices emanate from people who share experiences of exclusion and common social rejection. Here people find identification with groups in a larger social context, negotiate and transform negative identities, and resist exclusion.

Scholars have addressed the experiences of such peoples and their communities which have been subjected to different bases for exclusion ("other" status) such as sexual orientation (D’Emilio 1983; DeCecco 1984; Herek et al. 2002), physical disabilities (Becker 1980; Foster 1987; Cleve and Crouch 1989), and illness (Magen and Gladjchen 1999; Ussher et al. 2006). For example, in the U.S., the gay community flourished after WWII as large numbers of gay men coming from the war continued their relationships initiated while in the service (D’Emilio 1983; Bérubé 1990; D’Augelli and Garnets 1995). The war environment created the conditions for fostering gay identity, but social oppression forcing gay men into obscurity consolidated the formation of a gay community and collective identity (Herrell 1992; D’Augelli and Garnets 1995). The movement of equality sweeping the U.S. in the 1960s and 1970s allowed for the emergence of the Gay Pride (not stigma) Movement, stressing pride and encouraging gay men "out of the closets and into the streets" (Jay and Young 1972).

Unfortunately, the forces of exclusion absorb the vast majority of social science writing on people living with HIV (Bennett 1990; Weitz 1990; Atrill, Kinniburgh, and 
Power 2001). The body of knowledge informed by this literature is important, as is the vast medical literature on HIV/AIDS as an illness, but in order to improve upon effective HIV treatment it is the thesis of this dissertation that greater attention be paid to how people living with HIV can and do "live positive" lives. I propose that through processes of community affirmation involving rituals, symbols, and practices that are largely constructed and maintained by members themselves - and thus are not primarily in response to exclusion, some of Boston's HIV-positive Puerto Rican male population transform their lives to living better overall and not just to living long term with HIV. I recognize that not all people living with HIV/AIDS take this path and not all Puerto Rican men in Boston do, but my purpose in focusing on these particular men's experiences is to show that positivity takes many forms and even arises out of the most unexpected places. If hope can spring eternal from the depths of a "terminal" identity, then there may be reason to facilitate such hope for others afflicted by other stigmatized exclusionary forces including but not limited to HIV.

To summarize, on the basis of different conceptual frameworks for producing community, individuals come together by common exclusion and find a sense of solidarity and belongingness with others who share similar backgrounds and experiences, including perceptions of illness and social marginality. I argue that it is within this social environment, in community, that alternative experiences of illness and new constructions of meaning of living with HIV are negotiated, encouraged, and performed. Now, it has long been recognized that practices of discrimination and otherization are the primary force building and maintaining communities of exclusion. However, the argument advanced in this dissertation is different. The community described by my interviewees 
is one of affirmation of healthy living in the face of a grim outlook proposed by HIV; a community of extraordinary solidarity encouraging the wellbeing of one another; a community built out of intensive face-to-face contact where personal successesphysical, emotional, and social—is celebrated as a community success. The discussion in this dissertation is on a community of men living positive lives.

\section{Case Study: La Comunidad of Puerto Rican Men Living with HIV in Boston}

Exploring the positive adaptation to HIV exhibited by these men is crucial given the staggering number of HIV-affected Puerto Ricans. Among Latinos in the U.S., the Puerto Rican population has been the most affected by the HIV/AIDS epidemic. The CDC reports that in $2005,55 \%$ of all newly diagnosed cases of AIDS among Latinos in the U.S. were among Puerto Ricans (CDC 2007), although they comprise only $10 \%$ of the Latino population living in the U.S. (Census 2000). The disproportionate impact of HIV/AIDS in this community is felt in the urban areas where the largest numbers of Puerto Ricans reside, particularly in the northeast U.S. (Selik et al. 1989; Delgado and Santiago 1998; Perez y Gonzalez 2000). Puerto Ricans in Boston constitute 30\% of the city's Latinos yet, comprise a disproportionate $40 \%$ of all the HIV/AIDS cases (MDPH 2004). Males comprise $76 \%$ of these HIV cases in Boston.

In terms of new cases of HIV, the Puerto Rican population is at a higher risk of infection than any other group in Boston, including other Latinos. According to the Massachusetts Department of Public Health (MDPH 2001), poverty, low levels of education and illiteracy, and unemployment are factors contributing to the risk of contracting HIV and developing AIDS. Puerto Ricans in the city have one of the lowest educational attainment, lowest annual median household income, and higher 
unemployment than any other group in the city (Census.gov) (Table 1). These, among many other factors related to poverty, inequality, and discrimination place this population at a higher risk for HIV/AIDS. These factors also determine the resources available to Puerto Ricans and influence their responses to living with HIV as a chronic illness.

Table 1: Socioeconomic indicators by ethnic group in Boston (2007-2009) ${ }^{3}$

\begin{tabular}{lccc}
\hline & $\begin{array}{c}\text { Less than High School } \\
\text { education }\end{array}$ & $\begin{array}{c}\text { Median household } \\
\text { income }\end{array}$ & Unemployment \\
\hline White & $6.3 \%$ & $\$ 69.890$ & $3.8 \%$ \\
Black/African American & $21.7 \%$ & $\$ 34,543$ & $10.8 \%$ \\
Latino & $38.5 \%$ & $\$ 29,886$ & $9.16 \%$ \\
Puerto Rican & $36.9 \%$ & $\$ 16,877$ & $11.9 \%$ \\
\hline
\end{tabular}

\section{Methodological and Ethical Considerations}

With this imperative in mind, I relocated to Boston in February 2009 for nearly a year. I was well aware of the critical and sensitive nature of my study. When I began my field research in Boston in March, the greatest challenge was to protect the study's participants from the potential negative consequences identified by anthropologist Laura Nader in the early 1970s of studying underprivileged populations. In fact, she cautioned social scientists not to study "the poor and powerless because everything you say about them will be used against them" (Nader 1972:295). The negative impact of studying these communities was further reaffirmed more recently by Philippe Bourgois when he warned that "under an ethnographic microscope everyone has warts and anyone can be made to look like a monster" (Bourgois 2006:18). These concerns guided me to take extra precautions as I set off to start my research in the field given the population of the study.

${ }^{3} 2007$ - 2009 American Community Survey 3-year Estimates 
Ironically, the first concrete realization of the delicate nature of my study came very early even before I conducted the first interview, from something I did! Soon after receiving the approval from the different Institutional Review Boards (IRB) to conduct the study, my research came to a complete halt days prior to commencing the recruitment of participants. The excitement of finally being in the field, launching the study that had been planned for three years, and eager to start the focus groups and interviews, quickly drifted away as I realized that I had almost participated in stigmatizing the same men that I was recruiting to be participants in my study. Unbeknownst to me, including the word "SIDA" (AIDS) with Puertorriqueño in the recruitment flyer was not just an inconsequential decision intended to list the eligibility criteria, as I thought ${ }^{4}$. Instead, as pointed out by an outreach worker at a local HIV agency, there is a strong resistance to the word SIDA among Puerto Ricans and other Latinos. SIDA is highly stigmatized and it is closely related to dying. Instead, these men talk in terms of VIH (HIV) or "la condición" (the condition), not SIDA. Revising the flyer was simple and it proved to be effective in recruiting as well as in preventing negative publicity for my study. I realized early on that with minor changes, major accomplishments can be achieved. I am hopeful this would also be true to how HIV will be perceived when seen through the eyes of these men.

Another challenge I faced early on related to entering the world I intended to study. As an anthropologist, participant observation is one of the most powerful tools to capture subjects in their natural environment (Bernard 2006). Unfortunately, the nature

\footnotetext{
${ }^{4}$ Flyer read: "Si eres PUERTORRIQUEÑO, HIV-positivo (o con SIDA), y tienes 18 años de edad o mayor, entonces puedes participar en un estudio" ("If you a PUERTO RICAN man, HIV-positive (or living with AIDS), and 18 years old or older, you can participate in a study")
} 
of the population under study dictated that participating in support groups, group activities, psycho-educational programs, and social events was limited. The groundwork to obtain the support from different HIV agencies in Boston to conduct the study had been done a year before I arrived to conduct the field research. Furthermore, I had worked in this field for four years as an HIV/AIDS program evaluator and community researcher, which facilitated contacts to conduct this study. Being well known in the area helped to identify key stakeholders at each site to promote the study and assist with recruitment. Despite the interest and support I received, entering the social world of these men would take some time. All preparations and pre-research work had been done, but, nevertheless, I was an outsider who was attempting to study the experiences of HIV among Puerto Rican men. All the prearrangements were not sufficient to enter this community to observe it firsthand. However, the men, the individuals who shape the community, agreed to be participants in my study and share their stories. These men became the main source of information about their lives and the community which I could not witness personally. Although, in ethnic background, sexual orientation (of some), and seropositive status I am different from most of these men, because of our common interest in challenging perceptions of HIV I was eventually a welcomed outsider to their settings. More importantly, in the process, I gained their trust to tell their stories.

A final, more personal, consideration deriving from the work in the field was the psychological impact of being exposed to stories of human tragedy during research. As occurs with other researchers exposed to emotionally charged situations, collecting information can be psychologically overwhelming (Powdermaker 1966; Sterk 1989; Scheper-Hughes 2001; Bourgois 2006). The stories that these men shared with me in 
addition are filled with traumatic events, tragic circumstances, and periods of despair. In fact, it was not unusual for any of these otherwise tough men, hardened by experiences of living on the streets or from spending time in prison, to break down in tears during an interview while recalling events from their past ${ }^{5}$. As an ambitious researcher, on a couple of occasions I conducted three 2-hour long interviews on a single day. However, the gains of these productive research days were slowed down subsequently for days as I needed to separate emotionally and mentally from my subject to be able to continue the research. On these occasions, I was aware that these men did not have the same option and could not detach as I did. Instead, they cope with those events and their past in other ways. Some of these strategies are part of this dissertation. Learning how despite such extraordinary pain they found ways to "live positive" gave me doses of enough emotional strength to carry on so that I could translate their affirmation into words others would hear.

Part of having access to their social world is experiencing their lives. Although I cannot pretend to understand what they face daily, their accounts transmit a human story packed with feelings and sentiment that are easy to sense. These emotions are not detached from their narratives. I am committed to transmitting the stories of these Puerto Rican men in the following pages of this dissertation. My goal is for their voices to be heard and for them to drive the development of the larger story presented in this dissertation. My role in this exercise is to only contribute an interpretation. Whether this

\footnotetext{
${ }^{5}$ A clinical mental health specialist was on call during all the interviews in case of a need to ask for assistance.
} 
analysis is accurate or imprecise, my part should not diminish the value and power of the life stories that these men agreed to share with me.

\section{Study Design}

The study was designed considering the sensitivity of the subject. With that in mind, the data collection and analysis consisted of three different research phases: (1) exploratory research during phase one, followed by (2) in-depth data collection in phase two, and (3) a final stage to validate the study's findings during phase three. Given the limited access to gather data with participant observation activities, themes were first explored using focus groups. Previous studies have shown that focus groups are the ideal eliciting technique to research people impacted by HIV/AIDS (Morgan 1996; Guzman 2003). Themes from these groups were then explored in detail during the in-depth faceto-face interviews. The final validation stage was instrumental to validating the overall findings of the study (Kendall 2005). The main concern justifying this last phase of research was that given the close-knit group of these men, data contamination could have resulted when study details were shared among them. Another measure to strengthen the study consisted of excluding individuals who participated in the study from taking part in subsequent research stages. Including new participants in each phase was essential for testing and improving the validity and reliability of the findings using triangulation (Mathison 1988, Golafshani 2003) to make systematic comparisons in the final analysis (Pelto and Pelto 1996, Babbie 2004). 


\section{Data Collection}

A total of $50 \mathrm{HIV}$-positive Puerto Rican men shared their stories as part of this study. These men were recruited from different community-based organizations (CBOs) that provide HIV/AIDS services to Latinos in Boston using convenience sampling. Despite the limitations of this technique it was possible to capture variation in this group in terms of place of birth, HIV transmission category, and length of time living with HIV in addition to other common socioeconomic indicators (e.g., education, income, and employment). Table 2 describes the demographic characteristics and the HIV history of the men that participated in the study.

Table 2: demographics and HIV history of focus groups' participants $(n=50)$

\begin{tabular}{lcc}
\hline & Median (min, max) & N \\
\hline Age & $46(26,70)$ & \\
Length in the US (years) & $23(1,51)$ & \\
Place of birth & & $42(84 \%)$ \\
$\quad$ Puerto Rico & & $8(16 \%)$ \\
U.S. & \\
Education & & $28(57 \%)$ \\
$\quad$ Less than High School & $12(25 \%)$ \\
HS or GED & $9(18 \%)$ \\
Beyond HS & \\
Employment & & $6(12 \%)$ \\
Employed (PT or FT) & $44(88 \%)$ \\
$\quad$ Unemployed/Does not work & & \\
Length of time with HIV (years) & $15(2,25)$ & \\
HIV Transmission category & & $27(54 \%)$ \\
IDU ${ }^{6}$ IDU-heterosexual sex & & $12(24 \%)$ \\
MSM & & $9(18 \%)$ \\
Heterosexual contact & & $2(4 \%)$ \\
Other & & \\
\hline
\end{tabular}

The primary source of data to inform the study was collected from these men using two types of data collection methods: focus groups and in-depth interviews. As

\footnotetext{
${ }^{6}$ Injecting Drugs User

${ }^{7}$ Men who have sex with men
} 
already described, at the initial phase of research, four exploratory focus groups were conducted during a period of one month in which 19 HIV-positive Puerto Rican men participated ( $38 \%$ of the total sample). In one group, men identified having been infected with HIV by sharing needles (IDU) $(n=4)$; a second group was composed of men that contracted HIV with the use of needles and/or heterosexual contact $(n=7)$; another group was composed of men that self-identified as having been infected with HIV through sexual contact with a man (MSM) $(n=3)$; and a final group was composed of members of a residential program (regardless of transmission category) $(\mathrm{n}=5)$. The purpose of the exploratory focus groups was to identify themes describing the social lives of the participants and the forms of coping with HIV/AIDS, particularly in regards to identifying with other people living with HIV/AIDS and to coping with HIV long-term. The themes and categories that emerged from these focus groups were researched at length during one-on-one in-depth interviews in the second phase of research.

During the second phase of the study, 31 HIV-positive Puerto Rican men participated in the in-depth interviews using a combination of semi-structured protocols that lasted between 1.5 to 2.5 hours in length. The overall objective of the interviews was to collect data describing the participants' social lives guided by the specific dimensions identified during the focus groups regarding coping with HIV/AIDS, stigma, marginality, and community. The major task of the in-depth interviews was to understand how these men adjust and cope to a life with HIV/AIDS. These interviews helped (a) to capture the impact of HIV/AIDS stigma and discrimination along with social marginality in their lives and (b) to understand what coping strategies they deploy to respond to these factors, 
particularly looking for evidence pointing to the presence of solidarity and community among people sharing similar experiences of illness.

For HIV/AIDS service providers also provided invaluable complementary information to the study. Direct care staff who work with HIV-positive individuals from the agencies where participants were recruited were invited to participate in a focus group (Table 3). The purpose of this focus group was to identify CBOs' strategies and best practices (e.g., core values, policies, treatment approaches) that strengthen solidarity and community among their clients. Their input was also important for exploring the providers' experiences in serving this population to learn additional information they believed crucial to serving clients better, including the impact of the illness on the everyday lives of their clients/patients, importance of cultural competency in providing services, and barriers to access care. The information from this focus group was used primarily to assist in the design of the in-depth interview guide used during the second phase of research already described. Further analysis and discussion of the data from this focus group is outside the scope of this study and it will be part of future publications and research.

Table 3: Service providers' characteristics

\begin{tabular}{lcc}
\hline & \multicolumn{2}{c}{ Gender } \\
& Male & Female \\
\hline Case manager & 0 & 1 \\
Outreach worker & 1 & 0 \\
Counselor & 1 & 0 \\
Clinician & 1 & 0 \\
\hline
\end{tabular}


For reasons provided above - primarily owing to confidentiality protections within organizations providing services to people with HIV, participant observation was very limited in this study. Despite the limitations imposed by the HIV nature of the study already described I was invited as a guest to three different group activities. These opportunities, two peer-support groups and lunch with participants at an HIV agency, provided insightful data to complement the findings of the study. Although limited, these instances of participant observation allowed me to observe important everyday activities in the lives of these men to validate some of the information shared during the interviews.

Participation in the study was voluntary and confidentiality was assured following strict guidelines recommended and approved by the IRB. Furthermore, a Certificate of Confidentiality was obtained from the National Institutes of Health to insure maximum protection for these men. The certificate protects investigators from being required to reveal any information about subjects even under subpoena, and places the investigators under a legal obligation to protect subject confidentiality. All participants signed an informed consent form prior to participating in the study and received $\$ 30$ for their time at the end of the session. Even though many of the men interviewed encouraged me to use their real names in the final report of the study, the names that appear throughout the dissertation are pseudonyms to protect their identities, as outlined in the approved research protocol.

\section{Data Analysis}

To maximize the integrity of the data, the focus groups and interviews were recorded and transcribed. All the participants agreed to be recorded and each session was transcribed using the original language, the majority done in Spanish. Only three 
participants preferred to conduct the interview in English (Felix, Felipe, and Leo). Maintaining the text in its original language provides important benefits in terms of saving resources and time. Furthermore, an accurate transcription is critical for the analysis of qualitative data to safeguard the integrity of the research findings (Oliver, Serovich and Mason 2005).

The coding of the transcripts was conducted on the original language of the interview. The translation into English was performed once selected interview sections were included in the manuscript of the dissertation. The translations were conducted by an independent translator. All the translations were checked and edited for accuracy by this researcher. The sections of text included in the dissertation from the interviews in English are noted with a footnote throughout of the document ("English-speaking respondent - text in original language of interview"). When not noted, narratives from the interviews throughout the dissertation were translated from Spanish.

The data management and analysis were done using Atlas.ti, a computer assisted qualitative analysis software package. In addition to its capability for assisting with data coding, this software has additional functions to aid in organizing the data. The data management function was critical given the multistage design of the study and the amount of data involved (e.g., documents, memos, codes, etc.).

Prior to initiating a systematic data analysis of the transcriptions, a pre-coding stage was conducted. This exploratory data analysis included listening to the recoding of each interview and reading the transcriptions to explore for themes of analysis (Corbin and Strauss 2008), in addition to verifying the quality of the transcriptions prior to commencing coding. According to Corbin and Strauss (2008:163), "the idea behind the 
first reading is to enter vicariously into the life of participants, feel what they are experiencing and listening to what they are telling us." In other words, this stage is important to getting closer to the participants by familiarizing with the data. At this stage, particular attention was made to identify patterns in the data: commonalities, discrepancies, curiosities, metaphors, words selection, as well as outlier events and cases. The patterns and themes observed during this exploratory data analysis were documented using the Memo function integrated in the qualitative data analysis software Atlas.ti. In addition to organizing the exploratory notes methodically, the software permits to use memos as codes to link them directly to the text during the analysis. This feature facilitates the data analysis and, in fact, much of the analysis of the study was driven by the themes identified and ideas originated during this stage of analysis.

Once the exploratory data analysis was complete, the transcripts were coded to identify themes following a concurrent two-step metacoding approach (Ryan and Bernard 2000). During the first step, the transcriptions were coded for general categories describing the participants' social lives and experiences with HIV. These categories included: "life changes," "coping," "community," and "Puerto Ricanness." These categories were derived from the literature and observations of the researcher over several years of professional work in Boston. An additional coding category, "HIV life," was added to code the in-depth interviews as a result of analysis of the data from the focus groups (Table 4). The second step consisted of coding the text for emergent themes to documenting strategies for adjusting to living long-term with HIV and for coping with the stigmatized notions attached to the illness. Table 5 summarizes the total number of coding instances applied during each step at the different phases of research. 


\begin{tabular}{lcccccc}
\hline \multicolumn{7}{l}{ Table 4: number of coding instances by pre-determined code category } \\
\begin{tabular}{lccccccc} 
Category code & Stage 1: Focus groups & Stage 2: In-depth interviews & \multicolumn{2}{c}{ Total } \\
\hline Life changes & 33 & $21 \%$ & 292 & $14 \%$ & 325 & $15 \%$ \\
Coping & 31 & $20 \%$ & 129 & $6 \%$ & 160 & $7 \%$ \\
Community & 64 & $41 \%$ & 716 & $35 \%$ & 780 & $36 \%$ \\
HIV life & \multicolumn{2}{c}{ not coded } & 835 & $41 \%$ & 835 & $38 \%$ \\
Puerto Ricanness & 30 & $19 \%$ & 30 & $2 \%$ & 60 & $3 \%$ \\
\multicolumn{1}{r}{ Total } & $\mathbf{1 5 8}$ & & $\mathbf{2 0 1 9}$ & & $\mathbf{2 1 7 7}$ & \\
\hline
\end{tabular}
\end{tabular}

Table 5: number of coding instances by code type

\begin{tabular}{rcccc}
\hline Code type & Stage 1: Focus groups & \multicolumn{2}{c}{ Stage 2: In-depth interviews } \\
\hline General categories & 158 & $21 \%$ & 2019 & $67 \%$ \\
Emergent themes & 580 & $79 \%$ & 975 & $33 \%$ \\
Total & $\mathbf{7 3 8}$ & & $\mathbf{2 9 9 4}$ & \\
\hline
\end{tabular}

To complement the systematic qualitative data analysis, additional data mining techniques were performed to explore further the data for additional patterns and themes. First, I ran regular quotation frequencies, these are frequencies of the instances a code has been used to determine coding trends. This is a powerful technique to visualize the data and identify unexpected themes. For example, early in the coding process, a quotation frequency analysis revealed that the narratives were being coded with the code "new life" considerably more often than with codes capturing life changes post HIV ("life change positive" and "life change negative"). Upon running an analysis of the quotations for the "new life" code, it clearly showed an important trend in the perception of the impact of HIV among these men indicating that they did not feel their lives were just changed, but, 
rather, that they had been transformed. This analysis was central to the themes developed in Chapter 5 describing the positive lives of living with HIV.

In addition to running the quotation frequencies, at different stages of the coding I ran numerous analyses using the "word cruncher," Atlas.ti analysis function to run word frequencies. This feature allows quantifying how often words are being used in the interviews. This analysis is helpful in identifying word usage patterns and to discover meaning in words, such as the use of "we" instead of "I", words denoting time, the use of terms to refer to metaphors, etc. (Corbin and Strauss 2008). This analysis has limitations, primarily because counting words by itself does not differentiate between the text corresponding to the respondents and the interviewer. Despite this limitation, this type of analysis identified fruitful patterns to pursue such as the men's greater use of the term "HIV" ( $\mathrm{n}=982)$ as compared to "AIDS" ( $\mathrm{n}=123)$. In sum, the word frequency analysis helped to initially identify the pattern in the use of HIV term, a theme which is described in detail in chapter 4 .

During the coding of the data, the codes were organized in code families. A total of 12 code families served to organize the coding scheme of the study (Table 6). The code families were organized to help with the data analysis, primarily to aid in the writing of each chapter. 


\begin{tabular}{|c|c|c|c|}
\hline \multicolumn{4}{|l|}{ Table 6: Code family scheme } \\
\hline Family Code & Number of Codes & Coding instances & Chapters \\
\hline HIV life & 25 & 774 & 4 \\
\hline Community & 16 & 653 & 3 \\
\hline Life change & 4 & 296 & 5 \\
\hline Coping & 2 & 131 & $3-5$ \\
\hline Community values & 6 & 100 & 3 \\
\hline Cultural values & 3 & 84 & 5 \\
\hline Family relations & 2 & 76 & $3-4$ \\
\hline Puerto Rico & 3 & 47 & 6 \\
\hline Services & 2 & 46 & 6 \\
\hline Shared experiences & 3 & 45 & $3-4$ \\
\hline Free codes & 60 & 936 & $3-5$ \\
\hline In-vivo codes & 12 & 84 & $3-5$ \\
\hline
\end{tabular}

\section{Methodological Limitations}

It is worth noting some limitations of the study. First, the focus of the study was limited to HIV-positive Puerto Rican adult males (18 years of age and older). The study did not include other Puerto Rican populations such as females, transgendered persons, or youth. While the importance of including these populations in a study is well recognized, the population most affected in this group by the HIV/AIDS epidemic is among the adult males. Thus, because of the exploratory nature of the study, only males were included in the sample. The eligibility criteria at times became an issue during recruitment as some HIV-positive Puerto Rican females felt discriminated against by virtue of being ineligible for the study. Upon explaining in detail the scope of the study, they were reassured that they were not being victims of discrimination. Second, the study focused only on 
individuals who were already in care. While the importance to include out-of-care HIV/AIDS individuals is greatly acknowledged, they are particularly difficult to locate and would not have provided rich data on narratives of collective coping to living with HIV/AIDS. Third, the study's participants were recruited using a convenience sample. This is a diverse sample and may be representative of the experience of the HIV-positive Puerto Rican group selected to represent. However, it is also likely it is not representative given merely the small size of the sample. Nonetheless, despite the benefits of this convenience sampling to recruit hard-to-reach populations, the findings are representative of the experiences of the individuals that participated in the study and cannot be generalized for the entire HIV-positive Puerto Rican population on Boston. Finally, sensitive issues such as stigmatization, discrimination, and isolation cannot be verifiable through any means other than self report. The extensive training of the interviewer and familiarity with the target population helped establish the rapport needed to elicit accurate responses and minimize the impact of imprecise self reporting. This affinity was demonstrated by the many unsolicited offers received to contact health care providers to check medical records, verify health conditions, and review treatment history. Data from medical records were not needed for the study, thus this information was not accessed for any of the participants involved in this study. Further discussion of these limitations is incorporated in the Recommendations for Future Research section in the final chapter of this dissertation.

\section{Organization of Chapters}

The organization of the chapters is as follows. Chapter 2 discusses the history of the Puerto Rican community in Boston. The chapter presents the experiences of Puerto 
Ricans in the US, including in Boston, and examines the impact of the relationship between Puerto Rico and the US in shaping the everyday life of this community. Chapter 2 highlights the strong community building responses to issues of exclusion and inequality affecting the community, which in turn helped frame the strategies to respond to the HIV epidemic.

Chapter 3 begins the discussion of the HIV community by engaging in a detailed analysis of boundaries. The chapter examines the societal factors that predispose the HIV-positive community as well as the internal affirmation process establishing community membership that shape the interactions between members. Chapter 3 focuses on the duality of structure and agency in the process of community formation among HIV-positive Puerto Rican men.

Chapter 4 continues the discussion of community and depicts the everyday life for Puerto Rican men living with HIV as part of la comunidad. The description includes community-specific symbols, rituals and traditions, and practices engaged by these men that help to sustain and promote a sense of community. The discussion stresses the importance of community in promoting strategies to living positive for adjusting to living with HIV as a chronic illness.

Chapter 5 presents the narratives for living positive lives with HIV among Puerto Rican men in Boston. In particular, this chapter explores the specific psychological responses and positive social adjustments enacted by these men to living with HIV. The discussion shows how these strategies enhance the quality of life of these men, and in the process, contribute to destigmatize notions of HIV. 
Finally, chapter 6 discusses the contribution of analyzing the experiences of illness among HIV-positive Puerto Rican men with a community lens. Particularly, the discussion focuses on how to incorporate the findings to better the quality of life of these men. The chapter summarizes the overall study's contributions and limitations and provides suggestions for future research. Lastly, this chapter makes specific recommendations to enhance current HIV services and discusses specific treatment interventions for developing new programs of care for this population. 


\section{CHAPTER II.}

\section{PUERTO RICANS IN BOSTON}

Identifying a Puerto Rican in the streets of Boston is very easy, even in the middle of the winter when one is cloaked in heavy gear to protect against the city's harsh weather. Puerto Ricans proudly "label" themselves, with a Boricua y Orgulloso bumper sticker ("Boricuan and Proud"- a phrase denoting the proud recognition of the island's original Taíno indigenous heritage) or a "Puerto Rico" design printed on their winter hat, defying even the most exclusive brand name labels, or else with a giant flag draped over their balcony, adorning their homes and coloring their neighborhoods. Puerto Ricans don't hide; they proudly display their identity and reaffirm their presence in Boston as if making a political statement.

Notes from field research (Boston, MA)

\section{Introduction}

Positive experiences to living with HIV and responses to the illness among Puerto Ricans in Boston cannot be understood in a historical and social vacuum. Puerto Ricans' experiences in Boston, and the everyday life of the people in this community, need to be placed in the context of exclusion and reaffirmation rooted in the history of Puerto Rico and its political status in reference to the United States. For example, when I asked the study's participants to state their nationality as part of an initial demographic section during the interview, I received interesting answers from them. Most of the participants (81\%) responded with a proud “iPuertoriqueño!" (Puerto-Rican!) and some even boldly replied "iBoricua!" (Boricuan! - referring to the native Indians' name for the island). To my surprise, participants did not identify their nationality in terms of their US citizenship. In fact, only a handful of Puerto Ricans in my study (10\%) timidly responded to the question with "Americano" (American), at times as if asking a question

(“'Americano?”). Gabriel, a 60 year-old Puerto Rican-born man who has lived in the 
U.S. since he was a child, insightfully called attention to the ambiguity of the Puerto

Rican status in contrast to his clear notion of Puerto Rican national identity:

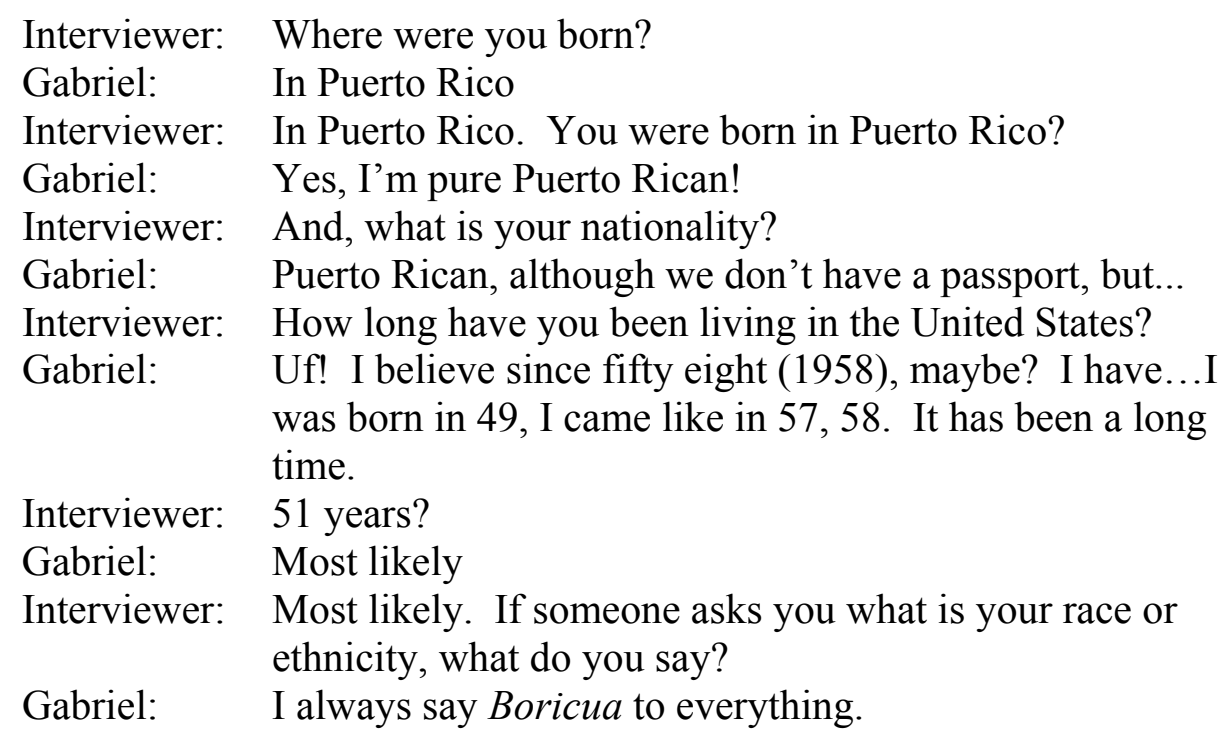

The fact that most of the study's participants did not acknowledge their United States (U.S.) citizenship at first appeared puzzling, particularly given the island's long historical relationship with the U.S., which dates back more than one hundred years. However, issues of identity among the Puerto Rican community in the U.S. are not only a controversial matter reflecting the political status of the island; they are rooted deeply in the nature of the historical colonial relationship between Puerto Rico and U.S. In fact, leading Puerto Rican scholars such as Jorge Duany (1996), claim that the cultural identity of contemporary Puerto Ricans living on the U.S. mainland can only be asserted within the colonial status of the US-Puerto Rico relationship.

The colonial ties between the U.S. and Puerto Rico have characterized the nature of Puerto Ricans' experiences in the U.S. since the U.S. obtained the island after the Spanish-American war in 1898. As Grosfoguel (2003) has suggested, Puerto Ricans live in a historical "subaltern position" within the U.S., susceptible to a second-class 
citizenship. Often, Puerto Ricans have not been accepted as equal citizens with equal rights where they settled. Instead, they have been generalized as part of an "underclass" (Tienda 1989), identified as a "culture of poverty" (Lewis 1966), and as a community on public welfare (Marger 1991). Perhaps Whalen (2005) best explained the colonial impact on the Puerto Rican experience in the United States. Colonialism, she concluded, "generated a political status that is ambiguous for Puerto Ricans living in Puerto Rico, and attitudes that often create a second-class citizenship for Puerto Ricans living in the States."

The exclusion status linked to the colonial relationship shapes the everyday life of Puerto Ricans in Boston as it does in other regions of the U.S. The saliency of this status merits a chapter in this study to give background to their experiences, including adding a context to the understanding of the responses to HIV among this community. For the study's participants and other Puerto Ricans in Boston, detachment from U.S. culture reinforces identity, promoting a sense of self-worth and dignity in the community, underscoring a culture of resistance present in the Puerto Rican diaspora, particularly when facing issues of poverty, marginality, and inequality (Diaz Quinones 1995; Thompson 1995; Flores 1999; Benmayor 1992; Duany 2000; Grosfoguel 2003).

\section{Puerto Rico-U.S. Historical Overview}

Puerto Rico is considered a "divided" nation, both physically and culturally (Flores 1993; Whalen 2005). According to the 2000 U.S. Census nearly half of all Puerto 
Ricans (48\%) live in the United States and their number is expected to surpass the population of Puerto Rico soon (Acosta-Belen 2006). ${ }^{8}$

The relationship between the United States and Puerto Rico dates back to at least 1898 with the U.S. invasion of the island during the Spanish-American War. Just a year earlier, Puerto Rican nationalists had declared independence from Spain (Perez y Gonzalez 2000) but their hopes for independence were squelched when the U.S. chose to turn Puerto Rico into a military outpost given its position as gateway to the Caribbean. United States control over the island was quick while awarding a status to Puerto Ricans did not take place until 1917 when the Jones Act was passed which granted U.S. citizenship to all Puerto Ricans (Jones-Shafroth Act, 1917). Citizenship helped make Puerto Ricans an attractive labor force beginning in World War I and much more so later in World War II and afterward. The Jones Act also made all eligible Puerto Rican males subject to the military draft. Within months, enlisted Puerto Ricans were serving the United States. military in World War I (Torres 1998). The U.S. military presence in Puerto Rico continued well into the twentieth century as the island became a central strategic military location for the United States. According to the Department of Defense, about 25 military installations existed on Puerto Rico in the 1990s (Department of Defense 1998), including the controversial Naval training bombing site on the Island of Vieques (Grosfoguel 2003).

The Jones Act established U.S. oversight of the Puerto Rican government as well. Permanent U.S. control of Puerto Rico was declared in 1950 when Public Law 600 was signed by President Harry Truman (Torres 1998). Public Law 600 officially established

\footnotetext{
${ }^{8} 2010$ U.S. Census figures have not been released at the time of this writing
} 
Puerto Rico as El Estado Libre Asociado (The Commonwealth of Puerto Rico) shortly thereafter with the adoption of the Constitution of the Commonwealth of Puerto Rico in 1952 (Perez y Gonzalez 2000). Under this new status, and upon request of the U.S. government, Puerto Rico was removed from the United Nations' list of protected territories, ending its condition as a colonial territory (Colon 1984). Puerto Rican colonial status was not officially addressed again until 1990 when the United Nations determined that "the commonwealth status is indeed colonialism under a different name" (Perez y Gonzalez 2000:33).

Driven by the economic expansion of the period, U.S. economic interests in Puerto Rico soared during and after WWII. Puerto Ricans were recruited to fill jobs in factories in the eastern United States during and after the war. With time, Puerto Rico itself became the object of industrialization in order to develop the island and, as some have argued, thwart a mass wave of Puerto Ricans to the mainland seeking better jobs (Falcon 2004; Matos 2005; Acosta-Belen 2006).

In 1948, “Operation Bootstrap” was launched to industrialize Puerto Rico. The project was well received by private enterprises in the United States seeking inexpensive labor and tax relief for their operations (Perez y Gonzalez 2000). In addition, the United States government had a special interest in the success of the project. In the early stages of the Cold War, Puerto Rico had become the showcase for the American model of development for third world countries in contrast to the Soviet socialist alternative (Grosfoguel 2003). Quickly, Operation Bootstrap transformed the island by shifting Puerto Rico from an agricultural-based economy to one dependent on manufacturing and tourism. 
The shift in the economy set the stage for the Puerto Rican "Great Migration" (Perez y Gonzalez 2000; Acosta-Belen 2006), a massive migration of Puerto Ricans to the United States. As Perez y Gonzalez (2000:32) explained, during this time, the island's agricultural sector was neglected and in continual decline, further increasing the loss of jobs and raising food prices. By 1950, one-third of the island's workforce was compelled to seek means of survival by (im)migrating to the United States.

As a result, Puerto Ricans began migrating to major U.S. cities in ever greater numbers between the 1950s and 1960s. Like their predecessors, many were recruited to take manufacturing jobs for low wages during the massive expansion of the U.S. economy in these years (Falcon 2004; Matos 2005; Acosta-Belen 2006). The arrival of Puerto Ricans, however, was not greeted warmly by veterans of the war and their families who were the descendants of earlier waves of migration, and the onset of prejudice against Puerto Ricans became evident. The Puerto Rican government, meanwhile, viewed this exodus as helpful given the turmoil in the local economy under Operation Bootstrap which had produced more potential workers than jobs for them (Falcon 2004; Matos 2005; Acosta-Belen 2006).

Despite the economic advantages, the mass migration of Puerto Ricans to the mainland accentuated the social and cultural intolerance in the U.S. of the period. The significant increase in migration brought to light the implications of having a large number of people speaking another language, having a different culture, and with a diverse racial mix arriving in a short period into a limited number of destination cities such as New York, Boston, and Philadelphia. Often Puerto Ricans viewed their migration — just as many other migrant populations — as temporary. However, given their 
low wages and the lack of good jobs back on the island, Puerto Ricans slowly transformed from temporary workers into permanent residents. Scholars have identified the impact of this status change as the beginnings of the racialization of the Puerto Rican community in the U.S. (Flores 1993; Guzman 1996; Rodriguez-Morazzani 1996; Torres 1998; Oboler 1999; Medieta 2000; Whalen 2005).

Racial tensions towards Puerto Ricans played a significant role in Puerto Ricans' weak incorporation into mainstream society in the United States. Puerto Ricans were faced with the reality of a proud American nation that questioned the value of citizens with different cultures, races, and even languages (Seda Bonilla 1972; Flores 1993; Rodriguez-Morazzani 1996; Rodriguez 1997; Duany 1998). This treatment was in part linked to the cultural and racial intolerance which characterized American society post WWII (Zhou 2002). During this period, many sectors of U.S. society loudly voiced antiimmigrant sentiments by pointing at immigrant groups' perceived failure to assimilate to "American" culture which they contrasted, albeit erroneously, to their immigrantcounterparts of the early 1900s. Puerto Ricans, despite being U.S. citizens, were treated as immigrants refusing to assimilate to U.S. mainstream values. Poor assimilation was soon voiced in negative generalization and perceptions towards Puerto Ricans:

Indeed, in the post war era, policymakers, social scientists, and the press increasingly spoke of Puerto Ricans in the language of "social problems." Instead of speaking of them as recruited workers who confronted discrimination, Puerto Ricans were portrayed as people with "social problems," who created even more "problems" for the communities where they settled. (Whalen 2005:230) 
The stigma placed on Puerto Ricans in the U.S. ignored that Puerto Ricans had been recruited to work in the U.S. and that they were forced to seek employment outside the island as a result of the economic changes imposed on Puerto Rico by U.S. interests.

It is true, however, that factors specific to Puerto Rican migration facilitated their cultural retention in the U.S. For example, as U.S. citizens Puerto Ricans enjoyed unrestricted travel between Puerto Rico and the U.S. Additionally, during the period of the Great Migration (1946-1964), Puerto Ricans arrived in such large numbers that they quickly formed cultural enclaves in several cities where they could speak Spanish, buy their own foods, have their own media outlets, etc. (Perez y Gonzalez 2000). Although this type of residential pattern characterized earlier European immigrants to the U.S., those immigrants' descendants had assimilated and were abandoning the inner cities for government-subsidized new homes in the suburbs (Jackson 1985). Puerto Ricans moved into the urban areas left vacant by other groups and their ethnic communities flourished because of the large numbers of new migrants coming to the U.S., particularly to the Northeast region of the country. In fact, as described above, the U.S. and Puerto Rican governments encouraged the migration to the U.S. as a solution to the lack of laborers in the U.S. and economic crisis on the island (Perez y Gonzalez 2000).

Puerto Ricans also retained their language, traditions, etc. owing to the fact that they continued to migrate between the U.S., where they would work for periods, and home where they could see family (Torres 1998). The resulting "revolving-door migration" pattern allowed Puerto Ricans "to have dual home bases that included human resources of relatives and friends in each place to meet specific needs" (Perez y Gonzalez 2000:37). The migratory trend facilitated by the U.S. citizenship contributed to 
strengthening Puerto Rican culture and identity in the U.S. despite the ongoing pressure to assimilate.

Aside from arriving in large numbers, occupying neighborhoods that became overwhelmingly Puerto Rican and not assimilating as they were expected to do, there is at least one additional cause of the strong stigma that arose during this period against Puerto Ricans: their poor socioeconomic indicators. As was true for most other immigrants to the United States had before them, Puerto Ricans entered U.S. society at the lowest levels of the social and economic structures. That was not a problem when the economy was dependent on in manufacturing, jobs which required few skills and little education. However, in the 1970s, the United States economy began a period of deindustrialization gradually eliminating the high demand for manufacturing labor which continues on to today (Acosta Belen 2005). Puerto Ricans were disproportionately hit hard given their concentration in low-end manufacturing jobs, forcing some back to Puerto Rico despite the ongoing economic crisis there (Whalen 2005). Second, lack of education and language skills prevented Puerto Ricans from accessing available jobs in the new developing technology-driven industries and the expanding service sector (Perez y Gonzalez 2000). Lastly, automatization and technological advances began replacing human labor, increasing the number of unemployed Puerto Ricans in the United States (Perez y Gonzalez 2000).

The socioeconomic conditions experienced by Puerto Rican has made them part of what Harrington (1969) categorized as the "other" America. An early study conducted by the U.S. Commission on Civil Rights in the 1970s showed that Puerto Ricans in the U.S. "remained at the bottom of the socioeconomic ladder" (Acosta-Belen 2006:147). 
More recent studies have not shown improvement in their economic and social indicators (Whalen 2005; Acosta-Belen 2006; Haslip-Viera et al. 2004). National data shows that Puerto Ricans continue to struggle socially and economically in the U.S. having some of the lowest socioeconomic indicators in the nation. According to Census data and as indicated in Table 7 below, Puerto Ricans in the U.S. are roughly $85 \%$ more likely to have an education below high school level than the average national population. In addition, their median household income fell $\$ 14,000$ below the U.S. average. They also experience higher unemployment than other groups (American Community Survey 2009).

Table 7: Socioeconomic indicators by race and Puerto Rican ancestry in the U.S. (2007-2009) ${ }^{9}$

\begin{tabular}{lccc}
\hline & $\begin{array}{c}\text { Less than High School } \\
\text { education }\end{array}$ & $\begin{array}{c}\text { Median household } \\
\text { income }\end{array}$ & Unemployment \\
\hline White & $10 \%$ & $\$ 55,906$ & $4 \%$ \\
Black & $19.3 \%$ & $\$ 34,415$ & $8.34 \%$ \\
Latino & $39.3 \%$ & $\$ 40,920$ & $6.11 \%$ \\
Puerto Rican & $27.3 \%$ & $\$ 37,052$ & $9.2 \%$ \\
\hline
\end{tabular}

\section{Puerto Ricans in Boston}

Puerto Rican migration to Boston followed similar patterns and encountered similar problems as their counterparts migrating to other cities in the Northeast although in smaller scale. Migration to the city took place in modest numbers between 1940s and 1960s and continued increasing in subsequent years (Matos 2005). According to Census data, by 1970 the Puerto Rican population in Boston was 7,333 yet by the end of the 1990 s, the Puerto Rican population had jumped to almost 28,000 , roughly $5 \%$ of the total

\footnotetext{
${ }^{9} 2007$ - 2009 American Community Survey 3-year Estimates
} 
population of the city and the largest Latino population in Boston (30\% of the total) (U.S. Census 2000).

Despite many similarities with the migration of Puerto Ricans to other major cities in the region, Boston was not the initial destination of many Puerto Ricans who were originally recruited to work in different agricultural parts of New England (Matos 2005; Gorlick 2006). In one of the few studies conducted on the history of the Puerto Rican community of Boston, Felix V. Matos $(2005: 205)$ revealed that "many Puerto Ricans were recruited to work on tobacco farms in the Connecticut River Valley near Hartford. From this area, the workers ventured and were enticed into Massachusetts or, finally into Boston." With time, Puerto Ricans were attracted to the city to work in lowskilled jobs in the industrial and manufacturing sectors that African Americans and other immigrants rejected (Piore 1979).

Puerto Ricans in Boston have historically struggled socioeconomically much like Puerto Ricans elsewhere in the United States. According to the 2007-2009 estimates, the Puerto Rican community has the lowest educational attainment with $37 \%$ having an education below high school level compared to $6.3 \%$ among the White population and $22 \%$ among Blacks (38\% among the Latino population as well) (American Community Survey 2009). They also have the lowest median household income than any other group in the city at $\$ 16,877$ per year, compared to $\$ 69,890$ for the White population and $\$ 34,543$ for Blacks (and $\$ 29,886$ per year for Latinos) (American Community Survey 2009). Unemployment is another major factor affecting the Puerto Rican community in Boston. Roughly 12\% of Puerto Ricans were unemployed between 2007-2009 compared 
to $4 \%$ for Whites and $11 \%$ for Blacks (Latinos reported $9.2 \%$ unemployment during the same period) (American Community Survey 2009).

\section{The Puerto Rican "Community" of Boston}

As the largest Latino/Hispanic group in Boston, Puerto Ricans have been able to take advantage of their long migratory history and cultural differences to create a strong and vibrant, yet socially marginalized, community (Matos 2005; Whalen 2005). As argued above, the relationship between the U.S. and Puerto Rico and the ensuing migrations between these two have produced a much stigmatized Boricua population viewed as having second-class citizenship despite being U.S. citizens (Benmayor 1992; Cruz 1998; Flores 1999; Dunay 2000; Grosfoguel 2003). Despite these conditions, Puerto Ricans in Boston have continued to find ways to build community, reaffirm their Boricua identity, and address their social marginality. This affirmation is not unique to Puerto Ricans nor to any migrant population nor to any stigmatized population, but it is important for the current study of how HIV-positive Puerto Rican men construct community to examine the broader context around them.

\section{Reaffirming "Puerto Ricanness"}

In Boston, as in other cities where Puerto Ricans have migrated, feelings of

Puerto Ricanness benefited, as mentioned earlier, by continual revolving door migrations to and from the island. Reaffirming their identity also involved (1) recreating traditions of life on the island such as foods and music and (2) engaging in activities of solidarity with other Puerto Ricans experiencing similar situations of poverty and discrimination, activities sometimes developing into full-fledged activism (Matos 2005). 
Despite many challenges, an established and vibrant Puerto Rican community became evident in Boston by the increased number of Puerto Rican businesses in the 1970s, established as the growing Boricua population concentrated in neighborhoods around the city. In Jamaica Plain, Roxbury, and the South End, family-owned bodegas (convenience stores) and larger supermarkets supplied traditional Puerto Rican products to the community. During the 1970s, the city also experienced an explosion of Puerto Rican culture in the media in the form of new Spanish radio stations and programs dedicated to Salsa music (Con Salsa with José Masó), Spanish-language newspapers (El Mundo), and television productions such as Mi Puerto Rico on public television channels (Matos 2005). In addition, recurrent city-wide cultural events marked the Puerto Rican presence in Boston. El Festival Puertoriqueño (The Puerto Rican Festival), which started in 1967 , continues to this day to be one of the most important yearly events celebrating Puerto Rican heritage and culture in Boston (Matos 2000).

The 1960s and 1970s were also of period of a heightened sense of solidarity among Puerto Ricans in Boston in response to the large influx of Puerto Ricans from the island. During this time, individuals and community initiatives were launched to provide resources in an effort to ease the relocation and settlement process in the city. Among the most innovative of these initiatives was the Puerto Ricans Entering and Settling Service (PRESS), an airport program welcoming Puerto Ricans with information and resources to those newly arrived from the island:

PRESS was one agency that provided a valuable service to newly arrived Puerto Ricans. Started in 1969 to 1970 by Conchita Rodriguez and other Puerto Ricans, PRESS had a small office at Logan Airport (Boston) to welcome arriving migrants and help them connect with relatives, employers, or services in the city. (Matos 2005:214) 
Other initiatives and programs for and by Puerto Ricans focused on improving the quality of their lives in Boston. The services included recreational activities, religious services, as well as educational programs specifically designed for the Puerto Rican community (Matos 2005). For example, Escuelita Agueybana (Agueybana School) emerged to educate young Puerto Ricans in Boston with a culturally-appropriate education model that was sensitive to their migratory experience. Primarily, "la Escuelita provided bilingual education and used Puerto Rican heritage and culture as a pedagogical strategy to teach children" (Matos 2005:212). Similarly, the Cardinal Cushing Center opened its doors in 1957 to work with the Puerto Rican community in the South End. The Center provided "social, recreational, religious, and educational activities for the Puerto Rican community, which by 1967 comprised about 20 percent of the South End's population (Matos 2005:210).

Initial community-building efforts focused on establishing a Puerto Rican enclave to provide the young community with a sense of Boricua identity reproducing much of the culture from the island (Whalen 2005). Community involvement was critical in recreating a familiar environment and reaffirming the values of Puerto Rican culture in Boston. These initiatives provided spaces to celebrate Puerto Rican heritage and show solidarity with other Puerto Ricans, thus paving the way for mobilizing the community to protect the civil and legal rights of Puerto Ricans as U.S. citizens.

\section{Community Activism}

For many Puerto Ricans in Boston, life in the U.S. did not prove to be a successful escape from the realities of poverty faced on the island. Many were faced with additional barriers and greater injustices than they had encountered in Puerto Rico 
(Thomas 1967; Cruz 2003; Matos 2005; Whalen 2005). Puerto Ricans in Boston faced adverse conditions as they tried to improve their lives and social position, maintain their cultural heritage, and keep their language. Inspired by its ideals of equality and motivated by the political activism of the Civil Rights movement in the 1960s and 70s, Puerto Ricans in Boston began participating in community activism to improve their condition (Matos 2005:201). The historical context and nature of the relationship between Puerto Rico and the United States proved to be an essential component for this empowerment process. Puerto Ricans in Boston began to understand themselves as neocolonial people, oppressed and disfranchised like Blacks yet with greater affinity to Latin Americans. Unlike many other "immigrants," however, Puerto Ricans enjoyed formal citizenship status while still sharing second-class socioeconomic citizenship. These injustices spurred many to take action:

Puerto Ricans did not passively accept unemployment and poverty, horrendous working conditions, or second-class status....Where they settled, Puerto Ricans sought to adjust and mold their new surroundings to meet their needs, as well as to improve conditions for themselves and others. They relied on social networks, the celebration of cultural traditions, involvement in existing community, the building of their own community organizations, and political activism. They used their U.S. citizenship to claim the rights that should have been theirs. (Whalen 2005:41)

In Boston, empowerment of the Puerto Rican community was shaped by community activism responding to issues of inequality and poverty (Matos 2005; Small 2004; Fortuna and Carvahlo 2006). As in other parts of the U.S. where Puerto Ricans settled, conventional forms of political participation were rejected by the community due in part as a result of the failures of Puerto Rican militant movements in the U.S. to gain the desired recognition of rights and equality for the community (Guzman 1996). As an 
alternative, community activism as the pillar for empowerment not only provided the arena for demands of recognition of rights, but also provided a space to celebrate Puerto Rican identity and to build a strong and active diaspora community as well.

Perhaps the most important example of community activism among the Puerto Ricans in Boston was the settlement of the community of Villa Victoria (Victory Village) located in the South End neighborhood. In the 1960s, the city's urban renewal plan called for converting many areas of the city where Puerto Ricans lived into commercial real estate. People living in these areas were scheduled to be relocated throughout the city (Matos 2005). Puerto Ricans mobilized and organized Inquilinos Boricuas en Acción (IBA), and organization to spearhead the efforts against the city's gentrification plan (Small 2004; Matos 2005; Fortuna and Carvahlo 200). Supported by community organizers, local architects, and religious leaders, IBA challenged the urban renewal plan with an alternative proposal: the development of the community of Villa Victoria. The housing complex resulted from the five-year struggle against urban gentrification in defense of a physical and cultural Puerto Rican space in Boston. Fortuna and Carvahlo (2006:11) concluded that "in the South End, the Villa Victoria community appropriated the urban space, building an enclaved community and adopting a protective and resistant strategy of social integration...Villa Victoria is certainly an example of cultural landscape preservation within the American context."

Puerto Rican community activism was also crucial in protecting Spanish, a key right to educating their children in their native language in the Boston and in the U.S. In 1970, the Massachusetts state legislature passed the Transitional Bilingual Education Bill, making bilingual education available in the state (Teruel 1973; Melendez 1981; 
Formisano 1991; de Jong et al. 2005; Matos 2005). Specifically, the law responded to a report documenting a high dropout rate among Spanish speaking children in the state, most of whom were of Puerto Rican descent (Task Force on Children Out of School 1970). The bill was the result of a two-year campaign organized by Puerto Rican community leaders and parents (de Jong et al. 2005; Matos 2005). Matos (2005:214) noted that the Puerto Rican active involvement in local bilingual initiatives contributed to the passing of the first bilingual law in the nation in Massachusetts:

In reaction to the report and to the passage of federal bilingual education legislation in 1968, community activists began to secure grants and force the Boston School Committee to organize several small clusters of bilingual education courses...The continuous involvement of Puerto Rican parents and community leaders led to an expansion of programs, the gathering of data needed to apply for federal grants, the development of Bilingual Education Programs in the Boston Public School System, and eventually the enactment of a statewide bilingual education law in 1970.

Boston Puerto Ricans' community-building project and activism as a response to poor social conditions provided the social spaces to reaffirm Puerto Rican identity and culture resisting the assimilation model expected for all "new Americans." That is, Puerto Ricans in Boston created and continue to create community not merely out of exclusion by the larger society, though that is important, but also by positively affirming themselves. The experiences and lessons learned from community activism provided the model for subsequent independent community organizations to emerge in response to the inequalities affecting Boston's growing Puerto Rican community.

\section{Community Multi-service Organizations}

In addition to engagement in community activism, Puerto Ricans in Boston triumphed against marginalization through the establishment of multi-service 
community-based service organizations (CBOs). During the 1960s and 1970s and funded by the Great Society programs, Puerto Ricans along with other Latinos founded organizations to respond to the different needs of the broader Latino community living in Boston (Uriarte 1987; Matos 2005). The emergence of these organizations served to formalize many of the initial social action programs and campaigns launched by Puerto Ricans responding to the social exclusion of their "unincorporated" migrants status. With time, these organizations and their agents assumed central roles as service providers and community advocates for the growing Latino community. The formation of these organizations stemmed from the realities of poverty, inequality, and discrimination experienced by Puerto Ricans and other Latino groups living in the city, a fact that would help strengthen community and cultivate community leadership.

The cultural and socio-political climates of Boston in the late 1980's, along with ethnic pride among Puerto Ricans were ideal elements that served as foundations for the emergence of Latino CBO's with a strong Puerto Rican component and leadership in the city. Learning from groups such as the Young Lords from New York (Guzman 1996), a Puerto Rican social-radical group seeking independence, groups of Puerto Ricans in Boston began developing agendas that targeted specific community issues such as housing, health care, and employment, while fostering a strong sense of identity and community solidarity through the CBOs. Consequently, many of the initial efforts of the agencies to provide for the community developed from political action and grassroots movements. As already described, Inquilinos Boricuas en Acción (IBA) was founded in the late 1960s in Boston as the leading community organization to meet the human and 
social needs of the community and to resist the unjust impact of Boston's urban-renewal project:

The IBA's philosophy centered on promoting a deep sense of identity and pride among the Puerto Rican residents of the South End [Boston], as a way to mobilize and empower that community. As a result, IBA ran numerous educational, cultural, political, and job-training programs. (Matos 2005:211)

Another major component for the success to organizing Latino CBOs in Boston was provided by special funding programs made available by state and federal agencies. In a detailed analysis of the development of the Puerto Rican and Latino CBOs in Boston, Matos (2005:213) noted that between the 1960s and 1970s, "the federal government provided funds to help groups 'help themselves.' To fight the [community's] problems and to be recognized by government agencies as worthy recipients of federal and state support, Puerto Ricans and other Latinos started to organize community service organizations." During this time, some of the most prominent Latino CBOs in Boston were created with the financial support of these government programs (Matos 2005). Moreover, the availability of public funds encouraged many community agencies to begin modeling their social projects with a new, more professional, formal, and strategic approach. This fact was crucially important for the new agencies to endure over time and continue providing services to the community uninterrupted. Consequently, the critical socio-political factor, set in motion by the struggles of the Civil Rights movement of the period, resulted in the active support from government of efforts to combat inequality and discrimination.

Among the agencies benefitting from government funding, La Alianza Hispana (The Hispanic Alliance) was formed in 1969 to address the impoverished conditions of 
Latino students in the Roxbury area of Boston (La Alianza Records 1960-1999). By 1970, the agency was incorporated as a multi-service organization, which sought and obtained public funding from Boston's Model Cities Administration Program to expand its operations and services. Today, operating on a budget of roughly two million dollars, La Alianza Hispana's programs work to mitigate the detrimental effects of poverty and play a significant role in strengthening Puerto Rican and other Latino families in Boston offering a variety of programs to meet the social needs of the community (www.laalianza.org). Currently, the agency offers services in education, public health, employment and training, elder care, and counseling in the greater Boston area to over 2,000 Puerto Ricans and other Latinos annually (La Alianza Records 1960-1999).

The development and success of these community organizations in Boston had other positive impacts for the Puerto Rican community in addition to the enhancing access to social services. Involvement in the community agencies served as training grounds for emerging leaders of Boston's Puerto Rican and Latino community (Torres 1998; Matos 2005). Participation in community services agencies became essential in order for leaders to gain understanding about the issues affecting the community as well as to obtain public support for those running for public office. "As is often the case, political leaders of the Latino community gained connection, credibility, and organizational experience through their leadership in social service organizations" (Matos 2005:217). Puerto Rican-born Nelson Merced, for example, the first Latino to be elected to the Massachusetts House of Representatives in 1988, served as the executive director of La Alianza Hispana between 1981 and 1985 (Diesenhouse 1988). Similarly, Felix D. Arroyo, a native of Arecibo, Puerto Rico, served as the Director of Advocacy at the 
Hispanic Office of Planning and Evaluation (HOPE) until he was elected as the first Latino to the Boston City Council in 2003 (Walker 2003).

Direct involvement in local and state government has been important to gaining access to elected representatives and other Latino community leaders who, in turn, could lobby for the continuation of funding to community agencies. Often, city and state Latino political representatives visit Boston's community agencies to learn about the community's needs, to personally respond to funding changes, as well as to gain insight into effective community interventions. For example, Councilman Arroyo and CubanAmerican Massachusetts Senator Jarrett Barrios frequently visit Puerto Rican and Latino CBOs and receive updates on the state of the community (LHI 2004).

\section{"La comunidad"}

Boston's Puerto Rican community-building strategies provided a social arena for residents to develop a community conscience and reinforce a prideful identity rooted in their participation in and contribution to the community as a whole. Puerto Rican scholars assert that this dynamic and charged process of community-building is an example of "overcoming challenges and creating alternatives" found among communities of exclusions (Jimenez 2005: 113). In providing for the social needs of their community on the one hand, and the promotion of communal identity and ethnic pride on the other hand, Puerto Ricans have shown great resilience against the stigma and exclusion they have suffered for generations. Thus, marginalization, as Clifford (1997:261) explains, is not a terminus but a genesis of community:

Diaspora communities, constituted by displacement, are sustained in hybrid historical conjunctures. With varying degrees of urgency, they negotiate and resist the social realities of poverty, violence, policing, 
racism, and political and economic inequality. They articulate alternate public spheres, interpretive communities where crucial alternatives (both traditional and emergent) can be expressed.

The process of collective organizing on behalf of the interests of community challenged the traditional spaces and contributed to the process of community-building and social action. The emergence of community-specific programs, agencies, and leadership accentuated the need for community self-reliance highlighting the condition of exclusion affecting the Puerto Rican community and other Latinos in Boston (Matos 2005). As Uriarte (1992:2) described,

responding to these conditions of exclusion, alienation, and isolation, Latinos have sought to build a strong, but separate community. This was not their initial goal. In fact, the struggle for inclusion has been the most powerful force in the social organization of Latinos in the city. But faced with continued inattention to their urgent needs, Latinos have followed the patterns of the Black community in developing a set of organizations that run parallel to mainstream Boston institutions.

In essence, Puerto Ricans filled the vacuum left by the broader society as well as by local social institutions through their strategies of community affirmation. As if modern day social alchemists, they have made great efforts to turn rejection into acceptance and respect. Their job is not over as Puerto Ricans as a whole continue to be located by the broader society as socially inferior, but as the case of American Jews attests, what threatens a distinctive community identity most is not rejection but acceptance into the mainstream. However, as if de-industrialization, the decline in state spending on social services after the Great Society efforts ended, the deterioration of inner cities as a consequence of disinvestment and the tide of drugs were not enough, in the late 1980s along came a particularly difficult affront to the Puerto Ricans in Boston: HIV and AIDS. 


\section{Puerto Rican and Latino Response to HIV/AIDS in Boston}

The impact of the community's actions to empowering and meeting the needs of the Puerto Rican and Latino community has been most significant in the area of public health and health care in Boston. It did not take long before agencies, which originally emerged to address a particular health issue (e.g., substance abuse, mental health) affecting the community, began experiencing processes of professionalization, expansion, and service diversification, and eventually became advocates for the health of all Latinos in the city of Boston and the state. The development and empowerment of these agencies was particularly crucial in responding to the HIV/AIDS epidemic when it reached the Latino community in the 1980 s.

In Boston, community service agencies were the primary institutions that responded to the spread of HIV and AIDS which disproportionally affected Puerto Ricans and the greater Latino community much as poorer segments of the urban populations around the country were affected. Concerns that the impact of AIDS on Latinos was being ignored by government institutions and newly founded AIDS agencies (AIDS Action Committee, Boston Living Center) mobilized Latino community leaders into taking action following the same strategies for community activism of the 1960s and 1970s (Laws, personal communication, March 22, 2011; Aguilú, personal communication, March 29, 2011). For example, a group of Puerto Rican and Latino health professionals in the late 1980s organized the Latino Health Network, later becoming the Latino Health Institute (LHI), to address the AIDS epidemic among the Latino community and respond to the lack of services (Aguilú, personal communication, March 29, 2011). LHI's co-founder, Hortensia Amaro, stated that "LHI was born out of 
adversity" (www.lhi.org). Presently, LHI receives over 2.5 million dollars annually just in federal funding to support its multiple HIV/AIDS programs and services in the Boston and Greater Boston area. After more than 25 years, LHI has "become a full-scope Latin American public health organization, with important agendas in the areas of Research, Policy, Education, Service, and Consulting" (www.lhi.org). Today, LHI is a leading provider of HIV services for Latinos as well as a key resource in HIV research, policy, and advocacy in Boston.

Many community organizations in Boston continued leading the fight against HIV by formulating strategies and programs that include cultural awareness as an essential component to health care and service delivery for minorities. For example, the Multicultural AIDS Coalition (MAC), the oldest minority AIDS serving organization, was founded in 1988 to provide services to the minority population, including Latinos (Laws, personal communication, March 22, 2011). Unlike MAC, other organizations preceding the AIDS epidemic also became involved in responding to the spread of HIV/AIDS affecting the Latino community by caring for the needs of HIV-positive Latinos. For example, at the onset of the epidemic, the Hispanic Office of Planning and Evaluation, Inc. (HOPE), a multi-service agency established in 1971, convened a statewide conference to address the impact of HIV/AIDS among the Latino population of the state (HOPE, n.d.). Out of these initial efforts, HOPE established El Centro de Apoyo Pedro P. Zamora Support Center in 1991 (www.hopemass.org), "a peer support center for Latinos living with HIV/AIDS, [which provides] monthly networking meetings, weekly congregate meals and weekly gender-specific and joint peer support group sessions for Latinos and Latinas living with HIV/AIDS in Boston"(www.hopemass.org). As 
illustrated by HOPE's initiative, the development of culturally sensitive and appropriate programs that address both the culture and the health care needs of individuals have been recognized to be one of most important elements in effectively caring for the well-being of diverse populations.

Moreover, the cultural approach to the interventions used by agencies like LHI and HOPE, among others, redefines "what living with HIV/AIDS" means and empowers clients, patients, and consumers with health, housing, employment, and ultimately selfesteem. The role of these agencies in assisting Latinos to move from stages of sickness, homelessness, and unemployment into successful fulfilling lives is accomplished through culturally-specific clinical interventions, services, and policies. Since established in 1989, the Boston Living Center (BLC) has grown to become the largest community center serving the HIV/AIDS population in Boston (www.bostonlivingcenter.org). Although originally BLC emerged to serve the needs of the gay White community of Boston affected by AIDS, with time, and with the collaboration of Latino agencies, BLC extended its services to meeting the needs of HIV-positive Latinos (Laws, personal communication, March 22, 2011). These agencies' community peer support model has been key for members adjusting successfully to HIV "to thrive with HIV, rather than simply cope" (www.bostonlivingcenter.org). The holistic approaches practiced by these agencies, including involving HIV-positive people in the care of their peers, not only are intended to address the well-being of the individual living with HIV/AIDS, but are also carefully crafted to empower individuals by celebrating their identity, culture, and by promoting their dignity. The comprehensive and inclusive approach to care provided by these agencies in the fight against HIV/AIDS has been significant because, undoubtedly 
they provide the context that enable the processes of community formation discussed in the following chapters.

\section{Chapter Summary}

The purpose of this chapter has been to attest how Puerto Ricans in Boston engage in community-building strategies to protect Puerto Rican socio-cultural survival and to access critical resources needed by that community. Although I have shown that these strategies emerge out of stigma, poverty, marginalization, and inequality they are, nonetheless, positive outcomes. People can be defeated by the difficulties they face or they can take these difficulties as motivations for change. I do not claim that community organizations nor the community as a whole have solved the problems of Puerto Ricans (nor of the other Latinos for that matter); that would not be accurate for they continue to face many challenges as evidence by the poor socioeconomic indicators in the community. However, as I transition into examining the particular community building efforts of a subset of Puerto Ricans living in Boston - those saddled with even more difficulties owing to their HIV status - it is important to keep in mind the "community" they have surrounding them. Providing an overview of both the challenges and resources Puerto Ricans in Boston face and enjoy was the purpose of this chapter, laying a foundation for the following chapters

The participation of Puerto Ricans living with HIV in community-building and affirmation involves similar processes to those discussed here, including the celebration of strong HIV-specific cultural identity and advocating for wellbeing of its community members. The community-building experiences described by these men also address similar issues of social marginality, primarily the stigma of HIV. However and unlike 
most of the Puerto Rican community-building activities described in this chapter, $l a$ comunidad described by Puerto Rican men living with HIV involves some additional specific factors that arise from adjusting to living with HIV. These strategies, discussed at length in the following chapters, point to modes of interaction in which these individuals, with a community of peers, negotiate and deploy norms to living positive with an HIV diagnosis. 


\section{CHAPTER III.}

\section{DIAGNOSED “COMMUNITAS:” ESTABLISHING LA COMUNIDAD}

You feel better when you know you aren't the only with HIV. Because it is something lonely, something horrible, horrible, horrible... Yes you have to accept that this is your new family, your new community. If you can find some support in the world here you find it, in the community. Because nobody can know how you feel. But those who know how you feel is because they are going through the same thing, you understand? Because when you have HIV, you don't have friends. Nobody wants to know about you, you have to accept yourself. Accept that your life isn't over and that you haven't died, you continue to live knowing that there are a lot of people in the same place you are, and they are fighting for their life...My community is my happiness. The world is my nightmare, do you understand ? Leaving that world and entering my community is getting out of that pain, anguish, everything that is bad. But my community is different. There I am loved.

- Benedicto, 38-years-old, diagnosed with HIV in 1987, emphasis mine

Men like Benedicto enter the world of HIV when they are diagnosed with the illness. An HIV diagnosis goes further than simply describing the seropositive status of a person, however; it defines a clear boundary between people who are HIV-positive and those who are not. That is, an HIV diagnosis not only renders a diagnosis of illness, but also entry into a social category. As illustrated by Benedicto, being HIV-positive draws a permanent line of social distinction with real life consequences between two different worlds: the HIV-positive and the HIV-negative. The boundary established by the diagnosis is a key defining element of la comunidad.

Similar to Benedicto, many of the men in the study described living with HIV in terms of belonging and being part of a unique "community." In this sense, for the men I interviewed, la comunidad is a "culturally meaningful unit" where they find a connection as well as a sense of unity and belonging with others (Goldin 1984: 122). Carlos, 
diagnosed with HIV in 1987, clearly described his feelings of this community when asked what binds them together:

Because they are a group of people that share the same pain. The same concern. The same concern and those ties have to be there. They have to be because we have a fight that is always the same but that many times doesn't go well. But who can better understand but someone who is...who walks in the same shoes.

Ignacio, a middle-aged recovering injecting drug users (IDU), described la comunidad as a "family" where he can be himself and be understood. He explained, you "can talk openly, without having to hide anything. Do you understand? I find it to be like what we call an 'open book', you know, when I'm with people like me."

Other men highlighted the community's safe and welcoming environment in their descriptions. For example, Lazaro, a 38-year-old U.S.-born man infected with HIV from having heterosexual sex, and Gabriel, a 60-year-old native of San Lorenzo, Puerto Rico, who contracted HIV from his male lover, identified la comunidad as a place to be with peers where they are accepted and loved without being "singled out" (señalado) because of who they are. Similar to these men, Ivan, HIV positive for 14 years at the time of the interview, stressed the importance of this community for his emotional and psychological wellbeing. "Well it makes me feel, well, you understand, that I am normal. A person that doesn't have anything, you understand?" Recovering a sense of normalcy and equality after being diagnosed with HIV was repeated by these men as an important feature they find in their self-defined community. Perhaps Benedicto, adding to the distinction between "his community" and the rest of the world, summarized the differences best by pointing out the characteristics of the community: "It is a community 
where everyone has the same thing. We consider ourselves equals. There isn't any discrimination."

For these men, the HIV diagnosis functioned as the crossing into the HIV community (Charmaz 1991). Roth and Nelson (1997) discussing the impact of an HIV diagnosis, sustain that the diagnosis is an important element in the life of a person living with HIV. In fact, they contend that an HIV diagnosis is seen as a "necessary rite of passage into the AIDS community" (Roth and Nelson 1997:171). Although an HIV diagnosis is tantamount to entering a new life, likened to a communion with HIV-positive peers, it is the boundaries or "thresholds" (Gennep 1960) that define the HIV community that a person is entering upon diagnosed. Understanding what culturally distinguishes those who are HIV-positive from those "who are not," that is, regardless of the medical diagnosis, is central to the argument put forth in this study. Knowledge about the values, beliefs, and practices establishing and reinforcing this community's boundaries is needed to answer questions asking what characterizes this unique cultural unit: How are the community's boundaries constructed? How are they negotiated? How are they reaffirmed to sustain the community over time? Analyzing the boundaries of this HIV community, thus answering these questions, is the subject of this chapter.

\section{Boundaries, Boundary-work, and Community}

Boundaries are essential when defining communities. The notion of social boundaries was first explored at length by Fredrick Barth in his work Ethnic Groups and Boundaries (1969). In that acclaimed analysis, Barth analyzed the processes behind the formation of peoplehood along lines of ethnic identity. He argued that it is at the boundaries where these identities are consolidated, but only in reference to other groups. 
That is, one only knows who one is when one knows who one is not. Focusing primarily on ethnic groups, Barth maintained that people see themselves as different when the cultural expression and content of a group is contrasted and differentiated with that of another group - even when they cannot be objectively distinguished culturally. In this way, the differences permit us to distinguish between members and non-members through a "membership which identifies [the group], and is identified by others, as constituting a category distinguishable from other categories of the same order" (Barth 1966:296). Jenkins (2004:97) explained that according to Barth's model, "the interactional construction of (external) difference generates (internal) similarity, rather than vice versa." In this manner, the boundaries of a group are created and established in reference to another group(s) providing the content to determine group membership and the persistence of cultural differences (Barth 1969). Consequently, group categorization and identification rest on the distinctions established between "us" and "them" delineated by ideally clear, but often blurry, social boundaries (Gieryn 1983; Anderson 1991; Becker 1999; Pattillo-McCoy 1999; Lichterman 2005).

Following Barth's line of argument, a literature on "boundary-work" emerged focusing on the processes of drawing boundaries, creating and subsequently maintaining the "us" versus "them" distinction to differentiate groups (Gieryn 1983, Anderson 1991; Becker 1999; Pattillo-McCoy 1999; Lamont and Molnar 2002; Lichterman 2005). Thomas Gieryn (1983) coined the term "boundary-work" in an effort to describe the practices establishing the demarcation between scientific work and non-scientific work. According to Gieryn (1983:781) "boundary-work describes an ideological style found in scientists' attempts to create a public image for science by contrasting it favorably to non- 
scientific intellectual or technical activities." Gieryn (1983) explains that these practices in the scientific community take place to: (a) exercise dominance of discourse over competing domains and interpretations (expansion), (b) to diminish the authority of rival work with claims of non-science (monopolization), and (c) to protect members by exempting them from accountability (protection of autonomy). In his study, Gieryn noted the flexibility and ambiguity of social boundaries, which permit people to draw and redraw boundaries strategically, "routinely accomplished in practical, everyday settings" (Gieryn 1983:781). The instrumental feature of boundary-work highlights the ability to establish hierarchical differences and statuses (Lamont and Monar 2002). Ultimately, the differentiation highlighted by Gieryn served to distinguish "who is a scientist" from "who is not scientist," but more importantly, it helped explain the processes involved in and consequences of establishing well-defined separate groups.

The boundary-work framework is essential to understanding community. Important in the processes of community formation are the notions contrasting "us" and "them", creating difference determining in-group and out-group distinctions (Tajfel and Turner 2004). Anthony Cohen's (1985) work redefining community as a symbolically constructed social organization has also contributed to the understanding of boundaries in defining community. His approach, like Gieryn's, highlights the agency of community members in the construction of the group's boundaries. The symbolic notion of community centers on the idea of individuals being responsible for the production of meaning for their group (culture) defining the boundaries of their community. Similar to the notion proposed by Barth (1969), Cohen recognized the dual process in which the commonalities among people also function to differentiate them from others. However, 
unlike the social boundaries described by Barth, Cohen describes members involved in establishing commonality and, thus inherently, difference, along boundaries drawn symbolically in the minds of people. In this manner, group membership is stipulated by a process of self-awareness of belonging that can be, as described previously, subtle for and even invisible to outsiders (Day 2006). Boundaries, in Cohen's sense can be blurry, even undetectable to anyone who does not belong to the community. Consequently, community is constructed in the minds of people through shared processes of assigning meaning to symbols, rituals, and traditions, thus becoming real in their collective recognition and performance in social settings. As argued by Cohen (1985:118),

The symbolic nature of the opposition means that people can think themselves into difference. The boundaries consist essentially in the contrivance of distinctive meanings within the community's social discourse. They provide people with a referent for their personal identity. Having done so, they are then expressed and reinforced through the presentation of those identities in social life.

In other words, following Cohen's argument, people participate in boundary-work by exercising identification and membership with their community, asserting, as also claimed by Barth, the difference from others. The key here is that boundaries are asserted, not that the peoples they divide are identifiably distinct. Boundaries can be and this is the case with those infected with HIV, but the analytical emphasis is on asserting difference (agency) over measurable difference.

Boundaries are important to processes of defining community in two ways. First, a community's members are involved in the production of the cultural identity defining their group and in so doing construct symbolic boundaries of belonging. As such, agency plays an important role as it refers specifically to the "capacity to create, reproduce, 
change, and live according to their own meaning systems, the powers effectively to define themselves as opposed to being defined by others" (Bhattacharyya 2004:11). The interaction of individuals in the processes of community formation varies given the practices of each community. Given that humans are naturally social, people need others to survive. In some cases, community can be defined with minimum degrees of choice or input from the majority of its members in the processes, but their participation is crucial once established. That is, even if members have had nothing to do with creating the boundaries that define them, they must participate in doing the boundary-work of maintaining these differences in order for their group to retain its differences from others. A nation-state is a good example illustrating this form of community upon which participation from citizens is limited during the formation, but essential to reaffirming the community in the celebration of its shared symbols, traditions, and culture (see Anderson 1991; DeLugan 2008). Most people may not be aware that they participate in boundarywork with daily practices by singing their national anthem, pledging allegiance to their flag, even wearing the jersey of the national soccer team. However, these shared practices reinforce a sense of nationalism and the nation, whether performed intentionally or subconsciously.

In contrast to the low participation of everyday people in forming the boundaries of nation-states, people can exercise much more agency over the formation of communities of their own choosing (e.g., clubs). The emergence of the gay community in the U.S. during the 1960s and 1970s exemplifies a case in which members who previously had been ostracized as outside the acceptable norms of mainstream community, turned excommunication into a new community - the gay community. 
Members themselves were, and continue to be, the principal agents in the formation and ongoing social reproduction of that community, including the production of its symbols, traditions, and cultural spaces (see ; D’Augelli and Garnets 1995).

Second, boundaries matter in defining community because these have a capacity to generate a feeling of commonality and belonging through practices of differentiation and otherness. Such feture makes "real" the often symbolic distinctions between "us" and "them" (Lamont and Molnar 2002). Inherent in community boundary-work are the notions of belonging and collective identity. As described in detail in the Introduction to this dissertation, these features work together to create and delineate the nature of the social relationships of the group. In fact, community cannot endure without these critical characteristics that help cement the collectivity of human experiences into social units (McMillan and Chavis 1986; Wood and Judikis 2002). As previously presented, the sense of belonging is created through a shared "consciousness of commonality" even in the absence of real social homogeneity (Dyck 2002). In effect, "belonging" is constituted in a dual process - internally among people who are diverse members but also externally where the diverse group is viewed as a homogenous unit (Amit 2002; Olwig 2002). In the context of boundary-work and explaining this duality, Lamont and Molnar (2002:170) contend that "individuals must be able to differentiate themselves from others by drawing on criteria of community and a sense of shared belonging within their subgroup." The group's collective identity plays a major role in this process to consolidate the members' sense of belonging to a community (Cohen 1985; Anderson 1991). Jenkins (2004) explains that collective identification highlights similarity while establishing difference. Such perceptions of belonging and identity define the nature of the community, which in 
turn generate feelings of heightened bond among members (Mason 2000:32). In this way, a collective identity and feelings of attachment to a community reinforce sentiments of identification, concern, and solidarity among the group's members.

\section{Boundaries that Produce Communities of Exclusion}

The boundary-work framework is useful in shedding light on the role of boundaries as makers of social differentiation through exclusion in the formation of communities. The breakdown of spatially-defined community (i.e., a village or nation) with the modernization of society brought alternative forms of belonging and identification determined by common interests (see Cohen 1985; Anderson 1991; Appadurai 1996). Such processes of community formation built upon non-face-to-face generation of feelings of commonality also evoked processes of "otherization" by establishing and excluding people and groups characterized as socially different. Exclusion in this sense has functioned to establish status, define communities and redraw their boundaries, to determine who does and does not belong, as clearly described by Gieryn (1983). Similar processes of categorization are involved in constructing social classification stipulating differences and assigning social value to these differences (Young 2001; Lamont and Molnar 2002; Massey 2007).

According to Massey (2007) and the social psychology research upon which his analysis is derived, humans all categorize, but not all categories are used as the basis for social stratifications. Thus, people give meaning to different eye color and will call someone a blue-eyed or a brown-eyed person, but this distinction does not become the basis (at least in most societies) for assigning greater social status to brown-eyed over blue-eyed people. Yet gender is a social category where there is stratification and the 
same is true for many categories such as class, race, religion, etc. Not surprisingly, much categorization and differentiation aim "to maintain and achieve superiority over an outgroup on some dimension" (Tajfel and Turner 1985:16). In this sense, boundaries establishing a community of "others" become a means to enhance social differences and enable discrimination, preventing people from equally participating in society.

As suggested in Chapter 1, communities formed and defined by practices of exclusion provide a sense of identity and belonging to certain groups of people despite the ongoing efforts to exclude them from the broader society. In this sense, new identities and their corresponding cultural characteristics are being produced in community within the context of exclusion. In these communities, people find identification with groups in a larger social context, negotiate and transform negative identities, and in the process resist exclusion.

La comunidad articulated by the Puerto Rican men in this study fits well in the category of community of exclusion, but it also, as I argue in this dissertation, is one of affirmation and inclusion. In this case, the large HIV community is clearly and permanently defined medically by the diagnosis and consistently reaffirmed socially with notions of stigma. Yet, while these HIV-related characteristics are externally defining factors of larger HIV community, the HIV-positive men in this study also engage in boundary-work to create and define their own community, la comunidad, on their own terms. They will not be defined through exclusion but live positive through active community processes of inclusion and affirmation performed with their own boundary work. This construction of community from the inside, driven by the members themselves, reaffirms and sustains this group of HIV-positive men. Through building 
community affirmatively they thwart the stigma attached to the illness and the stereotypes of people living with HIV.

\section{HIV Diagnosis: the Gateway into Community}

Shocked by the HIV diagnosis itself, these Puerto Rican men must recover in order to face living the rest of their lives with HIV. They described how perceived notions and incomplete knowledge of HIV initially fueled fears of what a medical diagnosis of HIV meant. With time, they gained knowledge about living with HIV from peers, health care professionals, research, even from cues from their own bodies. Being infected with HIV became the main preoccupation in the everyday lives of these men as they struggled to make sense of their new reality. The anxiety and loss of self-related to being HIV-positive, was reaffirmed by negative perceptions of HIV resulting from the men's experiences of discrimination and rejection because of their HIV status. These characteristics have framed the context for these men to feel part of a separate community, one labeled and ostracized because of HIV.

\section{Labeling the Community: Becoming "Ill" at Diagnosis}

An HIV diagnosis is a life-changing event fraught with emotions of despair and loss even as it opens up the gateway into new communities. The diagnosis is often associated with receiving a death sentence (Cherry and Smith 1993), an unwelcome invitation to stigma, discrimination, and rejection (Herek, G., et. al. 2002), and the anticipation of a life of uncertainty (Mishel 1997). Leo ${ }^{10}$, a 41-year-old diagnosed with HIV at age 28, clearly illustrates the life-changing impact he experienced when diagnosed:

\footnotetext{
${ }^{10}$ English-speaking respondent - text in original language of interview
} 
I did not suspect it at all. I was scared. I was nervous, you know. I went and got tested. In like two weeks later, after, you know, the results came back, I went in. They sat me down and they talked to me. What would happen if I did have [HIV] or what happened if I didn't? And I told them that I really couldn't, I really wouldn't know how to react to it because I really do not know what is, what really is the HIV or anything like that, or AIDS. I really have no knowledge about it. All I knew is that it was a disease that is not curable. So when the lady told me, when I was diagnosed, yes, I am positive..."You are HIV positive." But when she told me, I really lost it. I really lost it. I thought the world was going to end right there. That...it was the end of the world for me.

Despite his limited knowledge of HIV, Leo knew all too well that an HIV diagnosis was about the worst thing that could happen to someone. His case exemplifies how the consequences of the diagnosis have an immediate impact on a person's self-perception. Receipt of a "positive" diagnosis marks the inception of a new self, one defined negatively by illness (Roth and Nelson 1997). A person is now not a person; a person is now an "ill" (abnormal) person, an HIV-positive statistic. Yet, the diagnosis is the person's ticket as well into new social territories_-communities of HIV infected people and their caregivers.

Even though on average, these men have been diagnosed with HIV for about 15 years at the time of their interviews, they all could clearly recall the moment they received their HIV diagnosis. Among them, the most recently diagnosed was a participant who had been diagnosed in 2007, making him HIV-positive for just 2 years at the time of the interview. On the other end of the spectrum, one participant had been living with HIV for 25 years when I interviewed him. In fact, he was diagnosed in 1984, the year HIV was identified as the cause of AIDS (Osmond 2003), making him one of the first persons to have received an HIV diagnosis. Even the men who have been diagnosed with HIV for many years gave a detailed account of their diagnostic moment as if it had 
taken place just days before the interview. The participants recounted their experiences with compelling and emotional stories, which brought a few of them to tears as they "reexperienced" the moment (Charmaz 1980:137). Gabriel recalling his decision to get tested became very emotional:

Gabriel: Well looking back, I took the test because, as I said earlier, I had my first lover, that was my love, my first love, and we lived together for fourteen years. So, in 87, I lived in New York. There I met him and we lived together 14 years. We were both young (sobbing)...

Interviewer: Take your time and remember if there is something you don't want to answer we will simply go on...

Gabriel: (crying) no, it's okay. Is that it has been a while since I remembered that.... I still... have feelings for him and love him. So he got sick and in that time we didn't know about the disease or anything... But because of the illness he got sick real fast and lost a lot of weight and in the end we learned that he had the virus. He didn't last long, he didn't last long. Well, without medicine or anything, he didn't last long and he died in 1987, and still I waited almost until 1990 to ... to 1990 because I imagine the denial stops you from doing it, but when I started to...I moved to Boston where I worked with the homeless population, so I came across a lot of sickness in high proportions and I said, "I think I am going to get tested." It turned out to be positive and that still shocked me.

As suggested by Gabriel and examined in depth shortly, the experiences of receiving their diagnoses were traumatic rites of passage toward a permanent status change. Like most transitions in these rituals, it is traumatic and leaves an indelible mark.

Some men were informed about their HIV status at a health clinic or doctor's office after requesting a test because of the concerns about past sexual behaviors and drug use. A few men received their diagnosis in a similar setting, but were instead motivated to get tested by the memory of a partner who died from AIDS. In contrast, several other men received their diagnosis during incarceration after taking mandatory HIV tests for 
inmates, a policy that is enforced in some states. Yet, others agreed to be tested inside an outreach van just steps away from the shooting gallery they frequented, only to have been asked weeks later to stop by a nearby clinic instead of receiving their test results in the van like everyone else. Despite the differences in the locations and settings (see Table 8), the motivations for getting tested, or the care provided at the moment of the diagnosis, the diagnostic encounter narratives describe the life-changing impact of HIV shared by these men.

Table 8: Location of HIV testing and diagnosis

\begin{tabular}{lcc}
\hline Location & N & \% \\
\hline Medical setting (hospital, MD office) & 12 & 38.7 \\
Prison & 7 & 22.6 \\
Outreach van & 2 & 6.5 \\
Community agency & 5 & 16.1 \\
Other & 5 & 16.1 \\
\hline
\end{tabular}

Similar to Leo and Gabriel, other men experienced their world collapsing with the realization of being HIV-positive. Twenty-three other men (71\%) were equally "shocked" and in despair upon testing positive for HIV. "Well I was very, very stressed," recalls Diego after receiving the HIV diagnosis. "Like, like how do you say this, panic. A lot of panic. I thought I was going to die and I had a lot a lot of panic." For Samuel, knowing he was HIV-positive was equally overwhelming and despairing: "And the doctor told me 'you came out positive,' but the good news is that you can live with this.' But my mind was somewhere else. I didn't want to hear that. So I left and I tried to kill myself." He was not alone on this reaction given that a sense of desperation is common upon learning the HIV diagnosis. For example, Benedicto was not certain of how he was infected when diagnosed as a teenager in Puerto Rico, which made it even more difficult 
to accept his diagnosis. Upon learning of his HIV status, he felt engulfed by the virus, reduced to taking desperate measures to get rid of the disease: "I wanted to die. I tried to kill myself. I tried to choke myself. I didn't know how to take this away".

Other men described the HIV diagnosis as a shattering moment in their lives even when the risk of HIV was consistent with their lifestyle choices. For example, Victor, diagnosed with HIV at age 47, learned about his HIV status during a screening to participate in a clinical study. He was motivated to enroll in research by the cash incentive in order to sustain his drug use. Unexpectedly testing "positive" to HIV was as surprising as it was devastating for him: "When they told me that, they picked me up and in that moment my world fell apart. That was the last thing I expected was that hit." Similar shock was experienced by Manu. He decided to get tested after discussing his history of sexual behavior with men and women with a co-worker following an HIV prevention workshop they conducted together. Manu, 39-years old when diagnosed, described feeling claustrophobic and overwhelmed during his diagnostic encounter as he struggled to make sense of being diagnosed with HIV:

So [the HIV counselor] took me to a very narrow room and he was talking to me and asked me if I had gotten the antibody test and I told him "yes." He tells me "you know, your test came out positive?" But I didn't hear that. I only saw his mouth moving like a puppet. So as he told me that, the room kept getting even smaller and smaller. I felt that I was going to die due to the fact that I didn't have a lot of information. But because of the little I knew, fragments of information I had about HIV, I could pick up my pieces and move on.

An HIV diagnosis shutters the gateway to a normal, healthy life; they now have to accept that they cannot go back to being HIV-negative. In fact, the HIV-positive diagnosis boundary is neither porous nor blurry. Even if for years they invited this 
boundary by knowingly engaging in behaviors associated with transmission, having awareness of exposure to the virus, and even having a suspicion of being HIV-positive they feel an emotional jolt with the diagnosis. They have passed into the world of the HIV-positive. From the perspective of these men, the HIV diagnosis functions as the passage from a stage of health to a world of illness (Holohan 1977). As the diagnostic encounters demonstrate, it is traumatic and unforgettable transition. It is a time of fear and uncertainty, not a once-in-a-life-time opportunity for membership into a desired club. In retrospect, they can see this moment as pivotal toward finding community but during the moment itself, it is a passage into another world, the world of the "ill" and the "dying."

\section{HIV Diagnosis: The Rite of Passage into Community}

The anthropological concept of the rite of passage is helpful to understanding the labeling imbedded in the HIV diagnosis of an "ill" person and the redefining of the individual as a member of the HIV community. Arnold van Gennep in his seminal work Les rite de passage (1960) classified a group of rituals that mark transitions in which individuals change place, social positions, and generational statuses in a society. $\mathrm{He}$ defined these rites as "ceremonial patterns which accompany a passage from one situation to another or from one cosmic or social world to another" occurring in any society (Gennep 1960:10). His work was particularly insightful in identifying the structure of rites subdivided in three separate phases: separation rite, transition rites (also known as liminal phases), and rites of incorporation (Gennep 1960). His work was expanded by many others in Anthropology, including Victor Turner (1977). In particular, Turner (1977) made important contributions to the social understanding of 
rituals by further analyzing the characteristics of the liminal period during the transition phase in the rites of passage. Turner (1977) pointed that during liminality, individuals experience a period of ambiguity and submissiveness to authority to facilitate re-entering at the different status or stage.

In the case of HIV, receipt of diagnosis resembles the transition phase, liminality, between leaving the "healthy" world and becoming "ill," although not yet fully incorporating into the "illness" world of HIV. Being diagnosed "HIV positive" marks the labeling of the individual and the beginning of the changing of status. As these men described, the diagnostic encounter was a period of uncertainty filled with anxiety and fear. They entered into a liminal stage that lasted different length of time for different men; the transformation into an "ill"ness identity was not immediate nor did learning how to cope with living with HIV.

Ignacio was tested for HIV during the last phase of a longitudinal research study.

Shortly after receiving the HIV diagnosis, he recalls having an unexpected visit from a member of the research staff:

I went home and two days later, I heard a knock on the door and it was the guy...the guy I told you about, the guy from the interview that I had done in 1990. The same one that paid me showed up at my door and told me "let's go, you need help. Here where you live, you are not going to do anything. You can die here." Well, I welcomed him, I took his advice to what he was saying, and he told me "let's go to Boston, because there you can get better help. There you will get better services, and I suggest you go to Boston"... and I said "well let's follow your advice because I need help, the reality is I don't look good, I am really sick." And I didn't know anything about this condition. So, he brought me to Boston, he brought $\mathrm{me}$, and he settled me in a program and told me "you have to be here, I'm going to come to see you." 
In his case, the testing counselor from the research study took exceptional measures to ensure Ignacio would receive the appropriate care and services he needed to care for his new condition. Through several unorthodox actions, first, by making a home visit and, then, by taking Ignacio to a residential HIV program, demonstrate a perceived urgency for getting treatment upon receiving an HIV diagnosis. For Ignacio, the counselor's conduct reinforced his status as an ill person in need of urgent care, defined just days earlier by the HIV diagnosis. His actions also show that the medical view of an HIV diagnosis is to pull the newly diagnosed into the "community" of medical treatment, unaware that for many people there is a necessary liminal transition step needed. While well intended, the counselor's actions meant that Ignacio was not going to be afforded this transition stage (expressed by denial, uncertainty, etc.). The counselor likely feared that Ignacio was overwhelmed or perhaps even in denial with the diagnosis. Yet, either of these reactions to the diagnosis is well explained by experiencing the transitioning phase of entering the HIV world.

In many cases, being labeled "ill" is difficult to accept in the absence of physical symptoms related to the illness. Denial is a rational reaction to the diagnosis in cases when the person is feeling well, an important characteristic of the liminal stage as much as the submissiveness demonstrated by Ignacio. Gabriel noted how difficult it was to accept his diagnosis and being part of the "ill world":

I had trouble accepting it. Because I spent three years in denial before I took the test and since I felt so healthy. I said to myself "please, not meeee!" So I said "this can't be." But when, like I told you, when I heard about it I had trouble accepting it. But once I worked through my denial, I told myself "oh, you can't beat them, join them!" 
The confirmation of the seropositive status is a diagnosis of being ill despite the presence or absence of physical symptoms. As articulated by Gabriel, initially he resisted the medical as much as the social categorization imposed on him by the HIV diagnosis. He clearly articulates his denial in terms of an "us" vs. "them" distinction. Resisting the HIV status was buit on rejecting an association with ill people with whom he could not identify given the absence of physical symptoms, regardless of what his diagnosis indicated. At the same time, he was aware that he could not transition back to being "healthy" in the sense of being HIV negative. However, adjusting to the new "world" is a collective process. In his case, meeting other people living with HIV who were not sick helped him come to terms with his diagnosis. "I started seeing people that had the virus and didn't get sick. In the past like in 1987 I saw how everyone who had the disease died." For Gabriel accepting his new status was mediated by other men like him, who were "ill" but not sick. Clearly, the ill distinction is solely defined in terms of the diagnosis, not the level of sickness nor the presence of physical symptoms of HIV. Defining the "ill"

The transition newly diagnosed people undergo involves adapting to changes in their status; foremost among them is going from being independent to being an ill person needing the care of others (Holohan 1977). Similar to Ignacio's submissive demeanor towards the "treatment plan" proposed by the counselor when he unexpectedly showed up at his door, other men in the study assumed a similar dependency on others for decision-making upon learning of their HIV diagnosis. Marcos, 56 years-old at the time of the interview, was diagnosed with HIV in prison where he also received guidance and instructions to manage his new status. He recalled: 
[At prison] they give you therapy, they prepare you, for when you are released, and they tell you where you have to go. How to continue with your treatment. But for the moment, while you are there they provide you with therapy, they give you a lot of counseling and they prepare for when you get out, to be released.

Comparable to Marcos' experience, Mario received strict instructions to care for his HIV in a fashion similar to that of a parent making decisions on behalf of his child. In fact, he started attending support groups following a decision made on his behalf by his care providers:

[The case manager] is like my old man. So [the outreach worker] told him one day "hey, I want to take him over with me." And I looked at them and I said "take me where?" He told me "I think I am going to take you there, to this group." And I said "wow!" They were the ones who sent me here. Because in the past I didn't go to any groups, or to the psychologist, I didn't go to counseling... I never went to any psychologist, not even to the psychiatrist, to anyone.

Not only do men become dependents with an HIV diagnosis, they are also treated as if they were children. Some of the men, overwhelmed by the uncertainty and fears of being HIV-positive, adopt a submissive demeanor appropriate to their child-like status and in great contrast to how they would assert themselves as men. Following the directions of authority, they assumed their "sick role" (Parsons 1951). This form of interaction with an inescapable hierarchy mirrors the paternalistic model of physicianpatient interaction concerning decisions of health (Emanuel and Emanuel 1992; Levin et al. 1992; Coulter 1997; Charles et al. 1999). The interaction establishes a clear boundary between "ill" and "well" drawn by health care professionals exercising authority over the decision-making of the patient, and a boundary between authority and laity. As Freidson (1970:133) noted "the patient is incompetent to judge what is needed, and in order to be cured must put himself passively into the hands of the staff, obeying them without 
question and allowing them to do what they see fit.” During my interview with Victor, he confirmed Friedson's claims. During his diagnostic encounter, he was outspoken about his lack of knowledge on how to deal with his diagnosis, empowering the physician to take charge and relegating Victor to the vulnerable victim role:

Ah, they told me about my HIV and I said "so, what is this? What do I do?" And they told me "we can't do anything for me here." But, but...give me an idea or something... you have now put me here, I don't know, do I throw myself off the building or something because...I'm think about it, you know. And he went away..."

Receiving an HIV diagnosis parallels the characteristic described by Victor Turner of the liminality periods within rites of passage in which initiates are expected to submit to authority figures, people who possess the knowledge over the initiates' next stage in life. For example, medical professionals provide instructions for care after the diagnosis and these are seldom questioned initially by the newly diagnosed. Turner (1977:95) explains that this is key during the transition process because individuals are "being reduced...to a uniform condition to be fashioned anew and endowed with additional powers to enable them to cope with their new station in life" (Turner 1977:95). From this perspective, the passive disposition and willingness to accept proper care is essential for a newly diagnosed person to learn to live as an ill person with HIV. Again, Ignacio illustrates this attribute noted by Turner: "Well, already in the program, inside the program, they started teaching me, the people that teach inside the program started teaching me what HIV was, and how do you live with it."

Essential to the argument being presented here, however, is the second characteristic of the liminal stage identified by Turner: the formation of communitas. In general terms, communitas has been described as the "collective spatial and temporal 
dimension occupied by liminal personae" (Locke 1999:1). However, more specifically, Turner's notion makes reference to the special bonding that emerges among individuals who transition together. Initiates undergoing a rite of passage communally feel cohesion and equality during this time because they are going through a common experience. A profound feeling of belonging together, of comradeship results which Turner captures with his term "communitas" (Turner 1977).

Turner's characterization of liminality and the unique social relationships it generates among peers fits well with the stages of becoming "ill" from receiving an HIV diagnosis reported by the men in this study. As a rite of passage experience, receipt of an HIV diagnosis is strictly an individual experience, thus the solidarity of rites of passage in the classical sense with others described by Turner is not there for a newly diagnosed person. However, and here is Turner's communitas contribution to this study, from their accounts these men feel and experience liminality through denial, submissiveness, and a complete reduction of self upon receiving the diagnosis. For them, as in the case exemplified by Gabriel, it is in the joining of the "ill" domain — the HIV world—-that they gain communitas which they did not experienced during the diagnosis rite of passage. Communitas for them is not experienced during the diagnosis into the world of HIV, but is a product of their incorporation into the "illness" world of HIV with others who shared similar experiences of illness, including similar experiences of diagnosis. Those who have the status change do not re-emerge from the ritual—-the HIV diagnosis—-being publicly acknowledged as changed. However, from the perspective of these men, when they emerge out of the transition, upon accepting their HIV status, they are changed 
publically with and among their peers when they incorporate into the HIV world; they are now HIV-positive.

\section{HIV Identification}

Once diagnosed and admitted into the HIV world, managing life with the illness collectively is a critical determinant shaping the HIV community. HIV as an illness is at the core of the members' identity and worldview. Because of the labeling associated with the diagnosis, there is strong sense of identification that reflects the acquiring of symbols that others, the medical community, society, etc., imposed on them defining their persona associated to their HIV status. The defining system reinforces the distinction between sick and the well to strengthen the boundary between the healthy and the abnormal. More than anything else, people living with HIV represent themselves in terms of their illness thus reinforcing the boundary that encircles them. Among the men in my study, a common representation of self suggests that they assumed the HIV "ill" identification, imposed as part of the categorization into the HIV world. For example, Antonio, when disclosing his status to others, asserts "I am HIV, I'm HIV!” (“Yo soy $H I V$, soy HIV!"). Other men described themselves in a similar fashion as "a person who is sick," or "I'm sick," and even "I'm an HIV patient." These identifications were more salient particularly during intimate encounters with women:

I told her "look baby, like you can see, I know that when I got here you liked me and if I'd have flirted with you, you would have fallen." "No, I wouldn't have fallen" responded quickly. "Come on girl, I know you would have fallen, right now you are leaving the nest, and you would have fallen for me. And you know why I haven't tried it and I haven't done anything with you? Because I started doing drugs in Puerto Rico and the drugs fucked me up and I'm sick." I didn't tell her anything else. Few words are enough, because those who know, know. 
The ill identification is reinforced when referring to people who are not HIVpositive. In fact, these men highlight the difference by categorizing HIV-negative people as "being well," referring to them as "personas sanas" ("healthy people") or "personas limpias" (“clean people"). Mary Douglas' work helps to understand the symbolic language embedded in this distinction suggesting that they face an additional symbolic boundary—-the line between "clean" and "dirty" people. Douglas, in Purity and Danger (1966), offers a cultural explanation for taboo beliefs and ritual pollution in cultures, what she refers to as "dirt." According to Douglas (1966), dirt (uncleanness, pollution, etc.) is part of a system which is not foreign to a social system and order of a culture:

[Dirt] implies two conditions: a set of ordered relations and a contravention of that order. Dirt then, is never unique, isolated event. Where there is dirt there is a system. Dirt is the by-product of a systematic ordering and classification of matter, in so far as ordering involves rejecting inappropriate elements. (Douglas 1966:36)

From this perspective, what the men are saying is that with HIV they are now outside the normal order of things. These categorizations (infected, sick, etc.) stress the difference between "who is an HIV-positive person" in terms of illness in contrast to others who are well (clean, healthy, etc.). In essence, the adoption of these labels represents the status of these men who are outside of the clean, healthy, normal society, but not necessarily inside a community. And they will not get inside until they construct and transition into their own community of belonging.

The boundaries established by processes of categorization are not subtle. On the contrary, the distinction made incites attempts to redraw boundaries imposed by the 
labeling given the negative perception associated with being categorized as an ill person.

Felix ${ }^{11}$, for example, encountered such an experience during an exchange with a peer.

Felix: $\quad$ One time I was in this meeting and every time I said "I was sick," this American guy got mad.

Interviewer: He got mad?

Felix: Yeah.

Interviewer: Why?

Felix: $\quad$ He should have told me at the beginning, right, not to say that. Say that... he told me to say...some other word he said, you know. But he said he got mad because, because of his parents. He doesn't want his parents to think he is sick, you know. That he has a disease or whatever. I forgot what he said. I know he got mad every time I was saying that I was sick.

Interviewer: But you didn't know!

Felix: I didn't know!

Interviewer: So, then...were you supposed to say something different then, like I'm ill or...?

Felix: Yeah, something like that. I don't know. Some other word. I forget, you know, but I got mad. I was so mad I even forgot what he wanted me to say, you know. This is the way I feel, you know. I'm speaking for myself, you know. I feel sick, I feel sick! You know. Yeah, but he was mad because he doesn't feel that he is sick, you know...oh, he wanted me to say that he has a disease.

Perhaps, unbeknownst to him, Felix was reaffirming the illness label imposed on him by the diagnosis. The challenger's demand was not an effort to reject the medical nature of being diagnosed with HIV or the seriousness of the condition. On the contrary, his was an attempt to refocus HIV solely in terms of an illness separate from the person, one could argue, in an effort to redefine what it means to live with HIV. In the process, he was attempting to redraw the boundaries that categorize him as an "ill" person for having tested positive for HIV. Although, this dynamic takes place within the culture of the HIV positive treatment center, it nevertheless illustrates the resistance towards the re-

\footnotetext{
${ }^{11}$ English-speaking respondent - text in original language of interview
} 
classification of the individual because of testing positive to HIV. Efforts to resist the labeling are suggestive of its classification nature separating individual outside the normal order of things.

Medical anthropology scholarship in chronicity confirms the social labeling and categorization determined by medical diagnosis described by these men (Estroff 1993; Kendall and Hill 2010; Menderson and Smith-Morris 2010). As a theoretical framework, chronicity was proposed by Sue Estroff (1993:250) as "the persistence in time of limitations and suffering and the resulting disabilities as they are socially and culturally defined and lived." The approach is helpful to understanding chronic illness as a product of social processes and cultural factors (e.g., acceptance, stigmatization, re-definition of self) instead of as a set of biomedical facts summed up in a diagnosis - the common view held by traditional western medical models. Furthermore, illness as a social construction "consists of a fusion of identity with diagnosis" (Lindenbaum and Lock 1993:245) which is informed by the social and cultural ideas about illness, morality, and social roles, and morality diagnosing the social status of the diseased (Estroff 1993). From this perspective, HIV fits well within a discussion of chronicity. In fact, just recently Kendall and Hill (2010), looking at the dependency of antiviral medication in South Africa, laid the foundation for the conversation about the chronicity of HIV/AIDS. My study engages the discourse proposed by this scholarship and goes beyond the classical notion of chronicity. Specifically, for HIV-positive people living in a society where the chronic expectation of HIV is conceivable in practice because of readily available HIV treatment, chronicity can describe the complex adaptive process to the illness; as in the case of the men in the study, understating long term adaptation involves examining the relationship 
between the process and stages of becoming and accepting being chronically "ill" with HIV ("I'm sick") and the practices of boundary-work implied by the medical, yet socially defined, status of being HIV-positive ("I'm HIV”).

\section{Boundary-Work through Ostracism: Shared Experiences HIV-related Stigma}

At the clinical level, an HIV test is designed to determine a person's HIV seropositive status. However, while testing has an important medical purpose, it also draws an explicit social boundary (Alba 2005) where one of the criteria used to inflect social status is morality. An HIV diagnosis is not merely about distinguishing the ill from the well, it also diagnoses, intentionally or not, the person's moral and character judgment. Testing positive for HIV draws a permanent line of social distinction that labels a person as an HIV-diseased contagious person who, in the case of drug users and gay men, "brought" this condition upon himself through amoral behavior.

The diagnosis inevitably confers stigma. People who are HIV-positive are perceived as not only ill but also as a social ill. According to Varas-Diaz (2005: 170) they are viewed as "invasive agents in a healthy society." From this perspective, Chapman (2000:844) noted that HIV-positive people are characterized as "dangerous, contagious and as a threat" to the social order (much like Mary Douglas would have), thus justifying the stigma imposed on them. There is a bright social boundary that is thrown up around them to keep their threat distant from the larger society. In this sense, Chapman (2000:841) further concluded that "to be HIV-positive is to be untouchable." The social perception surrounding HIV shapes the new identity of an HIV-positive person and is made evident in enacted stigma (Parker and Aggleton 2003; Roberts 2006). Rudy, a 47-year-old living with HIV for 18 years at the time of the interview, summed up 
the practices of social exclusion inherent to HIV-related stigma describing the reactions of his friends once they learned he was HIV positive:

A lot of my friends didn't want me hanging out with them. They were afraid of....before, my friends and I used to smoke from the same cigarettes and drink from the same beer bottle. After they found out I had the virus everything changed. They slowly started to push me away. I heard comments that I had AIDS, to be careful, that I would infect them, things like that. Weird comments.

The treatment Rudy experienced is not uncommon. In fact, the men interviewed in this study share the common perception that HIV-positive people are stigmatized in society. For them, being HIV-positive represents a wall that prevents them from participating fully in society and limits their social interaction.

\section{HIV Stigma}

The notion of stigma is crucial to explaining the negativity of the boundaries which encircle people with HIV. Erving Goffman (1963) is credited with doing in-depth research on stigmatized populations and the notion of stigma. According to Goffman, stigma is "an attribute that is deeply discrediting within a particular social interaction" (Goffman 1963:3). The devaluing of individuals with stigma or stigmatization takes place when there is gap between the way a person should be considered and treated and the way the person is actually considered and treated in social environments (Ritzer and Goodman 2004). In his analysis, Goffman (1963:4) identified three types of stigma: "abominations of the body," for stigmas associated with physical, visible deformities; (b) "blemishes of individual character," related to the person's weak character and unnatural behavior; and (c) "tribal stigma" to denote the negative evaluation associated to all members of a stigmatized group. Ultimately, Goffman noted that stigma establishes a 
social boundary that categorizes and segregates individuals with an "undesired differentness" into a lesser, inferior social status, in contrast to "normals," those people free of negative blemishes (Goffman 1974:5). The labeling of the unstigmatized as "normal" is important since it carries with it the connotation not only of physical or psychological normality but also of moral normality. Having or not having a stigma, then, is a social category which like many others forms the basis for a hierarchical order.

Although HIV had not yet been identified when Goffman was writing his influential work (1963), many have made the connection between HIV and stigma. According to numerous studies, communicable fatal illnesses and diseases transmitted through choices of personal behavior are associated with the highest degree of stigma (Bennett 1990; Weitz 1990; Herek 1999). Since the first cases of AIDS were identified in the early 1980s, health campaign messages and the media's headlines have shaped the understanding and knowledge of HIV/AIDS with recurrent messages associating the illness to an individual's immoral character (Helman 2000). While there is now wider knowledge and understanding about HIV/AIDS 30 years after the first cases were identified, there are still strong remnants of stigma and discrimination against people living with HIV, particularly among gay men, drug users, and ethnic minority groups. As described in the introduction of this dissertation, HIV-related stigma and discrimination is evident in common feelings of avoidance and isolation, behavior justified with the belief that HIV-positive people are responsible for and deserving of their illness because of their amoral character and behaviors (Herek et al. 2002; Brimlow et al. 2003). 


\section{Experiences of Stigma: Separating the "Bad" from the "Good"}

The men I interviewed were well aware of the negative perceptions and judgments of HIV-positive people in society and the social boundaries drawn around them owing to their diagnosis. For example, Marcos, 56 years-old at the time of the interview, described how in Puerto Rico HIV is considered a virus for "bad" people: "the person that gets the virus, the person who has the virus, is a bad person. A bad person. It is a disease that only bad people get" (emphasis mine). Along similar lines, Marcelo, a 51-year-old MSM, remembered a family conversation attesting to the immoral character and "dirty" nature of people stricken by the illness when discussing the AIDS diagnosis of his cousin:

One day I heard my uncle because my mom asked him right in front of me: "and how is Caco?" And he answers my mom "there he is infected with AIDS because he is filthy"...If he said that, that day, of his own son, if he finds out about me what would he say: "look at him for fooling around with another man, look what happened!"

Manu, 56-years-old, also learned the extent of rejection that evokes an HIV diagnosis from a close friend who was not aware of his HIV status. He recounted their conversation: "A friend of mine told me "if I ever found out that a friend of mine has HIV, that has AIDS," because she doesn't know the difference between HIV and AIDS, “'I don't want that person in my house. I wouldn't eat, wouldn't eat not even drink in that glass." ",

Sixty-one percent of the men in the study themselves experienced stigmatization as a result of their HIV-positive status. Expressions of stigma are boundary-work practices aimed at excluding them from the possibility of living in the "normal" community, the uninfected, clean people. Setting these boundaries involves processes 
highlighted in differential treatment. In these cases, boundary-work done against them is with the goal of alienating them away from the normal. The most common experiences included discrimination and rejection. In some cases, these experiences were reduced to an isolated instance while other men experienced repeated and ongoing occurrences. Although most common experiences were related to differential treatment, the experiences of stigmatization suffered by these men illustrates the perception of HIVpositive people as contaminated and contagious individuals, and thus, as social threats and socially unfit that need to be removed from the community.

The categorization of HIV-people as a threat is perhaps the most extreme form of stigmatization experienced by these men. In such cases, people perceive HIV-positive people as dangerous. For example, Hernán experienced significant social stigma from being HIV positive soon after his diagnosis at his workplace.

Well I received a lot of threats from the faculty of River School when it came out that I was sick with AIDS. I received threats. I would receive notecards in my teacher's mailbox with vulgar comments like "scourge carrier," or "screwball," "get out of here, you could infect the whole faculty." Things like that.

Despite HIV being a very confidential and private matter, Hernán's diagnosis was leaked to his coworkers suggesting the need to alert others of the threat he represented.

Gossiping is effective boundary-work because it regulates the shared unwritten rules and regulations of a group. It serves to alienate those who do not belong, and, in so doing, promotes "cementing social bonds" among those who belong (Baumeister et al. 2004:111). These experiences are not limited to the work place. For example, Ignacio experienced a similar situation when he realized that being HIV-positive was perceived by others in his private life as a threat. He recalled how people went to extreme measures 
to warn women of his condition to make them aware of the danger of dating him. "Well, out of a sudden many people, because I make friends or try to meet them, and then comes another person and tells them 'no, be careful with that guy, and this and that.' So all that stopped in a tremendous way." Moreover, the men reported that the stigmatization was not limited just to them. In fact, the stigma of HIV spread to those with a close relationship to the HIV-positive person. Mario described this "courtesy stigma" (Goffman 1963) imposed on his brother when he disclosed his HIV status to a mutual friend:

She stopped being my friend. She never called me again. We never spoke again, nothing, nothing, absolutely, nothing. You know I said "wow!" She even stopped being friends with my brother. My brother and her were even closer, because I met her through my brother. So she stopped being friends with my brother I was like "wow!" There are people who are ignorant, who aren't educated about this, and I don't blame her.

The stigmatization boundary-work against those with HIV extends, not surprisingly, to intimate relations. For example, Nestor remembered a scenario when he disclosed his diagnosis to a woman he was dating. She reacted "What? That you what? You have AIDS? Oh Nestor! Oh, no! We can't be together, no, no, no! You forgive me. I love you very much. You are very good person, special, but no, no, no!' And she rejected me." Perhaps Carlos, diagnosed with HIV in 1987, best summed up the notion of being "untouchable" because of being HIV-positive:

In the love department things have changed for me. In the love area. Because even though I still have lots of love to give I feel like that American saying, I feel like "damaged goods." I mean, even though I have a lot of love to give, I am a person that is capable of loving in an intense way, but I recognize at the same time that I am inadequate to hold a relationship for having the condition. 
The perception of being "damaged goods" is another form of stigmatization resulting from the negative views of HIV and emphasized in the messages the men in the study receive in everyday interactions. These men often speak of themselves in these terms suggesting they have internalized the stigma, thus "holding a negative view of HIV disease and of themselves" (Lee et al. 2002:310). Victor, living with HIV for 18 years and also diagnosed with cancer, exemplified the internalized stigma of HIV during our interview.

Victor: I have my wife. I got married again and... Interviewer: Is she positive? Victor: $\quad$ No she is not positive. I've been with her 11 years Interviewer: But does she know that you are positive? Victor: $\quad$ Yes, she knows that I'm positive, that I have cancer. That what she has is a quarter of a husband.

In all these cases, the men were perceived as a threat. As Crandall et al. (1997:115) have noted, "the important threat with respect to AIDS in particular is the threat of contagion, sickness, and mortality associated with the illness." The stigmatization encourages individual and collective negative responses, practices intended to exclude these and other men from normal social interactions. Their experiences illustrate the processes by which everyday "normal" people do boundarywork against those with HIV, creating a lexicon of stigma for them: dangerous, contagious, incurable, amoral, etc.

The boundary-work performed with stigmatization is so virulent it is as if people do not have a virus but, rather, that they have become the virus what has been categorized as the "I am illness" ("Yo soy HIV") attribute of a stigmatized condition (Estroff 1993). This personification not only excludes HIV-positive people from participating in the 
greater society, but it also dehumanizes them sufficiently to merit their social quarantine. In some cases, my interviewees described being treated as "untouchable" such as happened with Diego. “One time I was at a program and a lot of people wouldn't sit next to me, they would sit far. It was a program for the homeless, for people searching for an apartment, to live "drug free." And I think it was because I had HIV." The negative beliefs towards HIV-positive people are reaffirmed in many forms, particularly in everyday settings. In addition to the discernment, everyday practices of stigmatization, for example, not seating next to someone who is HIV-positive, giving someone diagnosed with HIV plastic utensil, etc., accentuate the notion that HIV-positive people are ill, infected, and a risk for contamination.

\section{Buffering the Stigmatization}

The stigma of HIV redefines the life of an HIV-positive person. The extent of the social separation implied in the boundary-work enacted through stigma encourages these men to engage in anti-stigma practices. For example, in many instances, these men take actions to hide their diagnosis. These practices help to ameliorate the impact of stigma. Although some men did not report being stigmatized directly, they nevertheless engaged in proactive measures to ameliorate and even prevent the stigmatization. In these cases, when they successfully conceal their HIV status, HIV continues being stigmatizing in their lives. Goffman (1974:4) describes this form of stigma as discreditable stigma in which a person's discrediting "differentness" is not often perceivable but nevertheless triggers the management of stigma. This type of stigma perhaps best exemplifies the discrediting nature associated with HIV. These men, like Marcos, Marcelo, and Manu introduced at the beginning of this section, were made aware of the negative attitudes 
"normal" people hold towards HIV-positive people as expressed in conversations (discursive boundary-work), thus resorting to hiding their HIV status to prevent being stigmatized. Felix ${ }^{12}$, a 40 -year-old living with HIV for 7 years, summed up discreditable stigma:

Sometimes you hear people talking about people that have this disease and people that you know, and they don't even know that you got it, you know. Because you don't tell everybody that you got it, you know, because they are always going to be thinking about that. They don't want you around or something like that. So all that stuff worries me so that's why I don't...I have to choose who I can tell about it, you know what I mean?

In addition to hiding the diagnosis or being selective about disclosure, men engage in other strategies to prevent accidental disclosure and thus avoid stigma. For example, in an effort to conceal his status, Ivan hides his medications to prevent questions regarding his condition. "Because a person that enters and sees all of those medicine containers, they ask questions, some people ask 'what is that medicine for, what is that for, what is that?"' Marcelo also believes that the medicines can reveal his diagnosis. To prevent a possible disclosure, he has taken a more drastic approach with his medications than Ivan:

[The doctor] would prescribe me the medicine. I would go to the pharmacy and pick them up. I would take off the labels because someone could go to my home. People are curious and they could see the label that they can read, 'what does this mean?' I don't know, they could ask."

Another area affected by the discreditable stigma of HIV is intimate relationships. Similar to concealing medications as a way of preventing discrimination and rejection, some men follow or employ strategies of self-censorship as a way of concealing their

\footnotetext{
${ }^{12}$ English-speaking respondent - text in original language of interview
} 
entire "self" from disclosure. Mario, 40 years-old at the time of the interview, stopped having relationships because of his fear of women's reactions to his diagnosis. Fearful of this scenario, he decided: "Women would come up to me, you know and I would run from them. I would reject them for the fear of being...with time having to have to tell them that I am sick. Maybe because of fear of being rejected." Similar concerns were voiced by Marcos justifying his decision to change how he relates to women:

It bothers me a little bit, but...not so much...I've had relationships with women that have the virus (HIV positive). But it does bother me, I don't talk with women like I used to. Because of that matter that I don't want to be in a relationship and that the women falls in love and they don't have the virus. So then I go to, after we have a relationship, so then I go and I tell her the news like that. In that area I've taken myself off women. But I've been with women that have the condition (HIV) because I don't have to be afraid with them because they are like me.

The experiences of these men suggest other forms of stigmatization experienced despite HIV not being a visible condition. These practices to buffer the stigma by concealing HIV are not sustainable over time. Taking medications is difficult to keep hidden, particularly given the number of pills involved in HIV treatment; labels cannot be taken off permanently from medication without the risk of mixing medication, and even exercising self-censorship in relationships can be frustrating over time. As illustrated by Marcos, despite purposely avoiding relationships with HIV-negative women, he confesses he is bothered by having to make this change in his life.

The decision to conceal the diagnosis prevents them from fully participating in society and having a normal social life, highlighting a transition stage. Although it is possible to write an entire dissertation on stigma management, it is not the focus of this study. Yet, it was important to present the topic in some depth, particularly to illustrate 
the impact of discreditable stigma shaping the lives of these men, regardless of whether or not they were directly stigmatized for being HIV-positive. For these men, this form of stigma management is part of adjusting to their new world as part of the transition, when still liminal between two worlds. Although, it is impossible to go completely back to preHIV, it also it implies that they have not incorporated fully the HIV status. Marcelo exemplified this situation.

I was told "we called you because we have your results and you are HIV positive." They did the tests again. And then they sent me to a place in [Puerto Rico]. There they started giving me treatment, but I always have another problem, that I live like hidden from this disease. Since then on I live like....a secret.

He participates in groups and attends some social events organized by HIV agencies, however, he is overzealous about hiding his diagnosis out of fear of being discovered and rejected. "I live a life like I'm in hiding that I live with this disease," stresses Marcelo. "Like sometimes like I am distanced from the world. That's how I live my life with this disease." Ultimately, discreditable stigma can be as disturbing and devastating as enacted stigma (performed with discrimination) and equally socially defining of HIV-positive people. For Marcelo, the same fear of the consequences he has about being exiled and stigmatized if his diagnosis is discovered, he imposes on himself by separating himself from the world. His case, although more severe than others, highlights these men's need for balancing living with HIV as a permanent condition while at the same time being perceived as a social ill (Goffman 1974:35).

Whether HIV-related stigma is conspicuously voiced or subtly performed, it functions to draw socially stigmatized boundaries around HIV-positive people as diseased and contagious - unfit for membership within the "community" of the normal. 
Perceptions of being untouchable, undesirable, diseased and damaged contribute to lessening the quality of life of people living with HIV/AIDS and their sense of self. Such redefinition of self is in line with Charmaz's (1991) findings among other chronically ill men who lose "valued attributes, physical functions, social roles, and personal pursuits through illness and their correspondingly valued identity." Ultimately, boundary-work of stigma is determined by social and cultural forces that respond to the values and beliefs of a group and a dominant society to draw superiority on others, perceived as both socially and morally. Other social actors become involved and participate in the stigmatization given that "stigmatized groups are devalued not only by specific ingroups but by the broader society or culture" (Crocker and Major 1989:609), thus reaffirming the boundaries by participating in the ingroup-outgroup relation. In essence, HIV constitutes a "contagious moral blemish" (Goffman's 1974:35) upon which these men are redefined by membership into a stigmatized community at the time of their diagnosis. The stigma of HIV, enacted in boundary-work practices, plays a critical role the lives of people living with HIV, and as I argue in this dissertation, influencing the development of la comunidad, established out of viable permanent boundary-work practices that are sustained over time.

\section{Belonging: Inside the Boundary of La Comunidad}

The diagnosis of HIV and the stigma attached to the illness are social mechanisms drawing the boundary between those without and those with HIV. The boundary-work is done primarily by non-HIV infected people to circumscribe those with HIV. In other words, those with the diagnosis feel the boundary-work largely done to and against them. Yet, the HIV-positive men involved in this study are not mere passive spectators in these 
processes defining their lives with HIV. In fact, these men respond to others' boundarywork and redefine their lives as HIV-positive people constructing community and establishing belonging on their own terms. They engage in boundary-work to selfidentify "who they are" as people living with HIV. They develop a collective set of coping mechanisms that, when analyzed, can and should be viewed as constitutive of a "community" with distinctive cultural characteristics. Such perspective focuses the analytical gaze upon the agency of people making their community instead of the passivity of being categorized and excluded from the broader society into a group of mere "moral deviants." Contrary to the diagnosis-leading-to-stigma-and-exclusion view of the HIV infected, the constructive, agency view examines how these men create community replete with belonging and emotional closeness, a type of community they now find difficult to achieve with non-HIV positive people given some people's exclusionary boundary-work against them. This is the view of community construction through affirmative activities versus discriminatory practices. La comunidad these men speak of is one of belonging and integration through affirmation promoting positive values and practices to living healthy with HIV.

The emergence of la comunidad can also be examined in terms of the political economy of HIV/AIDS influencing the culture of HIV organizations including the services they provide, the philosophies guiding service delivery, and treatment models. This approach can reveal the factors that structure the environment and influence the social spaces shaping responses to HIV (Bielefeld and Scotch 1998; Gilks et al. 1998; Penner 1995; Altman 1999). Given the philosophies of these institutions to inform the models of care available to HIV-positive people to living with the illness with healthy 
choices, it is analytically relevant to examine la comunidad within the context of the organizations where these men receive services. However, this approach to understanding positive adaptation to living long term with HIV, while useful to shedding light on the structure where community is negotiated, does not fully convey the ways in which this group of men negotiates living with HIV beyond the confines of these organizations. The inadequacy stems from the fact that such an approach would overlook the men's own perspective in the community building process and the practices of boundary making and maintenance shaping the community. In contrast to such an analysis, I incorporate the men's viewpoints. By including insiders' (emic) perspectives I am better able to view how these men exercise agency through their everyday practices of defining, building and reproducing la comunidad on their own terms.

\section{Community Belonging: Membership Redefined}

One of the most difficult experiences in the lives of these men is coming to terms with their new status and accepting that they are HIV-positive. As illustrated previously, being diagnosed HIV-positive is a shocking and shattering moment met with despair, anxiety, and sense of loss. The process of coming to terms varies for each man, but it involves going through stages of denial, alienation, and then incorporation into the social fabric of the HIV world broadly speaking and the particular groups men join to cope in particular. Van Gennep and Turner would argue this is the most important part of the transitional, liminal stage of the rite passage into their new status in the HIV world. Acceptance in this process is central to develop a sense of belonging and being reintegrated into society with the new status. Membership into their HIV world, la 
comunidad, is effected once the individual accepts his HIV diagnosis, no longer tries to hide his crossing that boundary, and affirms this community as his own.

Acceptance of being an "HIV positive person" is central to affirming the HIV community, a process that is linked to the ritual of disclosure of the diagnosis to others. According to the men interviewed, there is an inherent relationship that exists between disclosure and being part of the HIV community. Gabriel identified this association while explaining his initial decision to keep his diagnosis a secret:

Well I thought I didn't want to tell anybody about it. I didn't want to talk. I didn't want anyone to know... to know that I was infected. I didn't want to associate with anyone who was infected so I wouldn't be singled out (...para que no me señalaran).

Despite accepting his diagnosis privately, Gabriel initially refused to be associated with anyone who was HIV-positive to prevent being identified as one of "them." His initial apprehension to disclose his status to others suggests that any association with people who are HIV-positive is an acceptance of being part of the "infected" community. This is not surprising given that at the diagnosis, as described in the previous section, an individual is labeled a member of a discredited community characterized by negative stereotypes, stigmatization, and even death.

Because of its challenges and risks, disclosing the HIV diagnosis is the most distinguishing form of boundary-work enacted by these men. Acceptance is empty of meaning unless it is accompanied with a public expression which is affirmed in rituals of disclosure. With disclosure, these men publically accept their status and recognize their identification with others who are HIV-positive, as discussed previously, acknowledging being part of the group characterized with negative stereotypes. Disclosing the diagnosis 
to relatives and close friends is often difficult because it exposes the person to stigma and rejection from loved ones (Roberts 2006). Despite the possible consequences involved, the majority of the men in the study (87\%) indicated that they had shared their diagnosis with family members and friends.

For many of these men, disclosure mirrored a "coming out of the closet" ritual. Minor illustrated the important ritual aspect of disclosure by calling a family meeting to share his HIV status.

I gathered everyone in the leaving room "This is what I have (HIV)!" They told me "you are our brother. We have to love you either way, sick or not sick." I told them "thank you" and to this date I've had their support. My mom even started to cry.

Likewise, Ramon decided to disclose his diagnosis to his family immediately after learning he was HIV-positive. However, his approach was a bit different:

I told my mom first and then she started preparing them for the news. Then, one day, they came here, and they were all here so I invited my doctor to my apartment to come to talk to them...my primary care doctor. First I talked to them and then [the doctor] talked and explained everything.

In addition to disclosing their diagnosis to family members, men shared their diagnosis with acquaintances in a similar ritualistic fashion. Many times, disclosure took place in environments of confinement taking advantage of the emotional safety provided by close-knit social spaces (Morrison et al. 2005). For example, Darío, upon learning his HIV status in jail, disclosed his status to his peers. He used his informal authority to inform his group immediately almost as if giving instructions or stating an inconsequential fact:

I liked having followers and being their leader in prison. So when I did the test when I went to get the results, I go to the office and I told them in 
the office "I don't want any runarounds, I don't want to be here more than what I need to, just tell me 'yes' or 'no.'” He showed me the results "yes, you are positive to the disease." And I said, "we'll talk later, ok. Later we talked about medications and stuff like that." So I walked out the door and started to tell my friends "hey, I tested positive in that test for the disease."

In a similar restricted setting, Felix ${ }^{13}$ remembers how he was encouraged to disclose his diagnosis at a residential drug program when others shared their HIV status. In his case, the scenario imitated a religious ceremonial invitation:

Yeah, there was about 6-7 of them. They were all in the closet, hiding! And what gave me, what gave me confidence was somebody else said that he was [HIV positive], right. And another person said he was. Well, let me say "me too!"

The experiences described by these men are similar to the "coming out of the closet" or “coming out” stories of disclosure among gays (Zimmerman 1984; D’Augelli and Garnets 1995; Gagne et al. 1997). As in the case of the gay community, public disclosure of HIV status facilitates the transition from a life in secrecy to one embracing the HIV identity and accepting public identification with others who are HIV-positive. In essence, public assertion of acceptance of the diagnosis functions as a symbolic boundary crossing (D'Augelli and Garnets 1995). Coming out with public acknowledgment of the new status is the end of the rite of passage. As Van Gennep and Turner would conclude, the transition involved in the rite of passage is complete with the re-entry into the HIV social world with a changed identity and new status.

\section{Belonging to Community: Socializing and Learning from Others}

The internal boundaries of the community are thicker than those traversed when the men receive their diagnoses. Being HIV-positive opens doors to the community of

\footnotetext{
${ }^{13}$ English-speaking respondent - text in original language of interview
} 
those living with HIV, but belonging is conditional upon being accepted into the community as well. That involves interacting with other people living with HIV (Roth and Nelson 1997). For many men in the study accepting being part of the community is a process that transpires as they learn about the illness while spending time with others who are HIV-positive, the socialization process. This was the experience of Gabriel, the man who was hesitant to associate with anyone who was HIV-positive because of fear of being identified with the HIV community.

But I started to overcome it, thank God, because of the...the support groups. There was one in particular, a support group at an agency here...Hispanic... and Planning. Yes, something like that. It was HOPE. So there I started to accept myself and knowing that there are others like me. And there were more than what I had imagined, so then, HIV has never affected me.

In the same way, Pablo recalls feeling empowered by being around others who were also living with HIV. He found strength in his HIV-positive case manager during this time:

Well, I introduced myself. My case manager said, "There is a new guest and I want you to meet him." I stood up and started talking. So, first she was telling me that it was a support group for people that have the same condition (HIV), so when I got there I didn't know anybody but her. She was the one giving me strength. So I was very very forward and brave and told them how I see things, how I am, where I am from, and she was saying, "That's it..." (clapping) and she clapped for me. So I was not intimidated and I had strength from within.

These narratives call attention to the fact that belonging to the community is not immediately determined by an HIV diagnosis, nor by being excluded from the "normal" population. In fact, actually crossing the boundary into community involves accepting la comunidad and being accepted by them, a process that requires learning about the community, being exposed to the social environment of HIV, and spending time with other HIV-positive people prior to being a part of the community. Luis described this 
process from his personal experience. He engaged in a creative strategy to become familiarized with the community.

It was a process. But I was going to groups and learning, and asking questions, you understand. I didn't go as a positive person but I went as a listener. I didn't tell anybody that I was positive. I went only as a listener, I went to learn. People would ask me, "So, how about you?" And I would say, "No, what happens is that I want to learn this, because, you know, I work in the field." A little white lie, you know? Before I did not accept [people with HIV] because I would say, because I didn't know, "Man, I'm not going to stand next to this person. Maybe that weal or something is going to jump on me and I'm going to..." Very ignorant, you understand. But then I learned and now I live with [people with HIV] around me. Like right now I go to the Boston Living Center and I share everything. I sit on a table. My English is poor, I speak it, I understand more than speak it, but I share with them, as my brothers, as if nothing was happening. And they ask me, "Are you okay?" And I say, "Yeah, I'm fine. I feel terrific." And I take my medications every day without missing one.

As suggested by these narratives, upon public acceptance of the HIV status, these men begin a process of socialization. They learn the values, beliefs, and, practices of the community and in so doing both help redraw and reaffirm boundaries. In Chapter 4 I go into a lengthy detail of the socialization process as well as these boundary-setting activities specific to la comunidad. For now, the goal is to highlight that there is a duality (being identified as a member and accepting being part of the community) in becoming part of the community. Belonging to la comunidad is not automatic.

\section{Entering the Community: Membership Rituals}

Disclosing the diagnosis in front of others who are HIV positive serves to draw lines of membership determining who belongs and does not belong to the community. An HIV diagnosis brings community membership into action; in other words, it initiates the processes for accepting a newcomer into being one of "them." However, as these 
narratives suggest, belonging to the community requires both being recognized as a member (having an HIV diagnosis) and having the desire to be part of the community, identifying oneself as a member of the community. As described by these men, the desire to be part of the community involves exposure to and evaluating aspects of the community before the decision is made. Boundaries in this instance play a key role since they determine inclusion in the community on the basis of the individual's acceptance of the diagnosis and the action to manifest such decision of being part of the community. Ultimately, belonging to the community occurs during a communal act when one joins a particular group of people living with HIV and discloses his diagnosis to the group's members. For these men, it can be accomplished with a simple disclosure ritual, a phrase in the presence of peers that denotes the crossing of the boundary: "My name is Marcos and I live with the virus." A similar process takes place among recovering alcoholics engaged in Alcoholic Anonymous as described by Humphreys (2000). He points out that “each time a member says 'I am an alcoholic' and tells the story about his or her alcoholism in front of the group, that identity becomes more firmly incorporated" (Humphreys 2000:499). Claiming "I have HIV" in public to others living with HIV stresses an identification that is linked to expressing belonging inherent to group membership, but also as a way of reaffirming the community.

Given the importance of HIV support groups, it is imperative to briefly describe the context where these groups take place. HIV agencies, groups, and programs are the foundational "architecture" of the community. These institutions provide social and medical services, as well as the support groups and social opportunities with a safe and welcoming environment where these men can disclose their status. Just to provide a 
context of the groups in Boston, 20 social and medical institutions were listed as providers of HIV support groups and programs in Boston (Peer Support Workgroup 2006). In 2006, a total of 67 different programs were offered throughout the city by these organizations for different populations and in different languages, 15 were facilitated exclusively by HIV-positive peers (22\%), 19 were co-led by HIV-positive peers and staff (28\%), and 33 were facilitated by program staff (49\%) (Peer Support Workgroup 2006). Of these, 17 (25\%) were offered in Spanish (Peer Support Workgroup 2006). Referrals to these institutions are made by physicians and testing counselors upon receiving an HIV diagnosis. Self referrals are also common, particularly among those individuals faced with a period of denial upon receiving the diagnosis. These institutions do not by themselves forge the community. Rather, as argued below, they enable the process of community formation to proceed. Without this organizational architecture supporting them it would be difficult if not impossible for these men to spend time on their community. The organizations sponsor and facilitate opportunities that the men use to build community, the most important of which is the peer support groups.

Another ritual transition from HIV infected (gateway into potential membership into the HIV community) to actual membership is sharing one's testimonial in one of these HIV groups. Although it varies, testimonials are normally shared as part of a normal "check-in" in most groups, or in others only when someone is visiting or joining the group for the first time. During the presentation, the group's members take turns introducing themselves and talking about their HIV history. Antonio gave an overview of a typical testimony: 
We identify ourselves. We give our name, we say where we come from. If you are from Puerto Rico then from Puerto Rico, Colombia, or whatever. So you tell everyone what you have, you give a little summary of how you became sick, for how long have you had it for. So everyone does the same thing and it helps to start the conversations.

With some minor variations, most personal introductions are similar and include telling one's name, length of time living with HIV, place/country of origin, and a short health status. Talking about the length of time with HIV and giving a health report is central to reframing the notion of dying linked to the diagnosis with messages of survival with HIV. Gabriel pointed to this feature:

You tell your name and some people introduce themselves telling how much time they've been living with the virus, which is nice for someone who is new to experience this to feel comfortable. It is good to say "my name is..." It's nice to say it because you don't know the person that comes how long has been infected, so if everyone says I have been with it for $5,10,3,2$ [years] so that person will feel better. Well I do it in a group so the person can feel comfortable in the group. It would be nice to tell how long I had it and if you live a healthy life, say you live a healthy life. Everything you can do to encourage the other person. Almost every time you start like that, by introducing yourself.

Although participating in sharing a testimony is a typical ritual involved with belonging to the HIV community, it is voluntary. The voluntary nature of the participation in groups is particularly reassuring for the newcomers, people who may not yet have come to terms that they are HIV positive let alone willing or able to admit it to strangers. Felix ${ }^{14}$ explained:

If you are new, you know, some places they leave you for last so that way you can see basically everybody's stories just about almost the same as yours, you know, so you can open up. But you don't have to talk if you don't want.

\footnotetext{
${ }^{14}$ English-speaking respondent - text in original language of interview
} 
Opening up to the group shows a willingness to participate in a key ritual that is formative of the community and also provides for its social reproduction and for the integration into it of new members. Moreover, as demonstrated by these accounts, sharing the testimony consolidates the notion of membership because it takes place when the members feel comfortable enough to talk openly about their condition in front of others serving as an example and mentor.

Sharing one's personal story with the group at one of the many opportunities offered, is important to experience acceptance with the condition as well. Disclosing your HIV status in the groups removes some of the fear of rejection when they are embraced by others. This was Samuel's experience when attending a group for the first time:

Yesterday was the first time. So everyone, it's call the "check in," how was your day.... I studied everything and I let everyone talk. When they got to me I said "I am new in the group and I've been positive like you since such year," because you can't go there unless you are positive. So I started talking and started to get more comfortable because later someone else raised their hand and said "welcome." You know, things like that, that make you feel, you feel...

In these groups, the men learn that they will not be rejected by their peers because of HIV. That is, while HIV excluded and stigmatized them vis-à-vis the broader society, inside the groups an HIV diagnosis is a defining characteristic for membership. The men are welcomed and encouraged not ostracized and dehumanized. This process is important to de-stigmatizing HIV since it shows that there is support not despite, but because of the HIV diagnosis. The testimonies help to generate a welcoming environment in a space everyone has the same condition. In turn, newcomers and regular 
members can identify with the experiences of illness of others facilitating a safe space to open up.

The public sharing of stories serves to witness and affirm the men's survival despite the diagnosis. They are not defeated individually and their sharing stories of survival promote a collective identity, one that cannot be acquired by those without HIV . Contrasting to their shattered experiences outside the world of HIV, belonging provides a different experience, one affirming both collectivity and individual members. New members are encouraged to share information about their lives by identifying with the stories being told. Luis explained the dynamics of sharing in the group with a newcomer:

You tell them "welcome to the group. What is your name? Where are you come from? Can you talk a little bit about yourself so we can get to know you?" So one of the guys that has been there the longest comes up and starts to open up. So when the new person sees that someone has opened up about his life, so then the new person feels relief and unwinds. He starts thinking "I am where I am supposed to be because people who have the virus as me are expressing their feelings, they are sharing their lives, so why can't I do it? And it feels good. Maybe that day he won't express what he has to express but as the days go by in the groups, the person keeps opening up, and when you realize it, he is participating in the support groups as a person has been there for 5 months or a 1 year.

People attending groups and members struggling with accepting the diagnosis can identify with the personal stories being told by others and can be more receptive to accepting the idea of being an HIV-positive person. This was the case of Diego.

It was hard in the beginning because you don't what is going to happen, you don't know if you want to go; going to a group is like saying to the world "I have HIV." I wasn't ready for that. But after I joined the group I started to accept it little by little and it helps to hear other people talk about their own experiences. Then I can talk about my experiences, also, like that helps a lot. 
These testimonies are compelling. As an outsider, however and unfortunately, I was barred from participating in most of these groups. This prevented me from observing first hand the rituals described by the men. Given this limitation, I extrapolate about the significance of these practices from the interviews with the men and from the few times I was invited to attend the groups a as a special guest when I was speaking about my project. The voices of these men, despite the limitation of my research, remain powerful.

Feeling part of the community is a process. As described by these men, it involves accepting their diagnosis, identifying as part of the community, and a willingness to share with others who are HIV-positive. Belonging to the community is crucial to defining who they are as people living with HIV. In the process, they engage in redefining the community by challenging the stereotypes commonly held about HIV. In fact, they reject the status of stigmatized death-sentenced victims by taking control over their lives. Instead of allowing the diagnosis to determine their lives, these men exercise agency to redefine themselves. This is how Mario explained it to me:

There are people who say "I live with HIV." No, HIV lives with me! Because I was here before HIV. I was here before HIV. HIV came after. HIV came to meddle in my life, so it has to adapt to me. Sometimes I don't have control over it but I look for the way to control it.

Mario's empowerment over HIV is compelling. His account sums up how these men participate in boundary-work with mechanisms to defining who they are, as people living with HIV, not in terms of being defined by HIV.

\section{Adopting the Norms of la Comunidad: a New Way of Living}

To this point, I have been articulating the process involved in the passage of Puerto Rican men with HIV into la comunidad. There are many steps in the process 
including their excommunication from the mainstream society upon their diagnosis, their long liminal period between knowledge of their diagnosis and their acceptance of it, their encounter with a potential new community—-the community of those afflicted with HIV, and several ritual steps that typically take place for these men to belong in that community— publicly announcing their diagnosis and a testimony about their experiences. These rituals open up the belonging into the community but to truly feel membership, to feel belonging, there is a process that involves greater learning and personal transformation. An important aspect of participation for these men in redefining the community is done by adopting and living the values and beliefs of the community to living positive and responsible lives. These men participate in reformulating the meaning of HIV with alternative frames of conduct contrasting their current, healthy and supportive lifestyle against their past, unhealthy and destructive lifestyles—lifestyles commonly linked to becoming HIV infected. In fact, everyday life espousing the values and following the norms of the community reaffirms the community's protective boundaries from with vis-à-vis the broader society with all its temptations. They build boundaries to protect themselves and the radical changes in their lives from the many forces of "dirt" that can contaminate them if they venture outside again:

I used to hang out on the streets, worked on the streets, and slept on the streets. The street's lifestyle. Drugs, weapons, everything that has to do with the streets, I was a criminal, to put it clear. So then, in life you don't appreciate your life in that lifestyle doing life in that way. Waking up using drugs, cocaine, marijuana, bla, bla, bla, you know.

Like Mario, the men I interviewed share common "delinquent" backgrounds. Just to illustrate, among this group of men, $87 \%$ have a substance abuse history, $58 \%$ have served time in prison, and a handful of them had specific markings tattooed in their arms 
linking them to well-known violent Latino gangs. Certainly, these men have experienced tough lives, yet they embrace extraordinary changes adopting the values and practices of their new community of HIV. In this sense, the community determines what is acceptable and not acceptable behavior for the members, drawing clear lines of membership to the community along moral boundaries (Espiritu 2001; Lamont 1992). The men have to make personal decisions to change their behaviors and beliefs so that they reflect the community continuously affirmed by other members as well. The culture within is not the culture without.

There is a strong association between the accepted value system of a community and its boundaries. The community's values and norms frame the expected behavior regulating how members relate to each other and to others outside the group. As Lawrence (1996:10) suggested, a group's internal structures function as boundaries creating "an integrated corpus of shared knowledge, conventions, and rules that simultaneously enable and constrain individuals and groups to communicate, produce, and reproduce the constituent of their culture." Along a similar line of thought, Barth (1969), in his analysis of boundaries among ethnic groups, also noted the importance of a value system within a group to regulate and evaluate the group's members. According to Barth (1969:299), "being a certain kind of person, having a basic identity, also implies a claim to be judged, and to judge oneself, by those standards that are relevant to that identity" (Barth 1969:299). Thus, belonging to a community is expressed and affirmed by following its standards (Barth 1969), which in turn serves to reaffirm its boundaries. 
Community Values and Beliefs: Trust, Respect, and Honesty

During the interviews, respondents identified a set of specific values and beliefs important to their community, describing their interaction with others in terms of trust, respect, and honesty. Albeit difficult to determine which of these is most salient for the community, "trust" was noted as significant in the everyday lives of these individuals for maintaining the privacy and the overall integrity of the community. For the men I interviewed, the most significant expression of trust within the community was confidentiality. Given the nature of HIV and the stigma attached to the illness, confidentiality is key to maintaining the privacy of the diagnosis and safety of people living with HIV. While discretion is a central requirement in all HIV-related programs, services, and activities, ultimately maintaining confidentiality rests on each individual. As Carlos explained, there exists a shared understanding and agreement on confidentiality in the programs.

Well, like I told you, what I like is a meeting where you feel totally comfortable. Like you don't have to worry about saying this or that, you know? Worry that he goes and talks and says it [out there] because in this program everything is very confidential.

As implied by Carlos, programs assisting people with HIV are evaluated on the confidentiality provided to participants. For Antonio, being familiar with a program and its participants is important before sharing personal information and committing to attending regularly. As he described it, confidentiality is not a given in all programs:

Almost every time you go to a group the thing, what the person most, I do the most is keeping the confidentiality. Because then you know, when you are new at a place, automatically, you don't go if you don't know the group, you don't start, you can talk about the addiction, but you aren't going to talk about something more personal because you fear that someone in the group is going to go out of the group and start talking. I 
like it more the group like Casa Iris, like the one they had in the Living Center which is a group where I have participated and confidentiality has never been broken by another person. I know the people there.

Confidentiality is critical because these men come to know each other's medical history, drug behaviors, criminal background, and sexual orientation. Private and personal information is shared during group meetings and informal conversations. Sharing is key to feeling community since they cannot share it with almost anyone outside la comunidad. They understand the sensitivity of this information and the responsibility to maintain confidentiality given the potential risk and consequences sharing this information outside the group would likely have. Disclosure of personal information, even when accidental, can be detrimental to their personal lives and for the credibility of a group. Marcelo explained the consequences when confidentiality is breached.

Something bad is that a person that is in a group can go out and spread the information in other places... Because a support group is called support not no-support, right? So, everything that is said there is confidential. If I'm in Dudley waiting for the bus and I am with my sister, my sister doesn't know anything about me. And there comes by someone that goes to Cambridge Care for Aids with me, I know him, and he comes and asks me "aren't you going to Cambridge Care?" So when that person leaves, my sister is going to ask me "what is Cambridge Care?" My sister, if she is intelligent, she will go to the computer, and she can conclude that I go to a place where people with the virus go.

During our interview Marcelo noted that this encounter had actually not taken place, but it illustrated a similar experience when a peer of his almost disclosed his HIV diagnosis. Although this was a scenario describing the potential risk of disclosing someone's HIV status, it is not far removed from real situations experienced by these men.

Juan: Confidentiality, there is no confidentiality. I don't believe in confidentiality. 
Interviewer: Have you had any problems with that?

Juan: $\quad$ Sure, yes. When I went to take the HIV tests, the HIV exam, the same people that know other people that have HIV told me "have you been hanging with this guy? Take care of yourself, protect yourself, something is telling me...I know him," and this and that about him.

Trust is central to the community's functioning for maintaining integrity. Given the nature of the group, breaches in trust can disrupt relations among the members of the community causing them to reevaluate where they seek care and even to sever ties with the community all together. As evidenced in the narratives, a breach of confidentiality undermines the trust in programs and the impact these can have in providing for the wellbeing of members, even of people living with HIV in general. On the other hand, maintaining trust and exercising confidentiality reinforces the lines of protection and privacy found in the community where every member participates by reaffirming the solidarity for one another.

Respect was also frequently identified by these men when speaking about $l a$ comunidad's values. Respect is particularly important because of the diversity among these men and given that many have suffered discrimination because of their HIV status, sexual orientation, or criminal history. For example, Benedicto described the importance of respecting everyone regardless of their differences. As a heterosexual man, he experienced a change in his feelings towards gays as he began spending time with them and others who were HIV-positive.

I learned to make friends because honestly right now I have more friends that are gay than straight. And honestly if I see a straight person talking bad about a gay person I say "wait a minute, hold your tongue because you don't know him!' I was very sexist: 'I am a man's man, I'm macho,' yes, me (speaking on a harsh tone)! But no, honestly it is very different, because I can't understand them because I am not gay. But having a 
friend that has feelings that I don't have, I stretch my arms to embrace him and say "don't sweat it my friend I am here fighting the same fight as you are." And that is the most expression...mutual respect that one has because discrimination is very ugly, and why am I going to think he is less than I am, it's not fair. We are all going through the same thing. The community is between gays, people who use drugs, bisexuals, people with regular families. We are all humans.

Respect in la comunidad plays dual roles. As described by Benedicto, respect implies the acceptance of others regardless of their differences and background, but also a "duty" to correct, almost reprimand, anyone who is "out of line," disrespecting or attacking a fellow member. The disciplinary role is, in short, a boundary-maintenance device that serves to reinforce the lines of acceptable conduct of respect and equality for all members.

Respect is also considered a source of value to be given and received within the community. Marcelo described how even a small act can be perceived as disrespectful discrediting one's value in the community.

So I suggest something at an agency, and no one cared. I called the person and asked "what happen to the suggestion I made, to put this in the rules of the group?" "Oh I forgot!" "I think those things shouldn't be forgotten" I answered to the person. So I leave the office upset, offended and feeling like my suggestion doesn't count. So, I count when I need to fill a form to get funding to maintain the agency, but my opinion doesn't count.

Acting in a respectful manner is expected from all members, including service providers and organizations. Perceptions or real instances of disrespect toward a member, as in the case experienced by Marcelo, can be seen as diminishing the worth of individuals as equal members of the community. Expecting respect reaffirms a sense of belonging through exercising membership that appeals to the standards of the community. 
Similar to trust and respect, honesty was highlighted as an important community value in many of the stories shared by these men during the interviews. In fact, honesty is expected as an essential value to living well with HIV. In the community, one's integrity is measured in terms of behavior towards others as a sign of HIV acceptance. Among these men, honesty was primarily exhibited when they would disclose their HIV status in particular circumstances. As Antonio explained it, being truthful with potential sexual partners, particularly with those who are not HIV-positive, is a sign of integrity and good character.

No, I can't hide to a person what I've got. I believe that it is better, I feel better with myself by being honest. Because it would be very easy for me to meet a woman, sleep with her, have sex, use a condom, and that's it. Because that's it, you wear a condom and that's it. But if a person loves me, wants me for something serious, for a stable relationship, so without me having talked to her about my condition. So, when I tell her, what will happen? She will say "what type of man are you that you didn't tell me you were sick?" I think it isn't fair for her, you know. And it isn't fair for me living with that stress on me thinking "shit, should I tell her, should I not tell her, what will happen when I tell her?" No, no, no I'm not good for that. So now, when I am in a relationship I tell her: "look, I know this is going to be difficult for you," but I tell her, "you know what, I have this condition."

Similar to Antonio's views, other men chose to disclose their HIV diagnosis as a normal part of their dating as a way of performing the value of honesty. Luis illustrated how he approaches disclosing his HIV status to potential partners despite the consequences of disclosure.

It is not easy to live with the virus, you know, and have the acceptance to tell a person: "look I am a patient of [HIV]. I have this. If you want to accept me like that, amen. If you don't want to accept me like that, well then, amen too." 
As in his case, despite the potential for rejection, disclosure is above all a moral obligation, one that reframes HIV with positive traits.

In addition to being a sign of good character, honesty is a responsibility. For many of these men, being truthful functions as a positive strategy to prevent putting others at risk of becoming infected. For Mario, sharing his HIV status with his partners prevents him from having to bear the guilt of knowingly infecting others.

I got sick from my wife. I never say anything to her or blame her for it. I never said "that bitch" or anything like that! I don't even think it, no, no, no. It happened. I got sick, but not everyone thinks the way I do. Not everyone will see it like me, you know? You accidentally infect someone, and a person gets sick because of your fault by accident, so that person will reproach you the rest of your life. They will accuse you and call a "dead dog" and will tell you how you are going to die and all (Tu sabes, $y$ te van a acusar y te van a decir hasta perro muerto, del mal que vas a morir, te van a decir de todo). It's not the same, you know. Besides, fuck, that is a burden in your conscious at least for me. My conscious is my best judge and it attacks me pretty hard when I act in some way I shouldn't. I don't like my conscious hammering me away: "fuck, do this the right way, why did you do this? that?" No, no I'm not good for that.

The moral framework described by these men contrasts against the construction of HIV-positive people as immoral and dangerous. Trust, respect, and honesty are not atypical to community; in fact, they are the foundation to most if not all communities. However, to this community, these values reflect the polar opposite of the values that these men lived beforehand and which contributed to their infections. If bad morals characterize how one becomes infected with HIV—as the outsider, "clean" world asserts, then insiders find ways to symbolically and materially clean themselves by assuming and living the good, clean values of outsiders. They become more moralistic than the outsiders as part of the redefining of themselves and the boundaries they assert. By conforming to the mandates of the community, HIV-positive people participate in 
challenging the standards for living with HIV along moral boundaries and healthy

practices discrediting the negative perceptions of HIV.

\section{Living in a Moral Community}

The moral boundaries of the community are reaffirmed with behaviors that respond to the standards of the group. In fact, the moral status of the community rests on the members' decisions to live positive and healthy lives exhibiting the values of the community. For the men I interviewed, living positive reframes who an HIV person is by adopting positive behaviors, healthy choices, and exercising self-control. Consequently and inherent to living positive, members must denounce and refrain from the destructive lifestyles and unhealthy behaviors identified with HIV transmission by the wider society.

The norms of the community primarily help in establishing the "ideal" behavior for an HIV-positive person. For example, Marcos identifies the characteristics of "bad" HIV-positive people:

Because many of them are leaving the same type of life they lived when they got infected. They continue on the same path, using drugs, drinking, they don't care about anything. A lot of them when they are in that stage of their life, I think, I'm not sure about how others feel about it, is that they don't want to live. Because if a person wants to live, from what I've learned you first think "ah, I've got the virus and I'm going to die tomorrow" I started to feel scared every time I went to sleep thinking I wouldn't wake up and I never wanted to go to sleep. That's why I started to use a lot of cocaine because I wasn't going to wake up. But those who are out there are in the same path and don't want to get off of it. They don't care. They don't want to live.

Yet, the expected standards for members are often not communicated in moral terms.

The men are careful not to appear morally superior or better than others, but instead share the norms in the form of advice encouraging peers to adopt a healthy lifestyle. As Carlos illustrated, casual "witnessing" to others is a very delicate but ongoing matter: 
I know a lot of other people that have friends that have the virus and they are going from bad to worse. It is not that I socialize but when I go for my walks and do my things I find them in different places. I always tell them, without preaching, because I am not someone to be preaching to anyone. Those are people that know as much or more than I do. But I always tell them that there is hope, and I ask them until when are they going to keep using drugs? Let them try it, that's the only thing that I can tell them without bragging that I am fine now.

Unbeknownst to them, in the process, these men reaffirm the moral boundaries of the community determining what it takes to belong in the community. Although in a very subtle manner, as shown by Marcos and Carlos, they participate by judging negatively people who continue on the path that led them to being HIV-positive. Leaving behind the old ways (drugs, drinking, living on the streets, etc.), adopting a healthy lifestyle, and staying healthy are part of being the ideal HIV-positive person, and thus emphasizing the "healthy" standards of the community. In essence, they are participating in boundarywork. Embedded in this internal boundary-work is the notion that rejecting the "deviant" and negative lifestyle is paramount to overcoming the diagnosis and to living a healthy life with HIV.

Many of the men I interviewed said that being part of the community requires "doing" and "being good." Yet, these behaviors are more than the result of a simple choice between right and wrong (e.g., whether to use or not to use drugs). These decisions are about life versus death; to live they have to live changed lives. The decision implies choosing between living versus dying with HIV:

It's thinking positive, every day I think and I say "I can live, I can live with this" provided that I do the right things right and that I follow the rules the way they are supposed to be followed. But as I say, if a person is an addict or an alcoholic and doesn't protect himself, that person is going to die. So I live my life positive saying "Luis you have to do it right." I do the best I can do. Day by day I fight (Luis HIV-positive for 12 years). 
Among the men in my study, they realize that there is a clear choice they can make between living and dying by ascribing to a "good" way of life of an HIV person. This is how Diego explained the two options and associated outcomes:

Well that is one thing that you see a lot when you are with people who have HIV. The ones that take care of themselves, they survive, and those who don't take care of themselves, little by little you don't see them and you know where they are. More than likely is because they are dead, or because they moved to another state. The majority is because they have died. Sometimes they drink alcohol or still use drugs or don't take care of themselves, I don't know what they do, but little by little you don't see them anymore.

Along with the life/death choices, being a "good" HIV-positive person means living an overall "positive life." For many of these men, after being diagnosed they embarked on a personal transformation eliminating everything that was negative in their life and replacing it with things that are positive.

It is something mental. I don't say in my mind "I am going to die now, my life is over." It's all positive. And that is something very important. Being around people that are positive is very important because there isn't any space in our life for negativity. Like depression, none of that. What we have to do is to have a clean life like you want it but without anything negative (Benedicto)

Given the substance abuse background of the population, a priority in cleaning the negatives from their lives entails overcoming a life-long use of drugs. As Felix ${ }^{15}$ noted, for many it is an ongoing struggle, but a desired one since the benefits are clear:

I [have] seen people that are HIV because they were using drugs at the time, right. And I see them clean for a lot of years. They look more responsible, more happy. And since I've been around the people, I want the same thing, you know. Even though, I still be thinking about going the other way, but this way feels better.

\footnotetext{
${ }^{15}$ English-speaking respondent - text in original language of interview
} 
In other instances, men freed themselves from poor influences that were counterproductive to their wellbeing. Pablo explained the importance of surrounding himself with positive and caring support:

People with the condition and without the condition, positive people, good people, because you cannot be surrounded by negative people, I always, the people around me are positive. If they see you depressed, they help you. If you see them so so you help them. We make a network and that gives us strength. We don't humiliate each other or anything like that.

Living a positive life even involves the cleansing away of the stigma associated with having the HIV virus. Although these men are aware that a cure is not available, their efforts to rid their bodies of HIV focus on achieving undetectable levels of virus in their blood by following the recommended medical treatment. Mary Douglas (1966) described cleansing activities as mechanisms for reaffirming social control by establishing a means to move from the impure back to the pure. As being "dirty" signifies being outside the social norm, purification rituals are central to restore the normal order of things (Douglas 1966). Purification for HIV-infected men is a matter of degree for the virus never completely leaves their bodies. But they can become as pure as possible, as free from the virus as they can, by purifying their blood through taking medications that suppress the virus and permit normal cells to thrive. Taking their medications, therefore, as described by Luis below, is critical to purification but the symbol of their degree of purity is the lab reports they receive:

Several months ago I started taking the medication. My viral load, right now, is undetectable, my cells went up again. It's like if nothing was happening to me. Yes, I do feel a couple of little things, my eyesight and that sort of stuff, but since I was a kid I was supposed to be wearing glasses. Those are minimal things. 
Taking medications is but one of a series of positive behaviors men in the community perform en route to improving their own status and, in so doing, the status of their community. Other activities include having a positive attitude, staying sober, and caring for their health. These are described at length in Chapter 5.

Policing the Boundaries of la Comunidad

As with all communities, there is an expectation that members abide by their norms, the guidelines for the expected behavior. They set the boundaries of acceptability and establish the restrictions on deviance (Crawford 1994). As Barth (1969:300) explained in his work among ethnic groups, the boundary "canalizes social life - it entails a frequently quite complex organization of behavior and social relations. The identification of another person as a fellow member of an ethnic group implies a sharing of criteria for evaluation and judgment. It thus entails the assumption that two are playing the same game."

Acts of deviance, the failure to perform the accepted standards, have punitive consequences as defined by each group. Unequivocal and clear expectations (values, behavior, etc.) not only establish and reinforce the boundaries but they also serve to marshal members' deviations when they occur. Among the men I interviewed, casual failures to meeting the norms of the community are addressed with temporary excommunication, the duration of which depends upon the level of the offense. In cases where the incidents are casual, the sanction is temporary. Orlando illustrated how minor offenses are addressed. "There are some people that arrive when they are high, and they are told to come another day. They don't get thrown off the group, but they are told to leave and come back another day when they are okay." On the other hand, in cases 
where there is a greater relapse, individuals at fault separate themselves from the community. The self-exile acknowledges what is expected in the community and the sanction to failing the norms. Antonio shared the case of a friend that had relapsed.

I don't like when a person that has the condition and instead of taking care of his or health, and instead of worrying about his health is wasting his time doing drugs. It bothers me that a friend of mine who has been doing good for so many years, and then one day I see him all high and wasted. You know, harming himself, but I know this is a good person. Like yesterday, yesterday I was standing at the bus stop, and there comes this guy I know. He was clean for a long time. So, I was telling him to come back, he has already been in rehab. He can do it... "Come one, let's go, come back. You can do the things right."

Excommunication, even when self-inflicted, is a common form of disciplining deviance such as when a person does not follow the tenets of the Catholic Church. In a situation where community membership is highly associated with not only feelings of belonging and support as well as access to medical resources, but also with survival, it makes greater sense to see that excommunication is an appropriate and tough form of discipline. Where does an HIV-infected person go who can no longer be normal, can no longer cross back into the non-infected world and who has broken the rules of membership in the remaining community?

Deviance in la comunidad is not, however, sanctioned with down-casting (Barth 1969), status downgrading (Espiritu 2001) or permanent outcasting (Crawford 1994) as in other groups and communities. Instead, "deviants" can travel back into la comunidad by crossing its boundary without penalty so long as they agree to live by the community's accepted norms. In essence, the punitive system serves to validate the norms (the boundary) requiring a positive behavior to participate in the community. Policing the boundaries maintains the integrity of group, given that acts of deviance are threats to 
defying the boundaries of the group (Erikson 1966; Lauderdale 1976). Thus, reaction to deviance, in the case of these men, is not in response to the "ill" behavior per se, but in reaction to reaffirming the boundaries of belonging of the community. Much as with human communities in general, exclusion is painful so the fact that la comunidad excludes is important to its ability to maintain a space for people who have long been excluded from so many other spaces in society. However, in several ways $l a$ comunidad's boundary-work is more affirming than demeaning. First of all, the inclusion requires people to take care of their health, monitor their own behavior, and exercise selfcontrol. This is not asking the men to do harm to others, but to do good to themselves and others. Additionally, though there is a boundary and it is policed, it is porous not prohibitive. Those who leave or are excommunicated can come back in. Finally, by refusing to engage in the same demeaning language used by greater society to do boundary-work against the HIV-infected, the community affirms its identity as opposite of most of the greater society, as affirming the HIV-infected. Most importantly, people who do not abide are expected to leave but they can come back when they make amends. "Policing" the conduct of community's members with this practice is another example of turning the negative boundary-work of the greater society into affirming boundary-work of la comunidad. Boundary-maintenance devices help to control the conduct and regulate the behavior in the community, and in the process solidify the group by observing and reinforcing positive norms collectively. As noted by Lauderdale (1974:662), "the redefinition of the moral boundary creates greater solidarity among nondeviants of the social system by reaffirming the common corporate membership." 
Since HIV affects all aspects of the HIV-positive person's life, belonging in community and staying there requires a transformation of individuals, thus the reason why it is important emotionally to mark the transformation with rites of passage.

Transformation involves self-awareness and reflection in which an individual must first accept being HIV-positive and then embrace a new way of life. These steps mirror the sober lifestyle experienced by recovering alcoholics in Alcoholics Anonymous. Sobriety, as explained by Cain (1991:214), "means a new way of life, with spiritual aspects of surrender to God or a Higher Power, humility, trust, honesty, and making amends for wrongs committed in the past or present." Similar to recovering alcoholics, the men in la comunidad redefine their stigmatized selves with positive values and beliefs, some even evoking similar spiritual guidance as AA members. However, in the case of the men I interviewed, evoking a "Higher Power" seems to be more of a personal choice, instead of a central piece to their transformation.

The community becomes the space where they participate in de-stigmatizing their new identity and status. This is not surprising. The symbolic reversal of the identity is a strategy adopted primarily by minorities and other disadvantaged groups to "'honour' the stigma, to render it as a positive value, and thereby, to destigmatize it" (Cohen 1985: 60). If once called queer to emphasize not only difference but inferiority, now queer is used affirmatively among the gay community. This illustrates Cohen's attributes of communities that are constructed symbolically. Consequently, the internalization of the community's philosophy to living positive is essential to reinforcing the identity transformation that empowers people over the effects of the illness and the negative stereotypes of HIV. 


\section{Agency and Boundary-work within the Structure of Community Organizations}

Before finishing the chapter is it imperative to discuss briefly the role of HIV organizations and institutions in the process of community building. An important question to ask is: Are these men freely exercising agency in building community with boundary-work practices or are they merely responding to the norms imposed on by the institutions of care? Do they really have agency in the process?

The growth of the HIV organizations and the proliferation of programs to care for HIV-positive people reflect the dramatic changes resulting in the increased life expectancy with the introduction of highly active antiretroviral therapy (HAART) in the 1990s (Hecht et al. 1999; Gallant 2000; Baumgartner 2007). Given their role as service providers, these organizations set the norms for the interactional dynamics among peer clients and thus, undoubtedly, influence the community-building process. Although, these organizations participate in the process, their influence is limited to setting the contexts and norms within which participants come in contact with each other to negotiate and define the specifics of the dynamics and long-term responses to living with HIV. That is, they provide the foundation upon which la comunidad is erected.

Health care providers have long adopted models of care that integrate peer support groups as part of meeting the needs of a population now living longer and longer with HIV (Knox 1989; Kalichman et al. 1996; Adamsen 2002). These groups were modeled after the social supports developed for coping with other chronic illnesses (Kalichman et al. 1996), establishing "a system of giving and receiving help founded on key principles of respect, shared responsibility, and mutual agreement on what is helpful" (Mead et al. 2001:135). As Mead and colleagues (2001:136) insightfully noted, the peer 
support provided in these settings responded to the HIV-positive people's need "to fully experience 'being who they are,' growing in the direction of their choice and, in the process of being supported in these goals, begin to help restructure larger systems.” In other words and underscored by Tanabe (2008), the organizations created the spaces within which affected members could shape what they needed culturally as well as medically. That is and as explained by Tanabe (2008:173 emphasis mine), within these organizations' settings, members themselves, "while reinterpreting their lives, provide new aspects of knowledge and the arts of life that contribute to the collective construction of an understanding of and solution to the HIV/AIDS societal experience of suffering."

Cultural community creation arising out of HIV is a new phenomenon which contributes to the autonomy of its members in elaborating responses in their own terms while still feeling connected to both a support system for their health needs and a cultural community of belonging for them to tailor to their more specific emotional, psychological and social needs. Contrary to other chronic illnesses that have a long history of specific structured therapeutic approach, alcoholism and drug abuse for example (Cain 199; Humphreys 2000), HIV-oriented community is relatively young in this sense. Although HIV has been at the forefront of public health discourse for roughly 30 years, ways of living with HIV are much younger dating back only to the late 1990s when medication treatment changed the diagnosis of HIV from a death sentence to life sentence—albeit surviving with a chronic illness. The social stigma that still prevails among those with HIV/AIDS and in contrast to those struggling from many other chronic illnesses reinforces this notion of infancy as society has not assimilated the idea of the chronicity of HIV. For individuals living with HIV, as in the case of the men in this 
study, organizations provide an important structure of support and encouragement to living healthy and long term with the illness. However, as they step outside of the boundaries of these institutions, the support dwindles as they enter the society of the "normals" informed by misconceptions and negative perceptions. Yet, through their own building efforts atop the foundation provided by the HIV support organizations, the men engage in boundary-work that enables community to develop and be sustained. The key here is sustenance and this is why boundary work is important; the men must be the ones to patrol the borders back into la comunidad after a member has transgressed them. By exercising agency — adopting and reaffirming norms, beliefs, and practices — these men define and sustain la comunidad, reflecting much of what they learn from health care providers, as a social entity with a unique culture and identity beyond the structures and boundaries of the HIV service providers.

\section{Chapter Summary}

The stigma of HIV draws important boundaries in the lives and communities of people living with HIV. Shared beliefs about HIV and those infected with it among the "normal" population provide social and cultural agreement for identifying and excluding individuals in society who are HIV-positive. Negative attitudes and behaviors are informed by moral judgments and perceptions of contagion, defining the meaning of HIV and redefining who or what an HIV-person is by membership in the stigmatized community. Negative treatment towards HIV-positive people clearly resonates with Goffman's notion of tribal stigma, referring to the "stigma that can be transmitted through lineage and equally contaminate all members of a family" (Goffman 1974:4). Such is the case of an HIV-positive person given that the highest rates of infection have 
been among members of groups that are often associated with socially deviant subcultures: IDU, MSM, prostitution (Nack 2008). In essence, HIV stigma functions to draw boundaries by identifying the stigmatized as an out-group, not belonging to the world of normals. In the process, as noted by Joffé, "once someone is positioned as the Other, it becomes easier to denigrate them" (Joffé in Chapman 2000:843).

Although this study does not focus on the influence of organizations and agencies in the lives of these men in community building, it should be noted that these institutions play a significant role nevertheless. Yet the argument proposed in this study, the agency of these men in setting boundaries defining la comunidad, is not at odds with the role of these organizations in the process. The organizations provide the structure where these dynamics take place and influence the process. What is evident in the narratives of these men, looking at the insider's perspective, as participants they take the process beyond the structure and the guidelines imposed by the professionalization of the care embodied in these organizations. Thus, instead of talking in terms of "because of" I would argue that despite the broader structures of the organizations and the professional traditions of counseling and peer support, these men create the specifics of the dynamics of a community with a separate identity. La comunidad is an expression of the empowerment that Adamsen (2002:224) described taking places in the lives individuals afflicted by lifethreatened disease and chronic illness influenced by institutions providing care, empowering individuals to transition from "victims to agents." This transformation is influenced by the structures of the agencies. However, the expressions of this empowerment, defined by the members themselves, are the result of the negotiations taking place within the organizations and beyond the discourses of the traditional models 
of care. Although, this study focuses only on the member's perspective, it acknowledges the role of the organizations in building community. However, more research is needed in this area, particularly examining the influence of health care providers to explore the degree of agency exercised by these men in the process.

In the HIV context, at least among the HIV-positive men I interviewed in Boston, the presence of a community of HIV-positive individuals, given the continuous mechanisms of stigmatization and moral exclusion to categorize them as social deviants, epitomizes the processes of symbolic struggle and boundary making and re-making in strategies to destigmatize, not only HIV, but their lives as well (see Hohonen 2003). They engage in efforts to reformulate what it means to be HIV-positive by living by standards of being "healthy," "positive," and "self-controlled" beyond the confines of the spaces of organizations, agencies, and programs into their lives and out into the streets. Their proposition serves more than to live in community to improve their quality of life individually. It is a bold, communal statement challenging a society—indeed a worldthat is comfortable otherizing and rejecting HIV-positive people on the basis of defining them as "ill," "diseased," and "contagious." Mario expressed this inconsistency perhaps even better:

Like once I told a girl that we were about to have sex [about my HIV] and she rejected me. So, that person rejected me because I had this disease. But someone told me that [she] was fooling around with different people, being with and jumping around with different people. And I say to myself "so, she rejects me because I am sick, but she is fooling around here, there, here, and there." I say, "shit, what's in her mind?" I can't. I let her be. I can't do anything about it, but sometimes you start thinking "shit, why do people, why people act that like that?" 
Despite the ongoing stigmatization and an implied moral contradiction noted by Mario, community-specific rituals, traditions, and practices further encourage the participation of these men and their commitment to affirming these boundaries helping to sustain the community over time. I discuss these in the next chapter. 


\section{CHAPTER IV.}

\section{A PLACE OF THEIR OWN: LIFE IN LA COMUNIDAD}

"[S]ometimes I wear the BLC (Boston Living Center) badge and I forget and people look at it and they see the little red ribbon so they know. And they ask me, 'Is that a group or something? Is it a club?' 'Well no, it's the BLC membership club,' I'll say."

"I have been [at BLC] for going on 2 years now. Since 2007. I have been there. I did all my classes. I did Bridges for Life. I did the Bridges [to] better understand myself. I found out that I can not only better understand myself but better understand the disease, the virus. That I don't have to be afraid of it no more."

"I am taking three meds: Norvir, Truvada, and Reyetaz. I take them daily."

- Leo $^{16}, 41$-year-old

In this dissertation I argue that these Puerto Rican men living with HIV have formed and live within a unique cultural community derived from their HIV experience, in la comunidad. Calling attention to the everyday lives of HIV-positive people as a "culturally meaningful unit" (Goldin 1984: 122) instead of just a group of individuals suffering from a common illness allows us to study their lives in different light. Such a perspective shifts the analysis away from a medical model of illness in which the "ill" are living in a state of abnormality and they need to be treated so that they can resume lives among the healthy "normal" society. Instead, this group of HIV-positive people can be viewed as inventing for themselves a new normality complete with cultural borders, boundary work practices, and cultural distinctiveness. The idea is not to ignore the role HIV plays in the lives of these men. On the contrary, what I propose is to further explore the impact of HIV has in generating a community by describing specific expressions

\footnotetext{
${ }^{16}$ English-speaking respondent - text in original language of interview
} 
where the identity and culture of the group are transmitted, communicated, and reaffirmed when presented in social life.

In the quotations from Leo which opened this chapter he begins to provide some of the language, terms, and "ways" that are unique to la comunidad. His life, like that of other people living with HIV, is influenced by being HIV-positive and the reality of living with an incurable condition. HIV dominates the self-identification of the men in this study, their terminal identity, and is the central theme defining the cultural space binding these individuals together.

La comunidad they described throughout the interviews is constructed through shared processes of assigning meaning to otherwise routine and daily practices linked to, and resulting from, living with HIV. Assigning community-building meaning to daily practices is reflective of Cohen's symbolic processes in constructing community (Cohen 1985). In the case at hand, the HIV community is constructed by these men through consensus on the symbols, rituals, and traditions that are rooted in living with HIV but which also define the community. This "consciousness of community," as termed by Cohen (1985:13), "refers to an entity, a reality, invested with all the sentiments attached to kinship, friendship, neighboring rivalry, familiarity, jealously, as they inform the social process of everyday life."

For the men I interviewed and as implied by Cohen, la comunidad becomes real in their collective recognition of it but that emanates from their performances of community making that take place in public as well as in private life. In this way, la comunidad is reaffirmed in everyday practices that represent and carry similar meaning to all members. Benedict Anderson (1991) also made reference to this phenomenon, 
describing communities as "imagined" in which members - although they probably never meet face-to-face - feel a sense of belonging and comradeship to an entity with a particular identity, specific culture, and unique history. In this sense, the community exists not only in the minds of these men, but in the conception of being related to one another through shared practices, with a common emotional communal investment in their collective wellbeing (Anderson 1991). Thus, it is at this level, as both Anderson and Cohen have pointed out, when the shared meaning of members' everyday lives translates into a sense of their communion as one, into their feeling of belonging. For the men in the study, the communion is expressed in their effort to living healthy with HIV as well as in sustaining and promoting an overall wellbeing to adjusting to HIV as a chronic illness. From this perspective, Marco's description of a series of healthy, but otherwise, unspectacular practices related to living with HIV become more meaningful to this discussion. "We all have to take medicine", he noted, "we all have to go to the hospital. We all have to get...eh...the flu shot. All, almost everyone, have to do the same."

\section{From Illness to Cultural Community}

What I argue that these HIV-positive men are doing—building community—is not totally without precedent. Using a cultural lens to understand how people living with a specific chronic illness or disability create their own community is a useful approach to understating the social and everyday life beyond a medical diagnosis. For example, the deaf or hearing-impaired population has been described as a cultural community (Becker 1980; Foster 1987; Van Cleve and Crouch 1989). A similar perspective has been taken in the study of recovering alcoholics engaged in Alcoholic Anonymous (Cain 1991; 
Rappaport 1993; Robinson 1979; Wilcox 1998; Humphreys 2000). Describing these communities briefly is important to the argument I make in this chapter.

\section{The Deaf Community}

As a cultural community, deaf people have a distinct collective identity. The emergence of community among the hearing-impaired is described as a process of cultural production and socialization by anthropologists and psychologists (Becker 1980; Foster 1987; Cleve and Crouch 1989). Scholars highlight how schools for the deaf function as the critical institutions responsible for bringing hearing impaired people together, teaching the community's special language (American Sign Language in the U.S.), exposing members to community norms, and educating them about community resources (Becker 1980; Cleve and Crouch 1989). Among schools for the hearingimpaired, residential institutions are crucial to the socialization of an individual into the deaf community. Becker (1980:37) sustains that "the focus on the group is part of a variant view of culture that is presented to deaf children in institutions and continually reinforced." These schools create a bounded social environment—a culture—in which children at early ages learn the norms, beliefs, and practices of that culture.

Deaf culture is shared and manifested in everyday life among their peers. Faceto-face interaction aids in the students' rapid internalization of the values of the community. They carry these values of the deaf culture with them upon graduation; in fact, most cities have Deaf social clubs providing spaces for on-going socializing beyond the school years (Becker 1980). These clubs serve as gathering places and often hold special events, including monthly socials, storytelling presentations, performances, and the screening of captioned films (Baynton et al. 2007). Aside from the entertainment 
value, these events contribute to building community cohesiveness, to creating cultural affinity. Studies conducted of the deaf population point to the role of social interaction among peers as a key component in community formation, primarily in response to social isolation (Schein 1968; Becker 1980; Foster 1987).

Expressions of the particularly experiences of deafness are central to deaf cultural construction, identity, and sense of belonging in their community. Sign language serves as an important symbol and praxis of the community. American Sign Language (ASL), a language system based on manual signs, is the first language of most deaf people in the U.S. (Stokoe 1960; Becker 1980; Baynton et al 2007;). In addition to being the preferred form of communication between community members, sign language is a "symbolic badge of identity in the deaf community" (Becker 1980:19). Despite being a visible indicator of membership, sign language also serves to reinforce one's worth as an individual belonging to the group as well as being an expression of pride in the community. Further evidence of the presence of this community is found in the numerous newspapers published by and for deaf individuals and groups (e.g., SIGNews), universities offering undergraduate and graduate degrees specifically geared towards deaf students (e.g., Gallaudet University), exhibitions and museums which focus on the deaf community (e.g., History Through Deaf Eyes), and extensive online sites providing resources and services for the community. As explained by Becker (1980:16-17), "linguistic and communicative differences as well as the socialization process have functioned to separate deaf people from the rest of society. These factors have promoted the formation of a community of deaf people." That is, deafness provided the basis for 
social inclusion of the deaf but also the realized potential for constituting a particular culture for deaf people apart from hearing people.

Hearing, therefore, is not just an ability; it is also a social category used to stratify (Massey 2007). There are at a minimum people who can hear fully (or "normally"), the "deaf" and the "hearing impaired." These are hierarchically organized and those who are deaf are excluded in some ways from the "normal" society, the hearing world, but that does not mean they form a community. As discussed previously, exclusion alone is not a determinant of community. When deaf people negotiate the meaning and specific cultural content of their exclusion from the normal society, and engage in the practices associated to internally defining the group, a community is produced, affirmed, and reproduced. From this perspective, deafness is not conceived as a physical disability, but instead, as a "distinguishing characteristic of a distinct community of individuals" with a separate culture and history (Cleve and Crouch 1989: back cover).

\section{The Alcoholics Anonymous Community}

Unlike deaf people, individuals participating in Alcoholics Anonymous (AA) form community on the basis of the transformation of their illness. According to the organization's principles, AA members come together as a community when they make a lifelong commitment to recover from alcoholism. The AA community has specific recovery-based values, beliefs, and practices that define the community and its boundaries. Participation in groups is key to inform participants of membership rites and the community's culture.

A quintessential AA ritual is sharing one's drinking story. One's drinking story is central to the storyteller's recognition of his or her status as an alcoholic which is the 
threshold for becoming a member of the recovery community. Each individual's "personal story" describes the progression of alcoholism and its impact on the social life of the person. It also typically depicts the recovery process as a complete surrendering to God for strength to stay sober and from whom to ask for redemption (Cain 1991). It is extraordinary that these stories parallel the original stories recorded in the AA's primary text, The Big Book, (first published in 1939) and they reflect the AA philosophy regarding alcoholism (Humphreys 2000).

AA has symbols, rituals, practices, and values, etc. It constitutes a culture that is learned by people in Alcoholics Anonymous. They learn to structure and tell their personal story from participating in AA groups, reading AA texts, and talking regularly with other members (Cain 1991). That is, just like other cultures, people pass on their cultural beliefs and practices from one generation to another.

Accepting alcoholism and sharing one's personal story in public during AA meetings serves to determine who belongs and who does not belong in the community just as deafness and the use of sign language indicate membership in the deaf community (Barth 1969). In addition to these fundamental membership requirements, as part of the AA community, members follow a series of norms and traditions. These are outlined in the 12-Steps and 12 Traditions of AA (Alcoholics Anonymous 1981). These texts delineate the principles of individual recovery from alcohol and group unity (Alcoholics Anonymous 1981).

With time, participants accept and internalize the AA core values as they embrace their new sober identity and membership in the AA community. Successful membership involves a complete identity transformation "from drinking non-alcoholic to non-drinking 
alcoholic" (Cain 1991:210). AA members adopt the stigmatized identification but transform its meaning into a positive collective identity defined by self-control and empowerment over alcohol. The internalization of the AA values regarding alcoholism is essential to the identity transformation that empowers members over alcohol and helps others live triumphant lives as "recovering alcoholics."

As a distinct social group, the culture and collective identity of the AA community is linked to the acceptance of alcoholism as a progressive incurable disease and, thus to promote the recovery from that condition (Humphreys 2000). In essence, recognizing that alcohol is a problem, not that life's problems lead to excessive drinking, is the most distinguishing feature of the AA community, allowing members to engage in recovery and accept being part of community by adopting the values and the practices of the community. From this perspective, recovering from alcoholism is a lifetime struggle that connects individuals to a unique community, one with well-defined culture, rituals, and traditions promoting living a life free of alcohol.

Summarizing the key elements in the Deaf and AA communities studied at length by social scientists with a cultural lens is important to similarly detailing the uniqueness of la comunidad identified by the Puerto Rican men in this study. The description of the Deaf and AA communities, although important, is not merely presented in this chapter to strengthen the argument put forth in this dissertation. More importantly, these examples provide cases analogous to the communities formed by people living with HIV. To reiterate, the central idea of this study is to conceptualize these Puerto Rican men in Boston as members of a unique, self-sustaining, cultural community determined by HIV and defined by living positive lives with the illness. 


\section{The Socialization Process}

The group of Puerto Rican men involved in my study has a distinct collective identity and culture. Similar to the experiences described for both the Deaf and the AA community, the community of men living with HIV I interviewed can be described as resulting from similar practices of affirmation and cultural production enabled by ongoing processes of socialization. For them, socialization into the community takes place within institutions that primarily emerged to provide care for and meet the needs of those people adjusting to living with the illness. In these organizations, these men learn how to live with HIV. In the process, they acquire the culture of la comunidad.

Participation in various HIV organizations was widespread among the men in the study. All 31 respondents from the interviews reported participating and receiving HIV services or taking part in activities at different HIV organizations. On average, the men reported participating 32 times in HIV-related activities during a typical month. On average, then, each respondent attends at least one HIV-related activity per day. These activities include (1) participating in HIV support groups or gatherings (e.g., lunch), (2) receiving HIV supportive services (e.g., case management, housing, or counseling), (3) going to HIV medical appointments, and (4) attending non-HIV-specific counseling meetings such as AA and Narcotics Anonymous (NA). The length of time of participation varied according to the nature of the activity, ranging from 2 hours at a weekly HIV support group to about 30 minutes at a doctor's visit. As anticipated, the respondents reported participating in HIV groups/gatherings more frequently than any other activity (see Table 9), attending 17 times on average in a month (CI: 0-42). 
Although these institutions and organizations play an instrumental role in the care and socialization of these men, peers living with HIV take on among themselves the primary socialization responsibility for new members. As I described at length in the previous chapter, seasoned members participate in transmitting the values and norms of the community, information that is central to informing and constructing the new HIV self. As Mario recalled,

Little by little when I got to HOPE, there I was able to learned about my CD4, about my illness, whether my peers got the virus like this, if they have deal with other medicines, about the doctors, how to deal with your doctor in your hospital. Things that you learned little by little because it doesn't happened overnight. I have learned it at these groups.

The social interaction with peers is where new members acquire the meaning of living with HIV from the community's perspective.

Table 9: Participation in HIV-related organizations

\begin{tabular}{lcc}
\hline & $\begin{array}{c}\text { Number of participants } \\
\text { N (\%) }\end{array}$ & $\begin{array}{c}\text { Average times in a } \\
\text { month }\end{array}$ \\
\hline HIV support groups and gatherings & $29(93.5)$ & 17 \\
Supportive services & $18(58.1)$ & 3 \\
Medical appointments & $31(100)$ & 1 \\
Non-HIV support groups & $16(51.6)$ & 12 \\
\hline
\end{tabular}

As in the Deaf and AA communities, face-to-face interactions are the primary mode where culture is transmitted and learned. Exposure to the everyday life of people living with HIV helps reframe the meaning of HIV from terminal diagnosis toward manageable disease and teaches them what they need to know to live with the illness. This knowledge is as much about living positive lives culturally as it is about taking their medication and other "illness"-oriented steps. This is particularly important to the 
process of coming-to-terms with being HIV-positive while addressing the fears of receiving an HIV diagnosis. For example, Ramón was exposed to the HIV community before he was diagnosed when, as a guest, he frequented HIV support meetings with his roommate. For him, learning from people who were HIV-positive was essential to accepting his condition when he was diagnosed some time later. He explains:

More or less I had experience. Like when I was going to the groups, before I knew I had the disease, I had already learned a lot. When the doctor told me that I was positive, the doctor was shocked and said, "I thought you were going to get scared." And me, "No, because I have heard what this is. I go to some groups and there is a man with HIV that has been going there for 20 years." I say, "Crap, 20 years and he is still standing and he is all chubby." But if I get the news without any information that I had, I don't know, sincerely, I tell you that I don't know.

Inviting HIV-negative people into support groups is a common dynamic used to encourage the support for HIV-positive people from relatives and acquaintances by exposing these individuals to information and knowledge about HIV. For Ramón, being involved with the HIV community helped him come to terms with his diagnosis.

While the majority of people are not exposed to HIV-related culture prior to being diagnosed, receiving information and spending time with others who are HIV-positive is paramount to learning to live with HIV once diagnosed. Ignacio illustrates the impact of learning about HIV had on his wellbeing:

Ignacio: $\quad$ Yes, it took me some time to accept it...I believe...I accepted it little by little according to the life I was living, learning, learning and that helped me get cured in the inside. Every time I learned something about HIV, that strengthened me, it helped me. What helped me accept it was... how do you say it... the capacity of understanding. Interviewer: Where did you learn that? Ignacio: I learned from my own experience, and living with others. I learned also from the doctors, from others. 
Similar to the socialization process taking place in the Deaf and AA communities, the men in the study learned a new culture centered on their condition. The community has a strong influence on their everyday lives as they learn from others how to live with HIV as a chronic illness but also how to relate to each other. As Cohen (1985: 15) noted, this function of the community is not surprising:

Community is that entity to which one belongs, greater than kinship but more immediate than the abstraction we call society. It is the arena in which people acquire their most fundamental and substantial experience of social life outside the confines of the home. In it they learn the meaning of kinship through being able to perceive its boundaries - that is, by juxtaposing it to non-kinships; they learn friendship; they acquire the sentiments of close social associations and the capacity to express or otherwise manage these in their social relationships. Community, therefore, is where one learns and continues to practice how "to be social." At the risk of substituting one indefinable category for another, we could say it is where one acquires "culture."

These men acquire the community's culture of living with HIV collectively while making strides to improve their quality of life. Learning the culture of the community while improving their health follows a common pattern described for other communities of "ill" people. As Becker (1980:37) found among the Deaf community, "in cultural terms, the group becomes a major part of the individual's perception because of its significance as a surrogate family." Similarly, as how it will be shown in the following pages, for the men in this study, la comunidad becomes the primary organizing structure in their social world. This lifetime socialization process is instrumental for the reaffirmation of the community and the transmission of its culture. Ultimately, through face-to-face interaction with their peers, these men receive an education on the HIV community and learn "how to be social" living with HIV. Here they learn the 
community's specific values, beliefs, and practices that make them as a unique cultural unit.

\section{Elements of Community}

Part of belonging to any community includes sharing a set of elements that define and reinforce the boundaries of the community culturally. These cultural markers are core to the community that is shared by the members. These in turn, drive the production and re-production of culture in the community giving meaning to the identity of these men living with HIV. As in the case of other communities, symbols, language, as well as rituals and traditions are the most salient cultural expressions of community.

\section{Symbols of la comunidad}

Symbols are fundamental in the construction of community, contributing to people creating, sustaining and reaffirming their collective identity. During the interviews I discovered that the cultural referents of this community were unique. These men did not describe the symbol of their community in terms of items such as flags, hymns, or artifacts. Instead they identified key individuals and organizations that emerged during the epidemic as HIV began spreading among the Puerto Rican population of Boston in the 1980s.

\section{HIV Personalities and Key Figures}

There are key individuals who are or have been critical in caring for people living with HIV. They play an important role in the lives of these men and come to symbolize in their very existence la comunidad itself, a place of care, welcoming and belonging. They are the heroes of the community. They are highly regarded in the community, almost viewed as being "mystical." Whether described in human or supernatural terms, 
these individuals are perceived as figures on a level similar to that of revolutionary heroes, religious saints or leaders of nation-states. As in the case of these communities, these individuals define community in terms of history and principles as well. Among the HIV positive men in interviewed, these "heroes" are key providers of care, they resist the negative perceptions of the illness, and have become powerful and influential role models on how to live with HIV. They find a common identity in the impact these heroes have made on the HIV epidemic in Boston.

One of the most respected and celebrated figures in the community is Iris Rivera, a Puerto Rican woman living with HIV who "has turned her illness into an adventure of service for others" (Celtics 2002). She is the founder of Casa Iris, an organization providing supportive services to Latinos living with HIV/AIDS. As a single mother of three, she has become a beacon of strength and inspiration to those living with HIV. Speaking about her diagnosis she commented, "I had to decide whether I wanted to live or die. I chose to live. HIV lives with me. I don't live with it. I'm in charge" (Be Healthy 2007). The respect for Mrs. Rivera is captured in the words of admiration the Puerto Rican men I interviewed have for her. This is how Antonio spoke about her when describing what motivated him to accept his diagnosis:

What has helped me has been...to find people like me (HIV). That I see them that despite being sick, they talk to others and try to help the community like Iris Rivera that made Casa Iris. I admire that lady a lot because she started with a little house, in her house, giving food to the sick ones. From that she did Casa Iris very big, and she is known. All the work that she does is from the heart. No one pays her. So I say, "I admire her for the example she is I would like to live like that also" 
Perhaps Mrs. Rivera's "hero" status is achieved and furthered by her constant desire to help others. For Marcelo, Mrs. Rivera's position makes her a credible resource, with access to critical information for the community:

I have a friend that for many years, for many years. She started a program. Maybe you know who it is. She made Casa iris. I'm always in contact with her and I'm always talking with her. She is...she knows everything. She is aware of everything.

Judith Ortiz is another legend in la comunidad. She works as an advocate at the Multicultural AIDS Coalition (MAC). Among her many duties, she is responsible for facilitating the weekly HIV support group for Latinos at Casa Iris. Although different from the public recognition that Mrs. Rivera enjoys, the respect and admiration Mrs. Ortiz receives is drawn from her energy and positive disposition despite, or because, of living with HIV. Mario described his idol in this way:

The first time I met [Judith], when I heard that woman speaking, I said "wow!" Because you could tell about her spirit and you have to say "this woman is unbreakable." This woman has the same condition I have so what stops me from being like her. So when I go to this group, I see Judith talking speaking like that with that smile, you know, that brightened her face. And inside, I was thinking "this woman is made of iron." And she would "this and that, and I have children, and this and that, and my husband, and this and that..." And me, "wow, what a woman!" One time when I saw her I told her "the first time I saw you, you were talking at BMC and you talked like this, this and this." She liked it. She felt good and started laughing, that big smile. I was stunned! I said to myself, "this woman has a spirit way too big," and I learned from her. I said "wow! I have to be like that."

There are many other individuals who are leaders and symbolize la comunidad. Among them, these men identified Elizabeth Sanchez, a program coordinator at HOPE, Carlos Maysonet, a case manager at LHI, Rafael Morales, a substance abuse counselor, and Marilyn Mojica, a health counselor at BMC. As in the case of Iris Rivera and Judith 
Ortiz, these other individuals are considered "community legends." Their status is widely recognized by community and government organizations. For example, Mrs. Rivera was recognized for her HIV work by the Boston Celtics, Boston's professional basketball organization, as one of the "Heroes Among Us" in 2002 (www.nba.com/celtics). She has also been featured in many newspapers and magazines including The Boston Globe and Hispanic magazine. Likewise, Elizabeth Sanchez's remarkable life story from imprisonment to eventually becoming a leader in the HIV community at El Centro Pedro Zamora (HOPE), was highlighted in the newsletter of the Massachusetts Parole Board in 2007 (www.mass.gov). In addition, her work has been recognized with funding from SAMHSA for an HIV education and prevention project she spearheaded in collaboration with a prominent health community agency (Parole News 2007).

The list of individuals working in HIV in the care of these men is extensive. Many names were mentioned during the interviews and their omission from this study is not intended to devalue their work, commitment, nor their contribution to the fight against HIV. What separates some individuals as key figures in the community from others is how they are perceived and what they represent for the men I interviewed. In the eyes of my respondents, these women and men are an integral part of the history and legacy of the Latino HIV community in Boston. They are synonymous with the history of HIV in Boston and the struggle for improving the lives of those impacted by the illness. They have become undisputed heroic role models for those living with HIV.

\section{Community Organizations}

Other important symbols of the community are HIV community organizations themselves. As individuals mobilized to address the impact of HIV in the city, they 
created important community-based organizations throughout Boston. These

organizations emerged initially to provide services, but these agencies have become referents for living positive with HIV in the lives of these men. Mario identified a couple of these key agencies and their importance:

Where I go is HOPE and Casa Iris, those are the only Hispanic places. The only Hispanic places. And there is where...where anything, there are people that know, that have knowledge, and anything I need I say "crap, I need this. I need this type of help." They can say, "listen, go to such place.' And there I contact people.

With time, these agencies have assumed central roles as service providers and advocates for the well-being of Hispanic people living with HIV. Leo ${ }^{17}$ illustrates how significant these agencies have become to a person who is diagnosed with HIV:

But with this virus, I just got to know BLC, AIDS Action. You know, those two groups, great services have been very helpful because I go for my housing. They do housing search at the AIDS Action. And when I go to counseling and I want to talk to somebody I go to BLC. You know, when I want to get away from everything I go to BLC. When I have lunch I go to BLC. When I want to talk to somebody about some legal work, then I go to AIDS Action. You know. It's a back and forth thing. Those two are really very helpful, they are really good.

In the age of HIV, community agencies stepped into serving people affected by the epidemic. Their services provide care for the overall social, physical, and emotional wellbeing of their clients. In addressing HIV with a holistic approach, these agencies have become pillars of the community in the eyes of these men, fighting not only against HIV, but also discrimination, social exclusion, and poverty, conditions linked to HIV (Baer et al. 2003; Farmer 2004).

\footnotetext{
${ }^{17}$ English-speaking respondent - text in original language of interview
} 
The Boston Living Center (BLC) is perhaps the most iconic organization in this community. The majority of the men I interviewed have ongoing contact with this organization. In fact, $87 \%$ of them were involved with the organization at the time of the interview (see Table 10). According to the agency's mission statement, BLC "is a nonprofit community and resource center whose mission is to foster the wellness of all HIV positive people and respond to the changing needs of the HIV/AIDS community" (www.bostonlivingcenter.org). The agency offers an array of services including support groups, classes, housing assistance, recreational activities (e.g., pool table, movie nights), computer lab, and meals. The daily lunch is very popular among the participants of this study, satisfying nutritional needs and promoting socialization. The Meals Program is a legacy of the history of the agency. The BLC was founded in 1989 by a group of people who gathered to have a Thanksgiving meal after being isolated from families and friends because of their HIV status (www.bostonlivingcenter.org).

\section{Table 10: Respondents with membership/receiving services from HIV CBOs}

\begin{tabular}{lc}
\hline Agency & N (\%) \\
\hline Boston Living Center (BLC) & $27(87)$ \\
Latin American Health Institute (LHI) & $18(58)$ \\
Casa Iris (part of Multicultural AIDS Coalition) & $16(52)$ \\
Hispanic Office of Planning and Evaluation (HOPE) & $11(35)$ \\
AIDS Action Committee & $9(29)$ \\
Cambridge cares about AIDS & $9(29)$ \\
Others (SPAN, MOCCA, Pathways, Centro Latino de Chelsea) & $9(29)$ \\
\hline
\end{tabular}

The BLC considers the individuals linked to the agency as "members" instead of clients or patients. Proof of HIV/AIDS status is the only requirement to gain membership. The decision to categorize the individuals affiliated with BLC as "members" in one of promoting the notion of community: "When you become a member 
of the BLC you become a part of a community..." (www.bostonlivigncenter.org). The membership status is important because it reinforces a sense of belonging to a community with a linkage to a physical space that is safe, welcoming, and supportive where members learn to be healthy and have the opportunity to socialize. Upon becoming a member, all services, including access to classes and recreation areas, are unlimited and free of charge.

Members take pride in their BLC membership, as exemplified by Leo who was quoted at the beginning of the chapter. Occasionally he forgets to remove his membership badge. He uses such occasions as an opportunity to show that he is a proud member of BLC. Like Leo, other men similarly shared their delight in belonging to this agency. For example, Antonio spends much of his time at BLC. For him, being there is part of his everyday routine.

Almost every day I go to the Living Center. Because in addition to the yoga that I do in an environment where I can feel good, there aren't any drugs, there is positivity there. They have a pool table. You can play dominoes. I can use a computer and practice using the computer, because there are computers. I have good friends and, in addition to that, I also eat well.

For many men, BLC provides the space where they can gather and socialize with their friends and peers. Gathering at the BLC not only reinforces community with daily face-to-face interactions, but it also contributes to building healthy relationships. The message of a healthy community is important to offset the negative stereotypes of people who are HIV positive. Orlando explains how the time spent at BLC helps him to live better:

There at [BLC] I shoot pool, I do things like art, drawings, computers. We talk, yeah. For me, for me I avoid being alone for a little while. It helps 
me more because almost always I'm alone, lonely, and when I'm in these groups, like I get more involved and I share with people. It has helped to avoid depression. Because right now I...I even stopped taking my medicine for depression. I don't take it anymore.

Messages encouraging people to thrive with HIV are central to the mission of BLC. Encouragement is central in all the programs, empowering members to live fulfilling lives. Members have the opportunity to live out normal healthy lives by participating in the many programs available at the agency. Some of the agency's activities challenge members to be in pristine health to participate. Diego described his experience in the agency's marathon team to run the demanding Boston Marathon:

I ran for the Boston Living Center. Yeah, we were two that have HIV that did it. He did it in like four and a half hours, something like that. He also has HIV and I have HIV, but the others didn't have HIV. They were people...supporters that support the Living Center.

For Diego his participation in the Boston Marathon's BLC team was unlike his peers since they mostly get involved by participating in different fundraising activities related to the team. Instead, he ran the marathon and finished the 26.2 miles course in 3 hours and 50 minutes; the average marathon time for men in the U.S. is 4 hours 32 minutes 8 seconds (Marathonguide, n.d.). For him running was an opportunity to feel "normal" as an HIV-positive person and celebrate being healthy. That is how most of these men feel when they go to BLC and the importance this agency represents in their lives; an indication of why the agency is so significant in their lives.

The BLC is not the only agency-symbol of the community. Others include Casa Iris, HOPE, AIDS Action, and "Latino Health" as many of the men refer to the Latin American Health Institute. These organizations share something in common: they lead the fight against HIV by formulating strategies and programs that include cultural 
awareness as an essential component to health care and service delivery. Sensitivity to the fact that those living with HIV are not all the same is important; reaffirming their heritage reinforces their self-worth and dignity. The development of culturally sensitive and appropriate programs that address the health care needs of individuals have been recognized to be one of most important elements in effectively caring for diverse populations (HRSA 2001). The cultural approach of the interventions found in these agencies supports and encourages redefining "what living with HIV/AIDS" means and empowers individuals with health, housing, employment, and ultimately self-esteem, assisting these men to move from stages of sickness, homelessness, and unemployment into successful fulfilling lives.

As I will explain in greater detail below, these institutions do not build $l a$ comunidad themselves, however. Instead, they enable the process of community formation in which these men produce and reaffirm community; as stated earlier, they lay its foundation or architecture. Without this social network, the community-building project described in this dissertation would look very different. These institutions empower the processes that support and reinforce the social fabric of la comunidad. As social spaces where these men come together, the agencies reinforce notions of solidarity and belonging, reinforcing the sense of community to confront the social environment of marginalization and loneliness. These organizations provide welcoming and safe environments where the men can be together facing in community the "little problem" they share in their lives. As community symbols, they enable community formation in the shared meaning they represent. As such, these institutions have become beacons embodying the community's norms and values. 


\section{HIV-specific "Language"}

Language also serves as an important cultural identifier binding the members of $l a$ comunidad together. The HIV-specific language is used as part of everyday conversations. Unlike the sign language used among the Deaf community which serves as a "symbolic badge of identity" (Becker 1980:19), the HIV-specific language serves another function. Primarily, the use of HIV-specific language is critical to communicating about one's condition. For these men and other people living with HIV, it is the shared way they communicate and understand both illness and wellness.

The HIV-specific communication includes speaking about the HIV medical indicators and treatments. Early during an interview, $\mathrm{Leo}^{18}$ exemplified the HIV-specific language upon asking him some general questions.

Interviewer: And, how would you describe your health: excellent, good regular or poor?

Leo: $\quad$ I am excellent...I am undetectable. My CD4 ${ }^{19}$ count is 891.

Interviewer: Oh, very good. You are not taking any meds, are you? Leo: Yes. Interviewer: You are?

Leo: $\quad$ I am taking 3 meds, Norvil, Travada, and Raitex. I take them daily.

An average person would not necessarily know that the risk for severe illness is higher with CD4 count below 200 to understand the implications of Leo's numbers. Similarly, only certain people would probably know that "undetectable" levels of HIV virus in the

\footnotetext{
${ }^{18}$ English-speaking respondent - text in original language of interview.

${ }^{19} \mathrm{CD} 4$ : Cluster of Differentiation 4, helper cells used as a measurement of the health of the immune system.
} 
blood are determined when viral loads ${ }^{20}$ are less than 400 copies $/ \mathrm{ml}$, and that even in his case, "undetectable" does not mean the body is cured of HIV. As suggested by Leo, there is a relationship between these indicators and one's health. Not only do these values account for the individual's health status, but they can also reflect one's lifestyle. As Manu described in his assessment of health, these indicators serve to determine actions needed to maintain a healthy body. "I have been diagnosed since 1993, since 1992, and I have lost so many, and my cell count is in 900. My viral load is in 10,000. I try eating nutritious foods, nutritious food to maintain my immune system strong." These measurements are suggestive of how well an individual is living a healthy life with HIV and staying away from drugs, eating and sleeping well, exercising, and taking the medications as prescribed.

The CD4 counts and Viral Loads are the primary indicators of health among people diagnosed with HIV. These indicators are the "lingo" used to convey one's status of health. Good numbers are a source of pride as good indicators equate with good health outcomes. For many of these men, determining how well they are doing physically with HIV is described by these indicators:

Roberto: With the meds that I have...excuse me... with the meds that I have, I have gotten to 950 the CD4 counts.

Gustavo: Yah!

Eduardo: $\quad$ I'm at 800

Roberto: now I'm in 800 around there

Jaime: $\quad$ I have gotten to 1000

Roberto: $\quad$ You have gotten to 1000?

As suggested in this group interaction, there is no need to explain what the numbers mean among these men. According to the CDC (1997:1), "accurate and reliable

\footnotetext{
${ }^{20}$ The amount of HIV virus in the body fluids
} 
measures of CD4+ T-cells are essential to the assessment of the immune system of human immunodeficiency virus (HIV)-infected persons." I am quite certain that the majority of these men have not read the CDC reports stressing the importance and significance of these indicators. Instead, for them, these values are part of their life and culture with HIV. These are not learned via study but via conversations in support groups, presentations, medical encounters, and their own research without having the need to be referenced in a CDC report. For these men, these values represent important signs of health and vitality and thus are part of their vocabulary and their conversations.

Unlike the health indicators which are common in the wider HIV community, other language patterns are specific to la comunidad. A unique pattern noted during the interviews in the communication among this group of men is the use of the word "AIDS." There was a strong resistance to using the term "AIDS" or "SIDA" (in Spanish) among these men. This interesting singularity reinforced the experience I described in the introductory chapter of this dissertation regarding the feedback I received on the study's recruitment flyer. The staff from an HIV program at a community agency in Boston was very critical of the flyer because it included "AIDS" in the text describing the eligibility criteria. The original flyer's text read: If you are a PUERTO RICAN man, HIV-positive (or living with AIDS), and 18 years old or older, then you can PARTICIPATE in a study and RECEIVE $\$ 30$ for your time. In addition, the flyer was decorated with color images of Puerto Rican flags and a map of the island to draw attention to the announcement. According to the staff's feedback, in general, the flyer reinforced negative perceptions about Puerto Ricans. In fact, it was suggested that including AIDS in the context of the flyer carelessly promoted a stereotype that all Puerto Ricans have the illness, suggesting 
that Puerto Rico is a nation of people with AIDS. In view of this feedback, the text of the flyer was revised and the word "AIDS" (or "SIDA") was removed. The images were included in this version. The revised flyer that was used for the recruitment of participants for the study read: If you are a PUERTO RICAN man, HIV-positive, and 18 years old or older, then you can PARTICIPATE in a study and RECEIVE \$30 for your time.

The reaction to the flyer and the pattern of avoiding the term AIDS is not surprising. There is a general consensus among these men that AIDS or SIDA is something very negative that must be avoided. This belief is based on the fact that AIDS is highly stigmatized and is strongly associated with death, and association clearly expressed in the narratives. During the interviews, any mention of AIDS or SIDA was viewed negatively or arose in a negative context. For example, Juan associated AIDS with very depressing images:

What happens is that sometimes I don't think because sometimes I say "I'm going to die. I'm going to die of AIDS. I'm going to die really horrendous in a bed. Laying on a bed, I'm going to get sores. I'm going to get rotten inside. I'm going to rot."

The association made by Juan is not without foundation as many of these men have witnessed the suffering experienced by someone dying of AIDS. "Shit, when I see a friend that is going down, decaying, that little by little is getting sick more and more, you start thinking, 'shit, will I look like that?"” explains Mario, "I have a friend that died of AIDS many years ago. Little by little I saw him suffer." In addition to death and dying, AIDS is associated with other equally disheartening images of stigma and discrimination. Luis recalled his own perception of people with AIDS prior to being diagnosed with HIV. 
He commented, "Before, in Puerto Rico, I would say, 'that guy, that guy has AIDS. I don't want that guy to come here. I would shut the door on him."”

Clearly the term AIDS is avoided as evidenced from the frequency of the men's usage of the term, or lack thereof, during the interviews. The literature is silent in this area, but nevertheless, the narratives speak clearly to this pattern. Aside from the rather small number of instances involving the discussion of negative perceptions, the term was sparingly used by participants when sharing a narrative of diagnosis (e.g., "he didn't say I 'have HIV', he said 'I have AIDS!'”), discussing an organization (e.g., AIDS Action Committee of Massachusetts), or referring to an event (e.g., AIDS Walk). Even in cases when making reference to their HIV/AIDS status, regardless of the AIDS clinical definition $^{21}$, they did not talk in terms of AIDS. In fact, in only three instances men did recall disclosing their HIV/AIDS status to others in terms of AIDS. In those separate cases the choice of words indicated a definite terminal status: "tengo SIDA" (I have AIDS).

Instead, during the interviews, the majority of the men preferred to use "HIV" or condición (condition), a common term referring to the illness. In these cases, when talking about or disclosing their status, they chose from an array of alternatives to communicate it to others, perhaps reflecting their perspective on the illness or the situation of the disclosure: "tengo la condición" ("I have the condition”), "tengo HIV" ("I have HIV"), "vivo con esto (HIV)" ("I live with this (HIV)"), "yo soy paciente de HIV" (“I'm an HIV patient”), "soy positivo a HIV" (“I'm positive to HIV”), or "HIV

\footnotetext{
${ }^{21}$ According to the AIDS diagnosis definition once an individual presents certain levels of Viral Load or experiences an AIDS-defining condition, that person remains diagnosed with AIDS.
} 
vive conmigo" ("HIV lives with me"). These expressions reflect a different perception and perspective as compared to AIDS. For them, these choices reflect their individual as well as collective reality of facing the HIV diagnosis. Symbolically, the selection of these terms represents and transmits their perspective on "living" with HIV not dying; a powerful positive affirmation that is transmitted in everyday exchanges in la comunidad.

There are many other subtleties that are very difficult to capture regarding communication in la comunidad. The observations on communication and language presented in this dissertation are limited and more research is needed to capture the adoption of terminology and pattern post HIV diagnosis. As other people who belong to a similar culture use language as a conceptual map to communicate (Hall 1997), these men's language is also influenced by their own specific experiences of HIV, and thus holds important meaning in their everyday lives. These subtleties in communication derive from their commonality of being HIV-positive and the shared experiences of living with HIV, and thus it is difficult to articulate as this level of communication refers to culture. For example, how can the significance of the National Football League's annual Superbowl or the celebration of the $4^{\text {th }}$ of July for Americans be explained? What is it that allows most Americans to interact, have conversations and expectations, and understand these events without specific instructions or explanations? These popular American events are difficult to express as well, but they are understood by those who have a common background and share in these experiences. For the men in these interviews, similar cultural language is learned and evoked in their commonality as HIV survivors as well as, at an additional deeper level, the specifics of their unique background (e.g., Boston, Puerto Rican, Latino, minority, etc.). 
Expanding on Anderson's (1991) Imagined Communities, the cultural language, the culture of life experience with HIV, is part of the imagination work that creates in them feelings of commonality. Unlike Anderson's conceptualization for supra-face-toface communities, the ongoing interaction and face-to-face contact described by these men parallels the role of the print media and museums as community-building tools described by Anderson for nations. From this perspective, the experiences are an important characteristic of the communication and culture of this community. Certainly, Anderson's argument is sound in explaining the nature of the cultural processes as building blocks of community. I believe that an equally valuable insight into the shared culture of this community was given to me by Mario, a 56-year-old US-born Puerto Rican living with HIV since 1985. This is how he summed up the underlying foundation of the community:

We call sit down and talk because we all have the same. The feeling is the same. We all are, we all are going through the same. So, it's simpler to talk to a person that is HIV positive than to a persona who is negative. It depends. First you have to know how you are going to talk to that HIVnegative person and how that person is going to act when you are talking about the virus. So, a persona that has the virus, you don't have to have fear because you can speak open, without fear.

\section{Rituals and Traditions}

Rituals and traditions are an important part of any community fostering the creation and recreation of commonality (Cohen 1985, Anderson, 1982, Muniz and O'Guinn 2001). In their enactment, people acknowledge the group's shared culture and call on the "consciousness of the community" described by Cohen (1985). In other words, these practices define and reinforce community with a set of habits and consistent behaviors performed by members. Similarly, rituals, as Douglas and Ishwerwood 
(1979:65) argued, "serve to contain the drift of meaning...[They] are conventions that set up invisible public definitions." Along these lines, traditions defined as a "set of practices which seek to celebrate and inculcate certain behavioral norms and values" (Marshall 1994:537) establish guidelines for policing and identifying violations of cultural norms. As "public definitions" and "guidelines," rituals and traditions are not inconsequential. Socially, they draw important boundaries that define any group or community. These, in turn, help to determine membership by identifying between those who participate and who do not participate in the performance, and by calling attention to those who fail to adequately perform them.

\section{Medicine Taking}

Many of the rituals enacted by the Puerto Rican men participating in this study are related to performing healthy disciplines that reflect the living positive notion defining the community. In fact, these rituals help to create and maintain the healthy culture of the community. In this regard, the most salient ritual in the community is related to HIV medication. For example, Felix ${ }^{22}$ discusses the common action of taking HIV medication as a ritual.

Yeah, I feel like a better person now. Didn't feel like nobody before. I felt sick...taking this medication all the time same thing day in and day out. It gets tired. But now, I just take it, you know, 9 o'clock at night, from 9-9:30pm every night I take my medication before I go to sleep.

As suggested by Felix, taking one's medication is performed in a ritualistic fashion, structuring the lives of these men. "Twice per day," explains Mario, "one in the morning and one in the evening, every 8 hours, or every 12 hours, something like that."

\footnotetext{
${ }^{22}$ English-speaking respondent - text in original language of interview
} 
Taking medication at first may appear insignificant. Unlike most rituals, taking medication is an unspectacular, often private act, repetitively and predictably performed at the same time every day (AIDSinfo 2008). This "small ritual of the ordinary," as Quantz and Magolda (1997) characterized this kind of ritual, however, is a matter of life and death, and thus integral to the wellbeing of the community. For these men, taking their HIV medication is more than simply choosing to partake in good treatment adherence practices. It determines whether they live or die. They do not think about taking medicine as somehow uniting them, but nonetheless the ritual is part of their commonality, their everyday life. Medicines keep these men healthy. Though taking them is mostly an individual act, medicine taking reinforces the sense of commonality in their shared dependence. Miner (1953:504) described how the Nacirema people ("American" spelled backwards) treated medicines as special "charms and magical potions without which no native believes he could live." Although, Miner's description ritualizes, with a touch of humor, the mundane use of medication and the pharmacological dependence of Americans, it highlights the role medicines play in the everyday life and health of people.

For the men I interviewed, Miner's depiction of medicine is apropos. For them, the ritual of taking the "magical potions" is a matter of survival. The overwhelming majority of the men $(n=30)$ were taking HIV medications at the time of the interviews; only one man reported having stopped taking medicines because his immune system was "healthy." "Presently I'm not taking medication," Minor announced happily, "my CD4 is 589. It's high." As exemplified by this participant, health status determines the frequency and amount of pills that each man takes. Manu, for example, was aware that 
he was more fortunate than many of his peers in that respect. "I take one pill per day that is called Atripla. I know for many it is hard because they take five or six pills." Other men like Pablo were not as lucky. "Yes, nine [pills] in the morning" he explains, "in the afternoon, at noon time, in the afternoon two more, it's $9,10,11,12,13,14$, y 7 in the evening before I go to bed." For some of the men, medical advances have helped to reduce the number of pills they take daily. "Right now I'm happier because I was taking 16 pills, 19 pills daily," Ignacio commented. "Now, with... in a new hospital that I'm at now, a new doctor, I'm only taking 3 pills." Yet, notwithstanding the medical advances, a cure for HIV has not been found and medicines remain the critical component of the treatment allowing the men to stay healthy despite the illness; taking medicine remains an important survival ritual within the community.

For the men in the study, the medication is a powerful symbol of HIV linking them to the community. As Ivan illustrated, even when men do not present illness-related symptoms, taking the medication is a daily reminder of self as an HIV-positive person.

I don't live with the virus because I'm not all the time thinking about it like before. Like when I saw it the first time, like I told you. Before, all the time, "no man, I'm not going to sleep because I'm not going to wake up. I'll be dead." But now, now I remember about the virus when I take my medicine.

Interestingly, by taking the medications and recalling their HIV status, the men reaffirm a connection to la comunidad. As with other rituals, the performance of taking the medicines establishes the identification with the group of people with the same condition, an act that is performed daily in order to stay healthy; in essence, it becomes an important daily ritual for sustaining the community. 
During their interviews, the men consistently noted how taking the medication is one of the most difficult aspects of living with HIV. Despite the well-documented benefits of the treatments (Crespo-Fierro 1997; Hecht 1998; Rodriguez Rosado et al. 1998; Chesney et al. 2000), adherence to HIV medication remains difficult even with improved treatments. Barriers include the complexity of treatments, fear of accidental disclosure, the stigma associated to HIV, and the side effects that can potentially interfere with everyday life and have a negative impact on the quality of life (Gordillo et al. 1999; Catz et al. 2000; Roca et al. 2000; Remien et al. 2003. However, given the benefits of taking the medication as prescribed, assistance programs have been put in place to help treatment adherence. Darío receives this assistance and described the logistics of the program.

Because I'm receiving [help] through a program, SMA, something like that, I don't know how to express it well...SM...something like that. Well, those people help people like me that have problems with the medication. I have a problem, for many years, I always tell the doctor and I have always look for this help. I need a person to go to my house to help me to check if I take my medicine. Because I will not get up at the right time. Today I take [the medication] at $8 \mathrm{am}$, tomorrow at $10 \mathrm{am}$, the next day at $12 \mathrm{pm}$, and it doesn't work like that. So, the person wakes me up, the person gets to my house at 7:30am every day.

As described by Darío, assuring that the medication treatment is followed as prescribed is enhanced by the help provided by an adherence program worker. The program is in place to promote healthy behaviors and treatment adherence. The health benefits of adherence to HIV medication are well documented in the medical literature (Friedland and Williams 1999; Paterson et al. 2000; Safren et al. 2001). Yet, unintended, the program's staff incite the participation of these participants in an important ritual, reaffirming community with each pill taken under their watch. In fact, the program 
reinforces the ritualistic essence of medication use with a strict adherence protocol preventing distractions and divergence from participating.

\section{HIV-related Activities}

Another important practice which galvanizes the culture in the lives of these men is attending HIV-related activities. These weekly practices involve attending specific support programs and groups. In particular, three activities were identified as important in this regard for the men participating in the study: (1) having lunch at the Boston Living Center (BLC) as well as attending the (2) Latino HIV support group at Casa Iris and the (3) Latino peer support group at HOPE (Table 11).

Table 11: Description of attendance to HIV-related activities

\begin{tabular}{|c|c|c|c|}
\hline & $\begin{array}{c}\text { Number participants } \\
\text { N (\%) } \\
\end{array}$ & $\begin{array}{c}\text { Average attendance } \\
\text { per month }\end{array}$ & $\begin{array}{l}\text { Meetings available in } \\
\text { recall month }^{23}\end{array}$ \\
\hline BLC lunch & $25(81)$ & $13(68)$ & 19 \\
\hline Casa Iris group & $16(52)$ & $4.6(92)$ & 5 \\
\hline HOPE group & $10(32)$ & $3.75(94)$ & 4 \\
\hline
\end{tabular}

The lunches at BLC are very popular among the respondents. The majority of the participants I interviewed $(\mathrm{N}=25,81 \%)$ regularly attend these lunches. The meal is free of charge to BLC members and their invited guests. It is offered at the premises of the agency located at a central location in Boston every Tuesday through Friday from noon to $2 \mathrm{pm}$. During the month of the recall research exercise, as a group, the respondents attended on average 13 times of the 19 days that the BLC lunch was available. Nineteen of the respondents attended 10 times or more during the month; three participants attended every day. The BLC lunch is known among HIV-positive people in Boston for

\footnotetext{
${ }^{23}$ July 2009
} 
being very healthy and nutritious, and providing a variety of choices. Gabriel, a regular attendee, described the lunch:

There are volunteers that will be serving you. And let me tell you, the meal is oriented for HIV people because is very nutritional. Is very nutritional. Not only do they have for people that eat meat, but for the people that do not eat meat. For vegetarians, they have a dish that they make for vegetarians. I do not eat meat. I don't eat beef. I eat chicken and fish. Chicken is meat but not ...I try not to eat the one with the hormones and all that. But that's just me. But when I'm hungry. If there isn't anything else, I eat that. So I always go for the...it is good because you have choice there...It's very good food. And an incredible salad. All kinds of salads, very good, excellent. I think only in Massachusetts you find that!

In addition to being a nutritious, the lunches provide important opportunities to socialize with friends and peers. When I interviewed Samuel he had just started going to BLC for lunch. He was invited as a guest and introduced to the other Latinos present. "I knew the one that took me there, so he introduced me to a couple of them. When I go to lunch I sat at a table with the Latinos. We start talking, and we start talking about music." As Samuel hinted, the conversations during lunch focused on topics other than HIV which is something I was able to observe when I was invited to the lunch by Victor, one of study's participants. The conversations ranged from talking about the Red Sox, discussing the agency staff's salaries, sports and athletes in Puerto Rico, to talking about other peers including a former staff member from another agency that is now part of BLC. In fact, the word "HIV" and "AIDS" were not mentioned rarely in conversations I observed. This was surprising at first, but, in general, had I not known the lunch was a program hosted by an HIV agency for people living with HIV, I would have mistaken it for a meal at a local cafeteria. 
Other observations from my visit are important to the illustration of this lunch ritual. My lunch companions seemed to know many people there. The only time they paused their conversation was to say hello to others in the dining room walking by the table. They looked very comfortable and confident projecting a striking sense of belonging. At each table, people were engaged in energetic conversations and laughter was constant. Food requests at the serving lines were addressed with attention and quickness showing a level of courtesy foreign to most South Florida restaurants I know. On my way to the lunch, I was anticipating an experience similar to what I observed during dinners at a homeless program (not related to this research). In that case, there was a clear disconnectedness and somberness in the faces and attitudes of the individuals participating in what can be best described as a "feeding ritual." Instead, the lunch at BLC more closely resembled the environment of a social club, where regular members gather to get a bite to eat, catch up, and socialize.

Another important observation worth noting is the uplifting impact associated with attending the lunch. I recall during the interview prior to the lunch, Victor seemed to be experiencing discomfort as he kept moving his hands over his face as trying to force ideas to flow. Although he was alert and focused, his facial expression was dull. He spent a lot of time talking about his cancer in addition to the HIV, the difficulty managing the symptoms of multiple illnesses, and overall not feeling well. Yet, at lunch, Victor seemed to revive! During the lunch, he did not talk about his illnesses; he did not mention anything about HIV, cancer, or any of his other medical conditions. His new demeanor was very different from the one I perceived during the interview. His eyes were widely opened and his face was radiant. He remained friendly and polite, but his 
level of energy and overall emotional mood changed, becoming livelier. This was an amazing transformation that remained throughout the lunch.

Attendance at support groups is performed ritualistically by these men as well. The majority of these men prefer to attend Latino groups exclusively. The group at Casa Iris is offered weekly on Monday nights from 6pm to 8pm. On Wednesday nights, HOPE hosts a similar group also from $6 \mathrm{pm}$ to $8 \mathrm{pm}$. Both locations are located in Jamaica Plain, a neighborhood in Boston just a short walk from the subway and other public transportation. These groups are well attended by the men I interviewed (Table 11). Sixteen men (52\%) attended at least one of these and 10 of them (32\%) attended both meetings weekly during the recall month. The men who reported participating in these groups were very consistent in their attendance. During the month of the recall, $80 \%$ of the respondents who attended the groups were present at all the sessions offered during that period. Ninety-two percent reported attending all five sessions at Casa Iris during that month and $94 \%$ reported participating in all four sessions held at HOPE in the same period.

These support groups are very different from the lunch at BLC. They are well structured and have a set, HIV-focused agenda at each meeting. Ramón highlighted the group structure. "You introduce yourself and...you introduce yourself to the entire group. Each one talks a little bit about their experience, and that's it. And the group continues. Then we continue the topic that was scheduled to be discussed today." The entire session is very ritualistic in nature. Although I was not allowed to participate in these groups because of confidentiality, during a rare visit to one of these groups, invited as a guest, I witnessed the rituals involved in the groups described by the men. At arrival, 
a table was set up with traditional Puerto Rican food: pernil (roasted pork), maduros (fried sweet plaintains), arroz con gandules (rice and pigeon peas), and flan (custard dessert). Soon after grabbing a plate of food and finding a seat around a long table, the group's facilitator, an HIV-positive individual, asked one of the participants to read the rules of the group. This "volunteer" reader changes every week. Emphasis was giving on respecting each other and maintaining the conversation confidential. Immediately, without instructions, one by one, in a clockwise sequence, the participants started introducing themselves, giving an HIV report, health update, and any other information they felt pertinent. As a guest seating around the table, I immediately learned the liturgical format of this ritual and gave my own "check-in.” Individuals' check-ins were only interrupted by salutations of welcome (e.g., Hola Ramón!) and were followed by applause. Once everyone had checked in, the facilitator made general announcements and introduced the session's topic. In short, the ritual of introductions and the reading of the rules facilitated and reinforced the integration of all the participants, old and new.

Another notable difference between the groups and the lunch at BLC is the topics discussed during their sessions. The central conversation is guided by the group's facilitator on an HIV-related topic. Lázaro summed up the main themes of discussion in the groups at Casa Iris and HOPE:

Lázaro: [We talk] about depression, about how to take the medication and all that; how to take care of yourself.

Interviewer: Is there times that you talk about topics that are not related to HIV or is always about HIV?

Lázaro: $\quad$ Sometimes we talk about topics that are not about HIV Interviewer: Yes? What for example?

Lázaro: Like...drug use. That it is not good. 
HIV and related subjects are prominent in the discussion within these groups. For some attendees, this can be a problem, particularly for attendees still struggling with their diagnosis. As Mario noted, participating in these groups is not for everyone and it requires a level of maturity and acceptance living with the illness:

There are many that have left because we would talk about the illness all the time. But then I say, "Those are people that have not accepted yet. They don't have acceptance that they are sick." Because to be bothered all the time that we are talking about the illness, if you go to a support group for that, that what is for, to talk about the illness; to talk about not to be afraid to talk about it, or to hear things about it. But there is people that no, and I say "wow!" And they stop going to the group just because we would talk about that (laughing). Cada loco con su tema (To each his own).

As Mario indicates, in general, the support groups are designed to provide emotional and practical support to help people manage their health and the challenges they face with living with HIV (DiPasquale 1990; Bor and Tilling 1991; Gamble and Getzel 1989; Rible 1989; Spirig 1998). The primarily objective of these groups is to discuss the impact of the illness, talk about related contributing factors (e.g., drug addiction), and share experiences of living with HIV to improve the quality of life. Carlos embraced the goal of the groups in the message he gives to newcomers:

It is easier for some of us than others. Others are more predisposed to talk. I don't believe that anyone from the beginning tells everything that concerns him, but I believe that a sincere welcome, and for that persona to know that unconditionally, especially from someone with HIV, that we are there. We are all riding the same horse. We are all in the same bandwagon. And there is life after HIV.

A comfortable and safe environment is the key to good attendance. Providing Puerto Rican food also helps to generate a comfortable home-like experience in the meetings and is an attractive feature of the meetings. "We are in family," commented 
Lazaro, "there is always food. Yes, Mondays (Casa Iris) and Wednesday (HOPE). Hispanic food. Pork, chicken, steak." As suggested by Lazaro, the food is an important component of the groups and an element that is important to facilitate a relaxed and welcoming environment. Ramón observed that at times, they can even request their preference on the meal for the week. "Look, the other day we all got together...and asked a Chinese buffet," Ramón pointed, "they brought us all kinds of Chinese food, everything, nothing was missing. Now, this week everyone wants to eat KFC, Kentucky Fried Chicken. Sometimes we get our wishes." Having a voice in selecting the food is important for the group as it encourages a sense of ownership and empowerment, integral to the concept of health (Jones and Meleis 1993) to focus on living positive with HIV.

Although the groups are very structured, there is time for "unscripted" interactions. During my one visit as a guest I noticed socialization patterns between attendees similar to those described at the BLC during lunch. At the meeting, I observed many instances of people joking around, making fun of one another in a playful manner, and talking across the table about diverse topics not related to HIV. From their casual interaction it was easy to see that the attendees knew each other well. In fact, they were well aware of each other's personal lives, including birthdays, family relations, health and housing status. The level of intimacy is not surprising given the amount of time they spend together and the personal information that is shared at the meetings. In fact, as described previously, these groups become familia, a surrogate family, a point that was stressed repeatedly during the individual check-in.

The sense of togetherness was further emphasized on the healthy impact of the group as many attendees mentioned how glad they were to attend the groups. Many 
stressed the therapeutic properties of the meetings noting that despite the stresses in their lives when they get to the group they feel a sense of relief and they take this with them when they leave. They associate the social support resulting from the personal interactions taking place in the groups as critical to their health, an impact found among other illness support groups as well (Kalichman et al. 1996, Kendall 1992). This association was best voiced by Mario describing his experience at the groups.

I have learned a lot of things in the group. So, I feel good going to these groups. Not for the food, because there is good food, of course, I'm not going to lie to you. But besides the food, you feel good, you feel like you are in a family. So the sufferings of that person, are your sufferings also. The joy of having a good time, you also enjoy and feel good, because you enjoy it and you have a good time. At least, I have a good time.

\section{The AIDS Walk}

In terms of traditions, perhaps the most significant is the AIDS walk. In Boston, the AIDS walk takes place the first Sunday of June every year. This grassroots community event has been a part of the effort to fight HIV in the city since 1986 (Event Information, n.d.). Primarily, AIDS Walk Boston is an event that brings awareness about HIV/AIDS and raises funds to support the services of AIDS Action Committee of Massachusetts (AAC) serving people living with HIV in the state. In 2010, approximately 300,000 people participated in Boston's AIDS walk raising a total of \$35 million for the programs and services offered by AAC (Event Information, n.d.).

The AIDS Walk is a well-recognized symbol of awareness for the global HIV community, but it also acquires specific connotation for la comunidad. For the men I interviewed, participating in this yearly event is an important tradition, reaffirming their identity and an expression of being part of a wider community. Among the 25 
respondents that talked about the AIDS walk during the interviews, 72\% (18) participate in the event regularly and have done so for many years. Of those, more than half $(n=10)$ reported having participated in the 2009 AIDS Walk Boston, the most recent event at the time of the interviews.

Taking part in this tradition evokes a strong sense of self-identification as an HIVpositive person, but collectively as part of the global HIV community. The majority of the men participate in the AIDS Walk in block(s) representing an agency that provides services to them or that hosts support groups. Walking as part of the agency, in addition to showing support for and identification with the organization, is an opportunity for the men to display pride in la comunidad by representing important symbols through their identification with these agencies. Mario explains his participation: "With HOPE, with HOPE. And sometimes HOPE gets together with Casa Iris, but we wear the t-shirts of HOPE. We go to HOPE, Elizabeth gives us the t-shirts, and we go." Given their association with multiple organizations, it is not uncommon for the men to change affiliation from year to year. "Yes, the HIV [walk] here in Boston, with Casa Iris," responded Ramón when I asked him if he participates in the AIDS walk, "next year I'm going to do it with HOPE. I take turns. One time I did it with LHI also.”

For these men, the event is also an opportunity to share their illness in public without the fear of stigma or discrimination. For example, Pablo enjoyed being able to talk freely about his condition with others during the 2009 walk in Boston. "We put on the sweaters [of HOPE]... There were a lot of agencies there. I'm at the tables, picking up things from each table. And I shared a lot with everyone. I meet a lot of people. Yes, I like that." The AIDS Walk also represents an occasion to inform others about the 
illness. As Felix ${ }^{24}$ described, participating in the event entails more than walking for him. It is an opportunity to speak to others about the illness. "I stay, I don't walk. I stay working (laughing). Me and my wife stay, you know, giving out...giving out condoms, information about HIV and stuff like that."

In addition to these practices, for many of the men in the study, the AIDS Walk is also a safe opportunity to invite people into their HIV world. For example, Mario took advantage of the event to bring his family into his social world:

Mario: $\quad$ Yes, the AIDS walk. I don't miss it. Yes, I took my niece. She doesn't know that I have the condition.

Interviewer: She doesn't know?

Mario: I don't think so. I know that her mother told her once, "listen ..."

Interviewer: How old is your niece?

Mario: $\quad 15$

Interviewer: But she went with you to the walk?

Mario: $\quad$ Yes. I told her "listen, let's go to the walk" and she got excited. "Let's go." And she came with me.

Similarly, other men describe the event as an ideal means to reach out to friends and neighbors, introducing them to the AIDS community. "Yes, I went to the walk...yes, I went to the walk," recalled Darío, "I went with my neighbors, with a person that works at a program, and we walked. Now I remember, yes, I haven't missed any activity."

The six-mile walk is as much a physical as an emotional challenge for people living with HIV. Gabriel, for example, explained the test of endurance the walk represented for him after having a lung removed:

The AIDS Walk, because I thought I was not going to make the six miles with that heat. I said, "my poor lung, the only lung I have." It's six miles the one here (Boston). So I was afraid that I was not going to make it. But look, I did it very good.

\footnotetext{
${ }^{24}$ English-speaking respondent - text in original language of interview
} 
As alluded, to Gabriel, walking the event represents an accomplishment, a triumph over the physical limitations that HIV and other related illnesses impose on the men's bodies. The sense of wellness experienced by Gabriel with the completion of the course is a primary goal of the AIDS Walk. In fact, part of the day's events includes a Wellness Festival to encourage general wellbeing and healthy living. According to the organizers,

The Wellness Festival is AIDS Walk Boston's post-walk celebration of healthy living....Wellness is a goal for everyone that wants to lead a healthy lifestyle. AIDS Walk Boston promotes healthy living as a prevention method for HIV/AIDS as well as other important health issues. The benefits of a healthy lifestyle can improve the well-being of people from all walks of life, an important message that we hope our participants take away!...The Festival provides an interactive opportunity to learn about how to maximize your well-being and achieve a healthy lifestyle (Wellness Festival, n.d., emphasis mine).

For these men, the AIDS Walk has become an important part of their lives in community. As suggested by these narratives, the AIDS Walk is an opportunity to publically express, without fear, a part of their lives that is normally suppressed by stigma. The AIDS Walk is a powerful symbol of pride and identification of survival with HIV. Although, not all men share this viewpoint, even the reasons for avoiding the event are indicative of the meaning of the AIDS Walk, as suggested by Rudy's explanation for his decision to not participate in the Walk. He explained that he fears the consequences of his HIV status being "discovered" if he participated in the event. "No, no. Not everyone knows that I have the virus, not everybody. My neighbors do not know," he answered when I asked why he did not participate in the AIDS Walk. "I try to...because I still don't feel comfortable with people that are ignorant know about my condition [for 
fear] of discrimination; that they flat the tires of my car, that they start rumors where I live, false rumors."

Ultimately, as the descriptions of most men suggest, the AIDS Walk serves not only as an awareness event, but also deflects the stigma and negative perceptions of HIV in the greater society. During the event, those with and those without HIV walk together and in so doing help redefine HIV as another illness that afflicts people—not one to be more ashamed of than the others. In this way, the AIDS Walk generates positivity by promoting healthy living, community support for the fight against HIV, and celebration of the fact that people live positively with HIV. The AIDS Walk is an important annual tradition that these men count on to express and share who they are openly; the first Sunday of every June they can show off la comunidad.

\section{Social Life in La Comunidad}

At a time when community in America seems to be eroding with declining participation in social institutions suggesting a growing disconnection between people (Putnam 2000), the intensity of interaction and social life among the Puerto Rican men living with HIV, described in this chapter, portrays a strong social network and close-knit group that sustain the individuals' emotional, social, and physical needs. For them, their social relationships are important for personal growth as well as for living healthy lives with HIV. The web of social relationships is critical to providing the social and psychological support to balance life with HIV and promote healthy personal choices and lifestyles. In this sense, social relationships have a significant impact on normalizing life for these men. Normalcy, although influenced and determined by HIV, makes a 
significant contribution to their overall wellbeing and allows for a considerable social and psychological integration into society.

The level of interaction and ongoing contact among these men must be viewed, however, in light of their time availability. Among my respondents, none of them reported having full-time employment. When they were interviewed, the vast majority (71\%) reported receiving disability benefits (SSI) because of their HIV condition, while a small fraction (16\%) was working part-time. The rest (13\%) regarded themselves as unemployed. Although normal for many people living with HIV, having a great deal of time to devote to community building is likely to vary their experience than that of people living with HIV who hold full-time jobs and have family responsibilities. However, this dissertation documents that the time is not ill-spent (to use an apt metaphor). Conversely, the time and resources these men have and receive are put to good use, toward making the healthy choices within community that would be difficult if not impossible were they to suffer alone and particularly were they to lack the means to survive let alone thrive. A limitation of this research is noted here and I suggest that future research examine living in community among those who work while living with HIV too.

In the remainder of this chapter, I will extend my discussion of their social lives beyond la comunidad. The description includes a close look at their personal lives, looking specifically at their intimate relationships, marriage, and family life. These, I believe, provide a glimpse into the everyday life of these men and their community as well as to the boundaries they draw and maintain with their choices. 


\section{Sex and Dating}

Living with HIV presents a challenge to dating and, particularly, to having intimate relationships. As many of these men remarked in the interviews, disclosing HIV status to potential partners is challenging. Often such disclosures are received with rejection motivating some men to self-censor themselves from seeking romantic relationships. "Sometimes women approach me ..." explains Mario, "so, a couple of women have approached me and I ran away. I would reject them because of fear, fear of having to tell them that I'm sick. You know, perhaps for the fear of being rejected." Among others, the fear of disclosing their HIV status can have a life-altering impact on their desire to be in an intimate relationship. For example, Marcelo explained how his dating life has changed since being diagnosed with HIV:

My life changed in the way that never again I was interested in anyone else. Since that time, I have not been out with anyone. Women or men. Being a woman or being a man. I mean, I live my life like I live because I have to live in the world. I don't know about the future, but now that's how it is. I think that if one day I meet someone, I would have the obligation, I think, to tell that person about me. So, it's like I'm afraid to have a conversation like that, this and that...ah, no, all the things I imagine that could happen. All the things that I imagine (the participant sobs).

Aside from the fear of disclosure, other men simply accept the "damaged goods" diagnosis that accompanies being HIV-positive, rejecting the possibility of having normal relationships. Dario, for example, upon learning his HIV status in prison ended his relationship with his spouse despite her unconditional support for him.

I told her, my partner, but she told me she was with me $100 \%$. That the illness was like cancer or other illness. I told her "no." That this is a very sad case because I can't have normal sex with her and I have to use a condom the rest of my life. "It's sad that I have to tell you this," I said to her, "but is better that you look for a man that can give you children 
because I can't give them to you like I would like to give them to you and you have to redo your life." So she cried, threw a tantrum, she kept supporting me until I rejected her completely from prison. I told the prison guards, "when this girl comes to see me, do not let her in." That's how I ended that story.

As these narratives suggest, relationships become problematic and difficult for these men. They risk rejection, but to have sexual relations they put others at risk. To avoid being a health risk, men in the study resorted to taking other approaches instead of rejecting relationships completely. One man listed some options:

I know people that are healthy and are with others who are HIV, but it is a big risk. I haven't not been able to do it. I cannot take a risk like that. I prefer...to use my five fingers (showing his right hand to indicate masturbation) or to look for a striper and wear a condom, or look for a person that is like me (HIV-positive).

In fact, as implied by this man, a preferable option by many men is to have relationships exclusively with HIV-positive partners. Although similar precautions need to be taken when having sexual relations with partners who are HIV-positive to prevent re-infection and other sexually transmitted diseases (STD) (Crepaz and Marks 2003), there is a preference for being with someone who also lives with the condition. According to Marcos, "I don't have to be afraid because they are like me (HIV-positive). They take the medication like I take the medication, so it doesn't bother me."

Despite their predisposition to dating exclusively HIV-positive women, some men noted that there are only a very few number of women who attend support groups and HIV programs, making it difficult to finding suitable partners. In fact, this is something I observed during my visits to the support groups. The group with the most women in attendance during my visits had only 5 women out of a total of 19 attendees $(26 \%)$. Given this scenario, men like Juan, have even chosen "alternative options" to having a 
worry-free relationship, an option that perhaps he would have never considered previous to being HIV-positive. "Because I love women," he confided, "do you know to what extreme I have gone? To look for a transsexual! Emotionally, I said 'I can't have a healthy woman." I met some...there are many beautiful transsexuals, most of them are infected (HIV). A transsexual, of course!” For Juan, dating a transsexual is not ideal, however, as he later explained, it is safe and convenient given that this person is also HIV positive.

Being HIV positive does not necessarily prevent all men from having active social lives and intimate relationships. Ramón for example is very proactive when approaching women and disclosing his HIV status to them. Although he is aware of the risk of rejection, this has not been his experience. In fact, he believes that being honest about his HIV status is key to his success with women.

Before anything happens, before anything, I tell them first. That's my introduction: "I'm positive to HIV." And yes, many people think it is incredible because they are not regular women. They are professional women that I have had. It's not to brag, but what they like, how can I say this, is the honesty. That is bigger than anything. That is what I have noticed. With your honesty, you open doors. Because a person that is risking it, from a person that doesn't have to be with you but only because "he told me from the beginning without even having kissed me, before anything. He is taking care of me. That man is going to love me dearly. Why am I going to tell him 'no?' He looks good, this and that... with HIV." You can live a long time, because women here are very open minded.

Not all men follow his strategy. In other cases, men prefer to keep their HIV status secret form their partners. Yet, despite being proactive and taking the necessary measures to preventing a transmission, disclosing becomes unavoidable in long-term relationships. 
With time, Luis learned the benefits of being open about his HIV status in his long-term relationship.

She always asked me "listen, why every time you have relations with me you use condoms? Why, I'm not sick?" And every day that bothered me in my mind. One day I told her "look, I have to talk to you. This is what's happening, this, this, and this (HIV)." I love you, I appreciate you, I have always protected you and I don't want you to..." So she said, "you know what, if you would have told me from the beginning I was not going to despise you because of that because you were honest with me." And there I learned that there is acceptance. If the person doesn't want to accept you those are things of that person. But if the person is educated and is mentally ready, the person will accept you. Because this (HIV) is not something so outraged.

These stories show that a level of awareness about HIV and self-acceptance are important to having a healthy social life for these men. As they reminded me often, disclosure of the diagnosis is always difficult because people's reactions are unpredictable, but often expected to be negative. Yet, responses can be surprising. This was the case for Mario. In his case, he decided to disclose his HIV status as a way of avoiding having a relationship with a woman. Yet, the unexpected outcome left him bewildered:

And sometimes I say, "shit. HIV sometimes works to get [women]off my back, you know (laughing)." Like if I had a woman pursuing me, I could tell her "look, you know what, I'm sick" to get rid of her. But no, one time I thought about that and when I told the person that I was HIVpositive, then the person later said "I don't care, I want to be with you." And then I said, "wow, and now what do I do? What excuse do I use now?!”

Although a bit humorous, Mario's story reveals that HIV is not as taboo as it was before. In fact, many other men like Ramón, Luis, and Mario expressed that they have had relationships despite being HIV positive. As these stories illustrate, an HIV diagnosis does not represent a hindrance for living normal and active social lives. This is 
even more distinct among the men that are married and have constituted a family after being diagnosed with HIV.

\section{Marriage and Family}

Although these narratives are encouraging and suggest that HIV has not deterred these men from having a social life after making changes, there are challenges associated with HIV that can interfere with being married and having children. Not all the men believed that having a family life is possible after being diagnosed with HIV. Dario, for example, has given up his idea of settling down, getting married, and having children. During his time in jail he had time to evaluate the impact of being diagnosed with HIV on his plans to have a family.

It also changed in regards to having a partner. I had a plan for my life to be married with a wife, but that has changed. Thinking in prison, all the suffering, and needing a partner because I was there for many years and I need to enjoy being with a woman and having children. HIV also destroyed that plan.

At age 48, Darío still has not married and does not have children. Luis has a similar precautionary approach to having a family because of his HIV status. Unlike Dario, however, he has not given up completely on the idea of one day having a family, but he realizes that HIV makes it more difficult and that it will require special circumstances:

I want to have a son or a daughter. It can be done, but you have to follow a procedure, you have to find the right person. Those are long term goals. Is not like if you were a normal person that you can go, the woman gets pregnant, and that's it. My body is not the same like the body of a normal person. It's not the same.

Despite the concerns, HIV has not been an obstacle for marriage or for having a family for many of the men in the study. Seven men (23\%) reported being married at the time of the interview, six of those $(86 \%)$ wed after their HIV diagnosis. Another similar 
portion of the respondents, $29 \%$, reported having been married in the past, but were divorced or separated at the time of the interview; only one respondent identified his HIV diagnosis as the reason for his divorce. Thirteen (42\%) of the men I interviewed have never been married. Being a father was also important for these men and having children was reported widely by the respondents. In fact, more than half of the respondents had children at the time of the interview ( $\mathrm{n}=16)$. Among these respondents, they had 2.2 children on average, with the majority of them (75\%) having two children or less. One respondent reported having five children and was expecting his sixth child at the time of the interview. None of the children were reported as being HIV-positive.

Although these statistics would appear to indicate normal family patterns, marriage and family life take place within a context of illness. One way to handle it was to marry based on disease status. The majority of the married respondents (57\%) were married to someone also infected with HIV. These men explained that being married to someone who is also HIV-positive eliminates potential problems and creates a sense of normalcy. Felix ${ }^{25}$ explained.

Felix: $\quad$ You know, in a normal day, I feel normal because my partner, we both same...have the same disease. But I think that if she didn't have it I think everyday wouldn't be normal

Interviewer: No, why do you think that?

Felix: $\quad$ Because of the frustration of not getting her...not getting the person sick, you know.

Interviewer: So, it helps that your spouse is also HIV positive?

Felix: $\quad$ To me it does. Yeah. Because I don't have to go to the explaining to another person, which I already have been through that problem.

\footnotetext{
${ }^{25}$ English-speaking respondent - text in original language of interview
} 
Being married to someone who is also HIV-positive removes many apprehensions. However, this normalcy does not eliminate all the concerns and some aspects of married life continue to be dictated by the illness. As Ivan learned, intimacy with his wife was "interrupted" when he insisted they continue having unprotected sex because they were both HIV-infected. "My wife already told me, 'If you don't wear the hat (condom) there is no sweets (sex),"” he commented laughing, "Yes, last night. I told her, "Let's try something, let's see what happens?' 'No, you don't want to wear the condom,' she said. 'Ah, forget about the condom!'” Unfortunately, being married to a person who is also HIV-positive does not remove all the complications of the illness. The potential for HIV reinfection and the transmission of other diseases are paramount concerns altering people's behaviors, even in the intimacy of a marriage. In his case, Ivan does not seem to be bothered by the risk, but his HIV-positive wife is quick to turn down his advances until he agrees to engage in safe sex practices. The empowerment of his wife is very different than the cases described in much of the literature in which Latina women have difficulty to negotiate condom use (Gómez and Marin 1996; Raffaelli and Suarez AlAdam 1998; Amaro and Raj 2000).

As described by these narratives, there are significant hurdles to overcome even when the marriage involves a person who is also HIV-positive. In the cases when marriage is with someone who is not HIV-positive, the complications are greater. Discussing the implications of HIV in the marriage is critical. "If she doesn't want to accept me like I am, I can't do it," stated Benedicto as a requirement for his HIV-negative girlfriend for getting married. He went through lengths to making sure she was aware of the implications: 
I explained to her that this is an illness that is very very very severe and I told her that she can die also if she has contact with my blood. She can also get the same thing. At the end, we both went to counseling. She accepted me and we were married."

Benedicto described the ideal approach to establishing healthy relationships despite his HIV by speaking about the challenges, discussing the potential risks, and seeking counseling. On the other hand, while his case is illustrative of the ideal steps, not all men follow the same approach when laying the foundation for a marriage relationship. For example, Orlando's case was very different.

Orlando: I got married and I hid from my wife that I was HIV positive.

Interviewer: Ah, she didn't know?

Orlando: $\quad$ No. And then I went and told her. After we got married Interviewer: And what did she say?

Orlando: We had problems, but later she started looking for information. I also gave her information and then she...we got back together because she loves me and I love her. She is still not HIV-positive.

During the interview, Orlando commented that he did not disclose his HIV status prior to his wedding because of the fear of being rejected and losing the relationship. In this case, information about HIV and acceptance were crucial to mending the relationship once he disclosed his HIV status.

The concerns voiced by these men toward having a family life are real risks with potential lifelong consequences; the potential for an HIV transmission is particularly acute when having children. As discussed already, some participants expressed a desire to have children. However, because of their HIV status, many of the men I interviewed opted to avoid having any or additional children because of the potential risk of infecting the child regardless of medical treatments available. In their cases, there is a sense of 
sacrifice in that a life-long desire to have a family is set aside in order to ensure that another person is not infected with HIV. Yet, this is not a widespread belief among all the men I interviewed. For example, for Diego, having children was a calculated highrisk decision he was willing to take to satisfy his wife.

Diego: $\quad$ Yeah. So we, it looked like she wanted to take a chance and have a child. I don't know, I don't know what got in me and I said "ok" (laughter)!...The child has three months, thank God.

Interviewer: And has your life changed?

Diego: Yeah.

Interviewer: And is the child positive?

Diego: $\quad$ No, negative.

Interviewer: How lucky, that's great.

Diego: $\quad$ When we went to the doctor, the doctor told her that that was because she took the medications.

The concerns for transmission are valid. Despite the medical advances and proven techniques to reduce prenatal transmission (Mofenson 1999; Lindegren et al. 1999), HIV transmission is always a risk when having a child. This is something Benedicto and his wife experienced when having their first child.

We went to counseling. We went to counseling for medications and we were told the percentage that she could become HIV positive. So, we had our son. He is clean (HIV-negative), but she is positive (HIV). She is positive, but not at a severe level because she took a medication. But we didn't pass it to our son. The son is clean. He is 12 years old, his birthday was August $14^{\text {th }}$. Yes, he is the most beautiful thing that has happened in my life.

Wanting to have children and a family is a legitimate desire for men living with HIV as well (Paiva et al. 2003; Sherr and Barry 2004). The literature is scant in understanding the motivations and factors in the decision-making process to have children among HIV-positive men. However, studies noted that HIV-positive women who desire to have children are "often considered cruel and uncaring" (Ingram and 
Hutchinson 2000:118), experiencing a social condemnation similar to pregnant drug users (Bayer 1990; King 1991). Similar research has also determined that HIV-positive women who avoid having children give as their reasons not wanting to be seen as "negligent" and not wanting to infect the child (Kirshenbaum et al. 2004). Interestingly, Benedicto did not express guilt or remorse that his wife contracted HIV in the process of having a child. His attitude contrasts against the reaction of respondents who feared being responsible for infecting others with the virus. Repeatedly in the interviews, respondents expressed how the guilt and remorse of infecting anyone motivates them to be proactive to take positive measures to protect themselves and others from HIV. Yet, Benedicto's case may be different in many aspects. The fact that having a child was a mutual decision after having been counseled could have conceivably eased the blow when his wife became HIV-positive since the potential consequences were known and accepted by both. Perhaps, having a child overcame their anguish over his wife's infection. Ultimately, the impact of a family in the life of these men is very positive in spite of the risks and outcomes, and the possible social condemnation for their decision. This should not be surprising. Although limited, research has shown that the desire for fatherhood is strong among HIV-positive men and being a father gives meaning to their lives (Paiva et al. 2003; Sherr and Barry 2004). These findings were corroborated in the current study. "I did not think I could have a family, I couldn't get married, I couldn't have no children," $\mathrm{Leo}^{26}$ stated, recalling his initial thoughts after being diagnosed. "And I proved myself wrong. And then got married. I got a family. I got a beautiful daughter.

\footnotetext{
${ }^{26}$ English-speaking respondent - text in original language of interview
} 
If you see her you would go 'wow!' Everywhere I go with that girl every...is like a light!"

\section{Chapter Summary}

As a group, these men take part in the expressions of the community and participate in a social life shaped by HIV. Living a life commonly characterized and ritualized by the illness facilitates a sense of belonging through a shared "consciousness of commonality" even in the absence of homogeneity (Dyck 2002). Much as in all communities, there is internal diversity. The Puerto Rican men living with HIV share similar backgrounds and life experiences yet they are not identical as individuals. But in community, the individual is just one unit of analysis; the most important unit to examine is the community itself and its constitution. In this chapter, I have discussed the elements or building blocks of their community from its heroes and heroines, to its symbols, rituals and traditions. Through daily and episodic interactions and activities, the men and those who care for and care about them generate shared experiences and meanings. Whether communities are predominantly shaped by intra-group efforts (agency) or extra-group factors (structure), human interaction is critical to assuring their continuation and survival. As the evidence presented in this chapter suggests, involvement of members in the community production and re-production is present in all forms and expression of community.

La comunidad described by these men promotes "living" with HIV, presenting a sharp contrast to negative perceptions often associated to having an HIV diagnosis. Life with HIV is not without challenges for these men. Their social lives attest to the changes and adaptations that they have to make in order to live fulfilling lives. Despite the 
challenges, they continue affirming and reproducing community with a desire to living. The community's specific symbols, rituals, and traditions contribute to strengthen the community with values, beliefs and practices that reinforce their decision to living positive lives with HIV.

With no cure for HIV/AIDS on the horizon, it is important to see how the culture of la comunidad works in tandem with medical treatments to yield much more positive outcomes, more positive lives for people living with HIV. Living positive lives as part of this community incites members to make drastic changes in their lives which have farreaching effects above and beyond the afflicted. These changes are presented in the next chapter. 


\section{CHAPTER V.}

\section{LIVING POSITIVE LIVES WITH HIV}

I started searching for God. I started to think about myself and started to deal with my family. I started to think "shit, what I have done with my life?" Started seeing the person that you once were, that person that you are now, and the person who you can be. In the same prison, a man told me, I remember the words that [J.Q.] told me, he was a substance abuse counselor, and a Christian, he told us: "do not let your past be the tyrant of your future." And that, I always, well as of matter fact, I still remember. And that was like in 97 or 98 . And I never forgot those words. Because he always told us do not let your past be the tyrant of your future." Your past is your past, leave it behind. Look at it as an experience, like something to tell a story about, but don't let it affect your future. Try to...you can do it...you have the option to change. You can change. And why would you change for the bad, you can change for the good.

- Mario, diagnosed with HIV in 1995

Mario's self-refection, motivated by a counselor while in prison, reveals a wellmarked turning point in his life. Disguised in the philosophical foundation of his recollection is the very difficult proposition of breaking away from the past, leaving behind the reality and consequences of a life of drugs, crime, homelessness, and carelessness to start living a different life. Yet, despite the challenges embedded in making such a change, this is exactly what Mario and many other men like him have done after receiving an HIV diagnosis. Adopting a healthy and positive way of life is part of adjusting to long-term living with HIV.

The positive responses these men have to their HIV diagnosis reveal their empowerment over the illness and the autonomy many have found in their lives. For many of them, the decision to live better lives with HIV involves more than taking medication and seeing doctors regularly to care for their illness. As Mario points out, 
when he was diagnosed his life was defined by chaos and HIV was not the only issue he was facing:

Everything happened all at once: the disease (HIV), my wife leaving me, I couldn't see the kid that I had raised like if he was my son. It was a lot of things happening at the same time...too many things. So then, another criminal charge showed up, and I was like "wow." I said "I entered prison to do 3 years and ended up doing 10 !"

Dysfunctional relationships, family conflict, drug addiction, and criminal backgrounds are common realities faced by the men in addition to the HIV diagnosis. In order to adjust and to live better lives with HIV, individuals like Mario, take an active role in making changes to improve their overall lives.

La comunidad is crucial to the fact that these men make positive social adjustments to living with HIV. While a difficult concept to define let alone measure, "community" is an important framework to use when trying to understand the processes these men go through collectively in order to turn their lives around with HIV as a chronic illness and redefining its stigma. According to Cohen (1985:61), "at times, stigmatized individuals form and establish a closed community to shield the effect of the stigmatization. In this situation, the community is defined by the stigma attached to the individual, but the closed community offers a means of coping with it." In such cases, people use community defensively but still generate greater positive notions of their community vis-à-vis the larger society by redefining their stigma and endowing it with positive norms and values. For example, the "Black is Beautiful" campaign during the Civil Rights Movement was significant for highlighting the value of being Black and promoting a proud African American identity (Anderson and Cromwell 1977; Rawick 1967). Similarly, the gay community transformed "queer" from stigma into an embraced 
moniker (Alexander 2002; Hagg 1994). In such cases, the symbolic and social reversal

of the identity serve to "'honour' the stigma, to render it as a positive value, and thereby, to destigmatize it" (Cohen 1985:60).

As described previously, the broader society has long stigmatized and tried to shunt to the margins those living with HIV, but this dissertation testifies to the types of positivity that can be produced despite such negativity. It is easy to think of an HIV diagnosis as a death sentence, but for many of the men I met it has been actually a life sentence. They started living healthy lives because of HIV and this fact helps challenge the perception of HIV-positive people and HIV itself. The impact of a healthy lifestyle promoted by the norms of the community and galvanized through specific rituals and traditions is not just limited to health. In fact, these men adopt healthy behaviors and lifestyles to improve the overall quality of their life and wellbeing as well as those in their families and beyond. In the process, they re-engage in the larger society without relinquishing their personal value and individual worth. Instead they participate in society by making drastic changes to their lives and their social environments.

\section{Living Everyday Positive Lives}

Living positive with HIV is reflected in the everyday lives of these men. The process of adjusting to HIV requires an evaluation of all aspects of daily life and making adjustments in one's physical, emotional, spiritual, and social life. These adjustments are not random; they reflect the norms and values of the community in which the men participate. Consequently, a holistic approach to living with HIV is important to improving the overall quality of life of HIV-infected individuals and to reaffirming the community's positive values. Given the background of most of these men, living a 
positive life with HIV requires making drastic lifestyle changes, living meaningful lives, and assuming a sense of moral responsibility towards their peers. In short, the changes, in the majority of these men, require almost complete transformation from their prediagnosis lives.

\section{Changes in Lifestyle}

The HIV diagnosis typically initiated the men's critical review of their lives. Consistent with the life-changing impact of HIV described by Roth and Nelson (1997), many of the respondents engaged in prolonged conversations with me about their decision to change their "ways of life." Their accounts describe a common desire to alter a life characterized by risky behaviors and unrestrained lifestyles — conduct they linked to their HIV infection. For example, Diego highlighted the changes he made in his life since his diagnosis:

Man, I'm not careless and reckless like before. Now, you know, I'm more careful about taking care of myself because I know, this, the T-cells and the immune system are important for me to survive...I don't act like reckless like before because I know that my T-cells can go high and that is not good. So, first I stay far away from drugs and alcohol. So, mentally, meditation and prayer help me a lot. But also exercise and reading to clear the mind. Lately, I do a lot of exercise, a lot of exercise lately because my girlfriend is pregnant. Brother, after 42 years I'm going to have a baby! (laughing).

After living lives where they rarely, if ever, saw themselves as in power over the course of their lives, the study participants came to see themselves as being the primary agents responsible for enhancing their quality of life and making changes to adjust and live longterm with HIV. Despite the physical toll HIV takes on their bodies and the stigmatized perceptions attached to the illness, they feel they have control over their lifestyle to have a positive impact on their wellbeing. Luis explained: 
It's been twelve years since I've got the virus. Actually I don't feel bad. I have lost some eye sight. There have been things in my body that have been affected but I don't pay much attention to them. I try to do the best I can. Right now, I've been clean for a long time without using drugs, nor alcohol, trying to eat healthy, and keeping my body healthy. If I am going to have sex with a woman, well, I go ahead and put a condom. I protect myself. It is not like before when I did thing carelessly.

Many credit their change in lifestyle as the most critical step taken in their livesand necessary to preserve those very lives. "Yes because I didn't want to die" explained Gabriel when describing the changes he experienced after being diagnosed with HIV, "well, since I didn't die it seems that I got the instinct of self preservation so I started eat right. I started to feed myself better. I started exercising, that before I didn't even think about it!" A similar association between living healthy and staying alive was made by other men as a result of their interactions with other people living with HIV. For Hernán seeing his peers' health decaying reinforced his decision to adopt a healthy lifestyle:

Reinforce my discipline of taking my medicine, taking good care, don't drink alcohol, rest well, and eat right. Those are the types of things, because I've seen that people that aren't doing these things, they don't look good and they are not healthy as they could be.

For other men, the decision to make lifestyle changes is often made not when faced with possible death upon the HIV diagnosis, but when they feel they have wasted their lives, wasted their potential, and have no accomplishments to show for lives. Samuel, for example, wanted to change after realizing his life has been wasted on drug abuse:

I said, "It is over, I am stopping using drugs, it's enough." I surrendered I said "Lord do with me whatever you want," but I am not religious, but I know that there is something more powerful than me. And that was it. I stop, I asked for help from the parole. I told them, "I would like to go to a program for my condition" and they said to me "but what's different, because you've been saying that?" And I said "because I am tired!" And a parole woman said to me "I believe you and I will give you a chance." So she came for me. She took me to the parole office and I am now in a 
program where they take urine samples three times a week. They teach me about Professor Gorski, he is the professor that wrote the book "Staying Sober." So they teach how to manage your thoughts and all that. Because I said "it is enough, I am 40 years old. I have never had anything in my life." So I asked myself, "what am I doing with my life?"

\section{Drug-free Lives}

Addressing drug addiction is one of the most important lifestyle changes these men must make in order to stay healthy despite the illness. Repeatedly during the interviews, the HIV diagnosis was credited as the men's reason to stop using drugs. For example, Lázaro identified HIV has the only reason he was able to stop his drug addiction: "Because of the condition I could stay away from drugs, because if not I would still be using, honestly. Because I still love drugs but I know I can’t use them.” Similarly, Antonio noted the influential role of HIV in his motivation to overcome his lifelong drug addiction and the subsequent positive impact HIV had on his life. [HIV] has made me live a better life. I have more responsibilities. I value life more. I stopped using drugs which it was...what always screwed me up my whole life."

The HIV diagnosis has been a wake-up call to accept that drug use is not without consequences, and it has become the primary motivation to recovering to improve the chances of survival with HIV. As Orlando attested, staying clean from drugs was crucial to improving his physical health: "it's my health because I want to live more. I know that if I start using drugs I am going to find death. [HIV] also helps me to be smart about things." In addition to the health advantages, staying clean from drugs has other benefits. For example Minor served multiple prison sentences for various crimes he committed while under the influence of drugs, including one conviction for attempted murder. However, his life has been very different since he stopped using. "I am not using. I am 
not in the street like before, hanging in bad places for the police to come and arrest me. It has been two years, thank God, almost three, that I haven't had a case in court".

Despite the benefits, leaving behind a lifelong drug addiction is not easy and staying sober represents a continuous struggle for these men. Many take drastic measures to avoid relapsing and to stay clean from drugs. Nestor explains:

[HIV] has helped me to stay clean of drugs. I have been clean for 4 years, since I came to the United States from Puerto Rico. And I'm not going to tell you that I haven't thought about using. It hasn't been easy. I've thought about using and I've had to leave places because of the conversations in the shelters. Because I've been in shelters and, you know that in shelters there are people who drink, people who use drugs. Like you hear people talking about drugs and I was like "oh my God!" So, let me go away and get some water because I like it, I liked it. I was an addict for more than 20 years. Look at my arms (showing scars on his arms).

Other men I interviewed shared similar strategies. As illustrated by Nestor's determination to prevent a relapse, staying away from drugs is paramount for these men. For them, overcoming their drug addiction is a victory over the illness. As their accounts suggest, they go through great lengths to live healthy lives with HIV, free of drugs.

\section{Healthy Behaviors}

These men have also made other important modifications to their lifestyles. Often the respondents noted the changes they had made to daily behaviors to improve their health. Gabriel gave an account of the lifestyle changes he made since being diagnosed.

Keep eating well. Doing exercise. Trying to sleep well, getting to bed early. Before I stayed up, when I was young, I didn't mind going to bed late. Anyone would say, "There is a party; it's someone's birthday, it's a party." But I cut the parties. So, I started to think more on myself. I started to think about eating right. Started to think in all that to see if I could extend my life more than what was possible. 
For him, staying healthy required making lifestyle choices that contrasted those of the life he had during his HIV-negative younger years. Like Gabriel, other men incorporated healthy behaviors as part of their lifestyle. For some, being physically active became synonymous with health. Hernán, for example, integrated exercising as an essential part of his life:

I try to exercise four times a week on Mondays, Tuesdays, Thursdays, and Fridays. I go to the YMCA on Central Brench. I go at 8:30-8:45am and I do a full routine of exercise that includes personal grooming. I do it all at the YMCA until 10:30 in the morning.

Others instead embraced a spiritual discipline as central to bring order to their lives to living with HIV. In fact, consistently, respondents spoke about the importance of their spiritual life after being diagnosed with HIV. For example, Carlos begins his days praying. For him, prayer is a healthy alternative which allows him to better manage the stresses in his life:

As I'm making coffee I mediate a bit, I say "Lord thank you this day." I ask Him to give me today the wisdom to make the correct decisions, to be someone worth of your blessings. "Thank you this day, lead me, help me to manage all the difficulties, guide the way, and take control of my thoughts and of my actions." Because I am very good, but also I can be a bit bad, you understand me? And I can react as they me react to me, like in chemistry, "every action as a reaction." "Help me to stand the things that do not please me." Because I am one of those, like we say in my island, no tengo pelos en la lengua (I have not mince words).

Many respondents found that staying healthy was also very helpful to ameliorating the impact of depression often accompanying HIV. "No, I didn't let depression attack me," commented Ramon about being proactive to care for his health, "I am strong. I got into a gym. I started playing baseball because I played baseball in Puerto Rico. I looked for a team here and started playing baseball. I can still do it". 
Along the same lines, a healthy lifestyle has been important to addressing the overall emotional and psychological impact of HIV. As Antonio explained, for him yoga has been instrumental for staying upbeat and motivated daily:

I wake up and if I don't have energy, I start doing yoga that gives me energy, you know. It lifts my spirit. Because I have been taking yoga with a teacher for seven years. So, this inspires me to get out of bed and it inspires me to do stuff around the house. Because for everything that I do I have to find motivation, so my motivation is yoga. That is what I do.

Changes in lifestyle result in additional benefit to the respondents' overall psychological health. For example, some of the men pointed to the fact that their adoption of a healthier lifestyle in response to HIV has had a positive impact on mending distant or broken relationships with family members. In the majority of the cases $(90 \%)$, the HIV was known to the family, but the primary issue driving the estranged relationships was the drug addiction not the HIV infection. Many accounts illustrate the improvement in their relationships, particularly with their children, resulting from the decision to stop using drugs and adopt a healthier lifestyle instead. This was Marcos' experience:

With my kids I can now sit down and talk more with them and feel their love. Before I was...I was there but I didn't feel anything because my mind was always on the streets, it was somewhere else. So I wasn't there for them or for anyone else, let's put it that way, I wasn't there for anyone. But now I have the time and think and I act like a person... how can I say it, like a better person than when I was HIV negative.

Self-esteem was also impacted by the changes adopted. As Mario proudly noted, the positive impact on his health resulting from adopting a healthy lifestyle has been very noticeable in his appearance.

I started exercising, I never thought I would exercise in my life. My thing was to eat and enjoy life. I started exercising. I was pretty fat, I was 38 
on pants and I dropped to a 34. So I couldn't believe it. People would look at me and said "fuck, look at you!" By exercising, doing diet, sleeping right; I would go to bed early.

\section{Key Moments}

When I asked the men about their decisions to make lifestyle changes as a way of adjusting better to HIV I almost always triggered important memories. Many respondents identified a key moment that contributed to the change in their perception on how to live with HIV. Mario, just a few years after being diagnosed, recalled the key moment that turned his life around while in jail:

When I was diagnosed that I was sick I said to myself "what do I do know? Now I have a disease and on top of that am I in jail." A friend of mine sat with me and told me "Mario why don't you start looking for God?" And I said "look for God and publically..." because I don't know, I have never looked for God. I didn't know what that was. He told me "you don't lose anything, what would you lose?" And that was what shock me up and I said "I have everything to win." I can get something and I don't have anything to lose".

Part of the stories they related during the interviews included recalling a feeling of empowerment to confront their illness and face living with HIV over the long term. The narratives of these key events have in common a transition from a stage of despair and isolation to a positive outlook, dealing with the HIV diagnosis and taking control of one's life.

As in Mario's story, friends and concerned acquaintances play key roles in the men's turning-point moments. They offer concrete solutions, pathways to follow to leave behind a negative lifestyle or environment. Nestor, 50 years-old at the time of the interview, battled drug addiction for 20 years until a friend offered him an opportunity to clean up his life: 
My friend told me "You are good person," because I had helped him paint his mother's house, her fence, and inside and outside of her house. I never took anything from the house. He told me "you are the only addict that has entered my mom's house and I'm grateful you always respected my mother, nothing has ever been missing. Nestor... if I can help you with anything, to get rid of that trash (drugs) this and that...And I told him "I would like to get out of it and give myself a chance to see how much time I can stay clean." He told me "I am going to send you to Holyoke, Massachusetts. In Holyoke there is a Christian program where I have a friend of mine works and he is going to help you." He sent me...he got me an airline ticket, he gave me money, he gave me cloths, people from the program went to pick me up there at the airport, and they brought me to the program.

Family members were also the protagonists of important exchanges which propelled the men to make significant changes in their lives. According to the participants' accounts, these moments involving a relative were instrumental to the decision to change because of their show of acceptance of the man's diagnosis. At times, disclosing the diagnosis to family members revealed surprising support and understanding that led to personal changes. Orlando recalled:

My sister opened my mind. She is also positive and her husband is also positive. They opened my mind because a told her truth and she told she was also positive. It was a double surprise (laughing). She also is HIV. They helped me because they already had... how is it called...they were connected in the clinic, they were going to groups, and already knew some about it.

As suggested by these men, the intervention of another person has been central to encouraging and supporting the decision to change and seek better and healthier lives. Embedded in these narratives is the sense of isolation and lack of support that many of these men experienced immediately after before being diagnosed, but even perhaps prior to knowing their HIV status. Given that the experiences of isolation were the result of family rejection in response to the respondents' drug addiction, criminal history, or in 
disapproval of their homosexual orientation, it is equally significant to have family involved in their acceptance. The HIV diagnosis seems to trump the long negative histories by precipitating positive changes in their lives. As a result of the key turnaround moment, the participants gain a sense of empowerment to confront their illness and face living with HIV by adopting health-conscious lifestyles.

As described at length, the decision to live healthy with HIV requires a complete lifestyle change that involves breaking away from the addiction, overcoming years in prison, facing the challenges of living with HIV, and even, for some, the potential stigma of their sexual identity. The men I interviewed see themselves as being the agents responsible for enhancing their quality of life regardless of the challenges and the perceptions generally attached to HIV/AIDS and their social backgrounds. In most cases, the changes may not be as extreme as becoming a multiple marathon runner, as in the case of Diego (discussed in the previous chapter), but the individual lifestyle changes described in this chapter are consistent with improving the overall quality of life. Recovering from drug addition, exercising, eating well, meditating, and prayer are all behaviors contributing to better health and reducing stress to improve the quality of life with HIV.

\section{Meaningful Lives}

Another important aspect of living positive lives described by the participants has been giving meaning to their experience of HIV. Many participants recounted stories of how they have taken advantage of their HIV condition to educate others. In fact, the participants commented that because of their unique experience, they assume a new, positive role as educators, helping to prevent others from becoming infected with HIV. 
Their decision to teach others includes speaking about HIV to bring awareness and promoting safe behaviors to prevent the spread of HIV. Antonio's comprehensive outreach and prevention efforts illustrate this role:

I worry that young people won't go through what I have gone through. When I participated in Casa Iris I used to go to schools to give talks. Doing outreach. I would give out condoms. I went to Jackson to the Mission Hill. Around there I would give out condoms and would talk to people. I gave them cotton balls to clean their needles for them to take care of themselves. In the trains, I would stand around in Back Bay station and I would give packages with condoms.

Giving meaning to their HIV experience by being engaged in outreach efforts and informing people about HIV involves preparation and commitment. In fact, respondents reported undergoing schooling to become certified outreach workers and prevention educators. "I learned a lot about the condition and I can help other people. Because I took training for that," noted Lazaro immediately stating "I am certified" further validating his credentials as an AIDS expert. In the same way, Victor also received extensive training to carry out multiple functions in prevention education. He described the training he received from an HIV organization in Boston: "courses on how to live with AIDS and how to talk to people, you know. Be prepared to be a presenter...I have a diploma. I have a diploma certifying I am trained to do many jobs." In addition to the general HIV topics, other participants reported taking skills-building training courses to be culturally sensitive to specific populations. For example, this was the case of Benedicto. He explained his desire to participate in trainings to work with the MSM population (men who have sex with men):

I took many trainings about HIV and I am certified because of the many trainings I did. I've taken the MSM trainings. The reason I've done all these is because I want to understand my friends who have HIV that are 
homosexual. I don't want to offend anybody because I accept everyone the way they are. I don't judge anyone.

Youth are the primary target of many of the education and prevention efforts. As stated by Mario, many of these men share a common concern for the vulnerability and the risk youth face. This is not surprising since the majority of participants began using drugs while in their teen years. During their interviews, the men repeatedly expressed their desire to have a positive impact on the lives of youth by protecting them from drugs, thus reducing the chances of their becoming infected with HIV. During the interview, Dario described the importance to outreach to youth. "Young people need to listen that they are fucking around in the streets," he noted passionately "they don't care about anything!" In the same way, Samuel, was also very passionate to "save" the youth from the life he had been living:

So here with a different state of mind I want those in the HIV program to guide me the right way to talk to young people. I want to help the young people. I don't want them to do what I did. I want them to know that using drugs is not something cool. When they think like "look I use drugs so I'm accepted, I'm accepted." You don't have to use drugs to be accepted.

At the time of the interview, Samuel was in a 6-month drug rehabilitation residential program that prevented him from making such presentations. Upon completing the program he planned to start sharing his experience as a drug addict to educate the youth and to spare them from making the choices he made. Interestingly, he made this his first priority once he was released from prison after a 20 -year term.

In addition to the education of youth, the effort to reach out to people and inform them about HIV involves making presentations and speaking about the condition at different venues. Ramón described a typical "season" of public speaking engagements: 
In winter is when we are doing more....it is when we most work because then is when we give presentations at meeting. We go out and give meetings so we don't get stuck. We go to schools to give talks, to detox centers, and to rehab programs.

As noted, the prevention efforts include street outreach, presentations at schools, facilitating discussions at AA and NA meetings, as well as speaking at intimate private settings. For example, after receiving his certification, Victor focused on giving presentations to families in their own homes. "I would go to the homes. I would look for families that could find me, you know, about 8 or 10 people or more," explaining the logistics of a State-sponsored prevention campaign, ${ }^{27}$ and talked to them "about HIV. About HIV and sexually transmitted diseases, you know." Certainly, their life experiences, in addition to the credential, vested them with credibility as experts able to give informed opinions on the subject and speak to different audiences. In fact, the value of their testimony was even welcomed at the White House:

Lázaro: $\quad$ Yes, I went to the White House and spoke. Two years ago. George Bush was still in office.

Interviewer: Were you able to meet with him? did you get a picture? Lázaro: $\quad$ Yeah, I have it at home Interviewer: What did you have to do at the White House?

Lázaro: $\quad$ Talk about my experience, how I started using drugs, and how I got the condition...how I got infected

Giving time to the community is another way to have a positive impact and give meaning to the lives of those living with HIV. The community service they participate in varies from volunteering occasionally at an HIV program to working as a staff member at one of the HIV agencies. For example, Gabriel volunteers as a way to pay back the services he receives at the Boston Living Center. "I volunteer some once in a while.

\footnotetext{
${ }^{27}$ Program sponsored by the Massachusetts Department of Public Health
} 
Because you have to give back. So once in a while I volunteer and clean the tables during the lunch time." Although, Gabriel framed his motivation as a "duty" that was not the perception of others. As in other communities, members' involvement on the daily life is a way of serving and not seen as an obligation. As volunteers, other men reported getting involved in the operations of the agencies by participating in different administrative roles. Hernán spoke about his long-term involvement with various HIV agencies in the area:

I am on the board of Client Advisory Board (CAB). I have been with them for 10 years and lately, I have always been a member, but in the last year I was pointed, well I volunteered to be the Secretary and I was accepted. More than anything else that is I always the contact I have with HIV, aside from the groups I lead. I worked for the Living Center in the kitchen and in the membership committee. I worked in the AIDS Action Committee in the group I told you. I worked in the kitchen of the Living Center. These type of involvement with people with HIV.

While many of the men I interviewed reported participating in volunteer activities, two respondents at the time of the interviews reported working as paid staff at local agencies as a way of "giving back." "It is a way of demonstrating that I have compassion" commented Rudy regarding his job as a peer counselor at an HIV agency, "I feel good helping others and that gives me strength." Employment usually takes place after years of being a member of the agency. The familiarity with the agencies prior to becoming staff is a key motivation to seek employment and make a difference in the lives of peers. As Benedicto explained, HIV-positive people are the ideal staff to work with people living with HIV because they know what they are going through and can relate to them.

I have been going to the Living Center since '96. I didn't start working until two years ago. I was one of those people that would go there and 
wouldn't talk to anyone. I was repulsive, bad temper, because of my stress. But that is why now I can understand many people who are going through the same thing. I see them down. But by having a person, a friend that comes to you and tells you "what are going through?, you are ok?, how have you been?" To know that someone wants to know how you are and how you are feeling, is something else. It's something different. Is your acceptance.

Although only a small number of the respondents have paying jobs at the HIV agencies, a large number of respondents performed functions as peer counselors. Even though they are not paid for their services, they share their knowledge with others to give meaning to their experience with the illness. Carlos illustrated the importance of sharing information with others who are facing similar struggles:

But the little I know I have always cared to share it, especially with those who need it. Because there are people that you want to help by giving and telling what they know. It is not that you know everything, but what you know, you know. And there are people who don't perceive that well, people who doesn't want to hear us, people that don't listen, it goes in on one ear and out of the other. But there is no doubt [it helps], although I can't say how many people I have been able to talk with and give them honest advice, like brother with love. There has to be people that you will never see because there are people that pass through your life and they take the information you give them. Just like many people taught me that I have never been able to thank them.

\section{Moral Responsibility}

Living positive lives is also reflected in the moral responsibility the men express for each other. Expressions of genuine care and concern, along with adopting a healthy lifestyle and living meaningful lives, reaffirm the culture of the community. Muniz and O'Guinn (2001:424) described moral responsibility as the "sense of duty to the community as a whole, and to individual members of the community." Among these men, the moral responsibility is reflected in the wellbeing of their peers. In addition to the support the men provide one another during meetings and groups, their responsibility 
to encourage and assist others to stay healthy and live a positive life is central to their "sense of duty."

Encouraging others to stay healthy is paramount to the men I interviewed. Acting in accordance to this moral system is consistent with the community culture that approaches life with HIV as a life and death matter, one that can be managed with a positive lifestyle. That is, they redefine the meaning of living with HIV by encouraging healthy practices, a sharp contrast to the negative perceptions of HIV.

Promoting and encouraging healthy behaviors is transmitted in everyday casual interventions between these men, often taking place in informal settings. For example, Nestor takes advantage of every opportunity to encourage his peers.

You know when we ran into each other by chance in some place we say "hey, what's up? How are you? Are you taking care of yourself? Are you ok? You look good, I can tell you are taking care of yourself. Keep it up!" We encourage each other and that is good. I feel good when somebody tells me "you look good, I can tell you are taking care of yourself, keep it up. See ya. Take care! Let's go, we can do it!"

As described by Nestor, there is a mutual and reciprocal component to the support offered that is important. As in many other aspects of their lives, there is a shared sense of health/illness duality in which they see their own vitality in the health of others. Similar, they see their mortality in the sickness of others. Mario's tough love approach to encouragement is telling of this shared preoccupation.

If I have a friend that isn't taking care of himself and isn't going to the doctor, I have to hit him with the whip "get on with your business." Yes, because to a friend I am not going to be soft telling him "ay bendito!" no, no, no. I tell you the things on the spot, I'm going to give it to you. "Listen, get on with your stuff. What's wrong with you brother? Okay, go to the hospital. You have to take care of your health. Take care of it. What are you going to wait for, until is too late? Until you crash?" So you are rational and he tells you what he is doing. "Do I have to wait to 
see you lying on a bed? I don't want to see you in the hospital! No, let's go to the movies, let's go around, let's do yoga. I don't want to be going to the hospital to see people." I don't like it. I go to hospitals, I have gone to see my friends but you feel bad because you say "fuck" you know, and you have to think "Fuck, maybe I could be there also in the future!" That's why I... we have to take care.

These interactions, offering words of wisdom and encouragement, mirror the dynamics taking place in support groups. However, these are unstructured and spontaneous. At times, as described by Mario, acting within the moral system is not subtle and requires one to take on a chastising role in order to encourage peers to react and regain control over their health.

Being concerned is an important message transmitted in the sense of duty towards one another. Although these men are not trained mental health professionals, being attentive and showing genuine compassion has a positive impact on the wellbeing of all parties involved. Benedicto exemplifies this authentic interest for the wellbeing of his peers, an attitude that is reciprocal:

You have friends that support me and I do the same. When I see that a friend of mine is depressed I say "talk to me, come here and let's talk." They vent out about what is happening to them. The depression, depression is something many homeless experience because they don't have a home, because they don't have food. That still happens. In the level I am right now I am able to help others and teach them how to help themselves, just like I've helped myself. And they can do it for someone else.

The concern for others is a virtue that he hopes is learned and carried forward. For him it is a sign of character to live well with HIV: "Everything that I have I share. When you share, since I have received so much, when you share you feel something else" he commented during the interview. Explaining the point further he remarked, 
You are at the same level with that person and when you help they take the opportunity to say "thank you" and they look and they say "wow, this is my friend." When you give your friend you shirt, when he doesn't have one, it's something positive. That's because you want to see him feeling better.

Benedicto points to the need among these men to feel accompanied, loved, and cared for, tangible expressions that demonstrate that they are not alone. Whether they have been rejected or not by families and friends, they are aware that the support from peers is unconditional and comes with an additional understanding that can only be possible from someone also living the same condition.

Being available and prioritizing the needs of others is important for these men; compassion is an attribute embraced by members of the community. In Nestor's case, being compassionate has meant giving his time and resources:

Sometimes I go to a person, I put my arm around him, and tell me "what's up brother, I see that you are sad? What's happening?" "Man, I'm having problems with this and that..." "Do you want to talk, do you want to talk with me?" "No, no Nestor, no. I can't talk about this with anyone. I want to be alone." "I'm going to leave you alone but don't do anything bad man. If you want to talk with someone, call me. Here is my number." I learned that in Casa Esperanza. "Take my number and call me. Whatever you and I talk, lives and dies with us." Once someone called me and we met at the park. I had to use my last \$7 (laughing)!

The sense of duty displayed by these men reinforces the norms and values of the community. Additionally, encouragement and genuine concern for others are not only expected to be received but also given, even if this means emptying the wallet to help, as in Nestor's case. The moral responsibility is a reminder of the culture of the community, promoting healthy living and positive wellbeing for all. When one of the members' health decays, it is a collective reminder that good health can be fragile and, thus, all members are concerned. On the other hand, when a member is healthy it is also a 
reminder that living well is part of the community despite HIV, and thus an encouragement to all.

\section{Positive Cultural Values}

Living a positive life with HIV influences "traditional" cultural expressions of being Latino males. As previously stated, the process of adjusting to HIV promotes an evaluation of all aspects of daily life and generates changes to areas that negatively impact the lives of those with HIV. Behavior generally associated with one's culture is also influenced in this process. In other words, aspects of Hispanic/Latino culture are adjusted in the process of living positive with HIV. Although the interaction of HIV on the culture of these men may not produce such drastic changes as the ones described to their lifestyle, HIV has a positive impact on characteristics of being a Hispanic/Latino male that are linked to living a positive life with the illness.

\section{Illness and Culture - Scholarly Approaches}

The relationship between medicine and culture has been studied at length by medical sociologists, anthropologists, and psychologists (Kleinman 1980; Johnson and Sargent 1996; Mattingly and Garro 2000; Baer, Singer, and Sausser 2003; McElroy and Townsend 2004; Farmer 2006). A primary emphasis of the work conducted specifically in the subfield of illness and culture has been to study the cultural interpretation of disease. The focus of this scholarship has been to describe how different cultures explain, treat, and adjust to disease (Kleinman 1980; Hunt 2000; Mattingly and Garro 2000; Wikan 2000; McElroy and Townsend 2004). Arthur Kleinman is one of the most prominent scholars advocating for cultural interpretive or meaning-centered models. He is best known for the Explanatory Model (EM) framework where he argues that illness is 
not just physical but is also culturally constructed. According to Kleinman (1980:110) "explanatory models are the main vehicle for the clinical construction of reality; they reveal the cultural specificity and historicity of socially produced clinical reality, regardless of whether it is based upon scientific medical knowledge." Building on the EM framework, responses to the increase in interaction among peoples from varying cultural practices have encouraged another important area of study in the field. Cultural diversity facilitated by global trends of people moving across geographical borders has led scholars to explore the interaction between culture-specific medical systems. Of particular interest to these scholars has been to describe how different systems of health come together to form complementary cultural models described as medical pluralism, governed by a layering of choices and preferences reflective of the cultural diversity of any given society (Chrisman and Kleinman 1983).

The theoretical frameworks establishing relationships between illness and culture help us to understand the impact of disease on the everyday lives of people, particularly in the case of chronic illness. Certainly, these approaches are well suited for the study at hand. However, what I want to discuss in closing this chapter is the impact of illness on an individual's perception and performance of culture itself. More specifically, the task for this last section is to describe the influence that living in community with HIV has had on some traditional male Hispanic/Latino cultural practices. With this in mind, this section focuses on the micro-level of the intersection of culture and illness, and, thus, explores the individual as the unit of analysis instead of the larger group to which he belongs. This, I believe, can provide additional insight into the daily life of these men within la comunidad without making claims for the larger Hispanic group. 


\section{Machismo and Familismo}

During their interviews, the Puerto Rican men described significant changes to their behavior and conduct. These changes also affect how they live and experience important values associated with being part of the Latino/Hispanic culture. A common theme among these participants was performing the norms associated with certain cultural values, primarily to machismo and familismo. As important and predominant as these cultural norms are for Hispanics, in terms of HIV, these attitudes represent equally important protective as well as risk factors for HIV (Table 12).

\section{Table 12: Hispanic cultural values as risks and protective factors for HIV}

\begin{tabular}{|c|c|c|}
\hline Cultural value & Risk factor for HIV & Protective factor for HIV \\
\hline Machismo & $\begin{array}{l}\text { - Multiple partners } \\
\text { - Sexual aggressiveness } \\
\text { - Male domination } \\
\text { - Arrogance and risk taking } \\
\text { - Homophobia }\end{array}$ & $\begin{array}{l}\text { - Protection of family } \\
\text { - Provider and caretaker } \\
\text { - Leadership } \\
\text { - Positive role model }\end{array}$ \\
\hline Familismo & $\begin{array}{l}\text { - Negative view of homosexuality } \\
\text { - Ostracizing gay/bisexual family } \\
\text { members }\end{array}$ & $\begin{array}{l}\text { - Close connection with family } \\
\text { - Cooperation } \\
\text { - Social and emotional support }\end{array}$ \\
\hline
\end{tabular}

Machismo is a value emphasizing masculinity based on the traditional role of the male as the protector and caretaker of the family. Although valued by both men and women as a caring and strong characteristic, machismo also has disempowering and negative properties (Marin 2003; Sears 2008) which can significantly impact the spread of HIV. As a risk factor, machismo is often associated with the risky sexual behaviors Latino men engage in to prove their manhood and reinforce masculinity, including having multiple partners (Marin 2003; Levy et al. 2005), casual sexual relationships (Pleck et al. 1993), and engaging in unprotected sex (Diaz 1998; Galanti 2003; Marin 
2003; Jarama et al. 2005). In addition, the male pride exercised through machismo authority limits women's ability to negotiate the use of a condom and question when partners suggest the use of one. The outcome is that the machista male gets his way-unprotected sex over the will of women (Sears 2008).

Machismo beliefs also promote negative perceptions of homosexuality and increase homophobia (De La Cancela 1986; Ortiz-Torrez et al. 2000). The strong "macho man" image rejecting homosexuality often leads to self-imposed identity censorship. This was supported by the experiences of gay participant in my study such as Rudy:

That was what made me end my marriage. After three years of marriage my wife wasn't getting pregnant. So I knew that I liked men even though I had never been with a man. But I always had that on my mind...men, men, men.

Because of strong pressures to conform to this cultural norm, many gay/bisexual Latino men choose to hide their sexual orientation, resulting in increased risky behaviors contributing to the spread of HIV (Diaz 1997; Dolezal et al. 2000; Marin 2003; Diaz et al. 2004; Levy et al. 2005).

Familismo refers to traditional family values emphasizing the reliance on family (Herbst et al. 2007; Perez et al. n.d.). Specifically, familismo refers to loyalty, reciprocity, and solidarity among family members. Additionally, the family is recognized as a member's primarily if not sole source of support, inspiration, and strength. Familismo is associated with protection of the family even against its own members (Marin and Marin 1991). In this sense, family is valued above the individual, a notion akin communalism versus individualism. Because of this close intimate bonding, rarely 
are family ties disrupted, except in extremes cases (i.e., homosexuality). Although the strength of the family is highly valued for its social and emotional support, familismo has been identified as a source of tension for gay/bisexual Latinos and their families since homosexuality is not perceived to be part of the traditional family (Herbst et al. 2007; Zea et al. 2004) and thus threatens familismo. The alienation of homosexual members or denial of homosexuality to maintain the cohesiveness of the family is often associated with hiding the gay identity and increased risk behaviors, similar to the pattern associated with machismo. Consequently, this tension has been linked to the separation of gay/bisexual Latinos from their family and the reduction of family support (Marin 1998). Gabriel, for example, illustrated this point. He opted to move away from his family as a way of managing being gay:

My sister was the first person that knew that I was living with a man. I grew up in Connecticut and I went to live to New York so nobody would see me, so they couldn't find out about my life. But little by little I started telling them, thank God. I told my parents before they died. Long time before they died I told them. Well, I told them I was gay but not that I had HIV.

Among Hispanics diagnosed with HIV, men often avoid disclosing their HIV seropositive status to family members, thus forcing them to seek alternative sources of social and emotional support (Zea et al. 2004).

\section{"Positive" Machismo and Familismo}

In their HIV infection stories, my respondents often spoke about the negativity they felt from their families owing to the twin values of machismo and familismo. Here is a selection of their descriptions:

Well ... I knew I was gay since I was a kid, and I started young, at 14 years old. When I was older, I finished school at 18 and I went to live alone, I 
left my house. After, I began to sleep with men without using protection. So I stayed on the street, on the street, on the street, earning some money. So it got to the point that I started using drugs, and then I didn't care about anything. Since I was young, I did not care about anything. I don't care who I was having sex with, because the drugs, I was like selling myself. Because I did it, not because... so the day I got infected I knew because I heard talks about how that is transmitted. So I decided to get tested.

Pablo, infected with HIV from having sex unprotected sex with men

I [had] two lives. I had my street life and my home life, and I always tried to consciously separate them. I tried not to bring my problems from the street to home, or to take it out on my stepchildren or on my wife women, although we had some time we had arguments and there were several fights. But what happened is that she died [of AIDS] and I was in prison. I was taken to see her with shackles on. It was embarrassing, but it was to say goodbye. I couldn't consciously not do it. Well, after that well...I have been very quiet.

Carlos, infected with HIV from injecting drugs

Yes, yes because I know I was sleeping around with many low class women, low class women, women of the street. After I separated from the mother of...because my two children are from different mothers, so when I got separated from my daughter's mother, I started with my son's mother. So, when my relationship with my son's mother didn't work out either, I didn't want to lose her, but I was doing things that didn't make her happy. So, then we had a lot of fights and stuff. So to not be fighting so much, we said let's take... well it was her decision, she couldn't handle it anymore. But then, that was hard on me, so I started more, double more, what I had been doing. What I have been doing I started doing even worst...staying out every night with women.

Marcos, infected with HIV from having unprotected sex

These narratives document how these cultural values played a significant role promoting the men's risky behaviors that led to their HIV infection. On the other hand, the stories described by the participants indicate that post diagnosis, the same cultural values become protective. As explained below, the values become incorporated into the living positive lives with HIV. 


\section{Being a Positive Macho}

During the interviews, men described how their HIV status awakened their awareness of the importance of family life. They recognized that they had lived careless and irresponsible individualistic lives, often linked to drugs. After diagnosis, they began to desire to reconnect with loved ones. Restoring the relationship with their children was described as a priority for many of the men interviewed to reconnect and have a presence in their lives. "I also wanna talk to my daughters," declared Felix ${ }^{28}$ as his personal goal. He further explained his desire: "I haven't seen them in over 10 years...One is 30 and the other is about 29 . Then I got another son he is like 20 something...They don't even know I'm still alive because I left New Jersey and they were living in New York. They don't know where I'm at." Felix's long detachment from his children is not unique. In fact, it was a common experience reported by men. And it's not that unusual among Latino men even without the involvement of drugs. ${ }^{29}$ Recounting his relationship with his children, Victor explained the nature of this pattern:

I was a father that forgot my kids because while I was on the streets I never remembered them. So now that I got sick, so then, fuck, before I die I have to give...it's like, like I say...I have a term limit, I'm going to last less. So I am going to try that this time to be more...more...more favorable to my life and my children. That they can remember me more and love me more.

Like Victor, other interviewees made similar decisions to be better family men upon receiving the HIV diagnosis. For them, the clock "ticking" in their lives motivated them to get closer to their families and mend the relationships with their estranged children.

\footnotetext{
${ }^{28}$ English-speaking respondent - text in original language of interview.

${ }^{29}$ Among Puerto Ricans non-married females comprise $17 \%$ of the head of household with children under 18 years of age; $12.4 \%$ among Latinos (18\% Blacks, 9.6\% Whites) (American Community Survey 2009).
} 
The pressure imposed by the HIV diagnosis is reflected in the involvement with their children. "Well, now I'm...I'm in contact with my kids every day. I call them every day," commented Tomás describing the dynamic he has with his children after being diagnosed with HIV. He added, "I am there for them. When they need me I am there for them. I give them advice... advice about how I used to be and how I am now." Similarly, $\mathrm{Leo}^{30}$ spoke of the need to be a responsible and involved father despite being HIVpositive. For him, caring for his family meant taking the effort and passion he had for drugs and redirecting it towards his wife and child. "I am still not properly clean, even though I have not used since February, ${ }^{31}$ " he commented, "but I realize now I have a daughter, so I have responsibilities. I am married, I am legally married now. So that's my drug of choice now, my wife and my daughter."

Another positive expression of machismo adopted by the men involved taking the role as primary caretaker of family members. In some cases, this situation arose in response to assuming an expected cultural role in Hispanic families, such as caring for older parents. Marcos faced this situation:

I have my mother living with me. I brought here with me because she got sick in the mind, she got Alzheimer's and my brother couldn't take care of her because he is working and didn't want to leave his job. She needed someone looking out for her all the time. So my brother put her in a nursing home. When I found out that she was in a nursing home, I didn't think that was right, and I got really mad with my brother. I told him "why didn't you bring her to me?"

For Marcos, taking care of his ill mother was a cultural duty. Other men also reported assuming the care of parents to give them a better quality of life, something they would

\footnotetext{
${ }^{30}$ English-speaking respondent - text in original language of interview.

${ }^{31}$ Interview conducted in September of the same year (2009).
} 
not have considered while living their previous negative lives. For example, Mario brought his mother from Puerto Rico to Boston to get her better heath care.

So my mom has a lot of back problems and she was fighting with the Social Security in Puerto Rico. But in Puerto Rico she wouldn't have accomplished anything. So I told my mom "mami, come here, to Boston, Mass." So, we got here and immediately I look for...she got the Social Security, SSI. She already had surgery, thank God, her back and now she is like new.

Assuming the caretaker role extended to family members involved in precarious situation as well. Providing relatives with a safe place to live was a reason to become involved in the lives of family members. Antonio, for example, brought his nephew to live with him from North Carolina to get him away from a negative environment. For Antonio, it became an opportunity to mentor and encourage his nephew to live a proper life.

Like the other day that my nephew was here, I was talking to him and I told him "you don't have to do drugs to live life well. What you have to do is study. You are young. Look at this example here (talking about himself). You don't need another example. With me and what I'm saying is enough. I've been through everything. Listen to me. So, you go and study. Pick something you like that you feel...that you can wake up in the morning and say "shit, I am going to work but I love this job." So, I try to get that into his head because he has gotten in a lot of trouble. That's why he is here.

Taking a more proactive role in their own care was also reported frequently by many men, pointing to a significant change in the attitude towards self-care.

Traditionally, Latino men delay treatment and avoid routine medical care (Rodriguez 1983; Reinert 1986; Schwab and Simmons 1989). The delay in care among Latino men is often the reason health conditions go untreated for extended periods of time and develop into major illnesses (Reinert 1986; Higginbotham, Trevino, and Ray 1990; Spector 1997). On the other hand, according to the participants, the HIV diagnosis alters 
their traditions of delaying care. Instead, men take a more proactive approach to caring for their health. "Now I take better care of my health," commented Tomas. "Any pain, anything at all, I immediately go straight to see the doctor." Rudy also noted the change in the way he takes care of his health since being diagnosed with HIV. In fact, like Tomas, he does not take any symptom for granted:

Before I didn't worry about my health I didn't think about dying, I thought that I was indestructible. Since I found out that I have the virus I take a care of myself a lot, I am always looking out for my health. Every time I feel a symptom or something I go running to the hospital or I call my doctor. I am very aware of...I listen to my body.

These cases illustrate how the men have changed behaviors normally associated with a traditional macho attitude and adopted a different approach to their health-yet still one appropriate for men in that they are family leaders. In fact, as described in previous chapters, keeping regular medical apportionments is common and internalized as part of a new life with HIV. The intensive care has benefits, and in the case of Victor, it saved his life:

Yes because if I wasn't infected with HIV I don't think they would have found the prostate cancer or the liver cancer. When they would've been found I would have be dead. I would have kept doing drugs. I wasn't a guy of going to doctors. No, man, I didn't have to go for anything. But since... once I was HIV, I adopted a regime of going frequently to the doctor, every two months to do labs. So, every 6 months I get a lab and a physical. So out of those labs, we found the other illness, otherwise I would have been dead.

On a lighter note, men also reported engaging in activities normally not expected of "macho" Latino men. Life circumstances have forced them to do untraditional chores, particularly around the house. For example some of the best times for Minor are spent with his buddies cooking at the substance abuse residential program where he resides: 
Oh, we cook everyday and we always make a plate or two for those who don't have food. We cook intense...rice, steak, pork chops...roasted pork...mofongo, lasagna, pastries; forget it, we do everything! My mother taught me how to cook everything.

Unlike Minor, Ramon was not instructed in domestic work, but he soon learned after becoming independent and living on his own. Although he admits it has been a humbling adjustment, he makes the best out of his new situation:

I have an apartment and have it like all trendy...I do the cleaning, and cooking. I had to learn brother. Going to a supermarket, and having to get a shopping cart and pay with the blue card, the one for food stamps. That is women's stuff. In the past when I was with women I said "you go and do the shopping, you do the laundry." No, now it's me. I gather the dirty clothes in a cart and go do the laundry. It's better, I meet people. I meet pretty women doing laundry...(emphasis mine)

As already presented, men acquire a greater respect for women in the way the women treat them and protect them from HIV. However, whether the newfound value and respect for women facilitates engaging in activities normally performed by women is difficult to assess from these interviews. Though not evident from my data, living in the community, being exposed to different dynamics and culture, may influence the crossing of these otherwise traditional Latino gender lines to assume different roles, notwithstanding, still having a resemblance of traditional machismo in the process ("I meet pretty women doing laundry").

Being Gay is Okay.

Homophobia among Latino men is well documented in the academic literature and even encouraged by popular culture (VanOss Marín 2003; Diaz 1997; Muir and Seitz 2004; Leiner 1994). Interestingly, during the interviews some men described the changes they experienced in their attitude towards gays after the HIV diagnosis. Elsewhere 
(Chapter 3), I discussed Benedicto's acceptance of gays after being diagnosed with HIV.

He was very eloquent when describing his transformation. Before his diagnosis he was very homophobic ("I'm very sexist, I am a macho man, yes me!") but has since become a gay advocate, condemning discrimination towards gays. He was not alone in this transformation. Orlando experienced a similar change after spending time with gays at different HIV agencies and programs.

Orlando: You also learn. Because right now here in the Boston Living Center, there are a lot of gays and I share with them and they respect me. As long as they respect me, I don't have a problem. And you also learn from them, because many of them are intelligent. You learn, yeah.

Interviewer: And before, did you see people the same way or not? Orlando: No, I saw them different, they made me cringe. When saying "hi" or anything, I'm being honest. If I'm going to be honest, that was it. I was afraid to talk to them because someone else could say something. And now anyone, a Boricua, because there are many Hispanic gay people and they ask me for a ride in my car and I take them without a problem. I do not have that complex anymore.

When I asked Leo ${ }^{32}$ about how he felt about the diversity in the HIV programs and his experience socializing with gays in HIV groups, he also brushed off the difference as insignificant.

I am not gay, but I go there and there are a lot of gay guys friends. I know they are gay and that doesn't bother me. I respect them fully and they respect me. And there is a lot of them that say "so when are you going to leave your girl to come with me?" And then, "come on stop, you know." But then I talk to them as friends... They give me advises. They tell me "stay focus. Keep your head clean. Stay clean. Do the right thing."

Although reported less frequently, half of the men who reported being rejected because of their homosexuality recounted that their HIV diagnosis also produced

\footnotetext{
${ }^{32}$ English-speaking respondent - text in original language of interview
} 
important changes in relationships damaged because of negative views on homosexuality.

Individuals reported making an effort to get closer to their estranged families to mend relationships despite their sexual orientation. For example, Hernán, a middle-aged gay man had not had contact with his family since he was a teenager because of his sexual orientation. Having family support was important to him, but it was not forthcoming until he was diagnosed with HIV. This was his experience when he shared his diagnosis with his sister.

Yes, I had to convince [my sister] because when she, when I first told her (HIV diagnosis) she hit me with the thing about that [gays] should all be put against the wall and executed! Those are the attitudes. So I had to...but look, she was the one that called me and she was the one that said to me "well, brother, let's talk. I don't agree with homosexuality, it is against the laws of God, but you are my brother and I love you." And I said, I said to her, "well, at least." So then, with her I have continued having a relationship."

Hernán still does not enjoy a close relationship with his sister. But as he commented during the interview, having ongoing contact with her is an improvement compared to the lack of contact he had previously during most of his adult life with any of his family members. Rudy also reported some contact with family, characterized much like Hernán's situation. "The only [in my family] is my mother, my mother and my little sister. They have welcomed me. But beside them, all silence." Both these men are content with the changes, but acknowledged to me that their individual situation with their families is far from being perfect. Interestingly, these changes, as in the case of the other guys befriending gay men, were in response to, and perhaps only because of, the HIV diagnosis. 
As these narratives suggest, some men experienced changes in attitudes specifically associated with being a Latino man. For some, the transformation was a sharp change in attitude, as in the case of Orlando's beliefs about gays. In others, the change was more subtle, a bit less of the protective demeanor associated with the macho cultural role. Although brief, this discussion that engages these changes is important because it provides an additional positive impact from living a positive life with HIV. In addition, although brief, the discussion presented in this section can serve as a starting point for future research to understand, perhaps, the impact these men and the changes they embrace can have on their children and the families to protect them from engaging in risky behaviors, drugs, and even HIV.

\section{Chapter Summary}

Marathon runners, community leaders, peer counselors, public health advocates, and even White House honorees are not the typical images associated with HIV-positive people. In fact, these are probably not at all the associations that come to mind when HIV is mentioned. The most significant exception to this is perhaps Earvin "Magic" Johnson, the NBA basketball star from the Los Angeles Lakers. In 1991, at the height of his professional career with the Lakers, he disclosed that he had been diagnosed with HIV. Magic Johnson's announcement had an immediate impact on the perception of HIV, changing the public opinion and awareness about HIV (Kalichman et al. 1993; Sigelman et al. 1993; Brown and Basil 1995). In an instant, Mr. Johnson changed the face of HIV in the minds of Americans not only by educating others on how transmission takes place, but also by bringing awareness to the fact that even the socially privileged were at risk (Kalichman et al. 1993). Since his announcement, his celebrity status has 
been central to his efforts in fighting HIV, spearheaded by the "I stand with Magic" campaign, a nationwide HIV prevention campaign to end Black HIV/AIDS in the U.S. (www.magicjohnson.com/foundation/).

The men I interviewed alter common stereotypes about HIV as well and work to change the face of the illness despite not having the celebrity status of Magic Johnson. They are involved in similar processes in the de-stigmatizing of HIV through the ways they improve the quality of life - theirs, their families', their communities' and others'. They do positive work by engaging in practices to promote HIV awareness, influence youth with positive role models, and empower families by restoring relationships and assuming rightful responsibilities. Unequivocally, these efforts positively improve the perception others in their social networks have about people living with HIV. Living positive lives not only contributes to the overall wellbeing of the individual and his immediate relationships, but it redefines what HIV means to the broader society. Being HIV-positive is now more about living than about dying. As these men demonstrated with their HIV stories, living positive lives is about determination and perseverance to overcome challenges. Their stories are evidence of how the HIV experience has changed them for the better. Ultimately, they take pride in these transformations and they are proud to be living positive lives with HIV. 


\section{CHAPTER VI.}

\section{CONCLUSIONS}

This dissertation investigated a social phenomenon, community, specifically a community lived among a population whose numbers are increasing at an alarming rate: Puerto Rican men living with HIV. La comunidad, as they refer to their community, is built upon a foundation laid by community service agencies and tailored to the men's emotional, social, and psychological needs and accommodating their cultural characteristics as well. La comunidad is the outcome of prolonged shared affirmations to live with HIV by engaging in positive behaviors and by adopting healthy lifestyles - a clear contrast to the negative perceptions and death-saturated images often associated with an HIV diagnosis. Common perceptions of the HIV-infected as well as much research to date tends to portray them as multiply marginalized, the victims of illness, stigma, social exclusion, and poverty even if, as many would assert, the men's own behaviors brought such misery upon themselves. As revealed in the pages of this dissertation, these are indeed experiences the men live daily. However, this study goes beyond the shared negative experiences of being diagnosed with HIV. Instead, these Puerto Rican men in Boston are presented as actors who build community on the basis of shared positive practices and strategies for living healthy with HIV. Along with other HIV-positive peers who have also chosen to live this way, they promote, protect, and sustain the very community that influences and supports their decision to adopt positive transformations in order to live long term with HIV.

The notion of symbolic community proposed by Anthony Cohen (1985) is presented as the theoretical foundation for this study. In this dissertation, I applied this 
concept specifically to explain the process of community formation, not merely as a byproduct of the exclusion these men suffer, but, instead, by analyzing the responses to live healthy with HIV as driving the community-building process. The life changing impact of HIV sets the stage for an environment (emotional, social, and structural) where people living with HIV come together to negotiate and form a unique cultural community expressed in norms, beliefs, and practices that, although centered on HIV, are designed for living healthy. These expressions are the community boundaries that are defined and maintained in everyday settings by the men. The boundary-work framework, as adapted from Gieryn 1983, Lamont and Molnar (2002) and others, complements the analysis of community and provides the ideal approach to analyze the agency of these men embedded in the affirmation process giving meaning to la comunidad.

This study of la comunidad turned out to be more than an intellectual exercise in using a cultural lens to understand how people living with a specific chronic illness create their own community. Beyond the illness-specific norms, beliefs, and practices defining community, the collectivity inspired by symbols, and the communal bonding produced by rituals and traditions, the study is more than just about people living with an incurable medical condition. The study is about transformed lives, which is the principal finding I aim to transmit in this dissertation. As I argued already extensively yet which merits one additional explicit mention, this transformation takes place in the context of community, with the support, encouragement, and at times, "disciplining" of others. La comunidad is a place where lives are transformed and where these men, perhaps not exclusively, learn, adopt, and experience "positive living." 


\section{Contributions}

This dissertation makes a strong contribution to the literature of community, particularly in applying the concept to further develop understanding of how communities are formed and sustained. Many scholars assert the existence of community and thus analyze a community's characteristics; fewer devote their analytical time to documenting the processes behind community formation and sustenance. In my approach to analyzing community, I give much emphasis to the processes the actors themselves design and engage in when forming and maintaining their community. By doing this, the analysis focuses on the internal processes, community expressions, and the negotiation of boundaries allowing for a conceptualization of community driven by the meaning assigned by the actors themselves to its norms, beliefs, and practices. This makes community less the outcome of blackbox processes and further develops its conceptualization without perpetuating community as a loose social category empty of meaning. This approach to community, I believe, can be replicated to study similar populations in different social settings (HIV-positive Hispanics in Miami), other groups affected by HIV (African Americans), those with different chronic illnesses (diabetes, cancer, etc.), and newer stigmatized conditions (war veteran amputees and those suffering from post-traumatic stress disorder).

For example, in Chapter III, I was able to demonstrate the external-internal duality (structure-agency) involved in community formation with an analysis of boundary-work. The community building blocks constituted by structural factors set the conditions for community to emerge out of social exclusion. In this case, the stigma is administered simultaneously with the HIV diagnosis, predisposing HIV-positive people 
to be categorized as separate from the general population (and in need of being separated from that population to avoid contagion). However, as discussed at length, people who experience exclusion do not necessarily form community. Many persist as isolated individuals. What I found, however, is that some people find community even in exclusion and it is critical to observe how they negotiate community belonging as well as create the characteristics of belonging. These active individuals, the "otherized," are the primary actors inventing and regulating the norms, beliefs, and practices that ultimately define the community, whether it takes place within the context of exclusion or otherwise.

In this study, I explain that la comunidad is not built in response to social exclusion, but primarily in response to the illness, and the distinction is important. Although, the stigmatization of HIV-positive people is ongoing, the practices of living healthy to survive with HIV are the factors driving the formation of a community among these men. Community, thus, is not shaped by social exclusion; the greater reality affecting the people involved shapes the community-building process: surviving and living long and prosperous lives despite being diagnosed with HIV.

In its detailed attention to the building blocks and processes of community formation and sustenance, this study also contributes to understanding the notion of an "HIV community" popularly used in the HIV/AIDS literature. In that literature, the existence of an HIV or AIDS community is presented as a matter-of-fact static entity assigned to a population without much explanation, description, or concern for what it entails (Klosinski 2000; Shenoi et al. 2009). A study by Roth and Nelson (1997) of HIV diagnosis rituals and identity initiated a different conversation of the HIV community. 
For them, the AIDS community is not to be taken as a given and their study identified the processes involved in community membership, challenging the notion that a diagnosis is sufficient to belonging to an HIV/AIDS community. Their work was insightful in linking HIV/AIDS identification to a community that is a complex social construction. However, they did not study the community in depth. My study builds upon their work while also addressing this gap by exploring the building blocks, processes, and practices that are specific to the HIV community described by these Puerto Rican men. Understanding community as a social construct with its own norms, beliefs, and practices is important because it is within its unique social environment that members acquire the culture of being HIV-positive and redefine what it means to be an HIV-positive person, in other words, is where the re-formulation of the self (HIV-positive personhood) takes place for these men. As Chapter IV of this study describes, in la comunidad, these men learn about living with HIV and adopt positive lifestyle choices to enhance their quality of life. In the process, they engage in practices that challenge the perceptions of HIV and destigmatize HIV with everyday practices.

Community as a social construct was further highlighted by the process of socialization taking place in the lives of these men after the diagnosis. As noted, the socialization into the HIV world is initiated once the individual receives the HIV diagnosis; however, identifying and being part of the community take place once the individual accepts his new condition and adopts the norms and values of the community. For these men, learning to be part of la comunidad takes places in everyday settingsparticipating in support groups, attending lunch at an HIV agency, and during informal encounters in the street. Many of the men, as illustrated in this study, experienced drastic 
changes in their lives as they learn to live new lives with HIV from and alongside others. In fact, adopting healthier lifestyles and living positive lives are expressions of belonging by sharing in the community's values and norms. For example, being proactive against their drug addiction, engaging in exercise and eating well, even rejecting previously held homophobic attitudes are important changes reflecting the new values and norms learned within la comunidad.

The dissertation also makes a contribution to the anthropological literature of rites of passage. Many authors have identified a diagnosis as a rite of passage that transitions patients diagnosed with chronic conditions (Holohan 1977; Charmaz 1991), sexually transmitted diseases (Nack 2008), and even HIV/AIDS (Roth and Nelson 1997) into the community of the sick. Resting much of the analysis on Victor Turner's concept of liminality and the boundary-work framework, I was able to demonstrate that receiving an HIV diagnosis does not automatically denote that the transition into the HIV world from the healthy world of the "normals" has been completed. In fact, as anticipated by Turner, upon receiving an HIV diagnosis, these men experience ambiguity, anxiety, loss of identity, and an increased dependence on others--all characteristics of a liminal stage. The liminal stage varies in length of time and can extend for years until acceptance of the HIV condition is achieved and the joining of the community is finalized with rituals of incorporation, thus ending the rite of passage. This is key because the communitas emerging from the liminal stage described by Turner takes place under different conditions in this community and, I would expect, in other illness-communities because medical diagnoses do not take place collectively. Yet, communitas is very relevant in the construction of a community among diagnosed individuals because it cements the sense 
of belonging towards the community of peers. In this case, however, communitas is not experienced during the transition stage with the diagnosis, but is a product of integrating into the "illness" world with others who share similar experiences of illness, including similar experiences of diagnosis. In addition to contributing to expanding the knowledge of rites of passage, this information can help to formulate approaches to better assist newly diagnosed individuals. Being mindful of the complexity of the liminal stage post diagnosis will help to develop interventions that are conscious of the readiness of the individual to accept treatment.

My study makes significant contributions to the literature of boundary-work. Specifically, it highlights the effectiveness of the framework in identifying the process of community formation from the members' perspective. The boundary-work approach, as described at length in chapter 3 , unpacks the complex agency-driven community building process by highlighting the practices responsible to drawing and reaffirming boundaries defining community. In addition, I believe that my study extends the application of boundary-work to showing that "policing" need not be negative. On the contrary, as shown in this study, the disciplinary practices intended to maintain the boundaries of a community serve as important practices to assuring the well-being of the community and the health of its members.

On a related subject, while chronicity was not a primary framework in the discussion at hand, I believe, this study acknowledges the contribution of this scholarship by depicting the long-term adaptations to HIV. From this perspective, my study makes a contribution to the literature of chronicity by exploring the long term adaptation to HIV among the Puerto Rican community. Furthermore, examining the collective negotiations 
of living with HIV, looking at the processes involved in community building, given the stigmatized chronic nature of HIV, is nevertheless, an important characteristic of the chronicity of HIV. Such contribution is a challenges future research in chronicity to examine collective expressions and constructions of the "ill" that are equally "socially and culturally defined and lived" (Estroff 1993:250) as the illness itself.

Finally, this study makes an important contribution to the understanding of the lives of people living with HIV. The literature has described the processes of adjusting to non-stigmatized chronic illnesses and conditions that may become "de-stigmatized" with positive behavior change (e.g., alcoholism among recovering alcoholics) (Cain 1991; Humphreys 2000). In describing the lives of these men, important questions have been answered addressing the processes of adjusting to stigmatizing conditions among marginalized groups. Does adjusting to HIV mirror the process of accommodating to the life-changing impact linked to other chronic illnesses? What strategies do marginalized people employ to cope with HIV as a chronic illness in the U.S. that may differ from accommodating to other illnesses? How is the stigmatized notion of HIV managed, negotiated, and reframed with new meaning?

Through the stories of these men, I was able to describe the experiences embedded in adjusting to the chronic condition among a population affected by combined social stigmas and marginality. Through the pages of this dissertation, particularly in Chapters IV and V, I showed how these men adopt and internalize the norms of the community that help them to adjust and live long term with HIV in an environment that is supportive and health promoting. Coping, as illustrated in the dissertation, is not an individual process, but it takes place as part of a larger social unit involving agency and 
action in the community. Communal coping reinforces the notion of community by encouraging others to live healthy lives and to become actors in the prevention of HIV. The characteristic of la comunidad to encourage and promote wellbeing is important because it gives meaning to being HIV-positive and to the notion of living healthy. $A$ comunidad's impact in the health of its members, I believe, has important implications for public health, as discussed in the recommendations below.

\section{Recommendations}

Adopting a positive and healthy lifestyle has many advantages for people living with HIV. As demonstrated in this study, when done as part of the expected norms to belong to a community, adopting a positive and healthy lifestyle has a greater impact on the quality of life of HIV-positive people which, in turn, can have important ramifications for the greater healthcare system (e.g., better access to care, lowering costs of health care). Equally, given the impact of accountability in living positive lives that is encouraged and expected in la comunidad, embracing healthy lifestyles and living positive lives are important prevention strategies that minimize the risk of these men exposing HIV to others. Public health professionals working on developing effective prevention strategies may find it useful to understand how these internal patientadministered systems of accountability function as part of the culture of the community. In society, social context not only explains patterns of infection, but can also inform effective ways of preventing transmission. As Schiller and colleagues (1994:1337) wisely noted "the spread of the HIV infection and, consequently, AIDS is the product of human behaviors enacted in social contexts. Both the behaviors and the circumstances in which they occur are conditioned and shaped by culture and the larger social structure." 
Thus, specific social contexts (e.g., la comunidad) where people's lives are transformed may provide insights into strategies for not only coping with but also preventing the spread of HIV.

Other important recommendations to HIV services can be derived from the study. During the interviews, an interviewee angrily noted how some of his peers preferred to spend time shooting pool instead of attending support groups. His concern was that their poor attendance will jeopardize the support group since funding might not be justified for a group with low participation. In an age of scarce funding, his concerns are valid. However, this scenario depicts an interesting preference these men have. The data from this study show that much of the learning about HIV, encouragement, and reinforcement to live positive with HIV takes place within informal settings. This "informal HIV care" is a byproduct of spending time with each other, reinforcing the norms and values of the community, which contributes to the overall health of these men. Providers working with HIV-positive populations may find it useful to explore the importance of "informal" settings and expand the idea of treatment to include non-traditional venues and rituals such as "pool tournaments." Perhaps in these settings care can be provided with programs that focus on facilitating "socialization" instead of trying to force people to join a group they do not feel comfortable with or just to save a program from losing funding. Whether it takes place in a support group, while having lunch, or around a pool table, such informal interventions may better serve the needs of HIV-positive people by providing opportunities where they can engage with each other, develop trust and intimacy, thus promoting community building. 
Given the communal and social approach described by this study to adjusting to living with HIV, I proposed looking at existing interventions that can be modified and tested without having to start from scratch. Interventions that may provide particularly useful tools are those that have been successful in addressing trauma from a collective, community-oriented approach. For example, Project Joy (http://www.projectjoy.com), a Boston based organization, uses the concept of "playfulness" in providing services to children suffering from trauma. Project Joy "uses the power of play to heal and strengthen children whose lives have been deeply impacted by trauma. [The] mission is pretty simple. It is to ensure that nothing destroys the playfulness of children" (http://www.projectjoy.com). The project emphasizes collaboration, but the goal is to release stress and build community, have fun, and enjoy and share in joyful activities. Can this concept of "joyfulness" be applied to adults living with HIV? Can a similar intervention addressing trauma, anxiety, and depression with an informal approach to encourage positive community building be effective in addressing the impact of HIV? Public health professionals and health care providers can benefit from assessing interventions like Project Joy to challenge conventional interventions by developing, testing, and evaluating nontraditional approaches to fostering community as a form of care for HIV-positive populations.

Any recommendations to better the lives of people living with HIV unequivocally need to take note of the impact of social stigma. Although stigmatization was not a central component of the themes developed in this study, stigma nevertheless plays an important role in the lives of this group of men. As discussed in Chapter III, HIV continues to be categorized as an illness pointing to its victims' morality. One hopes that 
this widespread perception has diminished with the information available about HIV and AIDS, and according to reports, that seems to be the case compared to ten years ago (Herek et al. 2002). However, as witnessed by the men in this study, enacted stigma and discrimination are still part of the experiences of people living with HIV. The structural processes that permit and promote stigmatization to endure are part of our social fabric and have been part of society for centuries. For this group of men they also include in addition to HIV, the historical colonial relationship between Puerto Rico and the U.S. as well as the poor socioeconomic indicators linked to the migration experience, and their second class citizenship status. That, however, need not be a justification for the ill treatment experienced by people diagnosed with HIV/AIDS today. Thus, research and policy efforts must address the social stigma, discrimination, and exclusion that persist against people living with HIV/AIDS. One avenue which I have pursued fully in this dissertation is to examine how those affected by diseases, particularly diseases laden with moral and other stigmas, can and should be actively involved in building communities in which they can hold themselves accountable for their own health and health improvements, not only the greater health-providing structures surrounding them. Indeed, a potential application of the research in this dissertation is to enable the medical community to lower treatment costs for chronic diseases such as HIV/AIDS through the deliberate cultivation of patient communities. I do not mean to suggest that the medical/support services community create these patient communities; rather, I recommend that those involved in the medical treatment/support services side of disease be trained to identify potential leaders of self-help communities such as that I witnessed among Puerto Rican men in Boston and to assist them in developing these communities. 
If patients watch over each other and provide a culturally appropriate and nurturing environment for living positive lives, this can only be good to improve the quality of care and for trying to lower healthcare costs.

\section{Looking Ahead: the Future of Community Studies in HIV/AIDS}

Certainly, la comunidad I describe is not limited to these Puerto Rican men; there is a broad participation of other men and women. In this study, I only interviewed Puerto Rican men. During the limited opportunities I was invited "inside" the community, I noted that other individuals participate and belong to the community. In those opportunities, I also observed that Puerto Rican men are the primary actors driving and displaying the everyday processes of community-building, making them referents and legitimate voices able to depict la comunidad. However, it is necessary that future studies involve the voices of other members, particularly women and individuals from other Hispanics groups to have diverse and border perspective of all involved. Broadening the participation of the sample can answer important questions. How is the women's experience as a member of the community different/similar to the experience of the men? How is the community experience for transgender members? Do they feel accepted and welcomed in the community? Does legal immigration status make a difference in the participation of individuals in community-building and activities? These questions also make me reflect on another equally important aspect of my study. The men in the study live and participate in la comunidad, but what are the experiences of adjusting to HIV of those who do not? What keeps others from belonging to the community? What are the factors that play a role in the need of a "surrogate family" to belong to the community? The analysis of my data demonstrated that family rejection is 
not a predominant factor among this population as only six men reported feeling alienated from their family. Future studies will benefit from considering these questions aimed at exploring the diversity of experience of the members of the community. Also, important to explore are the factors keeping people from not being part of the community. Much can be learned about community from those who "qualify" and have membership rights but chose not to be part of la comunidad.

There are other interesting questions triggered by this research. The majority of these men does not work and have time to participate in the many activities described in the pages of this dissertation. What about single parents raising children that may not have the time to participate in the activities? How about HIV-positive people who have full time jobs? I suggest that future research examine the experiences of adjusting among single parents and those who work while living with HIV.

The research of this study was designed to capture the experiences of these men as they adjust to living with HIV. Of particular importance was the inclusion of how their ethnic Puerto Rican background played a role and was expressed in the $l a$ comunidad. Given that the majority of the individuals comprising the community are Boricuas, this was justified. An entire section of the interview was designed to gather these data. Repeatedly, this inquiry into ethnicity yielded no significant information, in fact, no information at all. This was surprising given that the exploratory focus groups had identified interesting themes related to reaffirming their Puerto Rican identity as important to adjusting to HIV. In these focus groups, this reaffirmation was manifested in their need to recreate Puerto Rican cultural values and idiosyncrasies to cope with HIV; for example, their distinctive sense of humor was noted to serve as a mechanism to 
avoid taking things "too seriously," including HIV. Thus, this is an important discrepancy that needs further attention in the future. I believe participant observation and involvement in the community will be key to shedding a light on understanding how Puerto Ricanness contributes, if at all, to coping with HIV and how it is reflected in la comunidad.

Another limitation of the study derived from the findings concerns gender. I was baffled by the fact that the majority of the community's symbols, the heroes, are actually heroines-women. The fact that the majority of the men I interview identified women as symbols in the community is a noteworthy finding that needs to be explored. The involvement of these women in the community can be analyzed case by case to determine their motivation to engage in HIV advocacy. For example, Iris Rivera became involved in HIV after her husband became ill with the AIDS soon after she was also diagnosed with HIV. Yet, there is also the unanswered question of why this group of men specifically identified women as the key figures in la comunidad and it is an important question that requires further research.

Finally, a limitation of this research, also noted in the Introduction Chapter of this dissertation, is the limited access I had to the community's activities. Participant observation is an important tool in ethnographic research (Bernard 2006). As explained, the nature of HIV requires that maximum confidentiality be granted to individuals to participate in activities, services, even in social settings by the agencies and programs. Although this is extremely important to safeguarding the identity of the individuals and providing a safe environment, it is difficult for researchers to conduct a study on community and observe the performance of community. After nine months of research, I 
was able to have access to support groups and other social activities (lunch at BLC) to perform some observations of the community. Although I was known in the community from my work at a local CBO and I had begun pre-research contact with these agencies a year before I started the data collection, trust takes time and must be earned in the community. I am certain that researchers that can spend significant time in the research field will be accepted and be able to participate in the community. That level of research can contribute to the study of HIV communities and provide a deeper level of understating of these social units. Future research will accommodate these additional data collection possibilities while always protecting informants' confidentiality.

\section{A Final Reflection...}

This dissertation is based on true stories! These are the real lives of thirty-one men. Their stories are representative of many others living with HIV. All is not positive in their lives. As I was seated at an office in an HIV agency in Boston talking to a community leader and an HIV advocate, a phone call came in about a client. He had just been arrested and was going to spend the weekend in jail. The tone of my conversation with the leader changed. Until then, it had been a very uplifting chat about research, programs, people, and families. Now, the news required a more somber tenor. This client's unfortunate development is part of the struggle in the lives of these men: fighting drug addiction, criminal history, depression, rejection, sickness - these are also part of reality for them. The stories described in this study show that they persevere and stay positive, but even among the strongest of them, at times, life can be overwhelming. This part of their lives has not been described in the pages of this dissertation. This tone of their lives is not part of this study. What has been described in the pages of this 
dissertation is the positive tone of their lives, the ones that are seldom written about, rarely heard, and infrequently spoken of: lives of positive living. With this, I did not intend to minimize or ignore the struggles and overpowering experiences these men face daily. On the contrary, with this study I intended to tell their stories and describe their positive lives, despite all these odds. I hope that in making this decision, I have done justice to their lives. 


\section{LIST OF REFERENCES}

Acosta Belén, Edna, and Carlos Enrique Santiago

2006 Puerto Ricans in the United States: A Contemporary Portrait. Boulder, Colo.: Lynne Rienner Publishers.

Adamsen, Lis L.

2002 "From Victim to Agent:" The Clinical and Social Significance of SelfHelp Group Participation for People with Life-Threatening Diseases.

Scandinavian Journal of Caring Sciences 16(3):224-231.

Aguilu, Eduardo

2011 Personal Communication. March 29, 2011.

AIDSinfo

Adhering to My HIV Treatment Regimen. Electronic document, http://www.thebody.com/content/art50168.html, accessed November 20, 2010.

Alba, Richard

2005 Bright Vs. Blurred Boundaries: Second-Generation Assimilation and Exclusion in France, Germany, and the United States. Ethnic and Racial Studies 28(1):20-49.

Alcoholics Anonymous, and Bill W.

1981 Twelve Steps and Twelve Traditions. New York: Alcoholics Anonymous World Services.

Alexander, Jonathan

2002 Homo-Pages and Queer Sites: Studying the Construction and Representation of Queer Identities on the World Wide Web. International Journal of Sexuality and Gender Studies 7(2-3):85-106.

Altman, Dennis

1999 Globalization, Political Economy, and HIV/AIDS. Theory and Society 28(4):559-584.

Amaro, H. and Raj, A.

2000 On the Margin: Power and women's HIV Risk Deduction Strategies. Sex Roles 42(7/8):723-749.

American Community Survey

2009 2007-2009 American Community Survey 3-Year Estimates. Census.gov. 
Amit, Vered, ed.

2002 Realizing Community: Concepts, Social Relationships and Sentiments. Rutledge.

Anderson, Claud and Cromwell,Rue L.

1977 "Black is Beautiful" and the Color Preferences of Afro-American Youth. Journal of Negro Education 46(1):76-88.

Anderson, Benedict

1991 Imagined Communities: Reflections on the Origin and Spread of Nationalism. London: New York: Verso.

Appadurai, Arjun

2003 Disjuncture and Difference in the Global Cultural Economy. In Theorizing Diaspora: A Reader. Braziel, Jana Evans and Mannur, Anita, ed. Pp. 2548. Malden, MA: Blackwell Publishing Ltd.

Appadurai, Arjun

1996 Modernity at Large: Cultural Dimensions of Globalization. Minneapolis, Minn.; London: University of Minnesota Press.

Arkin, William

1978 Military Socialization and Masculinity. Journal of Social Issues 34(1):151.

Atrill, Robert, Jamie Kinniburgh, and Lisa and Power

2001 Social Exclusion and HIV - A Report.

Babbie, Earl

2004 The Practice of Social Research. Thomson Wadsworth.

Baer, Hans, Singer, Merrill, and Ida and Susser

2003 Medical Anthropology and the World System: A Critical Perspective.

Westport, Conn: Bergin and Garvey.

Barth, Fredrik,

1969 Ethnic Groups and Boundaries: The Social Organization of Culture

Difference. Little: Brown.

Baumeister, Roy F., Liqing Zhang, and Kathleen D. Vohs

2004 Gossip as Cultural Learning. Review of General Psychology 8(2):111-121.

Baumgartner, Lisa M.

2007 The Incorporation of the HIV/AIDS Identity into the Self Over Time. Qualitative Health Research 17(7):919-931. 
Bayer, R.

1990 AIDS and the Future of Reproductive Freedom. Milbank Quarterly 68(Suppl 2):179-204.

Baynton, Douglas C., Jean Lindquist Bergey, and Jack R. Gannon

2007 Through Deaf Eyes : A Photographic History of an American Community. Washington, D.C.: Gallaudet University Press.

Be Healthy

2007 HIV: No Longer a Death Sentence. Be Healthy June 7(10).

Becker, Gaylene

1980 Growing Old in Silence. Berkeley: University of California Press.

Becker, Penny Edgell, and Inc NetLibrary

1999 Congregations in Conflict [Electronic Resource] Cultural Models of Local

Religious Life. Cambridge: Cambridge University Press.

Bemayor, Rina, Rosa M. Torruellas, and Ana L. Juarbe

1992 Responses to Poverty among Puerto Rican Women: Identity, Community, and Cultural Citizenship. Centro de Estudios Puertorriqueños, Hunter College.

Bennett, M. J.

1990 Stigmatization: Experiences of Persons with Acquired Immune Deficiency Syndrome. Issues in Mental Health Nursing. 11:141-154.

Bernard, H. Russell

2006 Research Methods in Anthropology (4th Ed.). Lanham, MD: AltaMira

Press.

Bérubé, Allan

1990 Coming Out Under Fire: The History of Gay Men and Women in World War Two. New York: Free Press.

Bhattacharyya, J.

2004 Theorizing Community Development. Journal of the Community Development Society 34:5-34.

Bor, R. and Tilling, J.

1991 Groups for People with HIV/AIDS. Nursing Standard 6(12):50-51.

Bourgois, Philippe I.

2003 In Search of Respect : Selling Crack in El Barrio. 2nd ed. Cambridge U.K. New York: Cambridge University Press. 
Brandes, Stanley H.

2002 Staying Sober in Mexico City. 1st ed. Austin: University of Texas Press.

Brimlow, D., J. Cook, and R. Seaton

2003 Stigma and HIV: A Review of the Literature.

Brown, W. J., and M. D. Basil

1995 Media Celebrities and Public Health: Responses to "Magic" Johnson's

HIV Disclosure and its Impact on AIDS Risk and High-Risk Behaviors.

Health Communication 7:345-370.

Brunt, Lodewijk

2001 Into the Community. In Handbook of Ethnography. Paul Atkinson, et al. eds. Pp. 80-91. London; Thousand Oaks, Calif.: SAGE.

Cain, Carole

1991 Personal Stories: Identity Acquisition and Self-Understanding in

Alcoholics Anonymous. Ethos 19(2):210-253.

Catz, S. L., J. A. Kelly, L. M. Bogart, E. G. Benotsch, and T. L. McAuliffe

2000 Patterns, Correlates, and Barriers to Medication Adherence among Persons Prescribed New Treatments for HIV Disease. Health Psychology 19(2):124-133.

CDC - Centers for Disease Control and Prevention

2007 Cases of HIV Infection and AIDS in the United States and Dependent Areas, 2005.

CDC (Centers for Disease Control and Prevention)

1997 Revised Guidelines for Performing CD4+ T-Cell Determinations in Persons Infected with Human Immunodeficiency Virus (HIV). Morbidity \& Mortality Weekly Report. Recommendations \& Reports. 46(RR-2):1-29 (1997, January 10).

Celtics

2002 Celtics Recognize the Heroes among Us. Http://www.Nba.com/celtics.

Census 2000

2000 United States Census 2000.

Chapman, E.

2000 Conceptualization of the Body for People Living with HIV: Issues of

Touch and Contamination. Sociology of Health and Illness 22:840-857. 
Charles, Cathy, Amiram Gafni, and Tim Whelan

1999 Decision-Making in the Physician-Patient Encounter: Revisiting the Shared Treatment Decision-Making Model. Social Science and Medicine 49(5):651-661.

Charmaz, K.

1991 Good Days, Bad Days: The Self in Chronic Illness and Time. New Brunswck, NJ: Rutgers University Press.

Charmaz, K.

1980 The Social Construction of Self-Pity in the Chronically Ill. Studies in Symbolic Interaction 3:123-145.

Cherry, K. and Smith, D.

1993 Sometimes I Cry: The Experience of Loneliness for Men with AIDS. Health Communication. 5:181-208.

Chesney, M. A.

2000 Factors Affecting Adherence to Antiretroviral Therapy. Clinical Infectious Diseases 30(Suppl 2):S171-6.

Chrisman, N. and Kleinman, A.

1983 Popular Health Care, Social Networks, and Cultural Meanings: The Orientation of Medical Anthropology. In Handbook of Health, Health Care, and the Health Professions. D. Mechanic., ed. Pp. 569-590. New York: The Free Press.

Clatts, MC. and Mutchler, KM.

1989 AIDS and the Dangerous Other: Metaphors of Sex and Deviance in the Representation of Disease. Medical Anthropology. 10 March(2-3):105-8.

Clifford, James

1997 Routes: Travel and Translation in the Late Twentieth Century. Cambridge, Mass.: Harvard University Press.

Cohen, Anthony

1985 The Symbolic Construction of Community .New York: Ellis Horwood Limited.

Colon, Jose

1984 Estado Libre Asociado: The Constitutionality of Puerto Rico's Legal

Status. Chicano Law Review 7:95-112. 
Corbin, Juliet and Strauss, Anselm

2008 Basics of Qualitative Research: Techniques and Procedures for

Developing Grounded Theory. 3rd ed. Los Angeles, CA: Sage

Publications, Inc.

Coulter, A.

1997 Partnership with Patients: The Pros and Cons of Shared Clinical DecisionMaking. Journal of Health Services Research and Policy 2:112-121.

Crandall, C. S., J. Glor, and TW and Britt

1997 AIDS-Related Stigmatization: Instrumental Ad Symbolic Attitudes. Journal of Applied Social Psychology(27):95-123.

Crawford, Robert

1994 The Boundaries of the Self and the Unhealthy Other: Reflections on Health, Culture and AIDS. Social Science \& Medicine 38(10):1347-1365.

Crepaz, N., and G. Marks

2003 Serostatus Disclosure, Sexual Communication and Safer Sex in HIVPositive Men. AIDS Care 15(3):379-387.

Crespo-Fierro, M.

1997 Compliance/adherence and Care Management in HIV Disease. Journal of the Association of Nurses in AIDS Care 8(4):43-54.

Crocker, Jennifer and Major,Brenda

1989 Social Stigma and Self-Esteem: The Self-Protective Properties of Stigma.

Psychological Review 96(4):608-630.

Cruz, Jose E.

2003 Unfulfilled Promise: Puerto Rican Politics and Poverty. Centro: Journal of the Center for Puerto Rican Studies 15(1):153-175.

Cruz, José E.

1998 Identity and Power : Puerto Rican Politics and the Challenge of Ethnicity. Philadelphia: Temple University Press.

D'Augelli, A. and Garnets, L.

1995 Lesbian, Gay, and Bisexual Communities. In Lesbian, Gay, and Bisexual Identities Over the Lifespan : Psychological Perspectives. Anthony R. D'Augelli and Charlotte Patterson, eds. Pp. 457. New York: Oxford University Press. 
Day, Graham

2006 Community and Everyday Life. London; New York: Rutledge.

de Jong, Ester, Mileidis Gort Gort, and Casey D. and Cobb

2005 Bilingual Education within the Context of English-Only Policies: Three Districts' Responses to Question 2 in Massachusetts. Educational Policy 19(4):595.

De La Cancela, Victor

1986 A Critical Analysis of Puerto Rican Machismo: Implications for Clinical Practice. Psychotherapy: Theory, Research, Practice, Training. Special Issue: Gender Issues in Psychotherapy 23(2):291-296.

DeCecco, J. P.

1984 Homophobia: An Overview. Journal of Homosexuality 10:1-2.

Delgado, M., and J. Santiago

1998 HIV/AIDS in a Puerto Rican/Dominican Community: A Collaborative

Project with a Botanical Shop. Social Work. 43(2):183-186.

Delugan, Robin Maria

2008 Census, Map, Museum (Revisited): El Salvador's Postwar Trans-National Imagination. 15(2):171-193.

D'Emilio, John

1999 Capitalism and Gay Identity. In Culture, Society and Sexuality: A Reader. Aggleton, Peter and Parker, Richard G., ed. Pp. 239-247. London: UCL Press.

D'Emilio, John

1983 Sexual Politics, Sexual Communities : The Making of a Homosexual Minority in the United States, 1940-1970. Chicago: University of Chicago Press.

Diaz Quinones, Arcadio

1995 La Memoria Rota. Rio Piedras: Huracan.

Díaz, Rafael M., George Ayala, and Edward Bein

2004 Sexual Risk as an Outcome of Social Oppression: Data from a Probability Sample of Latino Gay Men in Three U.S. Cities. Cultural Diversity \& Ethnic Minority Psychology 10(3):255-267.

Diaz, Rafael Miguel

1997 Latino Gay Men and Psycho-Cultural Barriers to AIDS Prevention. In Pp. 221-244. University of Chicago Press. 
Diesenhouse, Susan

1988 From 'Migrant' to State House in Massachusetts. New York Times.

DiPasquale, J. A.

1990 The Psychological Effects of Support Groups on Individuals Infected by the AIDS Virus. Cancer Nursing 13(5):278-285.

DoD (Department of Defense)

1998 Atlas/Data Abstract for the United States and Selected Areas - Fiscal Year 1997.

Dolezal, C., A. Carballo-Dieguez, L. Nieves-Rosa, and F. Diaz

2000 Substance use and Sexual Risk Behavior: Understanding their Association among Four Ethnic Groups of Latino Men Who have Sex with Men.

Journal of Substance Abuse 11(4):323-336.

Douglas, Mary and Isherwood, Baron .

1979 The World of Goods: Towards an Anthropology of Consumption. New York: Basic.

Douglas, C. J., C. M. Kalman, and T. P. Kalman

1985 Homophobia among Physicians and Nurses: An Empirical Study. Hospital \& Community Psychiatry 36(12):1309-1311.

Douglas, Mary

1966 Purity and Danger: An Analysis of Concepts of Pollution and Taboo.

London, Rutledge \& K: Paul.

Driver, Tom Faw

1991 The Magic of Ritual: Our Need for Liberating Rites that Transform our Lives and our Communities. 1st ed. San Francisco: Harper.

Duany, Jorge

2000 Nation on the Move: The Construction of Cultural Identities in Puerto

Rico and the Diaspora. American Ethnologist 27(1):5-30.

Duany, Jorge

1996 Imagining the Puerto Rican Nation: Recent Works on Cultural Identity. 31(3):248.

Duneier, Mitchell, Ovie Carter, and Hakim Hasan

1999 Sidewalk. 1st ed. New York: Farrar, Straus and Giroux. 
Durant, R.

1939 Watling: A Survey of Social Life on a New Housing Estate. London: P.S. King.

Durkheim, Emile

1965 The Elementary Forms of the Religious Life. Translated from the French. New York: Free Press (first published 1912).

Dyck, Noel

2002 "Have You been to Hayward Field?": Children's Sports and the Construction of Community in Suburban Canada. In Realizing

Community: Concepts, Social Relationships and Sentiments. Amit Vered, ed. Pp. 105-123. London, New York: Rutledge.

Elias, Norbert

1974 Towards a Theory of Communities. In The Sociology of Community.

Colin Bell and Howard Newby, ed. Pp. ix-xliii. London: Frank Cass.

Emmanuel, E.J. and Emmanuel, L.L.

1992 Apr 22-29 Four Models of the Physician-Patient Relationship. Journal of the American Medical Association 267(16):2221-2226.

Epstein, A. L.

2006 Ethos and Identity : Three Studies in Ethnicity. New Brunswick, N.J.:

Aldine Transaction.

Erikson, Kai

1966 Wayward Puritans; a Study in the Sociology of Deviance. New York:

Wiley.

Espiritu, Yen Le

2001 "We don't Sleep Around Like White Girls do": Family, Culture and Gender in Filipina American Lives. Signs 26:415-440.

Estroff, Sue E.

1993 Identity, Disability, and Schizophrenia : The Problem of Chronicity. In

Knowledge, Power, and Practice : The Anthropology of Medicine and

Everyday Life. Shirley Lindenbaum and Margaret M. Lock, eds. Pp. 247286. Berkeley: University of California Press.

Etzioni, Amitai

1993 The Spirit of Community: Rights, Responsibilities, and the

Communitarian Agenda. 1st ed. New York: Crown Publishers. 
Evans, A.; Lee, R; Mammen-Tobin, A.; Piyadigamage, A.; Shann, S.; Waugh, M. 2004 HIV Revisited: The Global Impact of the HIV/AIDS Epidemic. Skinmed 3(3):149-156.

Event Information.

In AIDS WALK Boston. Retrieved from

http://www.aac.org/site/PageServer?pagename=AIDSWALK_aboutwalk.

Falcón, Angelo, Gabriel Haslip Viera, Félix V. Matos Rodríguez, and Antonia Pantoja 2004 Boricuas in Gotham : Puerto Ricans in the Making of New York City. Princeton, NJ: M. Wiener Publishers.

Farmer, Paul

2006 Aids and Accusation: Haiti and the Geography of Blame. Berkeley: University of California Press.

Farmer, Paul

2004 An Anthropology of Structural Violence. Current Anthropology 45(3):305-325.

Festival Wellness

In AIDS WALK Boston. Retrieved from http://www.aac.org/site/PageServer?pagename=AIDSWALK_wellness.

Flores, Juan

1999 Pan-Latino/Trans-Latino: Puerto Ricans in the "New Neva York." In Identities on the Move: Transnational Processes in North America and the Caribbean Basin. Liliana Goldin, ed. Pp. 107-132. New York: Institute of Mesoamerican Studies, University of Albany.

Flores, Juan

1993 Divided Borders: Essays on Puerto Rican Identity. Houston, Tex.: Arte Público Press.

Formisano, Ronald

1991 Boston Against Busing: Race, Class, and Ethnicity in the 1960s and 1970s. Chapel Hill: University of North Carolina.

Fortuna, Carlos and Carvalho,Claudia 2006 Fostering Communities through Arts and Culture.

Foster, Susan

1987 Social Alienation and Peer Identification: A Dialectical Model of the Development of Deaf Community. 
Fraser, M.

1999 Classing Queer: Politics in Competition. Theory, Culture and Society 16(2):107-131.

Freidson, Eliot

1970 Profession of Medicine: A Study of the Sociology of Applied Knowledge. New York: Harper \& Row.

Friedland GH, Williams A.

1999 Attaining Higher Goals in HIV Treatment: The Central Importance of Adherence. AIDS 13(1):S61-S72.

Friedman, Philip

1955 The Jewish Badge and the Yellow. Historia Judaica 27:41-70.

Gagne, Patricia, Richard Tewksbury, and Deanna McGaughey

1997 Coming Out and Crossing Over: Identity Formation and Proclamation in a Transgender Community. Gender \& Society 11(4):478-508.

Galanti, G. A.

2003 The Hispanic Family and Male-Female Relationships: An Overview. Journal of Transcultural Nursing 14(3):180-185.

Gallant, J. E. JE

2000 Strategies for Long-Term Success in the Treatment of HIV Infection.

JAMA : The Journal of the American Medical Association 283(10):13291334.

Gamble, R. and Getzel, G. S.

1989 Group Work with Gay Men with AIDS. Social Casework: Journal of Contemporary Social Work 70(3):172-179.

Gellner, Ernest

1983 Nations and Nationalism. Ithaca: Cornell University Press.

Gennep, Arnold van

1960 The Rites of Passage. Chicago: University of Chicago Press.

Gieryn, Thomas F.

1983 Boundary-Work and the Demarcation of Science from Non-Science:

Strains and Interests in Professional Ideologies of Scientists. American Sociological Review 48(6):781-795. 
Gilks CF, Floyd K, Haran D, Kemp J, Squire B, Wilkinson D.

1998 Care and Support for People with HIV/AIDS in Resource-Poor Settings. Health and Population Occasional Paper in Sexual and Reproductive Health.

Goffman, Erving

1974 Stigma; Notes on the Management of Spoiled Identity. New York:

Aronson.

Goffman, Erving

1963 Stigma; Notes on the Management of Spoiled Identity. Englewood Cliffs, N.J.: Prentice-Hall.

Goffman, Erving

1961 Asylums; Essays on the Social Situation of Mental Patients and Other Inmates. 1st ed. Garden City, N.Y: Anchor Books.

Goldin, Carol S.

1984 The Community of the Blind: Social Organization, Advocacy and Cultural Redefinition. Human Organization 43(2):121-131.

Goldin, Carol S.

1984 The Community of the Blind: Social Organization, Advocacy and Cultural Redefinition. Human Organization 43(2):121-131.

Gomez, C. and Marin, B.

1996 Gender, Culture and Power: Barriers to HIV Prevention Strategies for Women. Journal of Sex Research, 33:355-362.

Gordillo, V., J. del Amo, V. Soriano, and J. Gonzalez-Lahoz

1999 Sociodemographic and Psychological Variables Influencing Adherence to Antiretroviral Therapy. AIDS 13(13):1763-1769.

Gorlick, Adam

2006 Holyoke's St. Patrick's Day Showcases More than Irish Pride. Boston Globe (Online).

Gray, R. E., M. Fitch, C. Davis, and C. and Philips

1996 Breast Cancer and Prostate Cancer Sef-Help Groups: Reflections on Differences. Psycho-Oncology 5:137-142.

Grimson, Alejandro

1999 Relatos De La Diferencia y La Igualdad. Buenos Aires: Felafacs/Eudeba. 
Grosfoguel, Ramon

2003 Colonial Subjects. University of California Press.

Guzman, Indira and Kwasnik, Barbara

2003 Focus Groups.

Haag, Laurie L.

1994 Queer Words, Queer Images: Communication and the Construction of Homosexuality. Vol. 11.

Hale, Henry

2004 Explaining Ethnicity. Comparative Political Studies. 37(4):458-485.

Hall, S.

1997 The Work of Representation. In Representation: Cultural Representations and Signifying Practices. Stuart Hall., ed. Pp. 13-75. London: Sage.

Harrington, Michael

1969 The Other America; Poverty in the United States. New York: MacMillan.

Haslip Viera, Gabriel, Angelo Falcón, Félix V. Matos Rodríguez, and Antonia Pantoja

2004 Boricuas in Gotham : Puerto Ricans in the Making of New York City.

Princeton, NJ: M. Wiener Publishers.

Hecht, F. M., Colfax, G., Swanson, M., and Chesney, M. A.

1998 Adherence and Effectiveness of Protease Inhibitors in Clinical Practice. In

Program and Abstracts of the Fifth Conference on Retroviruses and

Opportunistic Infections:Abstract \#151/Session 24.

Hecht, F. M.; Wilson, I.B.; Wu, A.W.; Cook, R. L. and Turner, B. J.

1999 Optimizing Care for Persons with HIV Infection. Society of General Internal Medicine AIDS Task Force. Annals of Internal Medicine 131(2):136-143.

Helman, Cecil

2000 Culture, Health, and Illness. 4th ed. ed.Oxford University Press.

Herbst, Jeffrey H., Linda S. Kay, Warren F. Passin, Cynthia M. Lyles, Nicole Crepaz, Barbara V. Marín, and the HIV/AIDS Prevention Research Synthesis (PRS) Team 2007 A Systematic Review and Meta-Analysis of Behavioral Interventions to Reduce HIV Risk Behaviors of Hispanics in the United States and Puerto Rico. AIDS and Behavior 11(1):25-47. 
Herek, G., J. Capitanio, and K. Widaman

2002 HIV-Related Stigma and Knowledge in the United States: Prevalence and Trends, 1991-1999. American Journal of Public Health 92(3).

Herek, GM and Capitanio, JP.

1999 AIDS Stigma and Sexual Prejudice. American Behavioral Scientist. 42(7):1130-1147.

Herrell, Richard

1992 The Symbolic Strategies of Chicago's Gay and Lesbian Pride Day Parade'. In Gay Culture in America. Gilbert Herdt, ed. Pp. 225-252. Boston, MA: Beacon Press.

Higginbotham, J. C., F. M. Trevino, and L. A. Ray

1990 Utilization of Curanderos by Mexican Americans: Prevalence and Predictors. Findings from HHANES 1982-84. American Journal of Public Health 80(Suppl):32-35.

Hillery, George A.

1955 Definitions of Community: Areas of Agreement. Rural Sociology 20(2):111-123.

Hobsbawm, E. J.

1990 Nations and Nationalism since 1780 : Programme, Myth, Reality.

Cambridge England; New York: Cambridge University Press.

Holocombe, S.

2004 The Sentimental Journey: A Site of Belonging. A Case Study from Central Australia. The Australian Journal of Anthropology(15):163-184.

Holohan, A.

1977 Diagnosis: the End of Transition. In Medical Encounters: The Experiences of Illness and Treatment. Davis, A. and Horobin, G., ed. Pp. 87-97. New York: St. Martin Press.

HOPE - Hispanic Office of Planning and Evaluation

Hispanic Office of Planning and Evaluation (HOPE). Electronic document, http://www.hopemass.org/.

Howell, Sgne

2002 Community Beyon Place. Adoptive Families inNorway. In Realizing Communiy. Amit Vered, ed. Pp. 84-104. London and New York:

Rutledge. 
HRSA (U.S. Health Resources and Services Administration)

2001 New HRSA Publication Focuses on Improving Cultural Competency.

Electronic document,

http://newsroom.hrsa.gov/NewsBriefs/2001/culturalcompetency.htm.

Humphreys, Keith

2000 Community Narratives and Personal Stories in Alcoholics Anonymous. Journal of Community Psychology. Special Issue: Qualitative Research on the Narratives of Spiritually-Based Communities 28(5):495-506.

Hunt, Linda

2000 Strategic Suffering: Illness Narratives as Social Empowerment among Mexican Cancer Patients. In Narrative and the Cultural Construction of Illness and Healing. C. Mattingly and L.C. Garro, ed. Pp. 88-107. Berkeley: University of California Press.

Ingram, D., and S. A. Hutchinson

2000 Double Binds and the Reproductive and Mothering Experiences of HIVPositive Women. Qualitative Health Research 10(1):117-132.

Jackson, Kenneth T.

1985 Crabgrass Frontier : The Suburbanization of the United States. New York: Oxford University Press.

Jarama, S. L., J. D. Kennamer, P. J. Poppen, M. Hendricks, and J. Bradford 2005 Psychosocial, Behavioral, and Cultural Predictors of Sexual Risk for HIV Infection among Latino Men Who have Sex with Men. AIDS \& Behavior 9(4):513-523.

Jay, Karla and Young, Allen. (Eds.).

1972 Out of the Closets: Voices of Gay Liberation. New York: Douglas Book Corp.

Jenkins, Richard 2004 Social Identity. Rutledge.

Johnson, Thomas M., and Carolyn Fishel Sargent

1990 Medical Anthropology: A Handbook of Theory and Method. London: Greenwood Press.

Jones, P. S. and Meleis, A. I.

1993 Health is Empowerment. Advances in Nursing Science 15(3):1-14. 
Jones-Shafroth Act

1917 Jones-Shafroth Act. Electronic document, http://www.loc.gov/rr/hispanic/1898/jonesact.html. Accessed: June 7, 2008.

Kalichman, S. C., K. J. Sikkema, and A. and Somlai

1996 People Living with HIV Infection Who Attend and do Not Attend Support Groups: A Pilot Study of Needs, Characteristics, and Experiences. AIDS Care 8(5):589-599.

Kalichman, Seth C., Robert L. Russell, Tricia L. Hunter, and David B. Sarwer 1993 Earvin "Magic" Johnson's HIV Serostatus Disclosure: Effects on Men's Perceptions of AIDS. Journal of Consulting and Clinical Psychology 61(5):887-891.

Keller, Suzanne

2003 Community: Pursuing the Dream, Living the Reality. New Jersey: Princeton University Press.

Kendall, J.

1992 Promoting Wellness in HIV Support Groups. Journal of the Association of Nurses in AIDS Care 3(1):28-38.

Kendall, S.

2005 Developing and Validating a Tool to Measure Parenting Self-Efficacy. J Adv. Nurs. 51(174):181.

Kendall, Carl and Hill, Zelee

2010 Chronicity and AIDS in Three South African Communities. In Chronic Conditions, Fluid States : Chronicity and the Anthropology of Illness. Lenore Manderson and Carolyn Smith Morris, eds. Pp. 175-194. New Brunswick: Rutgers University Press.

Keur, John and Keur, Dorothy

1955 The Deeply Rooted. A Study of a Drents Community in the Netherlands. Assen: Van Gorcum.

King, P. A.

1991 Helping Women Helping Children: Drug Policy and Future Generations. Milbank Quarterly 69(4):595-621.

Kirshenbaum, S. B.; Hirky, A. E.; Correale, J., et al.

2004 "Throwing the Dice": Pregnancy Decision-Making among HIV-Positive Women in Four U.S. Cities. Perspectives on Sexual \& Reproductive Health 36(3):106-113. 
Kleinman, Arthur

1980 Patients and Healers in the Context of Culture : An Exploration of the Borderland between Anthropology, Medicine, and Psychiatry. Berkeley: University of California Press.

Kleinman, D. V. DV

1997 The Social, Economic and Political Impact of the Global HIV/AIDS Epidemic. Oral Diseases 3 Suppl 1:S7-12.

Klosinski, L. E.

2000 HIV Testing from a Community Perspective. Journal of Acquired Immune Deficiency Syndromes: JAIDS 25(Supp1 2):S94-6.

Knox, M. D. MD

1989 Community Mental Health's Role in the AIDS Crisis. Community Mental Health Journal 25(3):185-196.

Kubrin, Charis E.

2005 Gangstas, Thugs, and Hustlas: Identity and the Code of the Street in Rap Music. Social Problems 52(3):360-378.

La Alianza Hispana records 1960-1999

La Alianza Hispana records 1960-1999. Electronic document, http://www.library.neu.edu/archives/collect/findaids/m55findprint.htm, accessed July, 4, 2008.

Lamont, Michele and Molnar, Virag.

2002 The Study of Boundaries in the Social Sciences. 28:167-195.

Latin American Health Institute (LHI)

2007 Electronic document, www.lhi.org.

Lauderdale, P.

1976 Deviance and Moral Boundaries. American Sociological Review 41:660676.

Laumonier, I.

1983 Presencia De La Tradición Andina En Buenos Aires. Buenos Aires: Ed. Belgrano.

Lawrence, Roderick J.

1996 The Multidimensional Nature of Boundaries: An Integrative Historical Perspective. In Setting Boundaries : The Anthropology of Spatial and Social Organization. Deborah Pellow, ed. Pp. 9-36. Westport, Conn.: Bergin \& Garvey. 
Laws, Michael Barton

2011 Personal Communication. :March 22, 2011.

Lee, D. and Newby, H.

1983 The Problem of Sociology. London: Hutchinson.

Lee, Rachel S., Arlene Kochman, and Kathleen J. Sikkema

2002 Internalized Stigma among People Living with HIV-AIDS. AIDS and Behavior 6(4):309-319.

Leiner, Marvin

1994 Sexual Politics in Cuba: Machismo, Homosexuality, and AIDS. Westview Press.

Lévi Strauss, Claude

1963 Totemism; Translated [from the French]. Boston: Beacon Press.

Levine, M.N., Gafni, A., Markham, B., et al.

1992 A Bed-Side Decision Instrument to Elicit a Patient's Preference

Concerning Adjuvant Chemotherapy for Breast Cancer. Annals of Internal Medicine 11:53-58.

Levy, V.; Page-Shafer, K.; Evans, J.; Ruiz, J. et al.

2005 HIV-Related Risk Behavior among Hispanic Immigrant Men in a

Population-Based Household Survey in Low-Income Neighborhoods of

Northern California. Sexually Transmitted Diseases 32(8):487-490.

Lewis, Oscar

1966 La Vida; a Puerto Rican Family in the Culture of Poverty--San Juan and New York. New York: Random House.

Lichterman, Paul

2005 Elusive Togetherness: Church Groups Trying to Bridge America's

Divisions. Princeton, NJ: Princeton University Press.

Lindegren, M. L., R. H. Byers Jr, P. Thomas, S. F. Davis, B. Caldwell, M. Rogers, M. Gwinn, J. W. Ward, and P. L. Fleming

1999 Trends in Perinatal Transmission of HIV/AIDS in the United States. JAMA 282(6):531-538.

Lindenbaum, Shirley, and Margaret M. Lock

1993 Knowledge, Power, and Practice : The Anthropology of Medicine and Everyday Life. Berkeley: University of California Press. 
Locke, Liz

1999 "Don't Dream it, be it": the Rocky Horror Picture show as Cultural Performance. New Directions in Folklore 3 (Formerly the Impromptu Journal)(3):1-3.

Loue, Sana, and Martha Sajatovic

2006 Spirituality, Coping, and HIV Risk and Prevention in a Sample of

Severely Mentally Ill Puerto Rican Women. Journal of Urban Health:

Bulletin of the New York Academy of Medicine 83(6):1168-1182.

MacIver, Robert

1931 Society: Its Structure and Changes. New York: R. Long \& R. R. Smith, Inc.

Magen, Randy H., and Myra Glajchen

1999 Cancer Support Groups: Client Outcome and the Context of Group

Process. Research on Social Work Practice 9(5):541-554.

Manderson, Lenore, and Carolyn Smith Morris

2010 Chronic Conditions, Fluid States : Chronicity and the Anthropology of Illness. New Brunswick: Rutgers University Press.

Mannheim, Karl, Edward Shils, and Edward tr Shils

1940 Man and Society in an Age of Reconstruction; Studies in Modern Social Structure. New York: Harcourt, Brace \& World.

Marger, Martin

1991 Race and Ethnic Relations: American and Global Perspectives. 2nd ed. Belmont, Calif.: Wadsworth Pub. Co.

Marín, Barbara VanOss and Gomez, Chythia A.

1998 Latinos and HIV: Cultural Issues in AIDS Prevention. HIVinsite (Online).

Marín, Barbara VanOss

2003 HIV Prevention in the Hispanic Community: Sex, Culture, and Empowerment. Journal of Transcultural Nursing : Official Journal of the Transcultural Nursing Society / Transcultural Nursing Society 14(3):186192.

Marín, Gerardo, and Barbara VanOss Marín

1991 Research with Hispanic Populations. Newbury Park: Sage Publications.

Marshall, Gordon

1994 The Concise Oxford Dictionary of Sociology. Oxford ; New York: Oxford University Press. 
Mason, Andrew

2000 Community, Solidarity and Belonging: Levels of Community and their Normative Significance. Cambridge University Press.

Massachusetts Department of Public Health (MDPH)

2004 HIV/AIDS Surveillance Report. .

Massachusetts Department of Public Health (MDPH)

2001 HIV/AIDS Surveillance Report.

Massey, Douglas S., and Russell Sage Foundation

2007 Categorically Unequal: The American Stratification System. New York:

Russell Sage Foundation.

Mathison, S.

1988 Why Triangulate? Educational Researcher. 17(2):13-17.

Matos Rodriguez, Felix V.

2005 Saving the Parcela: A Short History of Boston's Puerto Rican

Community. In The Puerto Rican Disapora. Historical Perspectives.

Whalen, Carment Teresa and Vazquez-Hernandez, Victor, ed. Pp. 200-

226. Philadelphia: Temple University Press.

Mattingly, Cheryl, and Linda C. Garro

2000 Narrative and the Cultural Construction of Illness and Healing. Berkeley:

University of California Press.

McElroy, Ann, and Patricia K. Townsend

1989 Medical Anthropology in Ecological Perspective. 2nd ed. Boulder:

Westview Press.

McMillan, David W., and David M. Chavis

1986 Sense of Community: A Definition and Theory. Journal of Community Psychology.Special Issue: Psychological Sense of Community, I: Theory and Concepts 14(1):6-23.

Mead, Shery, and Mary Ellen Copeland

2000 What Recovery Means to Us: Consumers' Perspectives. Community

Mental Health Journal 36(3):315-328.

Mead, Shery, David Hilton, and Laurie Curtis

2001 Peer Support: A Theoretical Perspective. Psychiatric Rehabilitation

Journal 25(2):134-141. 
Melendez, Sarah E.

1981 Hispanic, Desegregacion and Bilingual Education: A Case Analysis of the Role of "El Comite De Los Padres" in the Court-Ordered Desegregation of the Boston Public School (1974-1975). .

Miner, Horace 1956 Body Ritual among the Nacirema. American Anthropologists. 58:503-507.

Mishel, M. H.

1997 Uncertainty in Chronic Illness. Annual Review of Nursing Research 15:57-80.

Mitchell, Bonnie L. and Feagin, Joe R.

1995 America's Racial-Ethnic Cultures: Opposition within a Mythical Melting Pot. In Toward the Multicultural University. B. Bowser, T. Jones and G. A. and Young, eds. Pp. 65-86. Westport, CT: Praeger.

Mofenson, L. M.

1999 Can Perinatal HIV Infection be Eliminated in the United States? JAMA 282(6):577-579.

Moore, JW

1991 Going Down to the Barrio: Homeboys and Homegirls in Change.

Philadelphia: Temple University Press.

Morgan, D. L.

1996 Focus Groups. 22:129-152.

Morrison, S. D., R. Howard, C. Hardy, and B. Stinson

2005 Social Capital, Health and HIV Awareness of Girls in a Rural Caribbean

Community. International Electronic Journal of Health Education(8):1-11.

Muir, Kenneth B., and Trina Seitz

2004 Machismo, Misogyny, and Homophobia in a Male Athletic Subculture: A

Participant-Observation Study of Deviant Rituals in Collegiate Rugby.

Deviant Behavior 25(4):303-327.

Muniz, A. and O'Guinn, C.

2001 Brand Community. Journal of Consumer Research 27(March):412-432.

Nack, Adina

2008 Damaged Goods?: Women Living with Incurable Sexually Transmitted

Diseases. Philadelphia: Temple University Press. 
Nader, Laura

1972 Up the Anthropologist: Perspectives Gained from Studying Up. Report: ED065375. 28p.

Nahid Golafshani

2003 Understanding Reliability and Validity in Qualitative Research. The Qualitative Report 8(4):597-607.

Nisbet, Robert A.

1966 The Sociological Tradition. New York: Basic Books.

Oboler, Suzanne

1999 Racializing Latinos in the United States: Towards a New Research Paradigm. In Identities on the Move: Transnational Processes in North America and the Caribbean Basin. ed Liliana Goldin, ed. Pp. 45-68. New York: Institute for Mesoamerican Studies, University at Albany.

Oliver, D. G., J. M. Serovich, and T. L. and Mason

2005 Constraints and Opportunities with Interview Transcriptions: Towards Reflection in Qualitative Research. Social Forces 84(2):1273-1289.

Olwig, Karen Fog

2002 The Ethnographic Field Revisited: Towards a Study of Common and Not so Common Fields of Belonging. In Realizing Community. Concepts, Social Relationships and Sentiments. Vered Amit, ed. London: Rutledge.

Ortiz-Torres, B., I. Serrano-García, and N. Torres-Burgos

2000 Subverting Culture: Promoting HIV/AIDS Prevention among Puerto Rican and Dominican Women. American Journal of Community Psychology 28(6):859-881.

Osmond, Dennis

2003 Epidemiology of HIV/AIDS in the United States. Electronic document, www.hivinsite.ucsf.edu/InSite?page=kb-01-03, accessed March, 2007.

Paiva, V., E. V. Filipe, N. Santos, T. N. Lima, and A. Segurado

2003 The Right to Love: The Desire for Parenthood among Men Living with HIV. Reproductive Health Matters 11(22):91-100.

Parker, Richard, and Peter Aggleton

2003 HIV and AIDS-Related Stigma and Discrimination: A Conceptual Framework and Implications for Action. Social Science \& Medicine 57(1):13-24. 
Parole News

2007 Community Health Cener Provides Health Education and Harm Reduction to Parolees. Parole News. Massachusetts Parole Board(December 2007 January 2008):5-Availabel at http://www.docstoc.com/docs/734411/MASSACHUSETTS-PAROLEBOARD-Parole-News-M-a-s.

Parsons, Talcott

1951 The Social System. New York: Free Press of Glencoe.

Paterson, D. L., S. Swindells, J. Mohr, M. Brester, E. N. Vergis, C. Squier, M. M. Wagener, and N. Singh

2000 Adherence to Protease Inhibitor Therapy and Outcomes in Patients with HIV Infection. Annals of Internal Medicine 133(1):21-30.

Pattillo McCoy, Mary

1999 Black Picket Fences: Privilege and Peril among the Black Middle Class. Chicago: University of Chicago Press.

Peer Support Workgroup (Peer Support Workgroup of the Greater Boston/Metrowest HIV/AIDS Service Coordination Collaborative)

2006 HIV Support Groups and Peer Support Porgrams in the Greater Boston and Metrowest Areas.

: http://livingcenter.org/images/site/HIVPeerSupGuideJuly06.pdf.

Pelto, P. and Pelto, G.

1996 Research Designs in Medical Anthropology. In Medical Anthropology: Contemporary Theory and Method. Johnson, Thomas and Sargent, Carolyn F., ed. Pp. 293-324. New York: Greenwood Press.

Penner, Susan

1995 A Study of Coalitions among HIV/AIDS Service Organizations.

Sociological Perspectives 38(2):217-239.

Perez y Gonzalez, Maria E.

$2000 \quad$ Puerto Ricans in the United States. Greenwood Press.

Piore, Michael J.

1979 Birds of Passage : Migrant Labor Industrial Societies. Cambridge: New York: Cambridge University Press.

Piot, P. P., M. M. Bartos, P. D. PD Ghys, N. N. Walker, and Schwartländer B.B. 2001 The Global Impact of HIV/AIDS. Nature 410(6831):968-973. 
Pleck, J. H., F. L. Sonenstein, and L. Ku

1993 Masculinity Ideology: Its Impact on Heterosexual Relationships. Journal of Social Issues 49(3):11-29.

Plummer, Kenneth

1995 Telling Sexual Stories: Power, Change, and Social Worlds. London; New York: Rutledge.

Poundstone, K. E., S. A. Strathdee, and D. D. Celentano

2004 The Social Epidemiology of Human Immunodeficiency virus/acquired Immunodeficiency Syndrome. Epidemiologic Reviews 26:22-35.

Powdermaker, Hortense

1966 Stranger and Friend; the Way of an Anthropologist. 1st ed. New York: W. W. Norton.

Power, R.; Koopman, C.; Volk, J.; Israelski, D.; Stone, L.; Chesney, M.; Spiegel, D.

2003 Social Support, Substance use, and Denial in Relationship to Antiretroviral Treatment Adherence among HIV-Infected Persons.

AIDS.Patient Care.and STDs 17(5):245-252.

Putnam, Robert D.

2000 Bowling Alone : The Collapse and Revival of American Community. New York: Simon \& Schuster.

Quantz, R. and Magolda, P.

1997 Nonrational Classroom Performance: Ritual as an Aspect of Action. The Urban Review(29):221-238.

Radcliffe Brown, A. R.

1965 Structure and Function in Primitive Society : Essays and Addresses. New York, NY: The Free Press.

Raffaelli, M., \& Suarez Al-Adam, M.

1988 Reconsidering the HIV/AIDS Prevention Needs in Latino Women in the United States. In Women and AIDS: Negotiating Safer Practices, Care, and Representation. N. L. Roth \& L. K. Fuller., ed. Pp. 7-41. New York: Haworth.

Ramirez-Valles, Jesus, and Amanda Uris Brown

2003 Latinos' Community Involvement in HIV/AIDS: Organizational and Individual Perspectives on Volunteering. 15:90-104.

Rappaport, Roy A.

1979 Ecology, Meaning, and Religion Berkeley, CA: North Atlantic Books. 
Rappaport, Julian

1993 Narrative Studies, Personal Stories, and Identity Transformation in the Mutual Help Context. Journal of Applied Behavioral Science. Special Issue: Advances in Understanding with Self-Help Groups 29(2):239-256.

Rawick, George

1967 The Black Revolution in the US. La Critica Sociologica 4:5-11.

Reinert, B. R.

1986 The Health Care Beliefs and Values of Mexican-Americans. Home Healthcare Nurse 4(5):23-31.

Remien, R. H., A. E. Hirky, M. O. Johnson, L. S. Weinhardt, D. Whittier, and G. M. Le 2003 Adherence to Medication Treatment: A Qualitative Study of Facilitators and Barriers among a Diverse Sample of HIV+ Men and Women in Four US Cities. AIDS \& Behavior 7(1):61-72.

Ribble, D.

1989 Psychological Support Groups for People Living with HIV Infection and AIDS. Holistic Nursing 3(4):52-62.

Ritzer, George and Goodman,Douglas J.

2008 Modern Sociological Theory. 7th ed. New York, NY: McGraw-Hill Higher Education.

Roberts, Sandra James

2006 Countering Stigma: Collectively Counsleing and AIDS Identity. In Globalisation and New Identities: A View from the Middle. Peter Alexander, Marcelle C. Dawson, and Meera Icharam., ed. Pp. 171-189. Johannesburg, South Africa: Jacana Media (Pty) Ltd.

Robinson, David

1979 Talking Out of Alcoholism: The Self-Help Process of Alcoholics Anonymous. Baltimore: University Park Press.

Roca, B., C. J. Gomez, and A. Arnedo

2000 Adherence, Side Effects and Efficacy of Stavudine Plus Lamivudine Plus Nelfinavir in Treatment-Experienced HIV-Infected Patients. Journal of Infection 41(1):50-54.

Rodriguez, Victor M.

1997 The Racialization of Puerto Rican Ethnicity in the United States. In Ethnicity, Race, And Nationality in the Caribbean. Juan Manuel Carrion, ed. Pp. 233-273. San Juan: Institute of Caribbean Studies, University of Puerto Rico. 
Rodriguez-Morazzani, Roberto P.

1996 Beyond the Rainbow: Mapping the Discourse on Puerto Rican and Race. Centro 8(1-2):151-169.

Rodriguez-Rosado, R., I. Jimenez-Nacher, V. Soriano, P. Anton, and J. Gonzalez-Lahoz 1998 Virological Failure and Adherence to Antiretroviral Therapy in HIVInfected Patients. AIDS 12(9):1112-1113.

Rodriquez, J.

1983 Mexican Americans: Factors Influencing Health Care Practices. Journal of School Health 53:136-139.

Roth, N. L., and M. S. Nelson

1997 HIV Diagnosis Rituals and Identity Narratives. AIDS Care 9(2):161-179.

Ryan, G.W. and Bernard, R.

2000 Data Management and Analysis Methods. In Handbook of Qualitative

Research. Denzin, N. and Lincon, Y., ed. Pp. 769-802. Thousand Oaks, CA: Sage.

Safren, S; Ottoa, M; Wortha, J; Salomonb, E.; Johnsonb, W.; Mayerb, K.; Boswellb, S. 2001 Two Strategies to Increase Adherence to HIV Antiretroviral Medication: Life-Steps and Medication Monitoring. Behaviour Research and Therapy 39(10):1151-1162.

Sastre, Francisco

2000 Bolivianness Unbounded: Popular Religion and the Reconstruction of Identity in the Bolivian Community of Buenos Aires.

Schein, Jerome

1968 The Deaf Community. Washington, DC: Gallaudet College Press.

Scheper Hughes, Nancy

2001 Saints, Scholars, and Schizophrenics : Mental Illness in Rural Ireland. Berkeley, Ca.: University of California Press.

Schiller, Nina Glick, Stephen Crystal, and Denver Lewellen

1994 Risky Business: The Cultural Construction of AIDS Risk Groups. Social Science and Medicine 38(10):1337-1346.

Schoenberner, Gerhard

2004 The Yellow Star : The Persecution of the Jews in Europe, 1933-1945. New York: Fordam University Press. 
Schwab, T., and R. Simmons

1989 Collaboration in Action. Nursing Connections 2(1):35-42.

Sears, Jacqueline L.

2008 Machismo as a Determinant for HIV/STD Risk Behavior among Latino MSM. Ph.D. dissertation, Virginia Commonwealth University.

Seda Bonilla, Eduardo

1980 Réquiem Por Una Cultura (Ensayos Sobre La Socialización Del

Puertorriqueño En Su Cultura y En Ámbito Del Poder Neocolonial) [Por] Eduardo Seda Bonilla. Río Piedras: Editorial Edil.

Selik, R. M., K. G. Castro, M. Pappaioanou, and J. W. Buehler 1989 Birthplace and the Risk of AIDS among Hispanics in the United States. American Journal of Public Health 79(7):836-839.

Selznick, P. 1995 Thinking about Community: 10 Theses. Society 32(5):33-37.

Service, Elman R. 1958 A Profile of Primitive Culture.

Shenoi, S., S. Heysell, A. Moll, and G. Friedland 2009 Multidrug-Resistant and Extensively Drug-Resistant Tuberculosis: Consequences for the Global HIV Community. Current Opinion in Infectious Diseases 22(1):11-17.

Sherr, L., and N. Barry

2004 Fatherhood and HIV-Positive Heterosexual Men. HIV Medicine 5(4):258263.

Sigelman, C. K., A. B. Miller, and E. B. Derenowski

1993 Do You Believe in Magic? the Impact of "Magic" Johnson on Adolescents' AIDS Knowledge and Attitudes. AIDS Education \& Prevention 5(2):153-161.

Simoni, J. M., M. G. Martone, and J. F. and Kerwin

2002 Spirituality and Psychological Adaptation among Women with HIV/AIDS: Implications for Counseling. Journal of Counseling Psychology 49(2):139.

Simoni, J. M., and M. T. Ng

2000 Trauma, Coping, and Depression among Women with HIV/AIDS in New York City. AIDS Care 12(5):567-580. 
Skoll, Geoffrey R.

1992 Walk the Walk and Talk the Talk : An Ethnography of a Drug Abuse Treatment Facility. Philadelphia: Temple University Press.

Smith, L. T.

1939 Trends in Community Organization and Life. American Sociological Society.

Smith, M. K.

2001 Community. Electronic document, www.infed.org/community/community.htm.

Smith, Anthony D.

1991 National Identity. Reno: University of Nevada Press.

Spector, R. E.

2002 Cultural Diversity in Health and Illness. Journal of Transcultural Nursing 13(3):197-199.

Spirig, Rebecca

1998 Support Groups for People Living with HIV/AIDS: A Review of

Literature. Journal of the Association of Nurses in AIDS Care 9(4):43-55.

Sterk, C. E.

1989 Prostitution, Drug use, an AIDS. In In the Field: Readings on the Field Research Experience. C. D. Smith and W. Kornblum, ed. Pp. 91-100. New York: Praeger.

Stokoe, W. C.

1960 Sign Language Structure: An Outline of the Communication Systems of the American Deaf. Studies in Linguistics Occasional Papers 8.

Suarez, M., M. Raffaelli, and A. and O'Leary

1996 Use of Folk Healing Practices by HIV-Infected Hispanics Living in the United States. AIDS Care 8(6):683.

Suttles, Gerald D.

1972 The Social Construction of Communities. University of Chicago Press.

Tajfel, Henri and Turner, John C.

1985 The Social Identity Theory of Intergroup Behavior. In Psychology of Intergroup Relations. Worchel, S. and Austin, WG., ed. Pp. 7-22. Chicago: Nelson-Hall. 
Tanabe, Shiegeharu

2008 Imagined and Imagining Communities. In Imagining Communities in Thailand. Shiegeharu Tanabe, ed.

Tanabe, Shiegeharu

2008 Suffering, Community, and Self-Governmet. HIV/AIDS Self-Help Groups in Nothern Thailand. In Imagining Communities in Thailand. Shiegeharu Tanabe, ed. Pp. 161-193.

Task Force on Children Out of School.

1970 The Way we Go to School: The Exclusion of Children in Boston.

Taylor, Donald M.

2002 The Quest for Identity: From Minority Groups to Generation Xers. Praeger/Greenwood.

Teruel, Manuel

1973 Negotiating Change in the Boston Pulblic Schools: Bilingual Education. Ph.D. Dissertation, Harvard University.

Thomas, Piri

1967 Down these Mean Streets. New York: Knopf.

Thompson, Lanny

1995 Nuestra Isla y Su Gente: La Construcción Del "Otro" Puertorriqueño En our Islands and their People.Río Piedras, P.R.: Centro de Investigaciones Sociales y Departamento de Historia de la Universidad de Puerto Rico.

Tienda, Marta

1989 Puerto Ricans and the Underclass Debate. Annals of the American

Academy of Political and Social Science 501; The Ghetto Underclass:

Social Science Perspectives:105-119.

Torres, Andrés, and José E. Velázquez

1998 The Puerto Rican Movement: Voices from the Diaspora. Philadelphia:

Temple University Press.

Turner, Victor Witter

1977 The Ritual Process: Structure and Anti-Structure. Ithaca, N.Y.: Cornell University Press.

Turner, Victor Witter

1969 The Ritual Process: Structure and Anti-Structure. Chicago: Aldine Pub.

Co. 
Ussher, Jane, Laura Kirsten, Phyllis Butow, and Mirjana Sandoval

2006 What do Cancer Support Groups Provide which Other Supportive Relationships do Not? the Experience of Peer Support Groups for People with Cancer. Social Science \& Medicine 62(10):2565-2576.

Van Cleve, John V. and Crouch, Barry A.

1989 A Place of their Own : Creating the Deaf Community in America.

Washington, D.C.: Gallaudet University Press.

VanOss Marín, Barbara

2003 HIV Prevention in the Hispanic Community: Sex, Culture, and

Empowerment. Journal of Transcultural Nursing 14(3):186-192.

Varas-Díaz, Nelson, Irma Serrano-García, and José Toro-Alfonso

2005 AIDS-Related Stigma and Social Interaction: Puerto Ricans Living with HIV/AIDS. Qualitative Health Research 15(2):169-187.

Veatch, R. M.

2002 White Coat Ceremonies: A Second Opinion. Journal of Medical Ethics 28(1):5-9.

VerMeulen, M.

1982 The Gay Plague. New York Magazine May 31.

Vigil, James Diego

1988 Group Processes and Street Identity: Adolescent Chicano Gang Members. Ethos 16(4):421-445.

Walker, Adrian

2003 January 9 Felix D. Arroyo: A Quiet Leap for Latinos. The Boston Globe.

Warner, W. Lloyd, and Paul S. Lunt

1941 The Social Life of a Modern Community. Westport, Conn: Greenwood Press.

Warren, Roland Leslie

1963 The Community in America. Chicago: Rand McNally.

Weitz, R.

1990 Living with the Stigma of AIDS. Qualitative Sociology 13(23):38.

Whalen, Carmen Teresa and Vázquez-Hernández,Víctor 2005 The Puerto Rican Diaspora : Historical Perspectives. Philadelphia: Temple University Press. 
Wikan, U.

2000 With Life in One's Lap. In Narrative and the Cultural Construction of Illness and Healing. C. Mattingly and L.C. Garro, ed. Pp. 212-236. Berkeley: University of California Press.

Wilcox, Danny M.

1998 Alcoholic Thinking : Language, Culture, and Belief in Alcoholics Anonymous. Westport, CT: Praeger.

Wood, George S., and Juan C. Judikis 2002 Conversations on Community Theory. Purdue University Press.

Yarmolinsky, Adam

1971 The Military Establishment; its Impacts on American Society. New York: Harper \& Row.

Young, J.

2001 Identity, Community and Social Exclusion. In Crime, Disorder and Community Safety. R. Matthews and J. Pitts (eds), ed. London: Rutledge.

Zea, MC; Reisen, CA; Poppen, PJ; Echeverry, JJ; Bianchi, FT

2004 Disclosure of HIV-Positive Status to Latino Gay Men's Social Networks. American Journal of Community Psychology 33(1-2):107-116.

Zhou, Min

2002 The Changing Face of America: Immigration, Race/Ethnicity, and Social Mobility. In Mass Migration to the United States. Pp. 65-98. Walnut Creek, CA; United States: AltaMira.

Zimmerman, Bonnie

1984 The Politics of Transliteration: Lesbian Personal Narratives. Signs 9(4):663-682. 
VITA

\section{FRANCISCO SASTRE}

July 3, 1971

1997

$1998-2000$

$2000-2001$

$2002-2003$

$2003-2005$

2009

2009
Born, Montevideo, Uruguay

B.A., Latin American Studies and Spanish Stetson University

DeLand, Florida

M.A., Latin American Studies

University of Florida

Gainesville, Florida

M.S., Management

University of Florida

Gainesville, Florida

Principal Evaluation Associate Latin American Health Institute Boston, Massachusetts

Professional Resources Coordinator Latin American Health Institute Boston, Massachusetts

M.A., Comparative Sociology Florida International University Miami, Florida

Senior Evaluation Associate Latin American Health Institute Boston, Massachusetts

\section{PUBLICATIONS AND PRESENTATIONS}

Sastre, Francisco. Life in Community among HIV-positive Puerto Rican Men Living in Boston - preliminary findings. Center for Research on U.S Latino HIV/AIDS and Drug Abuse brown bag series. Florida International University. Miami, FL, April 2010.

Sastre, Francisco. Living Positive: Life in Community among Puerto Rican Men Living with HIV/AIDS in Boston. Society for Applied Anthropology 2010 International Meeting Merida, Mexico, March 2010. 
Sastre, Francisco. Living Positive: fears, challenges, and lives with HIV among Latinos Keynote address Hispanic forum - 2009 World AIDS Day. Arkansas State University, December 2009.

Sastre, Francisco. Living Positive: Life in Community among Puerto Rican Men living with HIV/AIDS in Boston. Marking 20 Years of AIDS in Sociology: Reflecting Back \& Moving Forward. Sociologists' AIDS Network Conference, San Francisco, August 2009.

Sastre, Francisco. One nation, many faces: HIV/AIDS among Latinos in the United States. Cultures in Context: HIV and Substance Abuse Research in the Southeast. Meharry Medical College, June 2008.

Sastre, Francisco. Study on the levels of basic HIV/AIDS knowledge among the FIU 1824 year-old population. FIU's Scholarly Forum, MARCH 2008.

Sastre, Francisco. An analysis of domains associated with levels of basic HIV/AIDS knowledge among Latinos in two educational settings (poster). 2007 American Public Health Association Annual Meeting (APHA), Washington, DC.

Sastre, Francisco. Puerto Ricans in Boston: Strategies of "Diferencia e Igualdad" for Building a Healthy Latino Nation in the age of HIV and AIDS. 2007 International Latin American Studies Association Meeting, Montreal, Canada.

Sastre, Francisco. Fighting HIV and AIDS with unequal resources: HIV/AIDS funding discrepancy in the U.S. (poster). 2006 American Public Health Association Annual Meeting (APHA), Boston, MA.

Sastre, Francisco. Puerto Ricans in Boston: The Building of a Healthy Nation. FIU's Scholarly Forum, MARCH 2006.

Laws, M.B., Sastre, F. (2003) Report on the Needs Assessment of the Multicultural Outreach Project. The Statewide Head Injury Program, Massachusetts Rehabilitation Commission.

Laws, M.B., Sastre, F. (2002) Report of Disproportionate Minority Contact: Phase I, Identification. State of New Hampshire, Division of Children, Youth, and Families.

Sastre, F. (2000) Bolivianness Unbounded: Popular Religion and the Reconstruction of Identity in the Bolivian Community of Buenos Aires. Master Thesis, University of Florida.

Sastre, F. (1999) "Copacabana: Hoy y Ayer la Protectora de un Pueblo" The Latinamericanist, University of Florida. 